UNIVERSIDADE DE BRASÍLIA

INSTITUTO DE CIÊNCIAS BIOLÓGICAS

PÓS-GRADUAÇÃO EM NANOCIÊNCIA E NANOBIOTECNOLOGIA

TRATAMENTO DE CÂNCER DE MAMA UTILIZANDO TERAPIA FOTODINÂMICA COM NANOEMULSÕES DE FTALOCIANINA DE CLORO ALUMÍNIO

Brasília, DF 


\author{
UNIVERSIDADE DE BRASÍLIA \\ INSTITUTO DE CIÊNCIAS BIOLÓGICAS \\ PÓS-GRADUAÇÃO EM NANOCIÊNCIA E NANOBIOTECNOLOGIA
}

LUDMILLA DAVID DE MOURA

\title{
TRATAMENTO DE CÂNCER DE MAMA UTILIZANDO TERAPIA FOTODINÂMICA COM NANOEMULSÕES DE FTALOCIANINA DE CLORO ALUMÍNIO
}

\begin{abstract}
Dissertação apresentada ao Programa de PósGraduação em Nanociência e Nanobiotecnologia do Instituto de Ciências Biológicas da Universidade de Brasília como requisito para obtenção do título de Mestre em Nanociência e Nanobiotecnologia.
\end{abstract}

Orientador: Prof. Dr. Ricardo Bentes de Azevedo

Brasília, DF 


\title{
TRATAMENTO DE CÂNCER DE MAMA UTILIZANDO TERAPIA FOTODINÂMICA COM NANOEMULSÕES DE FTALOCIANINA DE CLORO ALUMÍNIO
}

\author{
Dissertação apresentada ao Programa \\ de Pós-Graduação em Nanociência e \\ Nanobiotecnologia do Instituto de \\ Ciências Biológicas da Universidade de \\ Brasília como requisito para obtenção \\ do título de Mestre em Nanociência e \\ Nanobiotecnologia.
}

MEMBROS COMPONENTES DA BANCA EXAMINADORA:

Presidente e Orientador: Prof. Ricardo Bentes de Azevedo, Dr. Universidade de Brasília, UnB.

Membro Titular: $\quad$ Profa. Zulmira Guerrero Marques Lacava, Dra. Universidade de Brasília, UnB.

Membro Titular: $\quad$ Prof. João Nunes de Matos Neto, Dr.

Universidade de Brasília, UnB.

Membro Suplente: $\quad$ Prof. Luís Alexandre Muehlmann, Dr.

Universidade de Brasília, UnB.

Local: Universidade de Brasília Instituto de Ciências Biológicas UnB - Campus Darcy Ribeiro 
Dedico este trabalho à minha amada avó, Sebastiana Messias, in memoriam. 


\section{AGRADECIMENTOS}

"A gratidão desbloqueia a abundância da vida. Ela torna o que temos em suficiente, e mais. Ela torna a negação em aceitação, caos em ordem, confusão em claridade. Ela pode transformar uma refeição em um banquete, uma casa em um lar, um estranho em um amigo. A gratidão dá sentido ao nosso passado, traz paz para o hoje, e cria uma visão para o amanhã!"

(Melody Beattie).

Hoje, só me resta a agradecer a todos que de alguma forma me ajudaram a ser quem sou e a estar onde estou. Muito obrigada! 
"Será que não poderemos transcrever os vinte e quatro volumes da Enciclopédia Britânica na cabeça de um alfinete? [...] Tudo é possível, se você olhar o suficiente." 


\section{RESUMO}

O câncer é caracterizado por um complexo de alterações que afetam a atividade molecular intracelular e também as comunicações entre as células e tecidos. Dentre todos os tipos de cânceres existentes, o câncer de mama representa $25 \%$ do total de neoplasias no mundo, com possibilidade de metástases. Ressalta-se que as terapias atuais, incluindo a cirurgia, a terapia hormonal, quimioterapia e terapia de radiação, são pouco seletivas para a eficácia no tratamento do câncer de mama primário e metastático. Portanto, são necessárias novas terapias que possam ser mais eficazes no tratamento deste tumor, de modo a destruir a propagação de metástases. Um dos tratamentos em ascensão é o uso da terapia fotodinâmica (TFD), a qual envolve três elementos fundamentais, sendo eles: um agente fotossensibilizante ou fotossensibilizador, uma fonte de luz específica e moléculas de oxigênio. Ademais, o uso de nanoestruturas associadas à TFD, tem proporcionado bons resultados aos tratamentos para o câncer, pois aumenta a eficiência dos fármacos, no caso os fotossensibilizadores, utilizados. Assim, o objetivo deste trabalho, foi desenvolver um tratamento para o câncer de mama utilizando a terapia fotodinâmica, com uma nanopartícula contendo o fotossensibilizador cloreto de alumínio - ftalocianina, de forma a promover a mortalidade de células tumorais mamárias primárias e possíveis focos de metástases. Para tal, foram desenvolvidas e caracterizadas três nanoformulações, sendo elas: Nanoemulsão de Fatalocianina de Cloro-Alumínio (NE-ALCLFT), Nanoemulsão de Ftalocianina de Cloro-Alumínio com Ácido Fólico (NE-FO-ALCLFT) e Micela de Ácido Fólico (MIC-FO-ALCLFT). Para a caracterização, foram utilizadas as metodologias: análise de estabilidade, ZetaSizer, FT-IR, RAMAN, Microscopia eletrônica de Transmissão (MET) e de Varredura (MEV), análise por Espectrofluorímetro e o estudo da produção de espécies reativas de oxigênio (ROS). Posteriormente, foi realizado o estudo in vitro para avaliação da viabilidade celular e citotoxicidade, utilizando duas linhagens celulares, sendo uma de adenocarcinoma mamário (4T1) e outra de fibroblastos (NIH/3T3), pela avaliação do método colorimétrico MTT e análise morfológica das células pós-tratamentos por Microscopia de Fluorescência e contraste de fase. Nestes testes também foram avaliados a interferência da potência utilizada pelo LED para a aplicação da TFD, sendo testadas as potências $10 \mathrm{~mW} / \mathrm{cm}^{2}, 50 \mathrm{~mW} / \mathrm{cm}^{2}$ e $100 \mathrm{~mW} / \mathrm{cm}^{2}$. Por fim, foram realizados os testes in vivo e ex vivo, que incluem o estudo da biodistribuição das três nanoformulações pela via de administração endovenosa, por meio da avaliação de imageamento em tempo real no equipamento IVIS Lumina XR. Posteriormente ao estudo da biodistribuição, foi selecionada uma das nanoformulações (aquela que apresentou melhores resultados) para o tratamento do câncer de mama utilizando a TFD. Nesta última fase do trabalho, foram realizadas três formas de tratamento, sendo elas: sistêmica ( usando a administração do fármaco por via endovenosa e irradiação do LED também sistêmico (corpo todo do animal)), parcialmente sistêmica (com administração do fármaco por via endovenosa e irradiação apenas no local do tumor), e local (utilizando a administração do fármaco por via intratumoral e irradiação do LED também no local do tumor). Foram avaliados o peso dos camundongos, o volume tumoral, análises bioquímicas, hematológicas, análise por microtomografia computadorizada pelo equipamento PET/SPECT (avaliando o volume pulmonar e ósseo) e análise histopatológica. Os resultados apresentam todos os preparos das nanoformulações e suas respectivas caracterizações, sugerindo relevante estabilidade das nanopartículas. Os ensaios de viabilidade celular mostram que as nanoformulações apresentam citotoxicidade para ambas as linhagens celulares testadas, e que o uso apenas do LED (sem a presença dos nanoformulações) provocam o aumento da viabilidade celular na linhagem de fibroblastos. O ensaio de biodistribuição ressalta os principais órgãos atingidos pelas nanoformulações, sendo especialmente o fígado, baço e rins. Além disso, concluiu-se que a nanoformulação NE-ALCLFT, foi a que apresentou melhor biodistribuição para a região tumoral. Por fim, os tratamentos in vivo com o uso da TFD, apontam efeitos de necrose tumoral e infiltrados inflamatórios. Além disso, foi possível concluir que a melhor forma de tratamento, dentre as analisadas, foi utilizar a nanoformulação por administração endovenosa, e a irradiação do LED no local da região do tumor, onde apresentou $80 \%$ de eficiência do tratamento, com 4 camundongos apresentando todos tecidos normais $(n=5)$. Portanto, com este trabalho, foi possível desenvolver um método eficiente para o tratamento do câncer de mama, utilizando a TFD com uma nanoemulsão de ftalocianina de cloro alumínio, por administração endovenosa.

Palavras-chaves: câncer de mama, terapia fotodinâmica, nanoemulsão de ftalocianina de cloro alumínio 


\begin{abstract}
Cancer is characterized by a complex of alterations that affect intracellular molecular activity as well as communications between cells and tissues. Among all types of cancer, breast cancer represents $25 \%$ of the total number of neoplasms worldwide, with the possibility of metastases. It is noteworthy that current therapies, including surgery, hormone therapy, chemotherapy and radiation therapy, are not completely selective for efficacy in the treatment of primary and metastatic breast cancer. Therefore, new therapies are needed that may be more effective in treating this tumor, in order to destroy the spread of metastases. One of the rising treatments is the use of Photodynamic Therapy (PDT), which involves three fundamental elements: a photosensitizing or photosensitizing agent, a specific light source and oxygen molecules. In addition, the use of nanostructures associated with PDT has provided good results for cancer treatments, since it increases the efficiency of the drugs, in this case the photosensitizers, used. Thus, the objective of this work was to develop a treatment for breast cancer using photodynamic therapy with a nanoparticle containing the photosensitizer Chloro-Aluminum Phthalocyanine in order to promote the mortality of primary mammary tumor cells and possible foci of metastases . To that end, three nanoformulations were developed and characterized: Nanoemulsion of Fatalocyanine ChlorineAluminum (NE-ALCLFT), Folic Acid Chlorine-Aluminum Phthalocyanine Nanoemulsion (NE-FOALCLFT) and Folic Acid Micelle-FO-ALCLFT). For the characterization, the methodologies were used: stability analysis, ZetaSizer, FT-IR, RAMAN, Transmission Electron Microscopy (SEM) and Scanning (SEM), Spectrofluorimeter analysis and the study of the production of reactive oxygen species ). The in vitro study was carried out to evaluate cell viability and cytotoxicity, using two cell lines, one of the squamous cell carcinoma (4T1) and the other of fibroblasts (NIH / 3T3), by the evaluation of the MTT colorimetric method and the morphological analysis of the Post-treatment cells by Fluorescence Microscopy and phase contrast. These tests also evaluated the interference of the power used by the LED for the application of the PDT, being tested the powers $10 \mathrm{~mW} / \mathrm{cm}^{2}, 50 \mathrm{~mW} / \mathrm{cm}^{2}$ and $100 \mathrm{~mW} / \mathrm{cm}^{2}$. Finally, the in vivo and ex vivo tests were carried out, including the study of the biodistribution of the three nanoformulations through intravenous administration, by means of real time imaging evaluation in the Lumina XR IVIS equipment. After the biodistribution study, one of the nanoformulations (the one that presented the best results) was selected for the treatment of breast cancer using PDT. In this last phase of the study, three forms of treatment were performed: systemic (using intravenous drug administration and systemic LED irradiation (whole body of the animal)), partially systemic (with intravenous administration of the drug And irradiation only at the tumor site), and local (using intratumoral drug administration and LED irradiation also at the tumor site). The weight of the mice, tumor volume, biochemical and hematological analyzes, PET / SPECT (evaluating lung and bone volume) and histopathological analysis were analyzed by microtomography. The results show all the syntheses of the nanoformulations and their respective characterizations, suggesting the relevant stability of the nanoparticles. The cell viability assays show that the nanoformulations have cytotoxicity for both cell lines tested, and that the use of LEDs alone (without the presence of nanoformulations) provokes an increase in cell viability in the fibroblast lineage. The biodistribution test highlights the main organs affected by nanoformulations, especially the liver, spleen and kidneys. In addition, it was concluded that the NE-ALCLFT nanoformulation presented the best biodistribution to the tumor region. Finally, in vivo treatments with the use of PDT, point to effects of tumor necrosis and inflammatory infiltrates. In addition, it was possible to conclude that the best form of treatment, among those analyzed, was to use nanoformulation by intravenous administration, and LED irradiation at the site of the tumor region, where it presented $80 \%$ of treatment efficiency, with 4 mice presenting all normal tissues $(n=5)$. Therefore, with this work, it was possible to develop an efficient method for the treatment of breast cancer, using PDT with a chlorthal aluminum phthalocyanine nanoemulsion, by intravenous administration.
\end{abstract}

Keywords: breast cancer, photodynamic therapy, nanoemulsion chloro-aluminum phthalocyanine 


\section{LISTA DE FIGURAS}

Figura 1. Processo de circulação das células tumorais.

Figura 2. Esquema representando as interações das cascatas de sinalizações de fatores relacionados com a metástase do câncer de mama. Esta imagem resume a relação entre fatores de crescimento tumoral de células endoteliais adjacentes do sangue (SEC) e células endoteliais linfáticas (LEC)..............4

Figura 3. Ilustração dos subtipos de reação produzidos na TFD. ............................................................6

Figura 4. Estrutura química da Ftalocianina de Cloro-Alumínio. .............................................................. 10

Figura 5. Método de emulsificação espontânea. Preparação das Fases 1 e 2. .........................................20

Figura 6. Representação esquemática das nanoformulações NE-ALCLFT, NE-ALCLFT-FO e MIC-FO-

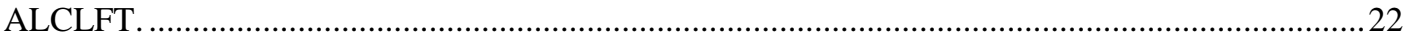

Figura 7. Representação esquemática do monitoramento da estabilidade nas nanoformulações. ..............23

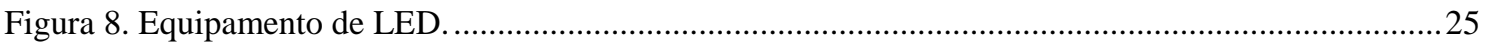

Figura 9.Ilustração da forma como foi distribuído o plaqueamento das células 4T1-luc. .........................28

Figura 10. Imagem da indução tumoral por inoculação ortotópica na quinta mama do camundongo. Foi utilizado $0,05 \mathrm{~mL}$ de suspensão celular contendo 1 x $10^{5}$ células da linhagem 4T1-luciferase (adenocarcinoma mamário). (A) Imagem em campo maior apresentando a lupa utilizada. (B) Momento da inoculação em campo menor. ........................................................................... 32

Figura 11. Administração endovenosa das nanoformulações..............................................................33

Figura 12. Administração da nanoformulação (na foto, a NE-ALCLFT) por via endovenosa na veia lateral caudal do camundongo. Foi realizada a administração de $100 \mu \mathrm{L}$ das nanoformulações, na

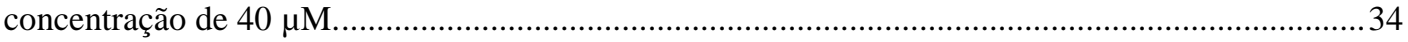

Figura 13. Imagem da cauda do animal após a administração endovenosa nanoformulação....................34

Figura 14. Imagens mostrando os procedimentos realizados no equipamento IVIS Lumina. (A) Visualização do interior da câmara onde os animais são colocados para fazer os procedimentos de imageamento. (B) Tem-se a visualização de como é feito o processamento da aquisição das imagens monitoradas pelo equipamento IVIS Lumina.

Figura 15. Vias de administração da nanoformulação para o tratamento. A. Endovenoso. B. Intratumoral.

Figura 16. Imagem da placa de alumínio usada para a irradiação do LED no tratamento local.

Figura 17. Aplicação da TFD. (A) Tratamento com aplicação da TFD, na forma de irradiação sistêmica.

(B) Tratamento com aplicação da TFD, na forma de irradiação local. .............................................39

Figura 18. Diagrama contendo a ordem cronológica das sessões de tratamento. ....................................39

Figura 19. Eletromicrografias de transmissão das nanoformulações.(A) NE-ALCLFT, (B) NE-ALCLFTFO e (C) MIC-FO-ALCLFT. Nanoformulações contrastadas por vapor de ósmio. População monodispersa de nanogotículas com morfologia esférica. Aumento de 100 mil vezes. ...................44

Figura 20.Micrografias de varredura das nanoformulações. (A) NE-ALCLFT, (B) NE-ALCLFT-FO e (C) MIC-FO-ALCLFT. Nanoformulações contratadas por metalização com ouro. Análise morfológica esféricas.

Figura 21. Espectroscopia no Infravermelho com transformada de Fourier. (a) MIC-FO-ALCLFT. (b) NE-ALCLFT-FO. (c) NE-ALCLFT. (d) ALCLFT. (e) Óleo de Rícino. (f) Cremophor. (g) Ácido fólico.

Figura 22. Análise de RAMAN.Os espectros caracterizam os compostos nanoemulsão sem ácido fólico e sem fotossensibilizador (linha em preto), a nanoemuslão com o ácido fólico e sem o fotossensibilizador (linha em vermelho) e a nanoemulsão com o ácido fólico e com o

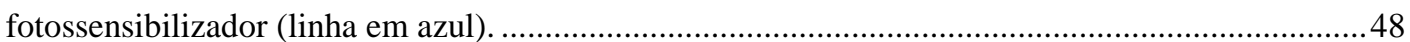

Figura 23. Avaliação da estabilidade física das nanoformulações ao longo de 300 dias. (A) Análise do diâmetro hidrodinâmico (DH) e do índice de polidispersão (PDI) da NE-ALCLFT. (B) Análise do DH e do PDI da NE-ALCLFT-FO. (C) Análise do DH e do PDI da MIC-FO-ALCLFT. (D) Análise do potencial zeta $(\mathrm{PZ})$ e do potencial hidrogeniônico $(\mathrm{pH})$ à temperatura de $37^{\circ} \mathrm{C}$ da nanoformulações. Os dados mostram que os valores de DH, PDI, PZ e pH, sugerem estabilidade física das nanoformulações em relação ao tempo analisado. $\mathrm{Na}$ figura, apenas a linha do $\mathrm{pH}$ da 
nanoformulação NE-ALCLFT, foi apresentado, pois as demais formulações apresentaram os

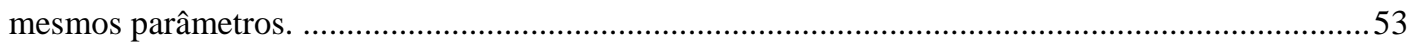

Figura 24. Análise estatística do espectrofluorímetro para quantificar a intensidade de fluorescência emitida pela NE-ALCLFT. (A) Mapeamento colorimétrico da intensidade produzida em relação a região de excitação e emissão. (B) A quantificação gráfica do mapeamento colorimétrico de intensidade de fluorescência. Os dados mostram que os melhores comprimentos de ondas estão situados no comprimento de emissão no intervalo de $680 \mathrm{~nm}$ à $800 \mathrm{~nm}$, com comprimento de excitação no intervalo de $600 \mathrm{~nm}$ à $700 \mathrm{~nm}$. A análise mostra o intervalo com maior intensidade de fluorescência emitida pela nanopartícula (região apontada pela seta). . .54

Figura 25. Análise do tempo de incubação das nanoformulações pelo equipamento IVIS LUMINA.Em A, B e C, mostra a imagem de bioluminescência obtida, tendo a escala colorimétrica de intensidade crescente de azul a vermelho. Em D, E e F, tem a imagem de fluorescência, tendo a escala colorimétrica de intensidade crescente de vermelho a amarelo. Ao lado das imagens, são fornecidos os gráficos obtidos pelas imagens, que expressa à quantificação de fluorescência e bioluminescência calculada pelo ROI (Region of interest) no software do equipamento, o que permite comparar a intensidade de fluorescência de cada nanopartícula. ....................................................................56

Figura 26. Viabilidade celular após a exposição das nanoformulações (NE, NE-FO e MIC-FO), nas células de fibroblastos murino (NIH/3T3 - A, B e C) e adenocarcinoma murino (4T1 - D, E e F).Os testes foram realizados sem a presença do fotossensibilizador, em concentrações seriadas (de $0,009 \mu \mathrm{M}$ à $20 \mu \mathrm{M})$, com um período de incubação de 15 minutos para as formulações NE, NE-FO e MIC-FO. Análise estatística: ANOVA em duas vias e teste de múltiplas comparações de Bonferroni.

Figura 27. Viabilidade celular após a exposição das nanoformulações (NE-ALCLFT, NE-FO-ALCLFT e MIC-FO-ALCLFT), nas células de fibroblastos murino (NIH/3T3 - A, B e C) e adenocarcinoma murino (4T1 - D, E e F).Os testes foram realizados com a presença do fotossensibilizador (Ftalocianina de Cloro Alumínio - ALCLFT), em concentrações seriadas (de $0,009 \mu \mathrm{M}$ à $20 \mu \mathrm{M}$ ), com um período de incubação de 15 minutos para todas as formulações. Análise estatística: ANOVA em duas vias e teste de múltiplas comparações de Bonferroni.

Figura 28. Caracterização bioluminescente do tratamentos com TFD. Imagem representativa observada no equipamento IVIS LUMINA após os tratamentos usando as nanoformulações e as diferentes potências.

Figura 29. Gráficos representando o percentual de viabilidade celular após incubação por 15 minutos e aplicação da TFD. Dez minutos de exposição ao LED com a potência de $10 \mathrm{~mW} / \mathrm{cm}^{2}$. (A) Linhagem de adenocarcinoma mamário (4T1) (B) Linhagem de fibroblastos (NIH/3T3). Concentrações utilizadas $(0,009 \mu \mathrm{M}, 0,019 \mu \mathrm{M}, 0,039 \mu \mathrm{M}, 0,078 \mu \mathrm{M}, 0,156 \mu \mathrm{M}$ e $0,312 \mu \mathrm{M})$ de (a,d) NE-ALCLFT, (b,e) NE-ALCLFT-FO e (c,f) MIC-FO-ALCLFT. Em ambos, utilizou-se o método colorimétrico de detecção por MTT. Estatística realizada por ANOVA, com pós-teste Bonferroni, p <0,001...........61

Figura 30. Gráficos representando o percentual de viabilidade celular após incubação por 15 minutos e aplicação da TFD. Dez minutos de exposição ao LED com a potência de $50 \mathrm{~mW} / \mathrm{cm}^{2}$. (C) Linhagem de adenocarcinoma mamário (4T1) (D) Linhagem de fibroblastos (NIH/3T3). Concentrações utilizadas $(0,009 \mu \mathrm{M}, 0,019 \mu \mathrm{M}, 0,039 \mu \mathrm{M}, 0,078 \mu \mathrm{M}, 0,156 \mu \mathrm{M}$ e $0,312 \mu \mathrm{M})$ de (a,d) NE-ALCLFT, (b,e) NE-ALCLFT-FO e (c,f) MIC-FO-ALCLFT. Em ambos, utilizou-se o método colorimétrico de detecção por MTT. Estatística realizada por ANOVA, com pós-teste Bonferroni, p <0,001

Figura 31. Gráficos representando o percentual de viabilidade celular após incubação por 15 minutos e aplicação da TFD.Dez minutos de exposição ao LED com a potência de $100 \mathrm{~mW} / \mathrm{cm}^{2}$. (E) Linhagem de adenocarcinoma mamário (4T1) (F) Linhagem de fibroblastos (NIH/3T3). Concentrações utilizadas $(0,009 \mu \mathrm{M}, 0,019 \mu \mathrm{M}, 0,039 \mu \mathrm{M}, 0,078 \mu \mathrm{M}, 0,156 \mu \mathrm{M}$ e $0,312 \mu \mathrm{M})$ de (a,d) NE-ALCLFT, $(b, e)$ NE-ALCLFT-FO e (c,f) MIC-FO-ALCLFT. Em ambos, utilizou-se o método colorimétrico de detecção por MTT. Estatística realizada por ANOVA, com pós-teste Bonferroni, p <0,001...........64

Figura 32. Alterações morfológicas e estruturais induzidas pela TFD utilizando as nanoformulações (NEALCLFT, NE-ALCLFT-FO, MIC-FO-ALCLFT) em células de carcinoma mamário (linhagem 
4T1).Análise após a incubação por 15 minutos das respectivas nanoformulações na concentração de $0,078 \mu \mathrm{M}$ e posterior aplicação da TFD. Dez minutos de exposição ao LED com as potências de $10 \mathrm{~mW} / \mathrm{cm}^{2}, 50 \mathrm{~mW} / \mathrm{cm}^{2}$ e $100 \mathrm{~mW} / \mathrm{cm}^{2}$. As imagens foram divididas em duas colunas, sendo a resolução de 20x (esquerda) e 40x (direita). (A) Controle (células sem tratamento); (B, C, D, E, F, G, H, I, J) Grupos Tratados. Nas células tratadas, é possível notar alterações estruturais, modificação citoplasmática, presença de debris e formas arredondadas. ..68

Figura 33. Alterações morfológicas e estruturais induzidas pela TFD utilizando as nanoformulações (NEALCLFT, NE-ALCLFT-FO, MIC-FO-ALCLFT) em células de fibroblasto (linhagem NIH/3T3).Análise após a incubação por 15 minutos das respectivas nanoformulações na concentração de $0,078 \mu \mathrm{M}$ e posterior aplicação da TFD. Dez minutos de exposição ao LED com as potências de $10 \mathrm{~mW} / \mathrm{cm}^{2}, 50 \mathrm{~mW} / \mathrm{cm}^{2}$ e $100 \mathrm{~mW} / \mathrm{cm}^{2}$. As imagens foram divididas em duas colunas, sendo a resolução de 20x (esquerda) e 40x (direita). (A) Controle (células sem tratamento); (B, C, D, E, F, G, H, I, J) Grupos Tratados. Nas células tratadas, é possível notar alterações estruturais, modificação citoplasmática, presença de debris e estruturas amórficas. . .71

Figura 34. Representação do modelo ortotópico de células tumorais de carcinoma adenocarcinoma mamário mamário (4T1-luciferase) na quinta mama do camundongo. A imagem demonstra a visualização da bioluminescência, visualizada pelo equipamento Ivis Lumina XR. (A). Aquisição de imagem em campo normal. (B) Aquisição de imagem com Raio X................................................72

Figura 35. Análise da biodistribuição in vivo pelo equipamento IVIS Lumina XR, medindo a intensidade de fluorescência das nanoformulações. (A) Representa a formulação NE-ALCLFT. (B) Representa a formulação NE-ALCLFT-FO. (C) Representa a formulação MIC-FO-ALCLFT. Foram analisado os intervalos $1,2,4,6,8,10$ e 12 horas.

Figura 36. Imagem da biodistribuição ex vivo da formulação NE-ALCLFT. (A) A imagem dos órgãos contendo a NE-ALCLFT, tendo o grupo controle e os intervalo de 6 e 10 horas. No gráfico (B) é possível observar a alta intensidade de fluorescência (quantificada pelo ROI), principalmente no fígado, pulmão e linfonodo sentinela. A medida que o tempo passa ( de 6horas para 10 horas), essa quantidade aumenta, no entanto, mantém-se proporcional na região do tumor................................76

Figura 37. Análise da intensidade de fluorescência da biodistribuição ex vivo da formulação NEALCLFT-FO. (A) A imagem dos órgãos contendo a NE-ALCLFT-FO, tendo o grupo controle e os intervalo de 6 e 10 horas. No gráfico (B) é possível observar a alta intensidade de fluorescência (quantificada pelo ROI), principalmente no fígado, pulmão, cérebro e linfonodo sentinela. À medida que o tempo passa (de 6horas para 10 horas), a quantidade de fluorescência decai para alguns órgão (rins, fígado e cérebro) e aumenta em outros (linfonodo sentinela e pulmão). Mantém-se

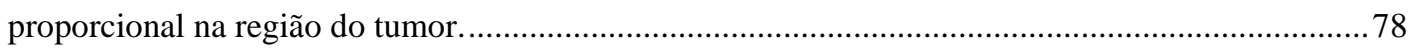

Figura 38. Análise da biodistribuição ex vivo da formulação MIC-FO-ALCLFT. (A) A imagem dos órgãos contendo a MIC-FO-ALCLFT, tendo o grupo controle e os intervalo de 6 e 10 horas. No gráfico (B) é possível observar a alta intensidade de fluorescência (quantificada pelo ROI), principalmente no fígado e pulmão.

Figura 39. Análise de bioluminescência e fluorescência pelas nanoformulações nos intervalos de $6 \mathrm{~h}$ e 10h. (A) Análise da bioluminescência do tumor, a qual representa o tamanho tumoral avaliado pela quantidade de bioluminescência presente na região. (B) Análise da intensidade de fluorescência das nanoformulações, quantificada em cada tumor nos tempos de $6 \mathrm{~h}$ e 10h. Estatística OneWayANOVA, $\mathrm{p}<0.05$

Figura 40. Avaliação do peso dos órgãos segundo as análises de biodistribuição ex vivo das nanoformulações. (A) Representa os órgãos do intervalo de 6horas. (B) Representa os órgãos do intervalo de 10horas.

Figura 41. Relação entre o peso dos órgãos e a intensidade de fluorescência presente em cada órgão. (A) Análise às 6h. (B) Análise às $10 \mathrm{~h}$.

Figura 42. Fotografia da região do linfonodo sentinela. (A) Animal que recebeu a NE-ALCLFT. (B) Animal que recebeu a NE-ALCLFT-FO. Note a coloração mais escura ocasionada possivelmente pelo acumulo das nanoformulações nesta região (setas). 
Figura 43. Análise do volume tumoral dos grupos nnão tratados com TFD (A) e dos grupos tratados com TFD (B). Variação do volume tumoral no decorrer das semanas de tratamento, sendo no total 6 sessões. Volume calculado segundo a fórmula: (Comprimento) x (largura) ${ }^{2}$ x 0,5. (A) Note que no gráfico dos grupos não tratados com a TFD, a escala do eixo Y é de 0 a $1000 \mathrm{~mm}^{3}$, e no gráfico dos grupos tratadas com TFD (B) a escala é de 0 a $100 \mathrm{~mm}^{3}$. Este aspecto é para a melhor visualização da análise de regressão do volume tumoral, comparando os grupos tratados e não tratados com a aplicação da TFD. ... 84

Figura 44. Imagens após terceira sessão de tratamentos com aplicação da TFD. (A) Tratamento sistêmico (endovenoso) com irradiação sistêmica. (B) Tratamento local (intratumoral) com irradiação sistêmica. (C). Tratamento endovenoso com Irradiação local.

Figura 45. Quantidade de animais (em porcentagem) que sobreviveram após todos os tratamentos. ........86

Figura 46. Imagens de tomografia computadorizada dos animais do grupo controle negativo (A) e controle positivo (B). As imagens apresentam corte transverso (a), sagital (b) e frontal (c). Note que o pulmão do grupo controle negativo, visualizado no corte frontal, apresenta coloração preta, a qual é indício da presença de ar no pulmão. Já o pulmão do grupo controle positivo, no corte frontal, não apresenta este mesmo aspecto. Setas ressaltando os pulmões.

Figura 47. Imagem tridimensional do animal do grupo controle positivo. Posição frontal em (direita) e sagital (esquerda). Ressalta-se a estrutura pulmonar e óssea do animal. ......................................... 87

Figura 48. Análise do volume ósseo (A) e pulmonar (B), dos grupos após os tratamentos. ......................88 Figura 49. Peso dos órgãos (fígado, baço e tumor) no dia da eutanásia dos animais. As análises estatísticas foram feitas utilizando Two-WayANOVA, com pós-teste de Bonferroni $(\mathrm{p}<0,05)$. Abaixo do gráfico, têm-se imagens de fotos mostrando o (A) Fígado (porção do lóbulo maior), (B) Baço e (C) Tumor do grupo LED, evidenciamento o aumento destes órgãos.

Figura 50. Peso corporal monitorado por 6 semanas (1 vez por semana) durante o período de tratamento por TFD em camundongos Balb/c portando tumores da linhagem 4T1-luc.

Figura 51. Análise bioquímica dos analitos alanina transaminase (ALT), aspartato transaminase (AST), isoenzima CK-MB, ferro e ureia. Esses analitos, visam as análises complementares das funções hepáticas (ALT eAST), renais (Ureia), cardíacas (CK-MB) e disfunções relacionadas ao ferro. Os testes foram feitos com base na análise estatísticas por Two-Way-ANOVA, com pós-teste Bonferrone, considerando $\mathrm{p}<0,05$

Figura 52. Prancha histológica retratando o baço e o fígado. Os grupos CONTROLE NEGATIVO, POSITIVO, E SISTÊMICO, apresentam aspectos habituais dos tecidos. No grupo LED, NEALCLFT, SISTEMICO-LOCAL e LOCAL apresentam focos neoplásicos. Todas fotomicrografias foram registradas em objetiva de 40x. Coloração por H\&E.

Figura 53. Prancha histológica retratando o cérebro e o coração. Em todos os grupos o cérebro retrata aspectos habituais do tecido. Já o coração, apresenta focos neoplásicos no grupo LED e trombos no grupo LOCAL, apresentando estruturas habituais nos demais grupos. Todas fotomicrografias foram registradas em objetiva de 40x. Coloração por H\&E. 101

Figura 54. Prancha histológica retratando o linfonodo contralateral e o linfonodo sentinela. Nos grupos do CONTROLE NEGATIVO, POSITIVO, LED, NE-ALCLFT, SISTÊMICO e SISTÊMICO LOCAL, está mostrando tecidos habituais deste órgão, já o grupo LOCAL, apresenta focos neoplásicos. Quanto ao linfonodo sentinela, tem aspectos neoplásicos nos grupos POSITIVO, LED, LOCAL e SISTÊMICO, tendo aspectos habituais nos demais grupos. Todas fotomicrografias foram registradas em objetiva de 40x. Coloração por H\&E. 103

Figura 55. Prancha histológica retratando a mama contralateral e a região tumoral. Em todas as regiões tumorais de todos os grupos, com exceção do CONTROLE NEGATIVO e DO SISTÊMICOLOCAL, apresentam áreas neoplásicas. O controle negativo mostra aspecto habituais do tecido. O grupo SISTÊMICO-LOCAL, apresenta áreas com fibrose. Já a mama contralateral, apresenta tecidos normais no grupo CONTROLE NEGATIVO, POSITIVO, LED, NE-ALCLFT, enquanto que no grupo LOCAL, apresenta uma área acentuada de infiltrado inflamatório, e no grupo 
SISTÊMICO, apresenta focos neoplásicos. No grupo SISTÊMICO-LOCAL, evidencia uma região hemorrágica. Todas fotomicrografias foram registradas em objetiva de 40x. Coloração por H\&E.105

Figura 56. Prancha histológica retratando o pulmão e os rins. Em todos os grupos, houve focos de células neoplásicas no pulmão em pelo menos um dos animais de cada grupo, com exceção do grupo CONTROLE NEGATIVO. Quanto às análises histológicas dos rins, há a presença de células neoplásicas no grupo CONTROLE POSITIVO, apresentando aspectos normais para os demais grupos. Todas fotomicrografias foram registradas em objetiva de 40x. Coloração por H\&E. …....107

Figura 57. Biodistribuição de nanopartículas de acordo com o seu tamanho..............................................113 


\section{LISTA DE TABELAS}

Tabela 1. Lista dos principais materiais utilizados neste trabalho.

Tabela 2. Lista dos principais reagentes utilizados neste trabalho.

Tabela 3. Lista dos principais equipamentos utilizados neste trabalho.

Tabela 4. Grupos experimentais para a TFD in vivo.

Tabela 5. Determinação do diâmetro hidrodinâmico, do índice de polidispersão e do potencial zeta da nanoemulsão (NE) e da nanoemulsão de ftalocianina de cloro-alumínio (NE-ALCLFT)

Tabela 6. Determinação do diâmetro hidrodinâmico, do índice de polidispersão e do potencial zeta da nanoemulsão com ácido fólico (NE-FO) e da nanoemulsão contendo ácido fólico com ftalocianina de cloro-alumínio (NE-ALCLFT-FO).

Tabela 7. Determinação do diâmetro hidrodinâmico, do índice de polidispersão e do potencial zeta da micela de ácido fólico (MIC-FO) e da micela de ácido fólico com ftalocianina de cloro-alumínio (MIC-FO-ALCLFT). 


\section{LISTA DE ABREVIATURAS E SIGLAS}

102 - Oxigênio singlete

ALCLFT - Ftalocianina de Cloro-Alumínio

ANOVA - Análise de variância

CCL5 - Quimiocina ligante 5 (Chemokine (C-C motif) ligand 5)

D.O. - Densidade óptica

DBF - 1,3-difenil-isobenzofurano

DH - Diâmetro hidrodinâmico

DMEM - Dulbeco Modified Eagle Medium (Invitrogen)

DMSO - Dimetilsulfóxido

DNA - Ácido desoxirribonucleico

E.P.M - Erro padrão da média

EPR - Permeação e retenção aumentadas

H\&E - Hematoxilina e Eosina

HER2 - Receptor do Fator de Crescimento Epidérmico Humano (Human Epidermal growth factor Receptor )

IL-6 -Interleucina 6

INCA - Instituto Nacional do Câncer

MIC-FO-ALCLFT - Micela de ácido fólico com ftalocianina de cloro-alumínio

MTT - Brometo de 3(4,5 dimetiltiazol-2il)-2,5-difenil-tetrazólio

NE-ALCLFT - Nanoemulsão de ftalocianina cloro-alumínio

NE-ALCLFT-FO Nanoemulsão de ftalocianina de cloro-alumínio com ácido fólico

PBS - Tampão Fosfato Salina

PS - Fotossensibilizador

ROS - Espécies Reativas de Oxigênio

SFB - Soro Fetal Bovino

TFD - Terapia Fotodinâmica

VEGF-A - Fator de crescimento endotelial A (Vascular endothelial growth factor A)

VEGF-C - Fator de crescimento endotelial C (Vascular endothelial growth factor $C$ ) 


\section{SUMÁRIO}

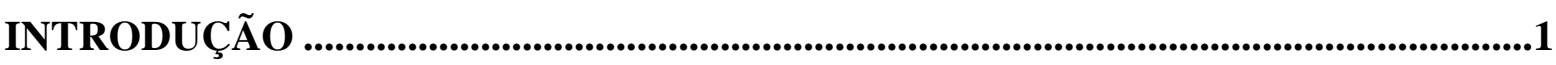

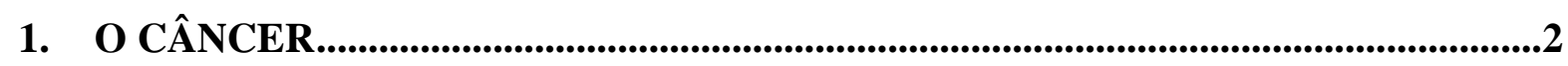

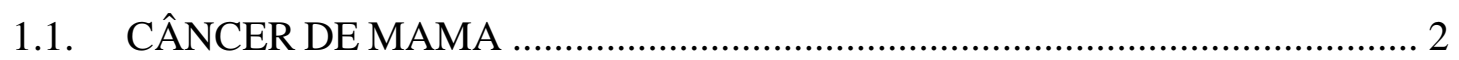

1.1.1. CÂNCER DE MAMA METASTÁTICO ……………………………..... 2

2. TERAPIA FOTODINÂMICA …..........................................................................

2.1. TERAPIA FOTODINÂMICA E O SISTEMA IMUNOLÓGICO ........................... 7

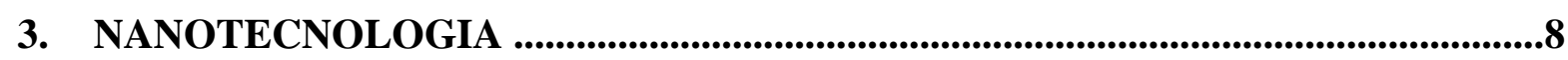

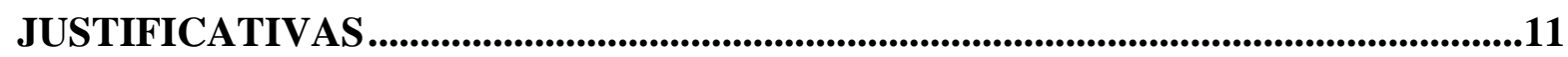

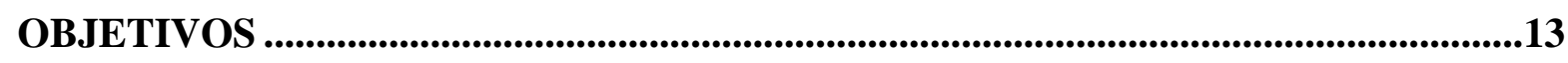

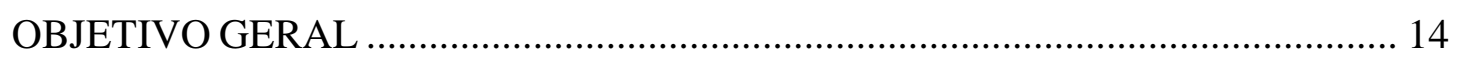

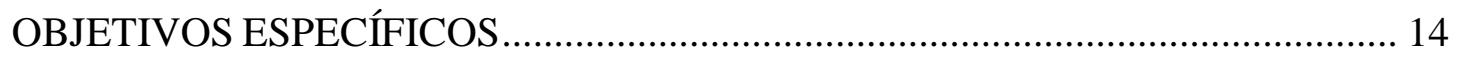

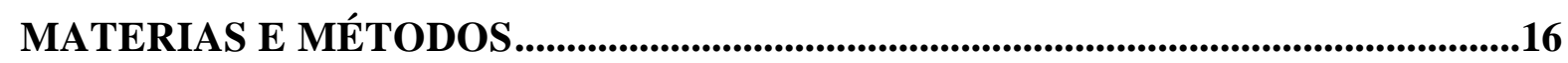

1. SÍNTESE DAS NANOFORMULAÇÕES: TÉCNICAS DE PREPARO ............. 20

2. MÉTODOS DE CARACTERIZAÇÃO DAS NANOFORMULAÇÕES (NE-

ALCLFT, NE-ALCLFT-FO E MIC-FO-ALCLFT) ……………………………....... 22

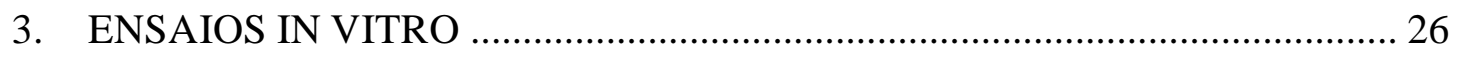

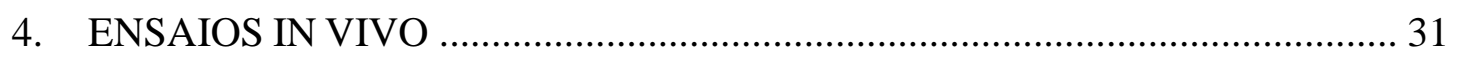

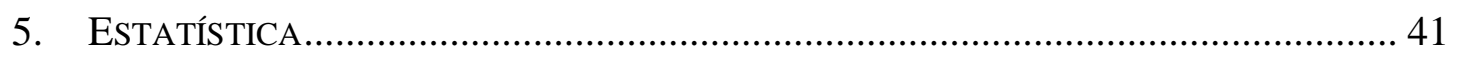

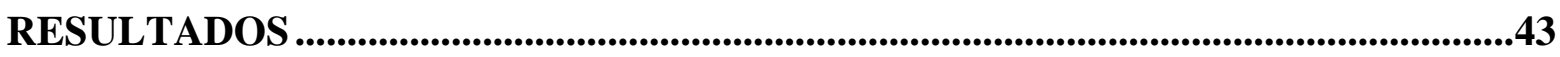

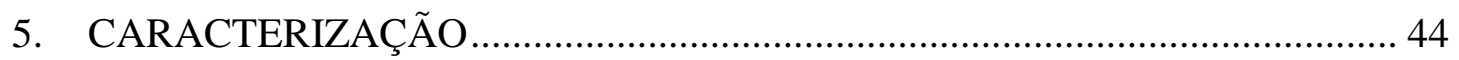

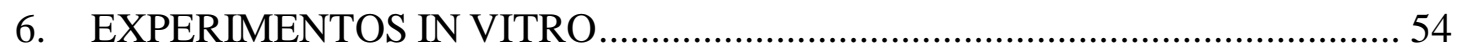

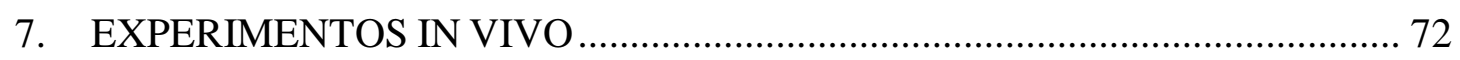

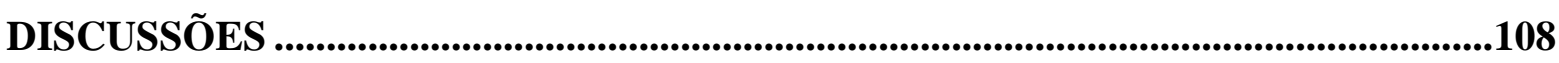

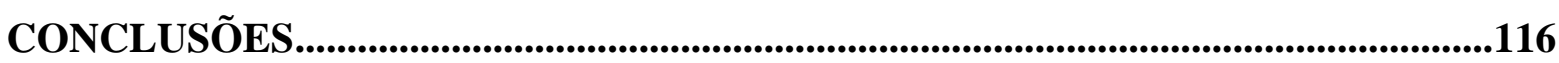

REFERÊNCIAS BIBLIOGRÁFICAS _......................................................................119

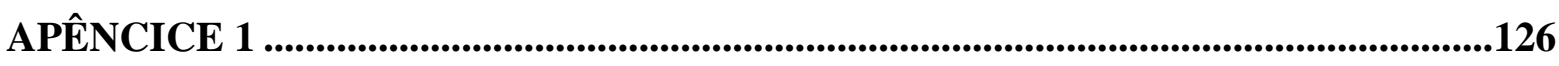

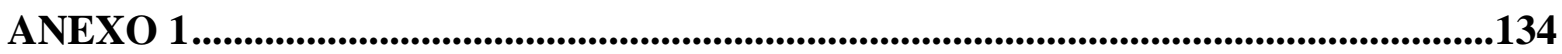




\section{O CÂNCER}

O câncer é caracterizado por um complexo de alterações que afetam a atividade molecular intracelular e também as comunicações entre as células e tecidos (HANAHAN; WEINBERG, 2011). Em nível genômico, ocorre frequente interrupção dos mecanismos de reparo do DNA, além da reprogramação sequencial genética e alterações epigenéticas, como mutação pontual, translocações e variação no número de duplicação, as quais podem resultar em expressão gênica aberrante (DU, 2014; WINSLOW et al., 2015).

Embora uma célula cancerosa possa abrigar milhares de alterações genéticas, apenas as células que apresentam fatores de crescimento seletivo, como a presença de alguns receptores, causam a transformação maligna e a progressão tumoral (KITAMURA, 2015). Assim, um dos focos na área "Genômica do Câncer", tem sido identificar essas células e compreender o mecanismo destes fatores de crescimento, a fim de entender a patogenicidade desta propagação celular desordenada que é ocasionada pelo câncer.

\subsection{CÂNCER DE MAMA}

Dentre todos os tipos de cânceres existentes, o câncer de mama representa $25 \%$ do total de neoplasias no mundo, além de ser o segundo tipo de câncer mais comum entre mulheres com faixa etária superior a 35 anos e uma das causa mais frequente de morte neste grupo (INCA, 2015).

O câncer de mama é uma doença heterogênea com múltiplos subtipos, sendo classificado em Basal (ou triplo negativo), HER2-positivo, Luminal A e Luminal B (FERTIG, 2015; WINSLOW et al., 2015). Desses, o primeiro é o subtipo mais agressivo e metastático, pois não expressam receptores de células típicas, como o de estrógeno e progesterona, o que dificulta as terapias hormonais ou a inibição de HER2 (FERTIG, 2015).

\subsubsection{CÂNCER DE MAMA METASTÁTICO}

Com o crescimento do tumor primário, ocorre o processo de angiogênese no qual se desenvolve um suprimento de vasos sanguíneos para apoiar as necessidades 
metabólicas do tumor (KIM et al., 2011; LIZOTTE, 2015). Essa neovascularização, possibilita uma rota de fuga pela qual as células tumorais entram no sistema circulatório do organismo (HUNTER et al., 2008) (Figura1), podendo atingir órgãos como o pulmão, o fígado, a medula óssea, dentre outros (MICHELL, 2010).

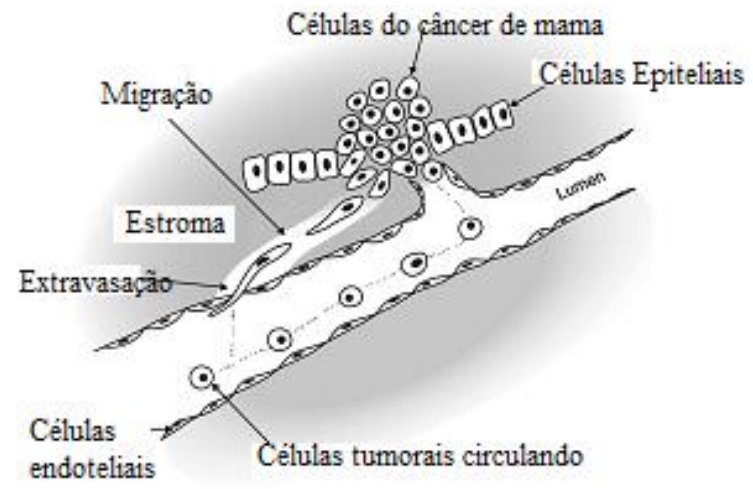

Figura 1. Processo de circulação das células tumorais.

Fonte: SCULLY, et al., 2012 (adaptado).

Em geral, a migração de células em metástase apresenta semelhanças com o trânsito de leucócitos, que é especialmente regulada por fatores de crescimento, quimiocinas, citocinas e seus receptores (MULLER et al., 2001). As citocinas e as quimiocinas representam importantes proteínas solúveis na sinalização celular para os mecanismos de funcionamento das células, além de desempenhar funções no sistema imunológico, (SCULLY et al., 2012).

No câncer de mama metastático, as moléculas de quimiocinas e citocinas podem desempenhar um papel na motilidade das células tumorais (SCULLY et al., 2012). Assim, para o crescimento tumoral e a disseminação de metástases é fundamental a secreção destas moléculas, as quais irão atuar na adesão, na manutenção, na migração e na proliferação celular.

Fertig e colaboradores (2015) relataram que a atuação da Interleucina 6 (IL6), da quimiocina CCL5, e dos fatores de crescimento endoteliais vasculares VEGF-A e VEGF-C, são fatores cruciais para o crescimento do câncer de mama e para a metástase basal, os quais, em conjunto, ajudam a promover a metástase cancerígena, e podem ser compreendidas da seguinte forma: 
A IL-6 foi associada à transição epitelial-mesenquimal (EMT), processo natural que ocorre durante a embriogênese. Neste processo, as células epiteliais perdem a sua polaridade e adesão celular, além de obter propriedades migratórias e invasivas a ponto de se tornarem células-tronco mesenquimais capazes de direcionar para órgãos distantes (DETHLEFSEN; HØJFELDT; HOJMAN, 2013; FERTIG, 2015). Este mecanismo está relacionado à capacidade das células fixas tumorais se tornarem células itinerantes (DETHLEFSEN; HØJFELDT; HOJMAN, 2013).

A quimiocina CCL5 foi relacionada à melhor sobrevida dos cânceres de mama, principalmente aos subtipos HER2+ e Luminal, onde se constatou que ocorre a sua superexpressão. (FERTIG, 2015; LEE et al., 2014).

Os fatores de crescimento vascular endotelial VEGF-C e o VEGF-A, são fatores angiogênicos e de crescimento linfangiogênicos, que quando superexpressos promovem o crescimento de vasos linfáticos no tumor (linfagiogênese intratumoral) (CHRISTIANSEN; DETMAR, 2011; FERTIG, 2015; SKOBE et al., 2001). Esse é um fato relevante, visto que a metástase do câncer de mama, ocorre principalmente através do sistema linfático, e o grau de comprometimento dos linfonodos é um fator chave no prognóstico para a doença (CHRISTIANSEN; DETMAR, 2011; KALLURI, 2003). Além disso, o estudo de Skobe e colaboradores (2011) ressalta que esse mecanismo de ação está interligado com as metástases pulmonares pelo câncer de mama primário (SKOBE et al., 2001) (Figura 2).

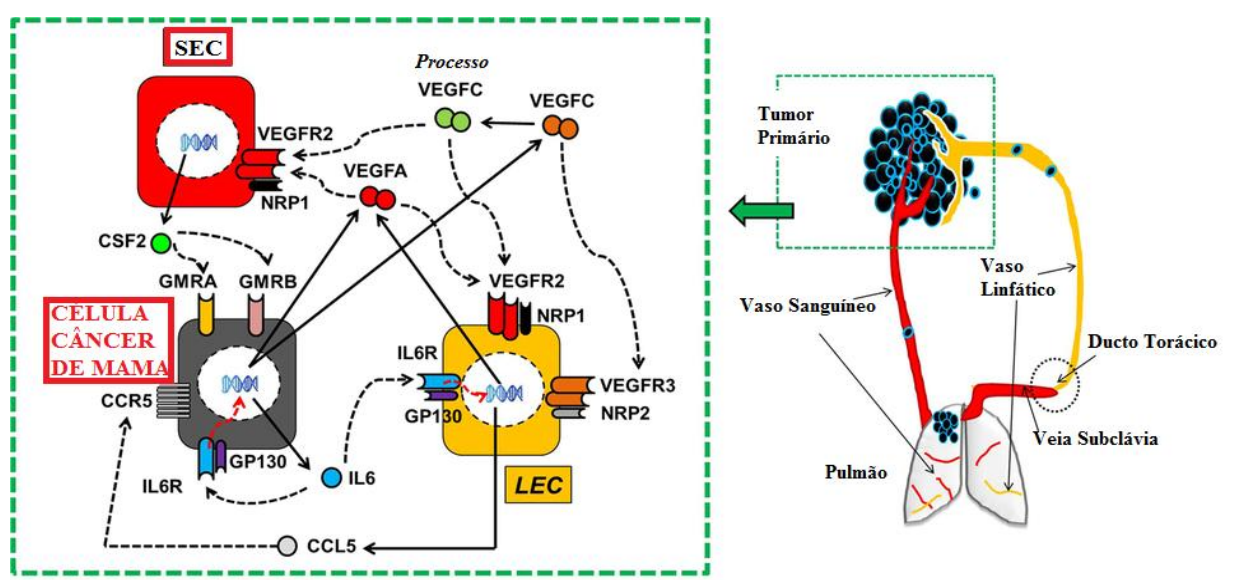

Figura 2. Esquema representando as interações das cascatas de sinalizações de fatores relacionados com a metástase do câncer de mama. Esta imagem resume a relação entre fatores de crescimento tumoral de células endoteliais adjacentes do sangue (SEC) e células endoteliais linfáticas (LEC).

Fonte: FERTIG et al., 2015 (adaptada). 
Vale ressaltar que as terapias atuais, incluindo a cirurgia, a terapia hormonal, a quimioterapia e a terapia com radiação, não são completamente seletivas no tratamento do câncer de mama primário e metastático (MUEHLMANN et al., 2014). Ademais a resistência à terapêutica é comum no tratamento de quaisquer subtipos do câncer de mama (FERTIG, 2015; GUELCHER; STERLING, 2011; KRIEGER, 2015). Portanto, são necessárias terapias que possam auxiliar no tratamento deste tumor, de modo a destruir a propagação metastática. Com isso, um dos tratamentos que está em ascensão para o tratamento do câncer, é a terapia fotodinâmica (TFD).

\section{TERAPIA FOTODINÂMICA}

No início do ano de 1900, Raab descreveu o efeito do corante Acridina na presença de luz visível para destruir um protozoário denominado Paramecium. Ele deu a este evento o nome de "Terapia Fotodinâmica" (RAAB, 1900). A partir disso, a terapia fotodinâmica (TFD) tem sido estudada e utilizada na área das ciências médicas para o tratamento de diversas patologias, inclusive o câncer. (DOUGHERTY, 1989).

Em 1978, Dougherty e colaboradores, fizeram o primeiro estudo clínico envolvendo neoplasias com a aplicação da TFD em humanos. Este estudo envolveu vinte e cinco pacientes com o total de cento e treze lesões, incluindo câncer de mama, de cólon, da próstata, melanoma, condrossarcoma, angiossarcoma, células endometriais, basais e escamosas, as quais todas apresentavam resistência a tratamentos convencionais. Estas lesões foram tratadas com um fotossensibilizador derivado de hematoporfirina $(\mathrm{HpD})$ por via de administração endovenosa e com aplicação local da TFD, obtendo resposta satisfatória total ou parcial em $87 \%$ das lesões, inclusive na erradicação completa de metástases que envolvia a parede torácica, mostrando pela primeira vez a possibilidade de tratamento com sucesso, utilizando a TFD, em tumores resistentes a outras terapias (DOUGHERTY et al., 1978).

O mecanismo de ação da terapia fotodinâmica envolve três elementos fundamentais, sendo eles: um agente fotossensibilizante ou fotossensibilizador, uma fonte de luz específica e moléculas de oxigênio (DOLMANS; FUKUMURA; JAIN, 2003).

Após a administração do fotossensibilizador, é realizada a irradiação com uma fonte de luz em um comprimento de onda específico para aquele determinado agente 
fotossensibilizante (MUEHLMANN et al., 2014), que absorve fótons de luz e se torna ativo. Este transfere a sua energia do estado fundamental para o oxigênio molecular, gerando espécies reativas de oxigênio (ROS) (CASTANO; HAMBLIN, 2006; AGOSTINIS et al., 2011; MUEHLMANN et al., 2014). Os ROS gerados podem oxidar macromoléculas celulares levando a morte das células tumorais por apoptose, necrose ou autofagia (GARG; AGOSTINIS, 2014; LI et al., 2009; REGINATO et al., 2013; WANG et al, 2015).

Posteriormente, o fotossensibilizador tanto pode decair de volta para o estado fundamental emitindo fluorescência (utilizado para imaginologia) (AGOSTINIS et al., 2011; DOLMANS; FUKUMURA; JAIN, 2003), ou pode ser submetido a um cruzamento de intersistema (o spin dos elétrons excitados inverte para formar um estado relativamente de vida longa: o estado triplete) (AGOSTINIS et al.,2011; WANG et al., 2015), Figura 3.

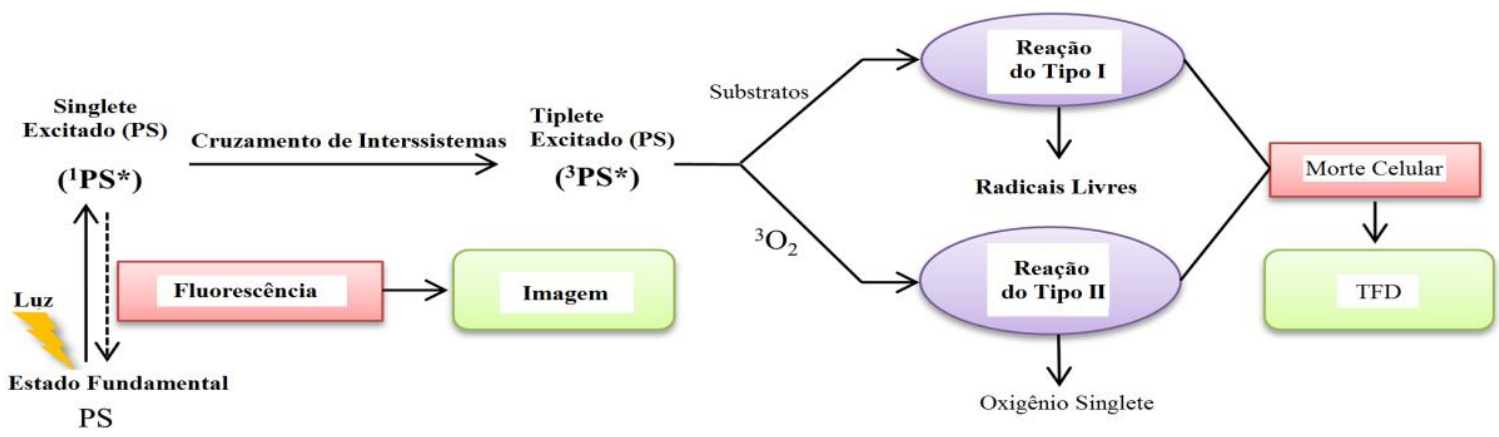

Figura 3. Ilustração dos subtipos de reação produzidos na TFD.

Fonte. DOLMANS; FUKUMURA; JAIN, 2003. (adaptado)

O oxigênio triplete pode interagir diretamente com um determinado substrato, como por exemplo, uma célula ou uma membrana, conforme ilustrado na Figura 3. Pode também reagir com o oxigênio molecular presente na região, para produzir produtos, tais como os radicais aniônicos, os superóxidos, os radicais hidroxila e os peróxidos de hidrogênio (AGOSTINIS et al.,2011; DOLMANS; FUKUMURA; JAIN, 2003). Ambas as reações, podem ocorrer simultaneamente, e a proporção entre estes processos, depende do tipo de fotossensibilizador, assim como, das concentrações de oxigênio molecular e do substrato local (DOLMANS; FUKUMURA; JAIN, 2003).

A localização subcelular do fotossensibilizador, depende das suas características estruturais químicas, tais como: carga iônica, grau de hidrofobicidade e grau de 
assimetria presente na molécula (WEISS et al., 2015). Fotossensibilizadores com cargas menos negativas tendem a ter maior captação intracelular e podem difundir através da membrana plasmática. Já os menos hidrofóbicos tendem a ser demasiadamente polar para se difundirem pela membrana plasmática, e, em consequência, sofrem endocitose (AGOSTINIS et al.,2011; ZAMARRAN et al., 2015) processo pelo qual a substância é absorvida pela célula por meio das invaginações das membranas, podendo ser fagocitada.

Outro fator relevante é relacionado ao processo angiogênico tumoral, que possibilita o aumento dos fotossensibilizadores nestes vasos sanguíneos (PIZOVA et al., 2012). A ativação destes na circulação, localizada nas células endoteliais ou ligada nas paredes dos vasos sanguíneos, resultam em danos nessas regiões (PIZOVA et al., 2012).

Estes danos levam a formação de locais trombogênicos e em consequência, promove inúmeras cascatas de reações, tais como a agregação plaquetária, a liberação de moléculas vasodilatadoras, a adesão dos leucócitos, a permeabilidade e a constrição do vaso sanguíneo (GARG; AGOSTINIS, 2014). Esses efeitos podem levar a estase do fluxo sanguíneo e hemorragias do tecido, levando a hipóxia tumoral pós TFD (AGOSTINIS et al.,2011).

\subsection{TERAPIA FOTODINÂMICA E O SISTEMA IMUNITÁRIO}

A terapia fotodinâmica no tratamento de tumores pode ocasionar a morte direta das células tumorais e danos vasculares, os quais são os principais responsáveis pela erradicação inicial do tumor (KOLTUN et al., 2014), além disso, também pode resultar na ativação de processos inflamatórios.

A principal característica do processo inflamatório é a liberação de mediadores na região tratada. Estes mediadores incluem componentes do sistema complemento, proteases, peroxidases, citocinas, fatores de crescimento e outros imuno-reguladores (KOLTUN et al., 2014; KORBELIK; HAMBLIN, 2015). Por sua vez, estes estimulam componentes como os glóbulos brancos, os neutrófilos e os macrófagos, que se direcionam para o local tratado (FRANÇA, 2010).

A atuação dos macrófagos no local do tumor irradia uma cadeia de processos que se inicia pela remoção das células cancerígenas por fagocitose, mas que também pode 
levar a ativação do sistema imunitário, por meio do recrutamento de Linfócitos T CD4 auxiliares, que então ativam Linfócitos T citotóxicos CD8 desencadeando processos de vias de morte celular (BELICHA-VILLANUEVA et al., 2012; KORBELIK; HAMBLIN, 2015; PIETTE, 2015). A ativação dos linfócitos T, não só induzem a necrose, como também pode induzir a apoptose das células tumorais ajudando no controle do tumor (PIETTE, 2015).

Assim, a TFD possui a vantagem de ser um imunoestimulador, enquanto que a cirurgia e a quimioterapia são imunossupressoras (OSEROFF, 2006). Portanto, os mecanismos anticancer da terapia fotodinâmica têm se mostrado eficientes em células tumorais, sendo também, menos invasiva comparada às terapias convencionais (BICAHO et al.,2013; MUEHLMANN et al., 2014, Longo et al., 2016). Atualmente, uma forma que tem melhorado a eficiência da TFD, é fazer o uso de nanocarreadores para o transporte dos fotossensibilizadores, de forma a diminuir a toxicidade destes no organismo, e aumentar a biodisponibilidade na região tumoral.

\section{NANOTECNOLOGIA}

As vantagens que as nanopartículas podem desempenhar no organismo quando associadas a um determinado fármaco, como os fotossensibilizadores, envolvem aspectos como o direcionamento específico para a região desejada, o aumento da disponibilidade do fármaco, conferir anfifilicidade à substância - o que permitiria o transporte por meio da corrente sanguínea e no tecido e impedir a degradação por agentes químicos (LUCKY; SOO; ZHANG, 2015).

Além de tais vantagens, outro processo relevante que ocorre com o uso de fármacos nanoestruturados é chamado de efeito de permeabilidade e retenção (EPR). Esse efeito é causado pela má drenagem linfática e vascularização anormal presente nos vasos do tumor, os quais apresentam capilares mais fenestrados (LUCKY, SOO, ZHANG, 2015). Estas características facilitam a difusão do "nano-fotossensibilizador" (no caso da TFD), aumentando a retenção desses no tecido tumoral e, por isso, causa seu acúmulo nesta região (WANG et al., 2008; LUCKY, SOO, ZHANG, 2015).

Diferentes nanopartículas já foram caracterizadas para a aplicação no tratamento do câncer como os lipossomas, as nanopartículas de ouro, as nanopartículas lipídicas 
sólidas (NLS), as micelas, as nanopartículas poliméricas, as nanopartículas magnéticas, as nanocápsulas, as nanoemulsões, dentre outras (YU, PARK, JON, 2012). Ressaltase que as nanoemulsões apresentam características importantes para o seu uso como nanocarreador, devido o fato de ser cineticamente estáveis à diluição (MUEHLMANN et al., 2015). Elas podem ser definidas como uma dispersão nanométrica de gotículas oleosas em uma fase aquosa (e vise-versa) estabilizada por um sistema adequado de tensoativo, cujo tamanho das partículas podem variar de $10 \mathrm{~nm}$ a $300 \mathrm{~nm}$ (MASON et al., 2006).

\section{a. NANOEMULSÃO DE FTALOCIANINA CLORO-ALUMÍNIO}

Os fotossensibilizadores são classificados de acordo com suas características químicas, como: 1) primeira geração, os quais são representados pelos grupos das porfirinas; 2) segunda geração, os quais têm como exemplo, os derivados de ftalocianinas (LUCKY; SOO; ZHANG, 2015; MUEHLMANN et al., 2015).

As ftalocianinas hidrofóbicas estão entre as moléculas de fotossensibilizadores mais eficientes no tratamento de câncer, pois apresentaram ter maior acumulação nestas células (MUEHLMANN et al., 2015). No entanto, o fato de serem hidrofóbicas leva à rápida eliminação pelo sistema fagocitário mononuclear, além de perderem significadamente sua atividade fotodinâmica em meio aquoso (MUEHLMANN et al., 2015; LUCKY, SOO, ZHANG, 2015).

Dentre estas ftalocianinas hidrofóbicas de segunda geração, destaca-se a ftalocianina de cloro-alumínio (AlClFt). A AlClFt, é uma molécula constituída de um macrociclo tetrapirrólico com um íon metal $\left(\mathrm{Al}^{3+}\right)$, Figura 4 (SILVA, 2013). A incorporação de um metal diamagnético, neste caso o alumínio, dentro do macrociclo fornece a ftalocianina propriedades fotofísicas e fotoquímicas mais favoráveis para a aplicação em TFD, tais como: alto rendimento quântico do estado tripleto, longo tempo de vida do tripleto, bem como alto rendimento de produção de oxigênio singleto, o que levam a processos fotobiológicos de produção de espécies reativas de oxigênio (SILVA, 2013), causando a morte celular. 


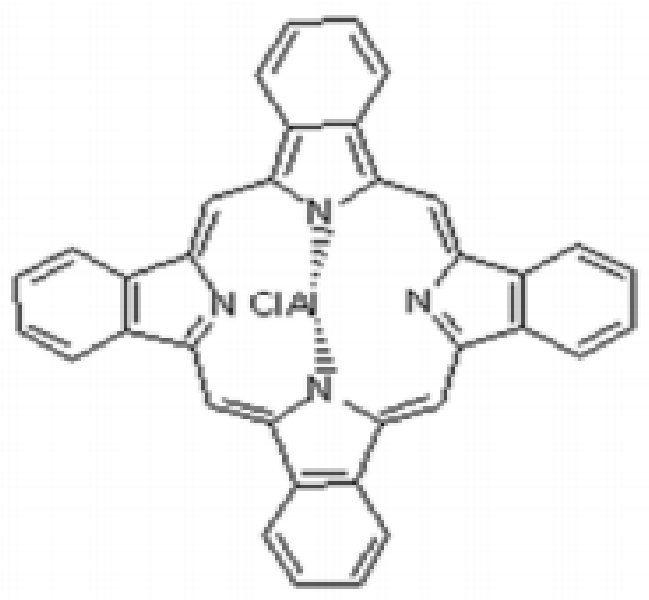

Figura 4. Estrutura química da Ftalocianina de Cloro-Alumínio.

Fonte: SILVA, 2013.

Devido a tais características a respeito da ftalocianina de cloro-alumínio ( $\mathrm{AlClFt}$ ), vários trabalhos tem se destacado utilizando esta substância para tratamentos oncológicos, de forma a potencializar seus efeitos para a terapia fotodinâmica utilizando carreadores nanoestruturados. Como exemplo, Muehlmann e colaboradores (2015) desenvolveram uma nanoemulsão (contendo a $\mathrm{AlClFt}$ ), que apresentou alta atividade fotodinâmica anticancer (MUEHLMANN et al., 2015). Outros trabalhos apresentados mostram a eficiência deste sistema contra células de adenocarcinoma mamário (MUEHLMANN et al., 2015).

Portanto, em vista dos referenciais apresentados, ressalta-se que a terapia fotodinâmica tem sido um tratamento promissor para o câncer, dentre outras patologias. E o uso combinado de nanopartículas neste modelo de tratamento, visa aumentar a eficiência terapêutica de forma a potencializar os fármacos, no caso os fotossensibilizadores, utilizados. Assim, o presente estudo visa utilizar nanoformulações de ftalocianina de cloro-alumínio para o tratamento de câncer de mama utilizando a aplicação da terapia fotodinâmica. 


\section{JUSTIFICATIVAS}


A terapia fotodinâmica no tratamento de tumores pode ocasionar a morte direta das células tumorais e danos vasculares, os quais são os principais responsáveis pela erradicação inicial do tumor (KOLTUN et al., 2014). A TFD também pode resultar na ativação e de processos inflamatórios. A principal característica do processo inflamatório é a liberação de mediadores na região tratada. Estes mediadores incluem componentes do sistema complemento, proteases, peroxidases, citocinas, fatores de crescimento e outros imuno-reguladores (KOLTUN et al., 2014; KORBELIK; HAMBLIN, 2015). Por sua vez, estes estimulam componentes como os glóbulos brancos, os neutrófilos e os macrófagos, que se direcionam para o local tratado (FRANÇA, 2010).

A atuação dos macrófagos no local do tumor irradia uma cadeia de processos que se inicia pela remoção das células cancerígenas por fagocitose, mas que também pode levar a ativação do sistema imunitário, por meio do recrutamento de linfócitos T CD4 auxiliares, que então ativam linfócitos $\mathrm{T}$ citotóxicos CD8 desencadeando processos de vias de morte celular (BELICHA-VILLANUEVA et al., 2012; KORBELIK; HAMBLIN, 2015; PIETTE, 2015). A ativação dos Linfócitos T, não só induzem a necrose, como pode também induzir a apoptose das células tumorais ajudando no controle do tumor (PIETTE, 2015).

Assim, a TFD possui a vantagem de ser um imunoestimulador, enquanto que a cirurgia e a quimioterapia são imunossupressoras (OSEROFF, 2006). Portanto, os mecanismos anticancerígenos da terapia fotodinâmica tem se mostrado eficientes em células tumorais primárias e metastáticas e, também, menos invasiva no organismo humano (BICALHO et al.,2013; MUEHLMANN et al., 2014, Longo et al., 2016). 
OBJETIVOS 


\section{OBJETIVO GERAL}

Desenvolver um protocolo de tratamento para o câncer de mama experimental com a aplicação da terapia fotodinâmica, utilizando nanoformulações contendo $o$ fotossensibilizador ftalocianina de cloro-alumínio, de forma a atingir as células tumorais mamárias primárias e possíveis focos de metástases.

\section{OBJETIVOS ESPECÍFICOS}

I -Preparo de três nanoformulações, sendo elas: nanoemulsão de ftalocianina cloroalumínio (NE-AlClFt), nanoemulsão de ftalocianina de cloro-alumínio com ácido fólico (NE-ALCLFT-FO) e micela de ácido fólico com ftalocianina de cloro-alumínio (MICFO-ALCLFT).

II - Caracterização das três nanoformulações, por meio dos métodos: análise do diâmetro hidrodinâmico (DH), carga superficial e índice de polidispersão (PDI) e pH, estudo da estabilidade das nanoformulações, análise morfológica por microscopia eletrônica de transmissão (MET) e de varredura (MEV), análise das interações químicas por espectroscopia no infravermelho (FTIR) e de RAMAN, análise de fluorescência pelo espectrofluorímetro, e quantificação de espécies reativas de oxigênio (ROS).

III - Análise da viabilidade celular e citotoxicidade in vitro em células tumorais de adenorcarcinoma mamário murino (4T1) e de fibroblastos murino (NIH/3T3), utilizando as três nanoformulações desenvolvidas.

IV - Análise dos tratamentos utilizando a terapia fotodinâmica in vitro com a aplicação de diferentes potências do LED $\left(10 \mathrm{~mW} / \mathrm{cm}^{2}, 50 \mathrm{~mW} / \mathrm{cm}^{2}\right.$ e $\left.100 \mathrm{~mW} / \mathrm{cm}^{2}\right)$ V - Estudo da biodistribuição das nanoformulações (NE-ALCLFT, NE-ALCLFT-FO E MIC-FO-ALCLFT), por meio da administração via endovenosa.

VI - Realizar o tratamento in vivo com a aplicação da terapia fotodinâmica, analisando as possíveis atividades antitumorais da nanoformulação, em animais com de câncer de mama induzido experimentalmente.

VII - Analisar três formas de tratamento da TFD sendo elas: sistêmica (com administração do fármaco por via endovenosa e irradiação do LED no corpo todo do animal), parcialmente sistêmica (com administração do fármaco por via endovenosa e irradiação apenas no local do tumor), e local (utilizando a administração do fármaco por via intratumoral e irradiação do LED no corpo todo do animal). 
VIII - Avaliar a resposta da terapia em decorrência dos tratamentos realizados, por meio da análise do peso dos camundongos, o volume tumoral, análises bioquímicas e hematológicas, análise por microtomografia computadorizada pelo equipamento PET/SPECT (avaliando o volume pulmonar e ósseo) e análise histopatológica.

IX - Mensurar a eficiência dos tratamentos propostos. 
MATERIAS E MÉTODOS 


\section{DESENHO EXPERIMENTAL}

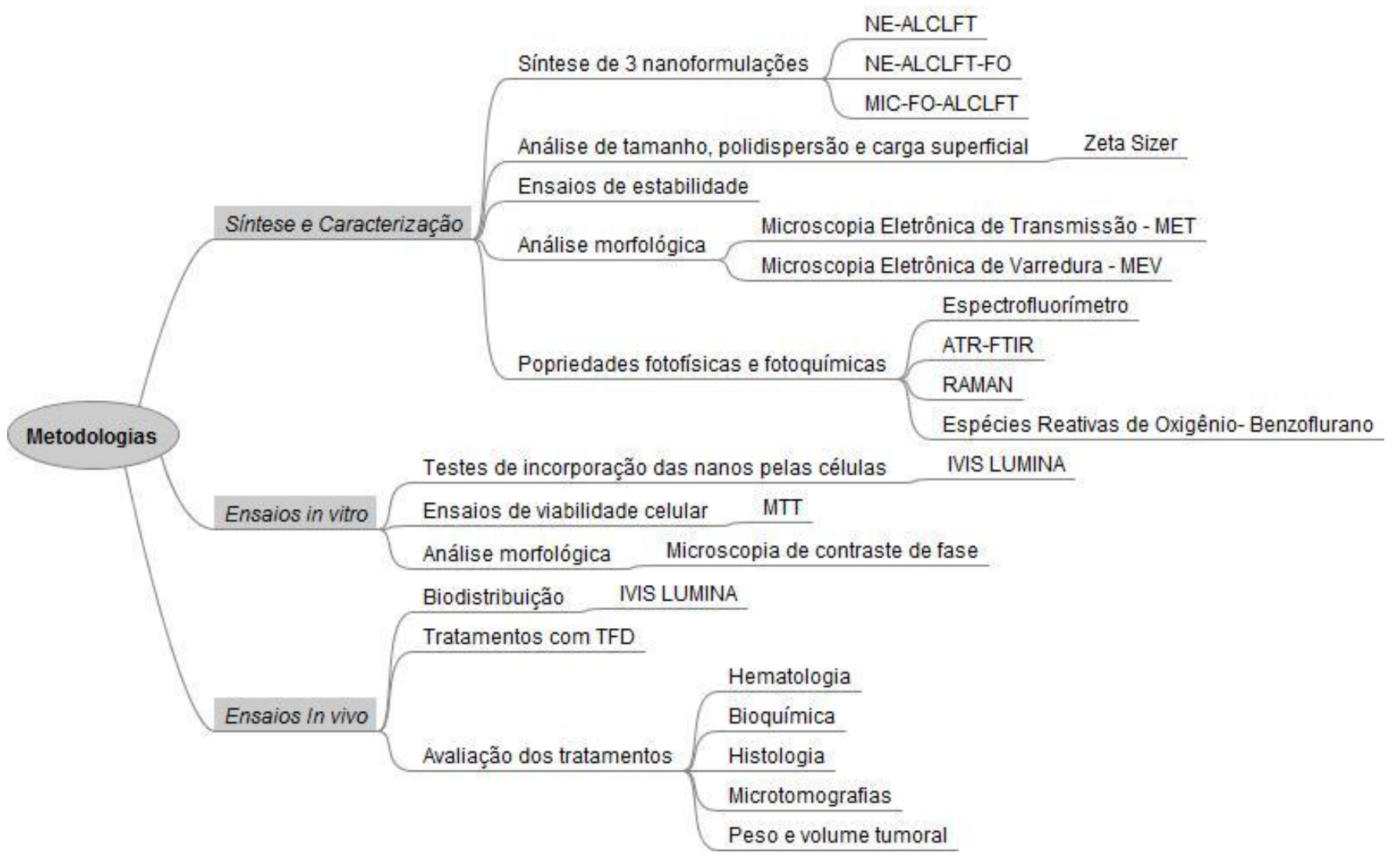




\section{MATERIAIS}

\section{Materiais, equipamentos e reagentes.}

A lista dos principais materiais, equipamentos e reagentes, encontram-se nas tabelas 1,2 e 3 .

Tabela 1. Lista dos principais materiais utilizados neste trabalho.

\begin{tabular}{|l|l|}
\hline \multicolumn{1}{|c|}{ Materiais } & \multicolumn{1}{c|}{ Fabricante } \\
\hline Criotubos & TPP, CHE \\
\hline Cubeta de quartzo 4 faces polidas & K24-135-Q, KASVI, EUA \\
\hline Filtro para Seringa $(0,22 \mu \mathrm{m})$ & TPP, CHE \\
\hline Frascos de Cultura $(25 \mathrm{~cm} 3$ e $75 \mathrm{~cm} 2)$ & TPP, CHE \\
\hline Hemocitômetro de Neubauer & C. A. Hausser \& Son, EUA \\
\hline Lâminas para Microscopia & Bioslide \\
\hline Lamínulas para Microscopia & Exacta Perfecta, BRA \\
\hline Lamínulas para Microscopia (redondas) & Glasscyto \\
\hline Micropipetas & Gilson. Inc., EUA \\
\hline Micropipeta Multicanal & Gilson. Inc., EUA \\
\hline Microplacas $(6,12,24$ e 96 poços) & TPP, CHE \\
\hline Ponteiras para Micropipetas & Axygen, EUA \\
\hline Seringas & Advantive, NLD \\
\hline Seringa de insulina & BD \\
\hline Tabela 2 Lista
\end{tabular}

Tabela 2. Lista dos principais reagentes utilizados neste trabalho.

\begin{tabular}{|c|c|}
\hline Reagentes & Fabricante \\
\hline 1,3-difenil-isobenzofurano (DBF) & Sigma-Aldrich Co., EUA \\
\hline Ácido Fólico & Across Organics, EUA \\
\hline ALT, Liquiform & LabTest, Brasil \\
\hline Antibiótico (Penicilina e Estreptomicina) & Gibco, USA \\
\hline AST, Liquiform & LabTest, Brasil \\
\hline Azul Trypan & Sigma-Aldrich Co., EUA \\
\hline Bicarbonato de Sódio & Sigma-Aldrich Co., EUA \\
\hline CK-MB Liquiform & LabTest, Brasil \\
\hline D-Luciferin & Sigma-Aldrich, EUA \\
\hline DMEM & Gibco, EUA \\
\hline DMSO & Mallinekrodt Chemicals, EUA \\
\hline Etanol 980GL & Sigma-Aldrich Co EUA \\
\hline Ferro, Liquiform & LabTest, Brasil \\
\hline Ftalocianina de cloro-alumínio & Sigma-Aldrich, EUA \\
\hline Insulina Bovina & Sigma-Aldrich Co., USA \\
\hline Kolliphor® (Kolliphor® ELP) & Sigma-Aldrich Co., USA \\
\hline MTT & Invitogen, USA \\
\hline Óleo de Rícino (Castor oil) & Sigma-Aldrich Co., EUA \\
\hline Paraformoldeiodo $4 \%$ & Sigma-Aldrich Co., EUA \\
\hline PBS & Laborclin, BRA \\
\hline Qualitrol CK & LabTest, Brasil \\
\hline Soro Fetal Bovino & Gibco, EUA \\
\hline Tripsina-EDTA & Gibco, EUA \\
\hline Uréia, CE & LabTest, Brasil \\
\hline
\end{tabular}


Tabela 3. Lista dos principais equipamentos utilizados neste trabalho.

\begin{tabular}{|c|c|c|}
\hline Equipamentos & Modelo & Fabricante \\
\hline Agitador Magnético & Q221M & Quimis, BRA \\
\hline Autoclave & Vitate 12 & Cristófoli, BRA \\
\hline Balança Analítica & AA200 & Denver Instrument, USA \\
\hline Banho Maria & $240-2$ & J. Prolab, BRA \\
\hline Banho Ultra Sônico & $\mathrm{T}-14$ & Thornton, BRA \\
\hline Bioquímico & ChemWell-T & LabTest, BRA \\
\hline Câmera Digital & Moticam 2300 3.0MP & Live Resolution, BRA \\
\hline Centrifuga de Bancada & Excelsa Baby & Fanem, BRA \\
\hline $\begin{array}{l}\text { Centrifuga com Rotor de } \\
\text { Placas }\end{array}$ & Universal 320R & LtettichZentrifugen,ALE \\
\hline Espectrofotômetro & Spectramax M2 & Molecular Devices, USA \\
\hline Espectrofluorímetro & RF-6000 & Shimadzu, Japão \\
\hline $\begin{array}{l}\text { Espectroscopia de } \\
\text { Transmitância na Região } \\
\text { do Infravermelho }\end{array}$ & Vertex 70 & Bruker, EUA \\
\hline $\begin{array}{l}\text { Espectrofotômetro } \\
\text { RAMAN }\end{array}$ & T64000 & $\begin{array}{c}\text { Raman Spectrometer, } \\
\text { Horiba, Japão }\end{array}$ \\
\hline Estufa & TLZ 10 & DeLeo, BRA \\
\hline Hematímetro & pocH-100iv & Diff \\
\hline Fluxo Laminar & CFLV 12 & Veco, BRA \\
\hline Incubadora de $\mathrm{CO} 2$ & 3425 & Thermo S. Inc.,EUA \\
\hline IVIS Lumina & XRIII & PerkinElmer, EUA \\
\hline Metalizador & SCD 050® & $\begin{array}{c}\text { Blazers Union AG, } \\
\text { Liechtenstein }\end{array}$ \\
\hline $\begin{array}{l}\text { Microscópio de contraste } \\
\text { de fase e fluorescência }\end{array}$ & $\begin{array}{l}\text { Invitrogen EVOS FL } \\
\text { Auto Cell Imaging } \\
\text { System }\end{array}$ & $\begin{array}{l}\text { Thermo Fisher Scientific, } \\
\text { EUA }\end{array}$ \\
\hline $\begin{array}{l}\text { Microscópio de Luz } \\
\text { Invertido }\end{array}$ & $\mathrm{Ck} 2$ & Olympus. JPN \\
\hline $\begin{array}{l}\text { Microscópio Eletrônico de } \\
\text { Transmissão }\end{array}$ & $1011 \mathrm{C}$ & Jeol Jem, Japão \\
\hline $\begin{array}{l}\text { Microscópio Eletrônico de } \\
\text { Varredura }\end{array}$ & Quanta Feg 250 & FEI Company, EUA \\
\hline Microtomógrafo & Albira & Bruker, EUA \\
\hline Purificador de água & Direct-Q3 & Millipore, EUA \\
\hline Refrigerador & DC39 & Eletrolux, BRA \\
\hline Rotaevaporador & RotavaporRII & BuchiSwitzerland, Suíça \\
\hline Zetasizer & ZS90 & Malvern/ Reino Unido \\
\hline
\end{tabular}




\section{SÍNTESE DAS NANOFORMULAÇÕES: TÉCNICAS DE PREPARO}

\subsection{Nanoemulsão de ftalocianina de cloro-alumínio (NE-ALCLFT)}

As nanoemulsões de ftalocianina de cloro-alumínio (NE-AlClFt) foram desenvolvidas no Laboratório de Nanobiotecnologia da Universidade de Brasília, pelo método de emulsificação espontânea segundo o protocolo estabelecido por Muehlmman (2015).

Basicamente o método de emulsificação espontânea é um método de baixa energia, que se baseia na dispersão de uma solução surfactante-óleo na fase aquosa. (ALMENDA, 2008).

Para a preparação das NE-AlClFt, foram utilizadas duas fases. A primeira fase consistiu em uma mistura de Cremophor ELP Kolliphor ${ }^{\circledR}$ (9 g), Óleo de Rícino (3 g) e solução de AlClFt (100 $\mu \mathrm{M}$, em $40 \mathrm{~mL}$ de etanol). Já a segunda fase foi formada por 100 mL de solução tampão PBS, Figura 5.
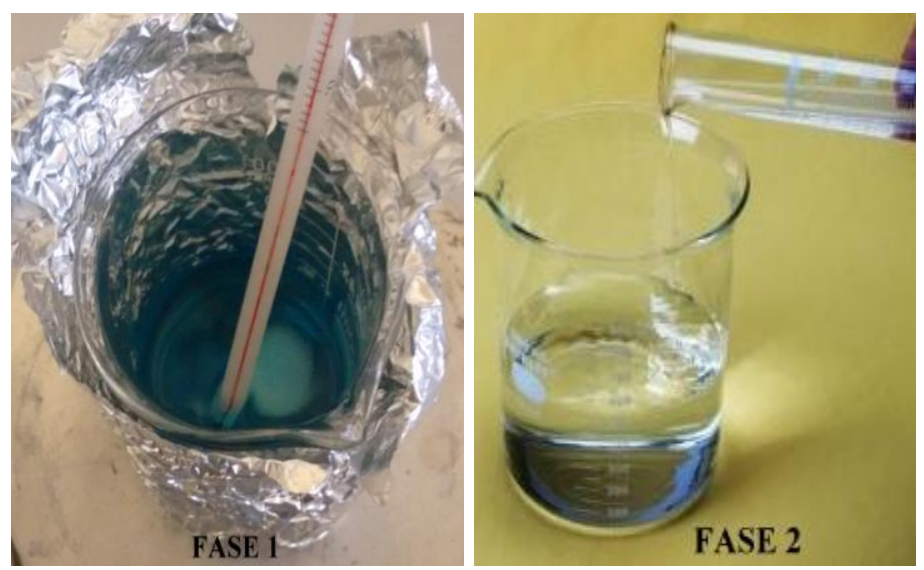

Figura 5. Método de emulsificação espontânea. Preparação das Fases 1 e 2. Fonte. Autor.

Posteriormente, as Fases 1 e 2, foram aquecidas a uma temperatura de $70{ }^{\circ} \mathrm{C}$, sob agitação branda. Com este aquecimento, o etanol que estava presente na solução da Fase 1 foi removido pelo processo de evaporação. Logo após a formação de uma solução homogênenea na Fase 1, esta foi misturada a Fase 2, ainda sob agitação branda e em aquecimento, até a formação de uma mistura homogênea de aspecto transparente. Após a adição da fase aquosa, a mistura foi mantida sob agitação e etanol presente na solução, 
foi então removido pelo método de evaporação utilizando agitador magnético com aquecimento por uma placa térmica. A solução foi então resfriada a temperatura ambiente.

A concentração final de ftalocianina nesta emulsão é de $40 \mu \mathrm{M}$ ou $23 \mu \mathrm{g} / \mathrm{ml}$. Por este mesmo método, também foram obtidas as nanoemulsões sem o fotossensibilizador $(\mathrm{NE})$.

\subsection{Nanoemulsão de ftalocianina de cloro-alumínio com ácido fólico (NE- ALCLFT-FO)}

Para a preparação da nanoformulação NE-ALCLFT-FO, foi utilizado o mesmo protocolo descrito para a formulação NE-ALCLFT, com as mesmas proporções dos reagentes. A única diferença, é que na fase oleosa, foi acrescentada 0,40 mg de ácido fólico, previamente preparada, na solução, a fim de que ocorresse a reticulação (crosslink) com a nanoformulação. Após a adição da fase aquosa, a mistura foi mantida sob agitação e os solventes foram então removidos pelo método de evaporação utilizando agitador magnético com aquecimento por uma placa térmica. Por este mesmo método, também foram obtidas as nanoemulsões com ácido fólico, sem o fotossensibilizador (NE-FO).

\subsection{Micela de ácido fólico contendo ftalocianina de cloro-alumínio (MIC-FO- ALCLFT)}

A micela de ácido fólico (MIC-FO-ALCLFT) foi preparada pelo químico e aluno de Mestrado Nichollas Serafim Camargo do Laboratório de Nanociência e Nanobiotecnologia, da Universidade de Brasília, UnB. Para tal procedimento, também foi utilizado o método de emulsificação espontânea, tendo como fase oleosa o complexo purificado de ácido fólico em dimetilformamida, e a fase aquosa utilizando tampão fosfato (PBS). Após a adição da fase aquosa, a mistura foi mantida sob agitação por 10 minutos e os solventes foram então, removidos por destilação a $40^{\circ} \mathrm{C}$ sob pressão reduzida (50 mbar) em rotaevaporador (RotavaporRII®, BuchiSwitzerland, Suíça). 
A síntese das nanoformulações foi realizada com base nos aspectos físico-químicos que caracterizam a estrutura destas nanopartículas. No caso, as nanoemulsões NEALCLFT e NE-ALCLFT-FO são constituídas por um núcleo oleoso, revestida por uma porção aquosa, tendo encapsulado em seu interior o fotossensibilizador ftalocianina de cloro-alumínio. A formulação NE-ALCLFT-FO possuem adsorvida em sua membrana o ácido fólico, o qual está reticulado na nanoparticula a fim de funcionalizar esta nanoestrutura. Já a micela MIC-FO-ALCLFT é formada pela diminuição da área de contato entre as cadeias hidrocarbônicas (cauda apolar) do surfactante (no caso, o próprio ácido fólico) e o tampão PBS (polar), já que são quimicamente incompatíveis (Figura 6).

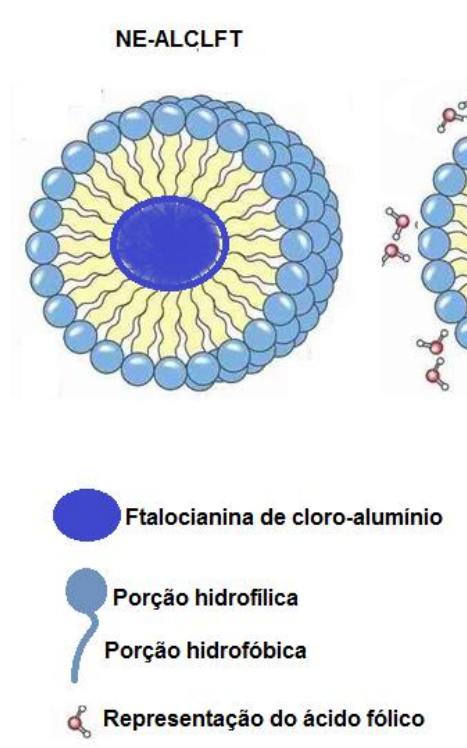

\section{NE-ALCLFT-FO}

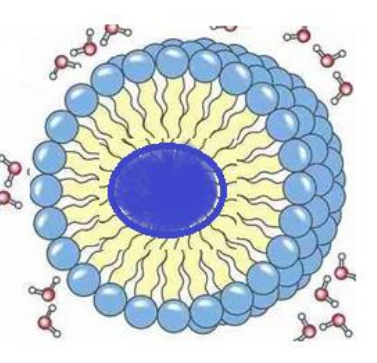

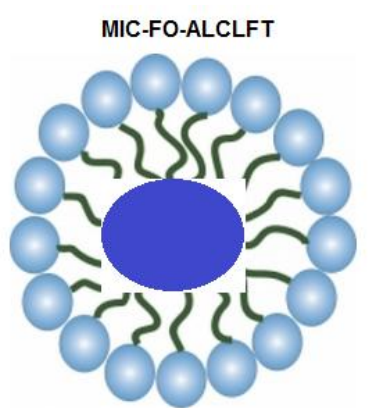

Figura 6. Representação esquemática das nanoformulações NE-ALCLFT, NEALCLFT-FO e MIC-FO-ALCLFT.

Fonte: $\mathrm{O}$ autor.

\section{MÉTODOS DE CARACTERIZAÇÃO DAS NANOFORMULAÇÕES (NE-ALCLFT, NE-ALCLFT-FO e MIC-FO-ALCLFT)}

\subsection{Determinação do Potencial Zeta}

Quase todo material macroscópico particulado, seja ele uma dispersão, suspensão ou coloide, adquire uma carga elétrica em sua superfície quando em contato com um líquido. Assim, o potencial Zeta é uma medida útil de tais cargas, e pode ser empregado para prever e controlar a estabilidade de suspensões, dispersões ou emulsões 
coloidais. Os valores do potencial zeta $(\mathrm{mV})$ foram determinados, utilizando o ZetaSizer Nano ZS 90 (Malvern Instruments, Malvern, Worcester-shire, UK) a $25{ }^{\circ} \mathrm{C}$. Os sistemas foram diluídos 1:100 (v/v) em água ultrapura, e os resultados expressos como uma média de 3 medidas.

\subsection{Medidas de tamanho hidrodinâmico (DH) e dispersão das partículas (PDI)}

As medidas de distribuição de tamanho e dispersão das nanoformulações são obtidas pela medida do movimento Browniano das partículas suspensas em água por espalhamento dinâmico de luz (DLS). Os diferentes sistemas foram diluídos 1:100 (v/v) em água ultrapura, e os resultados foram expressos como uma média de 3 medidas, utilizando o ZetaSizer Nano ZS 90 (Malvern Instruments, Malvern, Worcester-shire, UK) a $25^{\circ} \mathrm{C}$.

\subsection{Estudo da estabilidade das nanoformulações}

As nanoformulações sem o fotossensibilizador (NE, NE-FO, MIC-FO) e as nanoformulações contendo o fotossensibilizador ftalocianina cloro-alumínio (NEALCLFT, NE-ALCLFT-FO, MIC-FO-ALCLFT) foram monitoradas por um período total de 300 dias. Neste período, alíquotas de amostras das nanoestruturas, foram armazenadas a $37^{\circ} \mathrm{C}$, a fim analisar a influência da temperatura na estabilidade destas soluções.

As medidas de diâmetro hidrodinâmico (DH), potencial zeta (carga) e índice de polidispersão (PDI), foram mensurados, conforme já descrito. Também foram feitas medições de $\mathrm{pH}$ durante todo o processo. Os intervalos para as análises de cada amostra foram de: 1 dia, 7 dias, 15 dias, 30 dias e mensalmente até completar 300 dias, conforme a Figura. 7

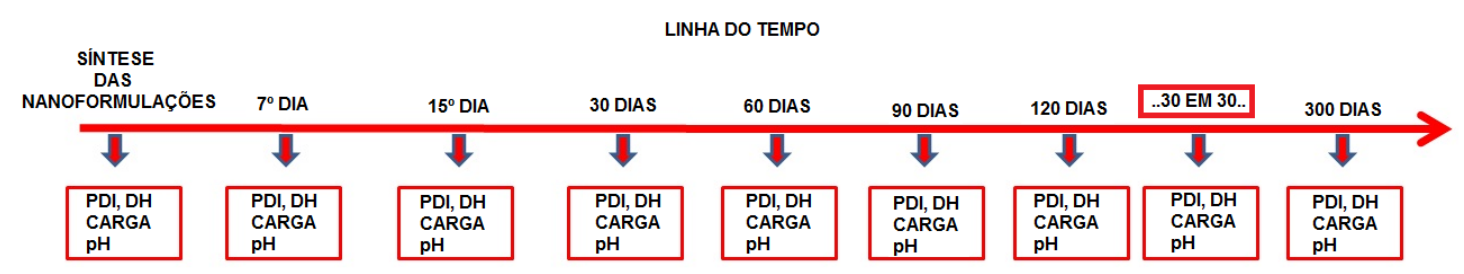

Figura 7. Representação esquemática do monitoramento da estabilidade nas nanoformulações. 


\subsection{Análise morfológica:}

\section{a. Microscopia Eletrônica de Transmissão (MET)}

Após a síntese das formulações (NE-ALCLFT, NE-ALCLFT, MIC-FOALCLFT, alíquotas foram analisadas por microscopia eletrônica de transmissão (MET JEOL JEM 1011®, Japão).

Para isso, as amostras foram diluídas em água destilada (1:100, v/v), a fim de evitar a formação de aglomerados de nanopartículas que poderiam atrapalhar a visualização das mesmas pelo microscópio. Em seguida, $10 \mu \mathrm{L}$ destas formulações foram adicionadas em telas de cobre (300 malhas), pré-preparadas com Formvar 0,5\%, e colocadas em uma placa de petri para a secagem das mesmas. Posteriormente, para a realização do contraste das nanopartículas, foi adicionado na placa de petri, $5 \mu \mathrm{L}$ de agente tetróxido de ósmio a $1 \%$ (p:v) ao lado de tais telas (para que as nanoformulações fossem fixadas por vapor) o qual permaneceu por 60 minutos. Posteriormente o agente foi retirado e a amostra foi analisada no MET.

\section{b. Microscopia Eletrônica de Varredura (MEV)}

A caracterização morfológica da superfície das nanoformulações - (NE-AlClFt, NE-ALCLFT, MIC-FO-ALCLFT), foi realizada em microscópio eletrônico de varreadura (MEV) (Quanta Feg 250, FEI Company, EUA). Uma alíquota de $20 \mu \mathrm{L}$ da suspensão das nanoformulações foi depositada sobre suportes de metal (stubs). A amostra foi deixada para secar em dessecador contendo sílica por 24 horas, em seguida foi coberta com ouro em metalizador Blazers SCD 050® (Blazers Union AG, Liechtenstein). As imagens foram digitalizadas utilizando uma câmera Nav-Cam ${ }^{\mathrm{TM}}$ (FEI Company, EUA).

\subsection{CARACTERIZAÇÃO FOTOFÍSICAS E FOTOQUÍMICAS}

\subsubsection{Equipamento de fonte luminosa para TFD}

Para todos os tratamentos com terapia fotodinâmica do presente trabalho, foi utilizado um equipamento de LED, desenvolvido pelo Prof. Dr. Paulo Eduardo Narciso de Souza e colaboradores, pertencentes ao Laboratório de Softwares e Instrumentação 
do Instituto de Física da Universidade de Brasília, DF, Figura 8. Este equipamento possui iluminação com comprimentos de onda específicos de $660 \mathrm{~nm}$ e $630 \mathrm{~nm}$. Além disso, permite a configuração de densidade de potência, fluência, tempo e distância a serem utilizadas nos experimentos.

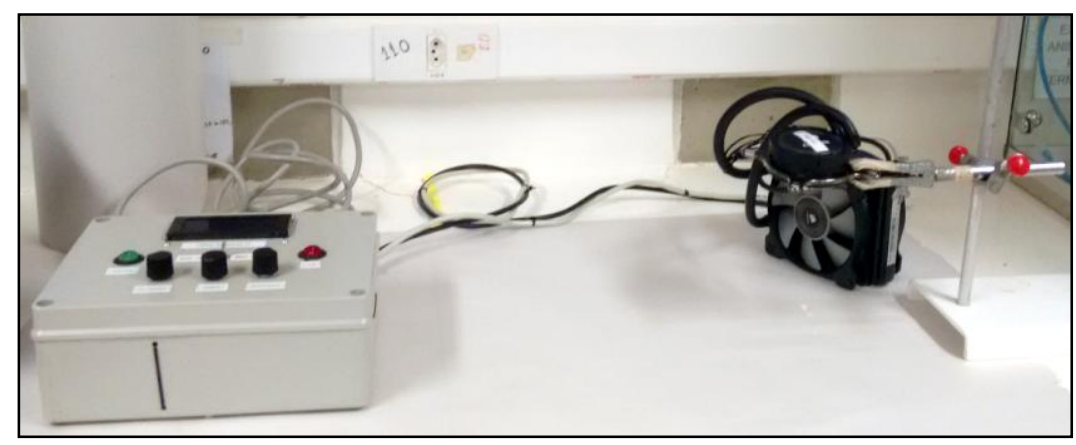

Figura 8. Equipamento de LED.

\subsubsection{Análise das nanoformulações pelo espectrofluorímetro}

O espectrofluorímetro nos permite realizar espectroscopia de fluorescência por excitação contínua, na qual podem ser obtidos parâmetros fluorescentes como os espectros de emissão e de excitação, rendimento quântico e anisotropia de uma determinada amostra. Assim, para que fossem verificados e obtidos os comprimentos de onda específicos de excitação e emissão da fluorescência das nanoformulações (NEALCLFT, NE-ALCLFT-FO e MIC-FOALCFT), foram feitas análises no espectrofluorímetro (RF-6000, Shimadzu, Japão), com auxílio do Prof. Dr. Jez Willian Batista Braga, pertencente ao Laboratório de Automação, Quimiometria e Química Ambiental (AQUA) do Instituto de Química da Universidade de Brasília, Unb.

Para a realização das análises, $3 \mathrm{~mL}$ de cada nanoformulação foram colocadas em uma cubetas de quartzos de 4 faces polidas (K24-135-Q, KASVI, EUA). Posteriormente, as cubetas foram colocadas no equipamento para a realização das leituras. O espectrofluorímetro foi configurado para que o monocromador de excitação do equipamento variasse de $300 \mathrm{~nm}$ à $700 \mathrm{~nm}$ (de $10 \mathrm{~nm}$ em $10 \mathrm{~nm}$ ), e o monocromador de emissão variasse de $600 \mathrm{~nm}$ à 1000nm (de $10 \mathrm{~nm}$ em $10 \mathrm{~nm}$ ), obtendo-se a intensidade de fluorescência produzida em cada combinação de comprimento de onda (emissão e excitação). As análises foram obtidas pelo software 
Spectrofluorophotometer, específico do equipamento, e as análises gráficas foram plotadas pelo software Origin7.0.

\subsubsection{Espectroscopia de transmitância na região do infravermelho (FT-IR)}

Os espectros de absorção na região do infravermelho foram obtidos mediante a técnica de transformada de Fourier (sigla em inglês, FT-IR) (Vertex 70, Bruker, EUA). Esta técnica foi utilizada por permitir o estudo das possíveis interações entre as substâncias utilizadas, proporcionando informações acerca da nova estrutura preparada. Os espectros foram registrados na região compreendida entre 4000 e $500 \mathrm{~cm}-1 \mathrm{com}$ amostras a serem analisadas pela técnica de ATR (Attenuated Total Reflectance).

\subsubsection{Espectroscopia Raman intensificada por superfície}

A espectroscopia Raman Amplificada por superfície (sigla em inglês, SERS) também foi realizada para caracterizar a interação das amostras das nanoformulações. Amostras isoladas de NE, NE-FO e NE-ALCLFT-FO foram preparadas e analisadas.

Para obtenção dos espectros de SERS foi utilizado um espectrômetro triplo (Jobin Yvon modelo T64000, Tripla Raman Spectrometer, Horiba, Japão). O feixe do laser de íon argônio foi focalizado na amostra por meio de uma lente cilíndrica, isto para evitar aquecimento das amostras e garantir a reprodutibilidade dos espectros de SERS, a qual forneceu uma densidade de potência de $0,1 \mathrm{~W} / \mathrm{cm}^{2}$. A linha 21 utilizada foi de $514,5 \mathrm{~nm}$ do laser de íon argônio com potência óptica na amostra de $200 \mathrm{~mW}$. A luz espalhada foi coletada na configuração de macro-Raman.

\section{ENSAIOS IN VITRO}

Para os testes in vitro, foram utilizadas as linhagens tumorais murinas de adenocarcinoma mamário (4T1, ATCC ${ }^{\mathrm{R}} \mathrm{CRL}-2539^{\mathrm{TM}}$ ) transfectadas com a enzima luciferase (4T1-luciferase ou 4T1-luc) e células de fibroblasto embrionário murinas $\left(\mathrm{NIH} / 3 \mathrm{~T} 3, \mathrm{ATCC}^{\mathrm{R}} \mathrm{CRL}-1658^{\mathrm{TM}}\right)$. As linhagens foram mantidas em cultura no Laboratório de Nanobiotecnologia da Universidade de Brasília, UnB.

\subsection{Manutenção das células e modo de preparação das células para os testes In vitro}


As linhagens celulares de 4T1 e NIH/3T3 foram cultivadas em meio DMEM (Eagle Modificado por Dulbecco) estéril. Ambas foram tamponadas com bicarbonato de sódio e suplementado com 10\% de soro fetal bovino (FBS) e antibiótico (100 UI/mL penicilina e $100 \mu \mathrm{g} / \mathrm{mL}$ streptomicina) a $1 \%$, pH 7,2. As células foram mantidas em frascos de cultura celular em uma incubadora à temperatura de $37^{\circ} \mathrm{C}$, em atmosfera de $95 \%$ de ar umidificado e $\mathrm{CO}_{2}$ a $5 \%$. Os experimentos foram realizados com a célula na fase logarítmica de crescimento.

Para a quantificação de células viáveis, $40 \mu \mathrm{L}$ de solução do corante Azul Trypan foram adicionadas em dez microlitros da suspensão celular. Este reagente é um corante incapaz de penetrar em celular com a membrana plasmática intacta, o que possibilita a distinção das células viáveis pelo princípio de exclusão de Azul Trypan. Por conseguinte, $10 \mu \mathrm{L}$ desta suspensão foram adicionadas em hemocitômetro de Neubauer. A concentração de células foi determinada segundo a contagem dos quadrantes laterais e por meio da equação:

Número de células contatadas $\times$ Fator de diluição x $1 \times 10^{4}=$ Número de células $/ \mathrm{mL}$ Número de quadrantes contados

Para a realização dos experimentos, após a quantificação, as células eram transferidas para microplacas de cultura de acordo com o experimento a ser realizado.

\subsection{Análise do perfil de incorporação das nanoformulações (NE-ALCLFT, NE- ALCLFT-FO e MIC-FO-ALCLFT)}

Para traçar o perfil de incorporação das nanoformulações pelas células de adenocarcinoma mamário sob diferentes tempos de incubação, foram plaqueadas $2 \times 10^{4}$ células da linhagem 4T1-luciferase em placa de 24 poços. Após 24 h, foram incubadas em meio completo, as formulações NE-ALCLFT, NE-ALCLFT-FO e MIC-FOALCLFT na concentração de $0,078 \mu \mathrm{M}$ em cada placa. As células foram expostas por 5, $10,15,20$ e 30 minutos de incubação com as nanoformulações sob as mesmas concentrações (Figura 10). 


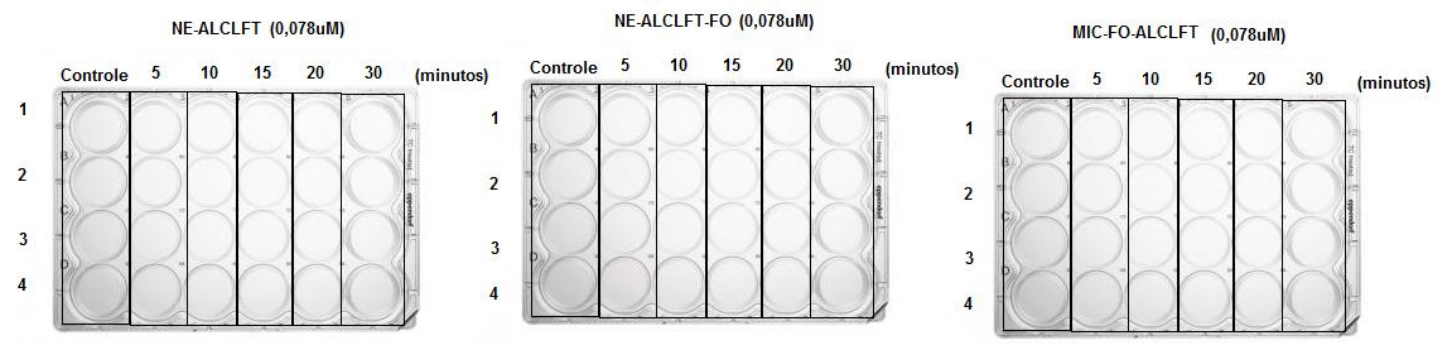

Figura 9.Ilustração da forma como foi distribuído o plaqueamento das células 4T1-luc.

Após esses tempos, os poços foram lavados duas vezes com PBS e foi acrescentado $5 \mu \mathrm{l}$ de D-luciferina (Sigma-Aldrich) na concentração de $15 \mathrm{mg} / \mathrm{mL}$ a cada poço, para a análise de bioluminescência realizada pela leitura no equipamento IVIS LUMINA (XRIII, PerkinElmer, EUA) . Ressalta-se que a luciferase (presente nas linhagens 4T1luciferase) é uma enzima que catalisa a reação bioluminescente de oxidação do composto luciferina, e neste aspecto, permite semi-quantificar o número de células vivas em uma determinada região pela intensidade de bioluminescência expressa.

Também foi realizada a leitura da fluorescência no mesmo equipamento, utilizando o comprimento de onda de excitação em $670 \mathrm{~nm}$ e de emissão em $790 \mathrm{~nm}$. Tais comprimentos são típicos da ALCLFT presente nas nanoformulações, para a análise neste equipamento, o qual foi verificado pelo experimento prévio no espectrofluorímetro.

Por fim, foi possível correlacionar à intensidade de fluorescência e de bioluminescência expressa em cada região da placa. Os dados estatísticos foram analisados pelo software Prism5.0, considerando-se a média e o desvio padrão das análises obtidas pelo software Ivis Lumina.

3.3. Ensaios de viabilidade celular no escuro (sem TFD) das nanoformulações sem o fotossensibilizador (NE, NE-FO, MIC-FO) e com o fotossensibilizador (NE-ALCLFT, NE-ALCLFT-FO, MIC-FO-ALCLFT) pelo ensaio de MTT

O ensaio de MTT (brometo de 3 (4,5 dimetiltiazol-2il)-2,5-difenil-tetrazólio), é uma avaliação da citotoxicidade por um método colorimétrico que quantifica a redução do reagente MTT em um composto conhecido como formazan, resultado da ação de desidrogenases mitocondriais. A presença destas desidrogenases ativas é um indicativo de viabilidade celular. Assim, este ensaio visou analisar a viabilidade celular das células 
(4T1-luc e NIH/3T3) incubadas com as nanoformulações sem o fotossensibilizador (NE, NE-FO, MIC-FO) e com o fotossensibilizador (NE-ALCLFT, NE-ALCLFT-FO, MIC-FO-ALCLFT) sem a presença de luz.

Para realizar este ensaio, as linhagens celulares (4T1-luc e NIH-3T3) foram semeadas em placas de 96 poços na concentração de $1 \times 10^{3}$ de células por poço com meio DMEM. Após 24horas, o meio de cultura inicial foi substituído por $200 \mu \mathrm{L}$ de meio de cultura contendo as nanoformulações em 12 diferentes concentrações $(20 \mu \mathrm{M}$, $10 \mu \mathrm{M}, 5 \mu \mathrm{M}, 2,5 \mu \mathrm{M}, 1,25 \mu \mathrm{M}, 0,625 \mu \mathrm{M}, 0,310 \mu \mathrm{M}, 0,150 \mu \mathrm{M}, 0,078 \mu \mathrm{M}, 0,039$ $\mu \mathrm{M}, 0,019 \mu \mathrm{M}, 0,009 \mu \mathrm{M})$.

Após 15 minutos de incubação com as nanoformulações, o fármaco foi removido, os poços lavados com PBS e foi adicionado meio de cultura por mais $24 \mathrm{~h}$. Após esta última etapa, foi adicionado solução de MTT (5 mg/mL, Invitrogen, EUA) e meio de cultura na proporção de $1: 10$. As células foram incubadas à $37^{\circ} \mathrm{C}$ por duas horas. Em seguida, a solução contendo MTT foi removida e então, foram adicionados $200 \mu \mathrm{L}$ de DMSO (Dimetilsulfóxido, Sigma-Aldrich, EUA) para a solubilização dos cristais de formazan. A análise de viabilidade em cada poço foi realizada por meio da leitura de absorbância em comprimento de onda de 595 nm no espectrofotômetro. Os dados foram analisados e plotados em gráfico de coluna pelo teste estatístico OneANOVA, com pós-teste Bonferroni no software GraphPad Prism 5.0.

\subsection{Testes de viabilidade celular utilizando as nanoformulações (NE-ALCLFT, NE-ALCLFT-FO e MIC-FO-ALCLFT), com aplicação da TFD mediante ensaio de MTT}

As células foram plaqueadas na mesma concentração utilizada para os testes no escuro, descritos acima. Transcorridos $24 \mathrm{~h}$ após o plaqueamento, as células foram incubadas com as respectivas nanoformulações (NE-ALCLFT, NE-ALCLFT-FO e MIC-FO-ALCLFT) nas concentrações $0,310 \mu \mathrm{M}, 0,150 \mu \mathrm{M}, 0,078 \mu \mathrm{M}, 0,039 \mu \mathrm{M}$, $0,019 \mu \mathrm{M}, 0,009 \mu \mathrm{M}$ por quinze minutos. Decorrido esse período, o sobrenadante foi removido e os poços lavados com PBS. A placa foi irradiada em PBS com LED em comprimento de onda de $670 \mathrm{~nm}$ por 10 minutos a uma distância de $10 \mathrm{~cm}$ da fonte luminosa. Para cada nanoformulação e célula, foram feitos três tratamentos diferentes, utilizando três potências diferentes, sendo elas $10 \mathrm{~mW} / \mathrm{cm}^{2}, 50 \mathrm{~mW} / \mathrm{cm}^{2}$ e $100 \mathrm{~mW} / \mathrm{cm}^{2}$, 
a fim de comparar a influência destes parâmetros na terapia em análise. Após a exposição, as células foram mantidas sob condições de cultivo por mais $24 \mathrm{~h}$ protegidas da luz e, então, a viabilidade das mesmas foi mensurada por ensaio de MTT em espectrofotômetro, como descrito no item anterior. Os dados foram analisados e plotados em gráfico de coluna pelo teste estatístico Two-ANOVA, com pós-teste Bonferroni no software GraphPad Prism 5.0.

Na tabela 5, encontram-se resumidamente os tratamentos realizados.

Tabela 5. Tratamentos realizados para a análise de viabilidade celular com aplicação da TFD.

\begin{tabular}{cccc}
\hline CÉLULAS & FORMULAÇÕES & CONCENTRAÇÕES & POTÊNCIAS \\
4T1-luciferase & NE-ALCLFT & $0,310 \mu \mathrm{M}, 0,150 \mu \mathrm{M}$, & $10 \mathrm{~mW} / \mathrm{cm}^{2}$, \\
NIH/3T3 & NE-ALCLFT-FO & $0,078 \mu \mathrm{M}, 0,039 \mu \mathrm{M}$, & $50 \mathrm{~mW} / \mathrm{cm}^{2} \mathrm{e}$ \\
& MIC-FO-ALCLFT & $0,019 \mu \mathrm{M}, 0,009 \mu \mathrm{M}$ & $100 \mathrm{~mW} / \mathrm{cm}^{2}$ \\
\hline
\end{tabular}

Após a leitura do MTT no espectrofotômetro, adicionou-se $5 \mu \mathrm{L}$ de D-Luciferina, nos poços das placas, e posteriormente foi feita a leitura da bioluminescência no equipamento IVIS LUMINA, a fim de qualificar a morte celular causada pelos tratamentos, por meio da intensidade expressa de bioluminescência, produzida pela reação enzimática da luciferina com a luciferase presente nessas células tumorais.

\subsection{Análise microscópica da morfologia das células de carcinoma adenocarcinoma mamário mamário (4T1) e fibroblastos (NIH/3T3), após os tratamentos com TFD.}

A análise das alterações estruturais e morfológicas causadas pelos tratamentos com a aplicação da TFD, utilizando as nanoformulações (NE-ALCLFT, NE-ALCLFT-FO, MIC-FO-ALCLFT), foi realizada utilizando um Microscópio invertido de fluorescência com contraste de fase, do Laboratório de Nanociência e Nanobiotecnologia, da Universidade de Brasília, UnB.

Para isso foi semeadas a quantidade de $2 \times 10^{4}$ células (4T1-luciferase e NIH/3T3) em placas de 12 poços. Após 24h, os tratamentos foram realizados, conforme descritos no item 3.4. No dia seguinte, as placas foram visualizadas e fotografadas pelo microscópio invertido de fluorescência com contraste de fase, nas magnificações de 20x e $40 x$. 


\section{ENSAIOS IN VIVO}

\subsection{Manutenção dos animais}

Para este trabalho foram usados camundongos fêmeas da linhagem BALB/c (Mus musculus) com 6 semanas e peso de 25-30 gramas (Biotério IPEN - CNEN/SP). Ao chegarem ao laboratório os animais ficaram inicialmente em observação por um período de 40 dias (quarentena) para só depois serem utilizados nos experimentos.

Os animais foram acomodados em caixas de polipropileno contendo maravalha, com temperatura controlada $\left(\sim 24{ }^{\circ} \mathrm{C}\right)$, ciclo circadiano automatizado $(12 / 12$ horas claro/escuro) e filtragem de ar no biotério do Departamento de Genética e Morfologia do Instituto de Ciências Biológicas, da Universidade de Brasília. A água e alimentação estavam disponíveis ad libidum em todo o tempo de experimentação.

Os experimentos realizados neste estudo foram aprovados pela Comissão de Ética no Uso Animal (CEUA) do Instituto de Ciências Biológicas da Universidade de Brasília, UnB Doc nº UnBDoC n. ${ }^{\circ}$ 66694/2016 (anexo I).

\subsection{Planejamento Experimental}

Os experimentos in vivo foram subdivididos em duas partes. A primeira parte teve como objetivo o estudos da biodistribuição das três nanoformulações (NEALCLFT, NE-ALCLFT-FO, MIC-FO-ALCLFT), a fim de escolher qual a melhor formulação, dentre estas, que mais se concentraria na região tumoral.

A segunda parte teve como objetivo utilizar a nanoformulação anteriormente escolhida para o tratamento do câncer de mama com a aplicação da terapia fotodinâmica (TFD).

\subsection{Indução Tumoral}

Para a indução tumoral, os animais foram submetidos à anestesia de quetamina (1 $\mathrm{mg} / \mathrm{kg})$ e xilazina $(0,1 \mathrm{mg} / \mathrm{kg})$ via intraperitoneal. Depois de anestesiados, os animais foram posicionados em suporte apropriado, e com o auxílio de uma lupa, foi realizada a inoculação por via ortotópica, na região da quinta mama do camundongo, com $0,05 \mathrm{~mL}$ de suspensão celular contendo 1 x $10^{5}$ células da linhagem 4T1-luciferase $\left(\mathrm{ATCC}^{\circledR}\right.$ CRL - $2539^{\mathrm{T} M}$, análogo ao estágio IV do câncer de mama em humanos) de câncer 
adenocarcinoma mamário de mama, de modo a induzir o tumor primário (Figura 11. $\mathrm{A}, \mathrm{B})$.

A.

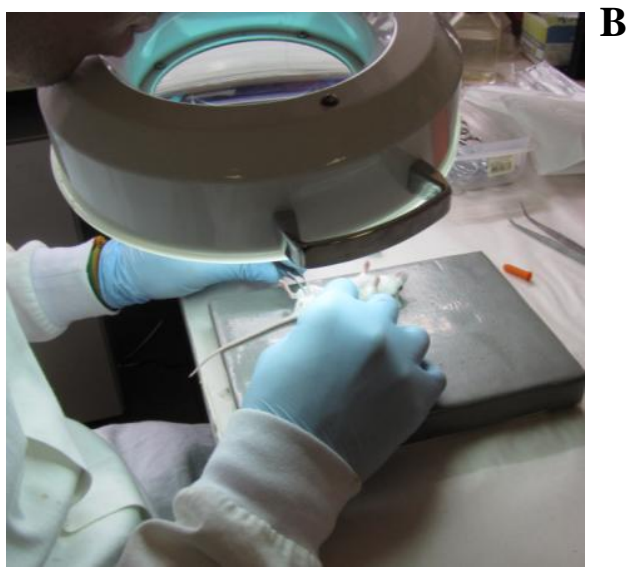

B.

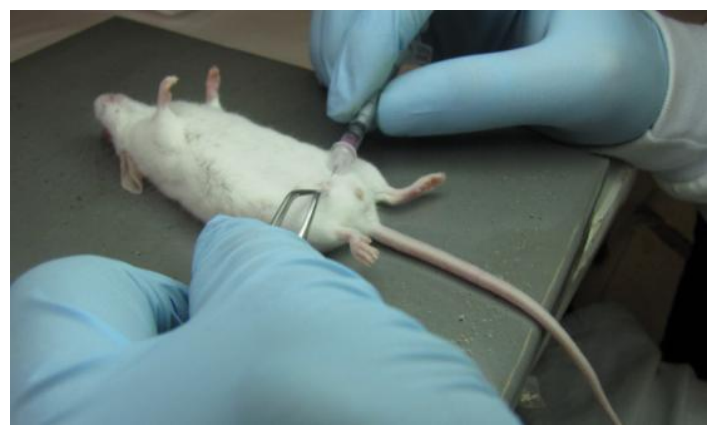

Figura 10. Imagem da indução tumoral por inoculação ortotópica na quinta mama do camundongo. Foi utilizado $0,05 \mathrm{~mL}$ de suspensão celular contendo 1 x $10^{5}$ células da linhagem 4T1-luciferase (adenocarcinoma mamário). (A) Imagem em campo maior apresentando a lupa utilizada. (B) Momento da inoculação em campo menor.

\section{$\underline{1^{a} \text { ETAPA }}$}

4.4. Análise da biodistribuição utilizando as nanoformulações NE-ALCLFT, NE-ALCLFT-FO e MIC-FO-ALCLFT em camundongos por via de administração endovenosa

\section{5.}

O estudo da biodistribuição utilizando as nanoformulações NE-ALCLFT, NEALCLFT-FO e MIC-FO-ALCLFT por administração via endovenosa, foi realizado usando um sistema de imaginologia em tempo real por meio do equipamento IVIS Lumina XR (Xenogen Corporation-Caliper, Alameda, CA, USA) disponível no laboratório de Genética e Morfologia da Universidade de Brasília, UnB. Para este experimento, foram utilizados no total 42 camundongos fêmeas da linhagem Balb/c (espécie Mus musculus), o qual foi dividido em duas partes: a primeira in vivo, e a segunda, ex vivo.

\subsubsection{Biodistribuição in vivo}




\subsubsection{Biodistribuição por administração farmacológica endovenosa}

Primeiramente, dezoito camundongos foram divididos em três grupos com $(n=6)$. Posteriormente foi realizada a indução tumoral por via ortotópica, conforme já descrito.

No $12^{\circ}$ dia, os animais foram anestesiados e foi realizado a tricotomização dos pêlos dos animais, para que não houvesse interferência ou dispersão da fluorescência quando fossem avaliados pelo equipamento IVIS Lumina ${ }^{\circledR}$.

No $14^{\circ}$ dia, os animais foram monitorados no equipamento IVIS Lumina ${ }^{\circledR}$, quando receberam $100 \mu \mathrm{L}$ (via peritoneal) de D-luciferina $(15 \mathrm{mg} / \mathrm{mL}$ ), para o acompanhamento do crescimento tumoral por análise da bioluminescência.

No $15^{\circ}$ dia, foi verificada a biodistribuição das nanoformulações, sendo que no grupo 1 foi analisado a NE-ALCLFT, o grupo 2 a NE-ALCLFT-FO e o grupo 3 a MICFO-ALCLFT. Para este procedimento, os animais foram anestesiados em uma câmara com fluxo laminar, onde se utilizou o anestésico inalatório Isoflurano na concentração de $1,5 \%$; e, em seguida, $100 \mu \mathrm{L}$ de cada nanoformulação (na concentração de $40 \mu \mathrm{M}$ ) foi administrada via endovenosa, pela veia lateral caudal dos animais (Fig. 12, 13, 14).

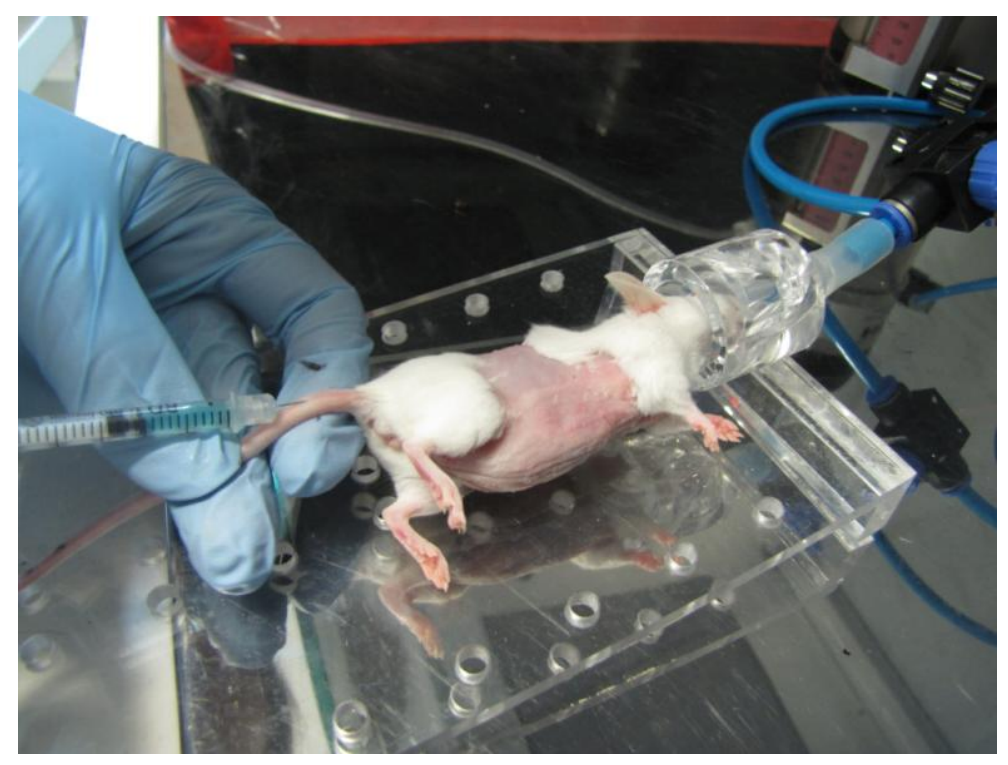

Figura 11. Administração endovenosa das nanoformulações. 


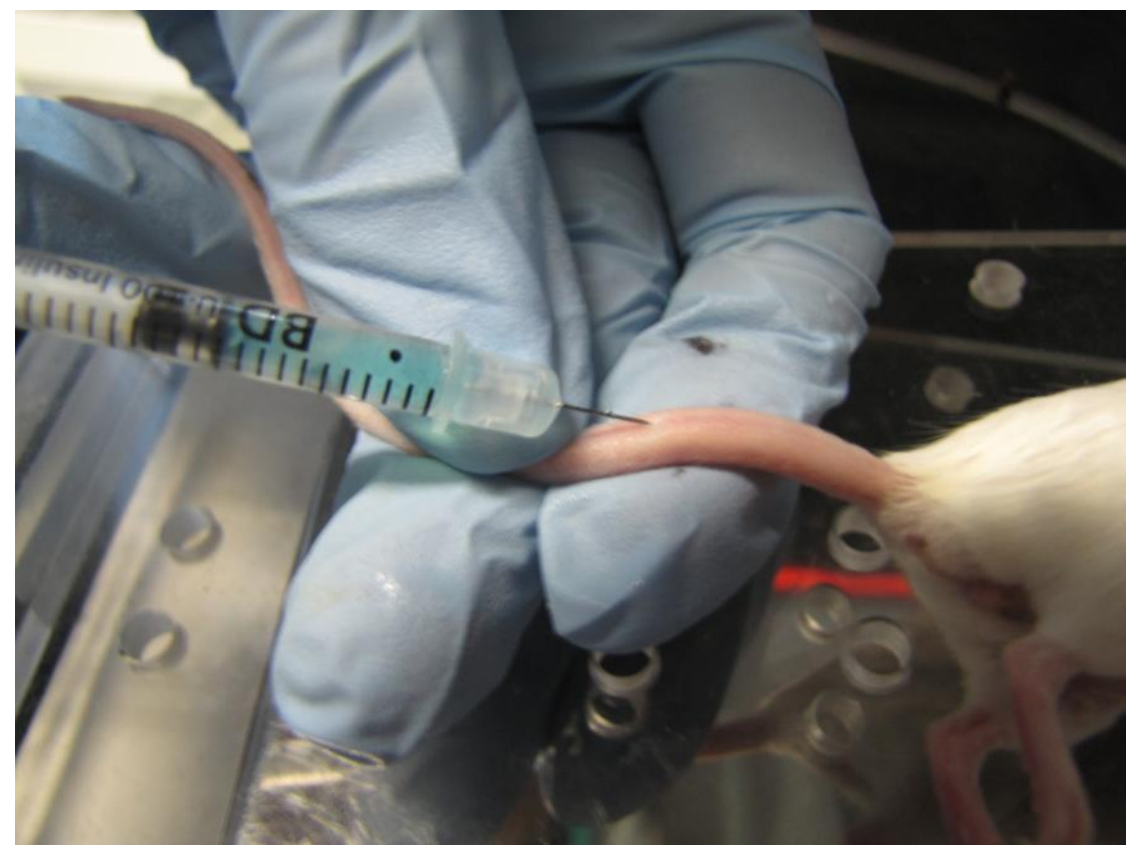

Figura 12. Administração da nanoformulação (na foto, a NE-ALCLFT) por via endovenosa na veia lateral caudal do camundongo. Foi realizada a administração de $100 \mu \mathrm{L}$ das nanoformulações, na concentração de $40 \mu \mathrm{M}$.

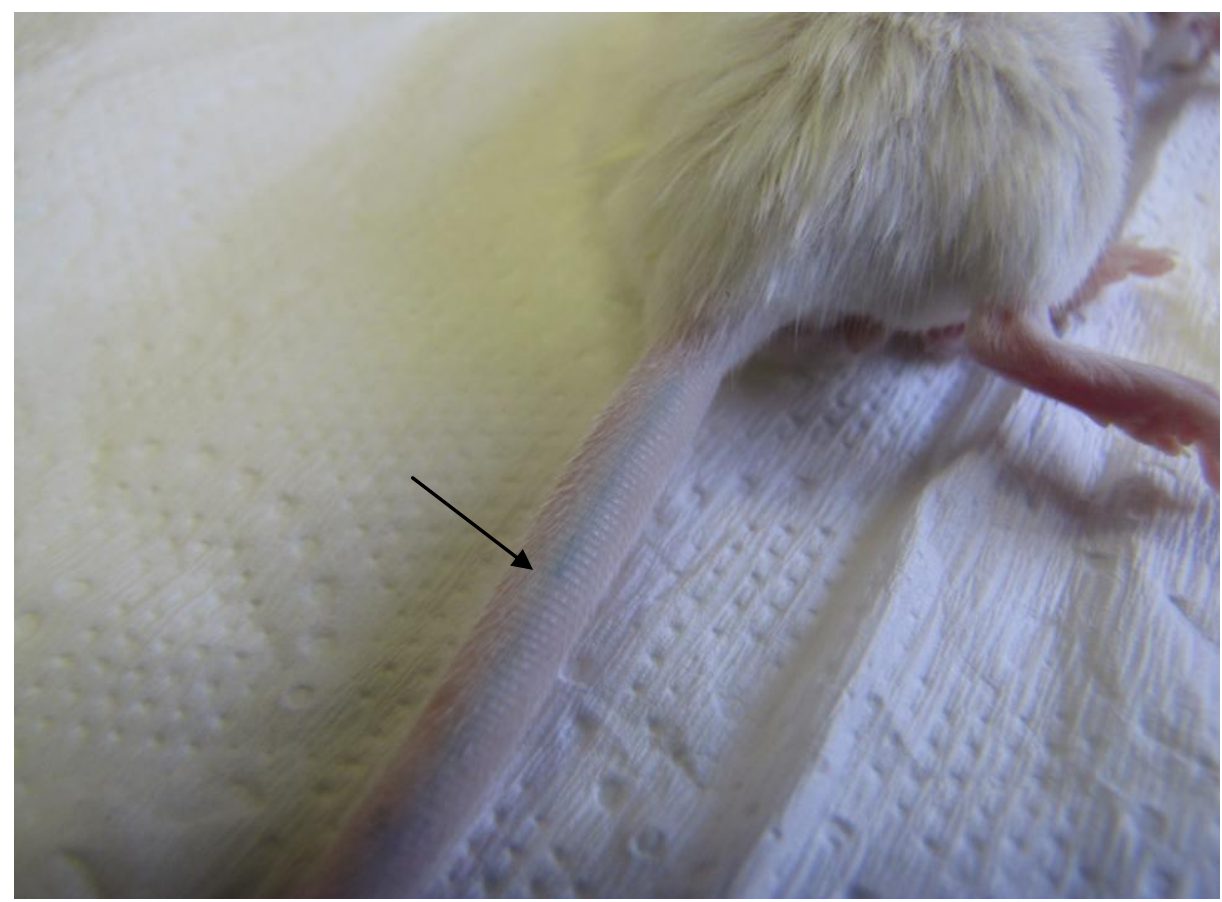

Figura 13. Imagem da cauda do animal após a administração endovenosa nanoformulação.

Após a administração do fármaco, os animais foram levados para o equipamento de imageamento animal IVIS LUMINA® onde ficaram sendo monitorados nos tempos de 0min, 50min, 2h, 4h, 6h, 8h, 10h e 12h (Figura 15. A, B). Nestes intervalos, eram 
obtidas imagens de fluorescência para a análise de localização do fotossensibilizador no organismo dos camundongos. É importante ressaltar, que durante o imageamento pelo IVIS LUMINA ${ }^{\circledR}$, os animais permaneciam anestesiados, para a realização do monitoramento dos animais, em que é utilizado o anestésico inalatório isoflurano na concentração de $1,5 \%$.

Transcorrido o período de interesse, foi realizada a eutanásia dos animais por meio da dose letal de anestésico $(60 \mathrm{mg} / \mathrm{kg})$. Os dados foram obtidos e analisados pelo software Living Image ${ }^{\circledR}$, e processados estatisticamente pelo software Prism5.0.

A

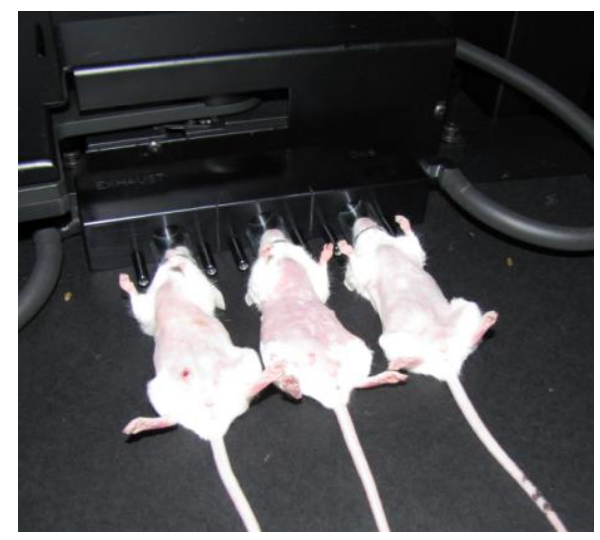

B

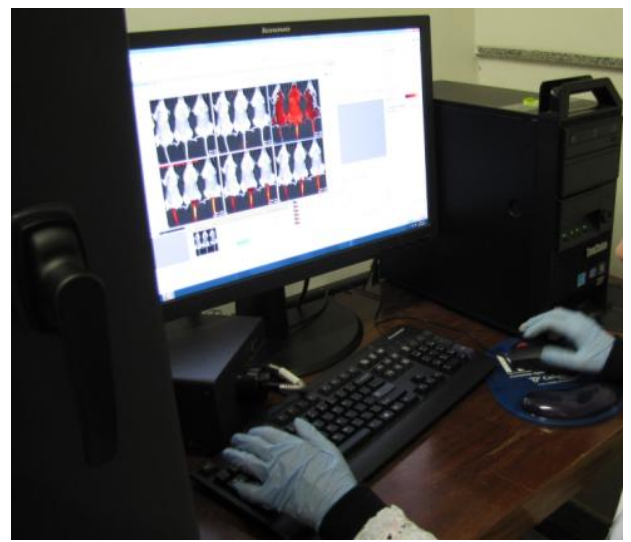

Figura 14. Imagens mostrando os procedimentos realizados no equipamento IVIS Lumina. (A) Visualização do interior da câmara onde os animais são colocados para fazer os procedimentos de imageamento. (B) Tem-se a visualização de como é feito o processamento da aquisição das imagens monitoradas pelo equipamento IVIS Lumina.

\subsubsection{Biodistribuição ex vivo}

\subsubsection{Biodistribuição após administração endovenosa}

A segunda parte dos estudos de biodistribuição farmacológica é uma continuação com base das análises dos resultados do procedimento anterior. As imagens adquiridas, foram analisadas e quantificou-se em qual dos intervalos realizados (0min, $50 \mathrm{~min}, 2 \mathrm{~h}, 4 \mathrm{~h}, 6 \mathrm{~h}, 8 \mathrm{~h}, 10 \mathrm{~h}$ e $12 \mathrm{~h}$ ) havia maior intensidade de fluorescência na região do tumor. Com base nessas análises, foram selecionados o intervalo de 6 horas e de 10 horas para a realização da biodistribuição ex vivo.

Para este experimento foram separados oito grupos $(n=3)$. Os grupos formados foram: Controle Tumor 6h, NE-ALCLFT-6h, NE-ALCLFT-FO-6h, MIC-FO-ALCLFT- 
6h, Controle Tumor 10h, NE-ALCLFT-10h, NE-ALCLFT-FO-10h, MIC-FO-ALCLFT10h. Posteriormente foi realizada a indução tumoral por via ortotópica, conforme já descrito. No $14^{\circ}$ dia, os animais foram monitorados no equipamento IVIS Lumina ${ }^{\circledR}$, para a análise do crescimento tumoral por análise da bioluminescência.

No $15^{\circ}$ dia, novamente foi realizada a administração das nanoformulções por via endovenosa na veia lateral caudal $(100 \mu \mathrm{L}$, na concentração $40 \mu \mathrm{M})$, nos respectivos grupos. Decorridos 6horas da administração, os animais dos grupos das 6horas (Controle Tumor 6h, NE-ALCLFT-6h, NE-ALCLFT-FO-6h, MIC-FO-ALCLFT-6h,) foram eutanasiados e os órgão excisados, sendo retirados o baço, fígado, rins, tumor, cérebro, pulmão, coração, linfonodo sentinela, linfonodo contralateral e a mama contralateral. Estes órgãos foram lavados com PBS e colocados sobre um papel de cartolina preta. Posteriormente, foram levados para o equipamento IVIS Lumina, para que fossem feitas as aquisições das imagens, de forma a monitorar a quantidade de fluorescência em cada órgão. As imagens foram processadas pelo software Living Lumina, e a intensidade de fluorescência quantificada. Os dados foram analisados estatisticamente pelo teste Two-ANOVA com pós teste de Bonferroni.

Este mesmo procedimento foi realizado com os animais do grupo das 10horas (Controle Tumor 10h, NE-ALCLFT-10h, NE-ALCLFT-FO-10h, MIC-FO-ALCLFT10h), ou seja, depois de decorridos 10 horas da administração das nanoformulações por via endovenosa, os animais foram eutanasiados e os órgãos excisados para a quantificação da intensidade de fluorescência no equipamento IVIS Lumina.

Todos os órgãos analisados (baço, fígado, rins, tumor, cérebro, pulmão, coração, linfonodo sentinela, linfonodo contralateral e a mama contralateral) foram pesados em uma balança analítica, para posterior estudo comparativo entre o peso dos órgãos e a intensidade de fluorescência presente, a fim de analisar a proporção entre esses dois fatores. Para esta relação, foi utilizada a fórmula matemática:

$$
\text { Concentração }=\text { peso/intensidade de fluorescência } \text {. }
$$

A principal finalidade destes experimentos foi selecionar o melhor tempo pós injeção dos nanomateriais para a aplicação da TFD nos tratamentos posteriores.

\section{$\underline{2^{\mathrm{a}} \text { ETAPA }}$}

\subsection{Tratamento com aplicação da Terapia Fotodinâmica (TFD)}


Para a realização destes experimentos, foram separados sete (07) diferentes grupos de camundongos Balb/c (Mus musculus) $(\mathrm{n}=5)$. O tumor foi induzido via ortotópico na quinta mama do camundongo, utilizando a concentração de 1 x $10^{5}$ células de linhagem 4T1-luciferase. A nanoformulação escolhida para a realização dos tratamentos, foi a NE-ALCLFT, com base nos resultados finas das análises da biodistribuição farmacológica. Após 15 dias da indução tumoral, os tratamentos foram iniciados.

Os tratamentos tinham como variação a forma de administração do fármaco e o modo de irradiação do LED para a aplicação da TFD. Os tratamentos foram administrados por duas vias diferentes: intratumoral e endovenosa.

A.

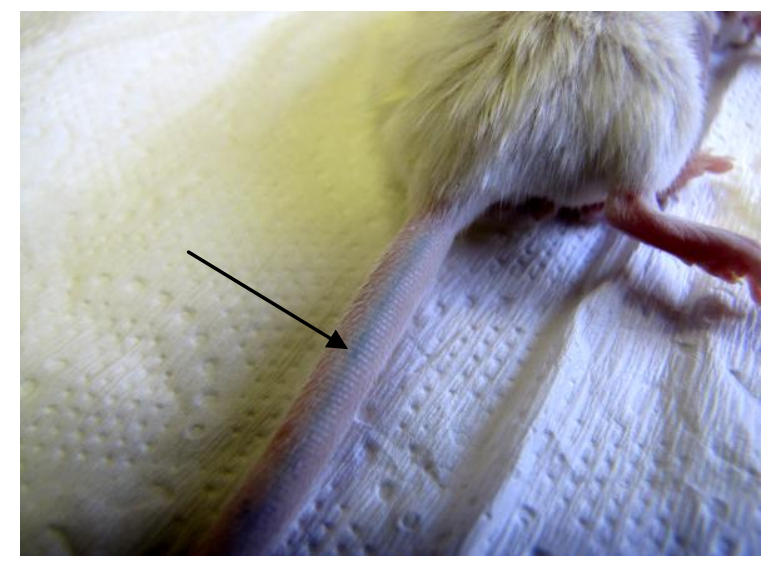

B.

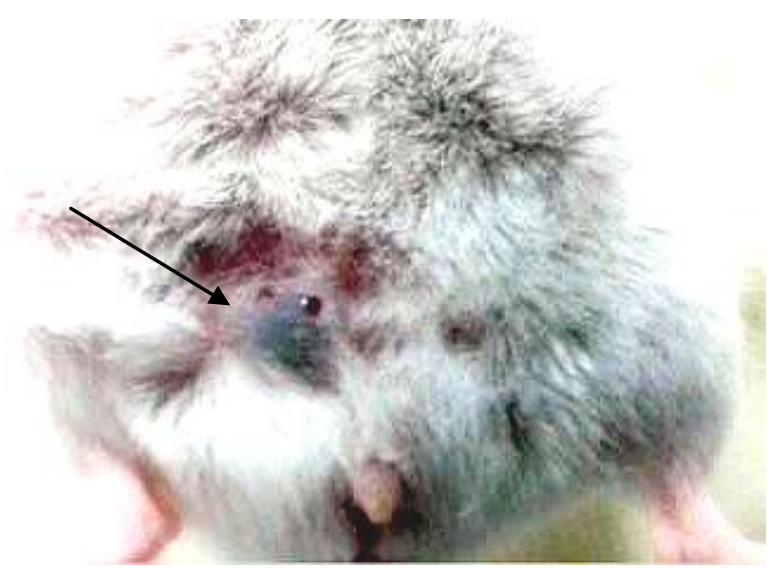

Figura 15. Vias de administração da nanoformulação para o tratamento. A. Endovenoso. B. Intratumoral.

Já a forma de irradiação do LED, foi sistêmica (no corpo inteiro do animal) ou local (na região do tumor). Além disso, também foi analisado o comportamento tumoral frente à apenas a irradiação do LED ou apenas com a nanoformulação (NEALCLFT). Para os tratamentos com a irradiação local, foi construído um suporte de alumínio, a fim de deixar apenas a região desejada sob a irradiação do LED, conforme a Figura 17. 


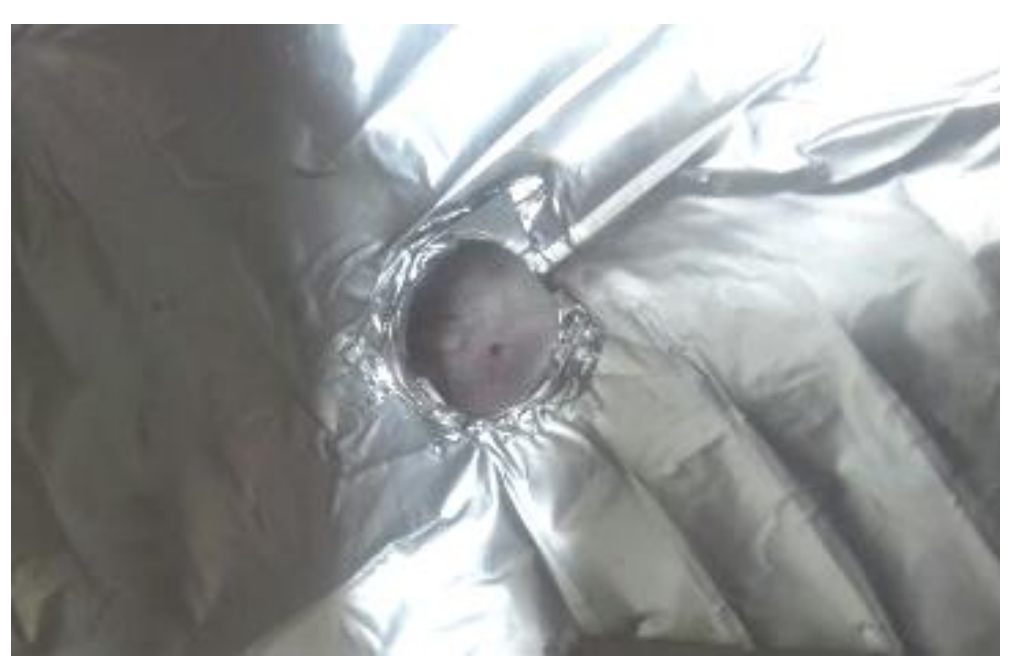

Figura 16. Imagem da placa de alumínio usada para a irradiação do LED no tratamento local.

Assim, na Tabela 4 estão descritos os grupos de tratamento, resumidamente.

Tabela 4. Grupos experimentais para a TFD in vivo.

\begin{tabular}{|c|c|c|c|}
\hline Grupo & Camundongos & $\begin{array}{c}\text { Forma de administração da } \\
\text { NE-ALCLFT }\end{array}$ & Forma de Irradiação do LED \\
\hline $\begin{array}{l}\text { 01. Tratamento } \\
\text { Sistêmico } \\
\end{array}$ & Balb/c (n=5) & Endovenosa & Corpo Inteiro (SISTÊMICO) \\
\hline $\begin{array}{l}\text { 02. Parcialmente } \\
\text { Sistêmico }\end{array}$ & Balb/c $(n=5)$ & Endovenosa & Local do tumor (LOCAL) \\
\hline $\begin{array}{l}\text { 03. Tratamento } \\
\text { Local }\end{array}$ & Balb/c $(n=5)$ & Intratumoral & Corpo Inteiro (SISTÊMICO) \\
\hline 04. Só NE-ALCLFT & Balb/c (n=5) & Endovenoso & NÃO IRRADIADO \\
\hline 05. Só LED & Balb/c (n=5) & SEM FÁRMACO & Corpo Inteiro (SISTÊMICO) \\
\hline $\begin{array}{l}\text { 06. Controle } \\
\text { Negativo }\end{array}$ & Balb/c (n=5) & $\begin{array}{c}\text { Animais saudáveis } \\
\text { (sem tumor e sem tratamento) }\end{array}$ & NÃO IRRADIADO \\
\hline $\begin{array}{l}\text { 07. Controle } \\
\text { Positivo } \\
\end{array}$ & Balb/c (n=5) & $\begin{array}{c}\text { Animais com tumor } \\
\text { (com tumor e sem tratamento) }\end{array}$ & NÃO IRRADIADO \\
\hline
\end{tabular}

Para a realização dos tratamentos por via endovenosa, foi administrado $100 \mu \mathrm{L}$ da nanoformulação NE-ALCLFT $(40 \mu \mathrm{M})$ na veia lateral caudal do camundongo. Já nos tratamentos por administração intratumoral, foi administrado $25 \mu \mathrm{L}$ de NE-ALCLFT $(40 \mu \mathrm{M})$.

Nos tratamentos utilizando a administração do fármaco por via endovenosa, aguardava-se 6horas para a aplicação da TFD. Já nos tratamentos utilizando a administração do fármaco por via intratumoral, aguarda-se 5 minutos para a aplicação da TFD. As configurações da irradiação do LED utilizadas para todos os tratamentos 
(tanto endovenoso como intratumoral) foram: densidade de potência de $82,78 \mathrm{~mW} / \mathrm{cm}^{2}$, a uma distância de $8 \mathrm{~cm}$, por um período de 15 minutos, gerando uma fluência de 74,502 $\mathrm{J} / \mathrm{cm}^{2}$, (Figura 18. A, B). A escolha destas configurações foi com base em estudos pilotos anteriormente realizada.

A.

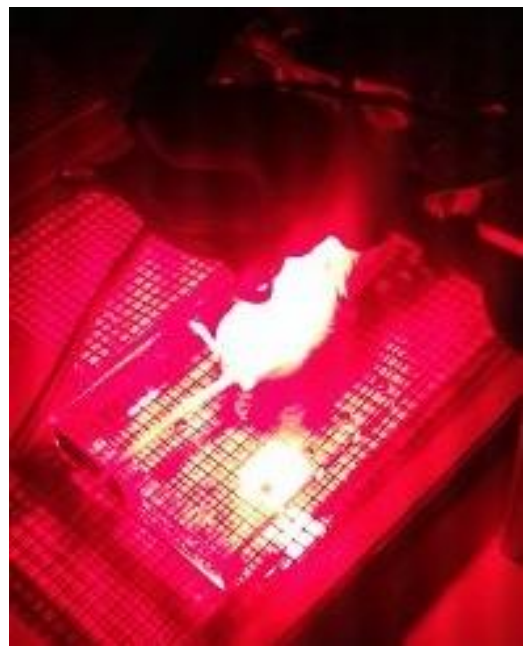

B.

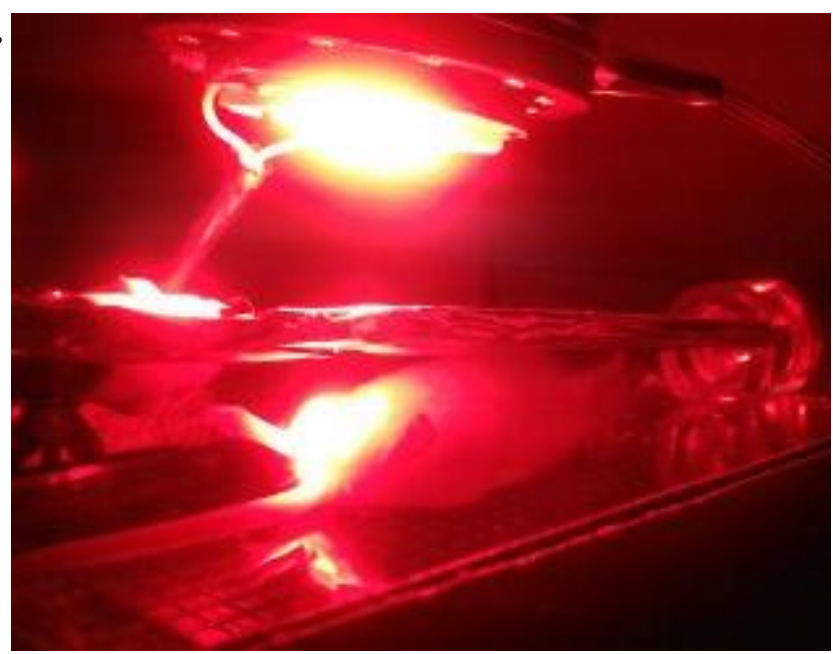

Figura 17. Aplicação da TFD. (A) Tratamento com aplicação da TFD, na forma de irradiação sistêmica. (B) Tratamento com aplicação da TFD, na forma de irradiação local.

Ao todo foram realizados 6 sessões de tratamentos de TFD,com intervalos de 3 ou 4 dias entre eles, a fim de minimizar possíveis efeitos adversos causados pela terapia. As sessões foram realizadas conforme o diagrama abaixo (Figura 19).

\section{SESSÕES DE TRATAMENTO COM TFD}

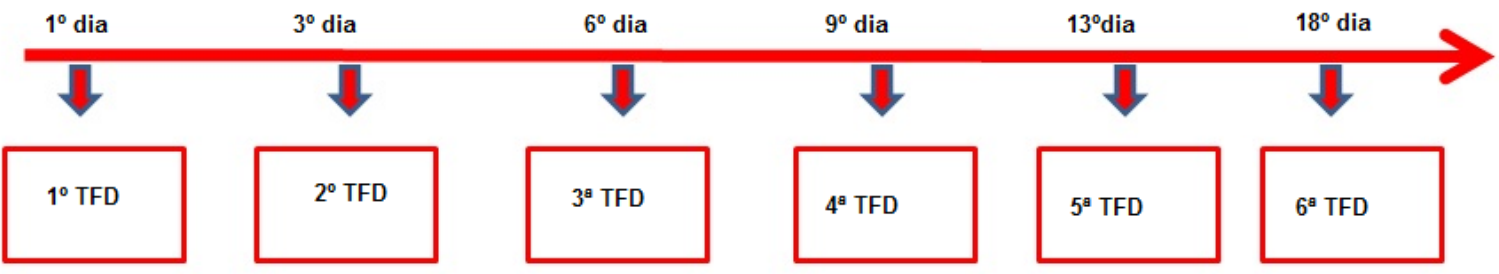

Figura 18. Diagrama contendo a ordem cronológica das sessões de tratamento.

Os animais foram pesados e monitorados semanalmente, tendo os tumores medidos com auxílio do paquímetro. 


\subsection{Avaliação do volume tumoral para determinação da curva de crescimento}

As dimensões dos tumores foram mensuradas, a cada 24 horas após cada tratamento, em todos os grupos experimentais, inclusive no dia da eutanásia, com auxílio de um paquímetro digital milimetrado (200MM Pd 200 Vonder $^{\circledR}$ ). O volume foi calculado por meio da fórmula abaixo, conforme descrito na literatura (RAMOS, K. L. V., 2014).

$$
\mathrm{VT}=(\text { Comprimento }) \times(\text { Largura })^{2} \times 0,5
$$

O peso dos animais foi determinado, semanalmente, por meio de balança digital e o peso dos tumores (no dia da eutanásia) em balança analítica modelo OHAUS ${ } 220$.

Após 10 dias decorridos da última sessão de tratamento, todos os animais foram eutanasiados para a realização dos exames complementares: hemograma, bioquímico e histopatológico.

\subsection{Avaliação do tumor por microtomografia computadorizada (MCT)}

Para a caracterização por imagem de MCT, foi utilizado o equipamento de Tomografia Computadorizada (TC) (Modelo PET/SPECT, Albira, Bruker, EUA). A caracterização tumoral neste equipamento foi realizada um dia antes da última sessão de tratamento, e dez dias depois. Para as análises, todos os animais foram anestesiados e posicionados no porta-animal do equipamento e fixados em decúbito dorsal, a fim de prevenir qualquer tipo de movimentação durante o escaneamento. Assim, foram realizados microtomografias do corpo inteiro do animal. Além disso, por meio do software Albira Software Suíte, pôde-se quantificar o volume do pulmão e o volume ósseo, a fim de verificar possíveis focos de metástases.

\subsection{Avaliação de marcadores bioquímicos}

Na eutanásia dos animais, amostras de sangue foram coletadas via punção cardíaca para dosagem de analitos bioquímicos, como uréia, aspartato aminotrasferase (AST), alanina aminotransferase (ALT), Ferro, e a isoenzima MB da creatina quinase (CK-MB). O sangue coletado foi condicionado em tubos de ensaio sem anticoagulante 
para obtenção do soro. As análises foram realizadas por meio do método cinético em aparelho automatizado (LabTest, Brasil).

\subsection{Hemograma}

Amostras de sangue coletadas foram avaliadas no hematímetro (LabTest,Brasil), a fim de verificar as alterações causadas pelo tratamento. Para isso, $300 \mathrm{uL}$ de sangue foi colocados em tubos apropriados para a leitura no equipamento. Os resultados foram analisados estatisticamente pelo software Prism5.0, verificando a média e o desvio padrão dos grupos.

\section{Análise Histopatológica}

Ao término da coleta do sangue, foi realizado o procedimento de eutanásia por meio de dose letal de anestésico. Em seguida, os camundongos foram colocados sobre um campo operatório e utilizando-se um bisturi, foi realizada a incisão frontal, reta, para a retirada dos órgãos: coração, pulmão, fígado, baço, rins, linfonodo sentinela, linfonodo contralateral, mama contralateral, tumor e cérebro. Em seguida, os órgãos coletados foram colocados em recipientes com solução de formol a $10 \%$ e tampão fosfato $(\mathrm{pH} 7,0)$. Os órgãos foram processados de acordo com os métodos histológicos padrão, sendo as lâminas coradas com hematoxilina/eosina (HE). Todas as lâminas foram analisadas e fotografadas no microscópio Invitrogen EVOS FL Auto Cell Imaging System (Thermo Fisher Scientific).

\section{Estatística}

Os resultados foram analisados pelo software Prism5 tendo a significância considerada com $\mathrm{p}<0,05$. A análise dos dados foi apresentada por gráficos também desenvolvidos pelo software Prism5. Cada dado foi analisado de acordo com a sua necessidade estatística. Assim, os testes foram analisados da seguinte forma:

- Para os testes de caracterização das nanoformulações NE e NE-AlClFt, foi realizado as média aritmética simples e desvio padrão das amostras em triplicatas, além do teste de Kruskal-Wall com pós-teste de Dunn.

- Para os testes caracterização de estabilidade das nanoformulações (NE, NE$\mathrm{AlClFt}$ em $4^{\circ} \mathrm{C}$ e $37^{\circ} \mathrm{C}$ ) foram realizadas os testes de Regressão Linear. 
- Para os ensaios In vitro, foram utilizados os testes "Two-Way ANOVA" e “One-Way ANOVA”, com pós-teste de Bonferroni.

- Para os ensaios In vivo foram realizadas medidas padrão de média aritmética simples, e teste "Two-Way ANOVA" com pós- teste de Bonferroni. 


\section{CARACTERIZAÇÃ̃O}

\subsection{Caracterização Morfológica por Microscopia Eletrônica de Transmissão}

Para a análise morfológica das nanopartículas foram realizadas eletromicrografias por Microscopia Eletrônica de Transmissão. Nestas, pode-se constatar que a NEALCLFT (Fig 20. A) e NE-ALCLFT-FO (Fig 20. B), apresentaram uma população monodispersa e de morfologia esférica. Já a MIC-FO-ALCLFT (Fig 20. C) não apresentou imagens com boa qualidade de resolução para a caracterização desta formulação com este método.

(A)

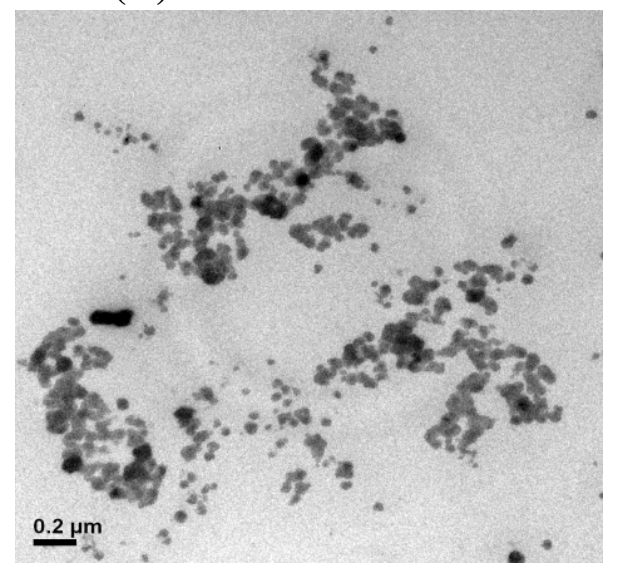

(B)

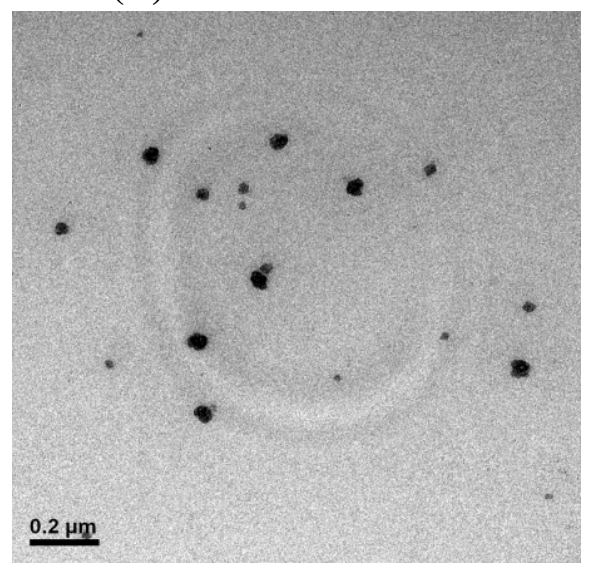

(C)

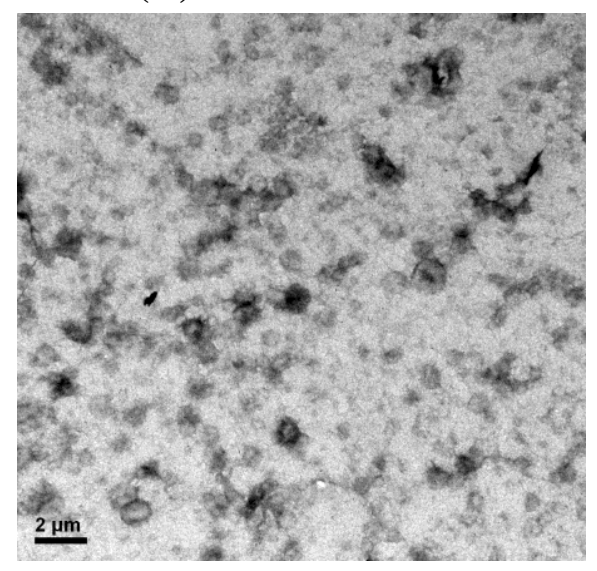

Figura 19. Eletromicrografias de transmissão das nanoformulações.(A) NE-ALCLFT, (B) NE-ALCLFT-FO e (C) MIC-FO-ALCLFT. Nanoformulações contrastadas por vapor de ósmio. População monodispersa de nanogotículas com morfologia esférica. Aumento de 100 mil vezes.

\subsection{Caracterização Morfológica por Microscopia Eletrônica de Varredura}

Para corroborar as análises morfológicas das nanopartículas, foram realizados micrografias por Microscopia Eletrônica de Varredura. Nestas, constatou-se que todas as nanoformulações em estudo, NE-ALCLFT (Fig. 21, A), NE-ALCLFT-FO (Fig. 21, B) e MIC-FO-ALCLFT (Fig. 21, C), apresentam morfologia esférica e com populações moonodispersas. 
(A)

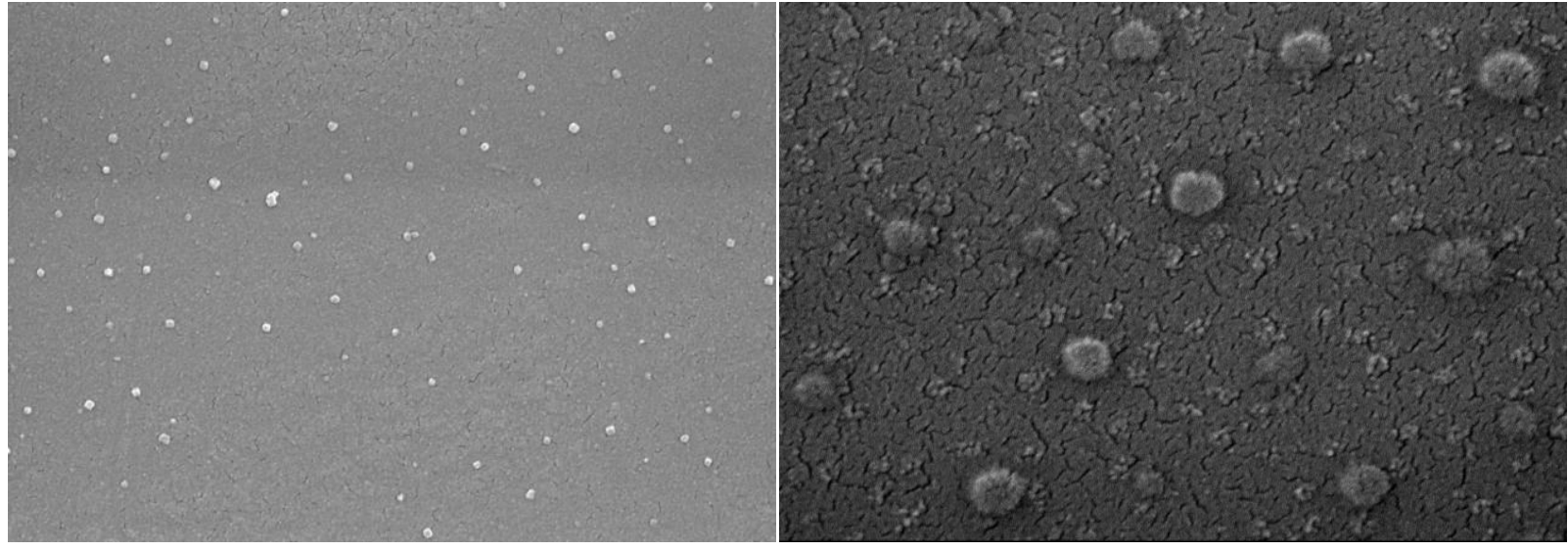

(B)

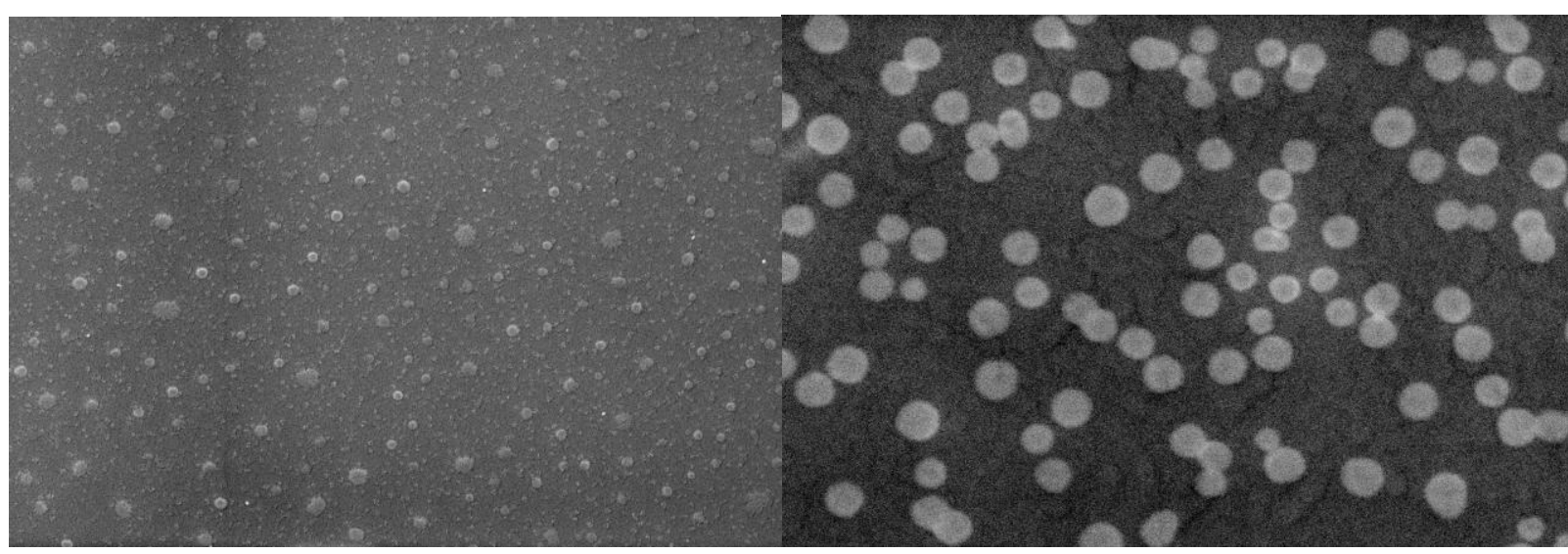

(C)

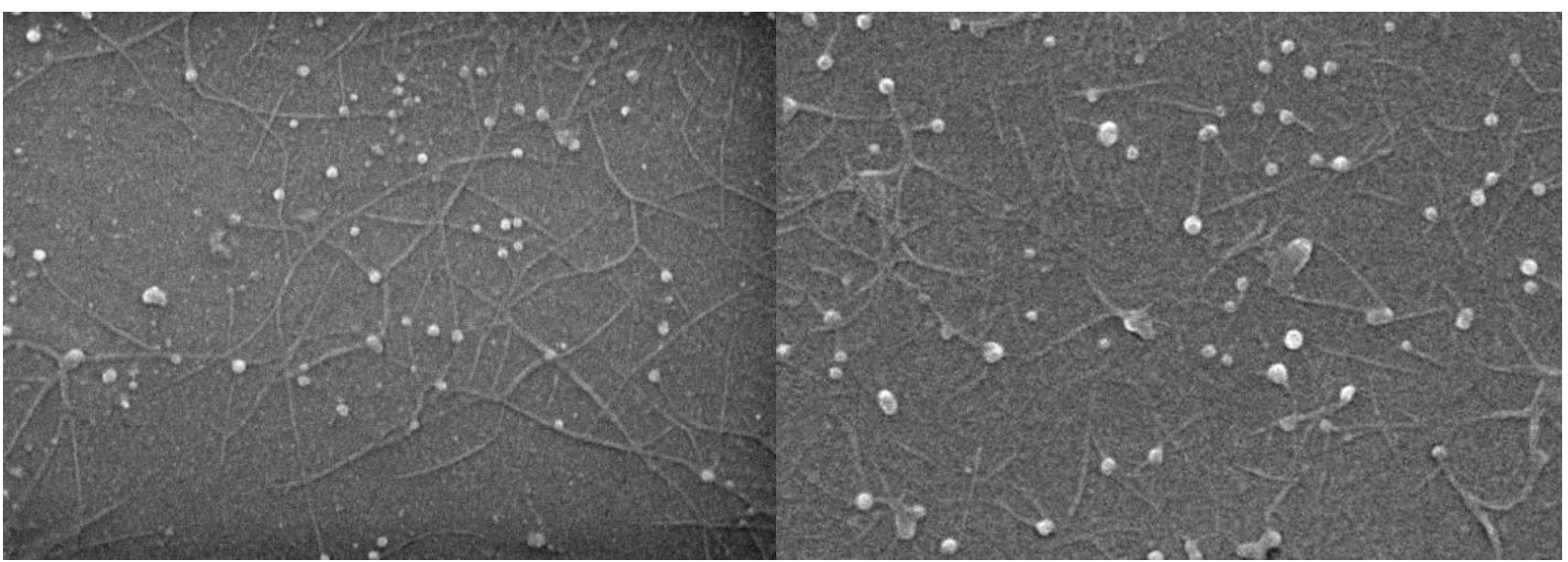

Figura 20.Micrografias de varredura das nanoformulações. (A) NE-ALCLFT, (B) NEALCLFT-FO e (C) MIC-FO-ALCLFT. Nanoformulações contratadas por metalização com ouro. Análise morfológica esféricas. 


\subsection{Espectroscopia no Infravermelho com transforma de Fourier (FT-IR)}

A partir dos espectros do infravermelho, pôde-se concluir os principais compostos que fazem parte da estrutura das nanoformulações, quando se compara os picos gerados pelos dados em análise. Na estrutura da micela tem-se o ácido fólico como principal constituinte presente, onde é possível detectar os principais picos de ambas as leituras das bandas, assim como, a presença do fotossensibilizador ALCLFT. Já as nanoemulsões (NE-ALCLFT e NE-ALCLFT-FO) constata-se a presença significativa dos picos do cremophor e do óleo de rícino, mas devido a presença destes picos em tais formulações, não é possível identificar o pico da ALCLFT, visto que este são mascarados pela intensidade do pico do cremophor (Fig. 22).

As vibrações moleculares apresentadas por este método mostram as bandas de do composto Cremophor situado na região entre $1000 \mathrm{~cm}^{-1}$ e $1250 \mathrm{~cm}^{-1}$, correspondente ao grupamento C-O de éteres presentes (Figura 22, f), denotando sua composição também nas bandas das formulações NE-ALCLFT-FO (Fig. 22, b) e NE-ALCLFT (Fig. 22, c).

Outra estrutura importante também presente nas formulações NE-ALCLFT e NEALCLFT-FO, é a presença do óleo de rícino onde mostra a banda próximo a $1750 \mathrm{~cm}^{-1}$, referente ao estiramento $(\mathrm{O}=\mathrm{C}-\mathrm{O}-\mathrm{C})$ presente neste composto.

Pode-se visualizar também, os picos das bandas próximo a $1.600 \mathrm{~cm}^{-1}$ pertencentes ao estiramento carbonílico de amidas do ácido fólico puro (Fig. 22, g), também presentes na MIC-ALCLFT (Fig. 22, a). 


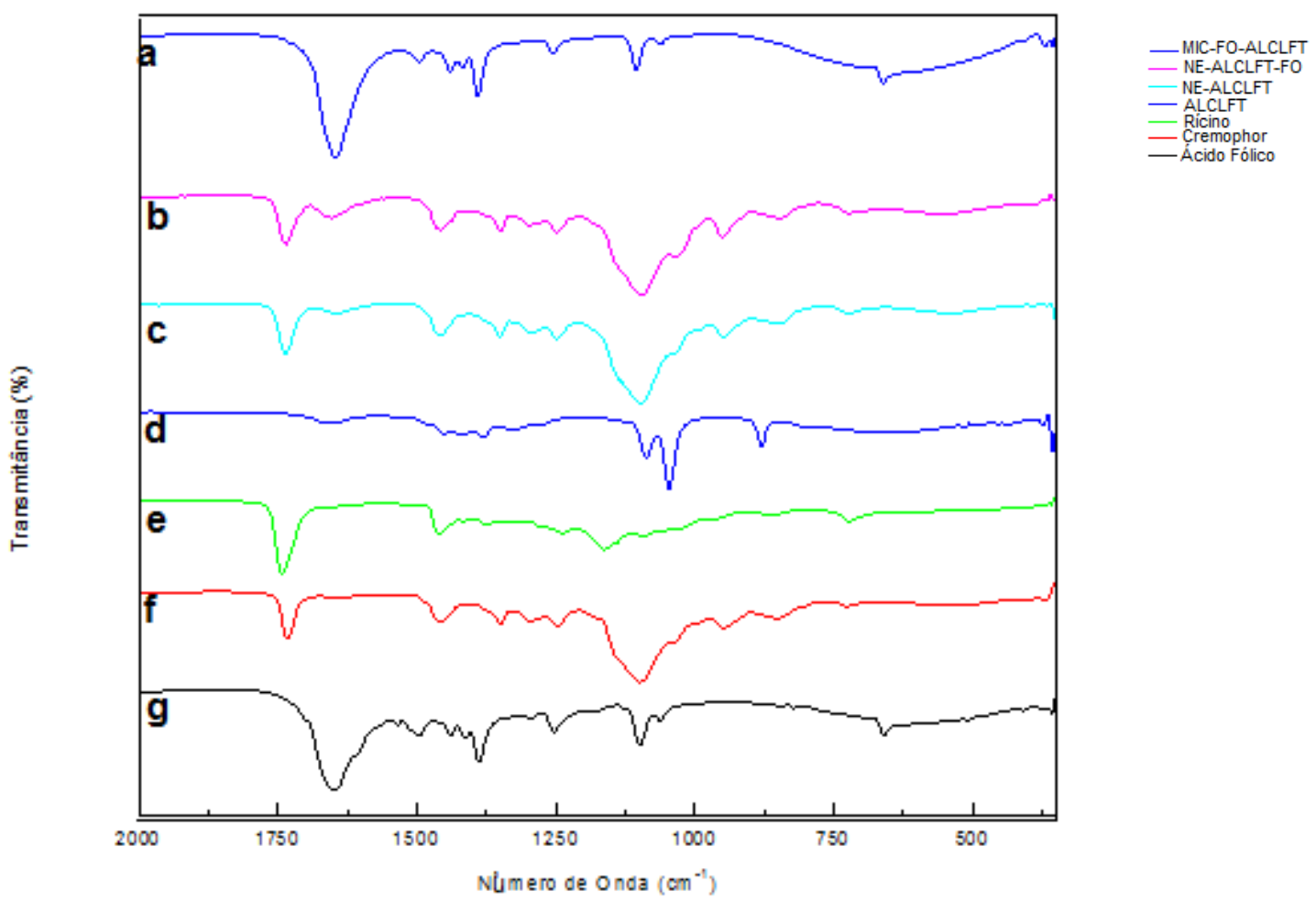

Figura 21. Espectroscopia no Infravermelho com transformada de Fourier. (a) MIC-FOALCLFT. (b) NE-ALCLFT-FO. (c) NE-ALCLFT. (d) ALCLFT. (e) Óleo de Rícino. (f) Cremophor. (g) Ácido fólico.

\subsection{Espectroscopia por RAMAN}

Nos resultados dos espectros do RAMAN, compara-se a nanoemulsão (sem ALCLFT), a nanoelmusão com ácido fólico (sem ALCLFT), e a nanoelmulsão com ácido fólico e o ALCLFT. Nota-se alta semelhança nos picos entre essas formulações, e um novo pico na região $3500 \mathrm{~cm}^{-1}$ da NE-ALCLFT-FO (Fig. 23).

Já o espectro do ácido fólico, pode apresenta vibrações nas regiões 1179 cm-1 $1508.7 \mathrm{~cm}-1$, e $1595.4 \mathrm{~cm}-1$ (Stokes et al., 2008). No entanto, como as nanoformulações sobrepõe em grande parte do delineamento espectral, os picos possivelmente foram mascarados por este fator. 


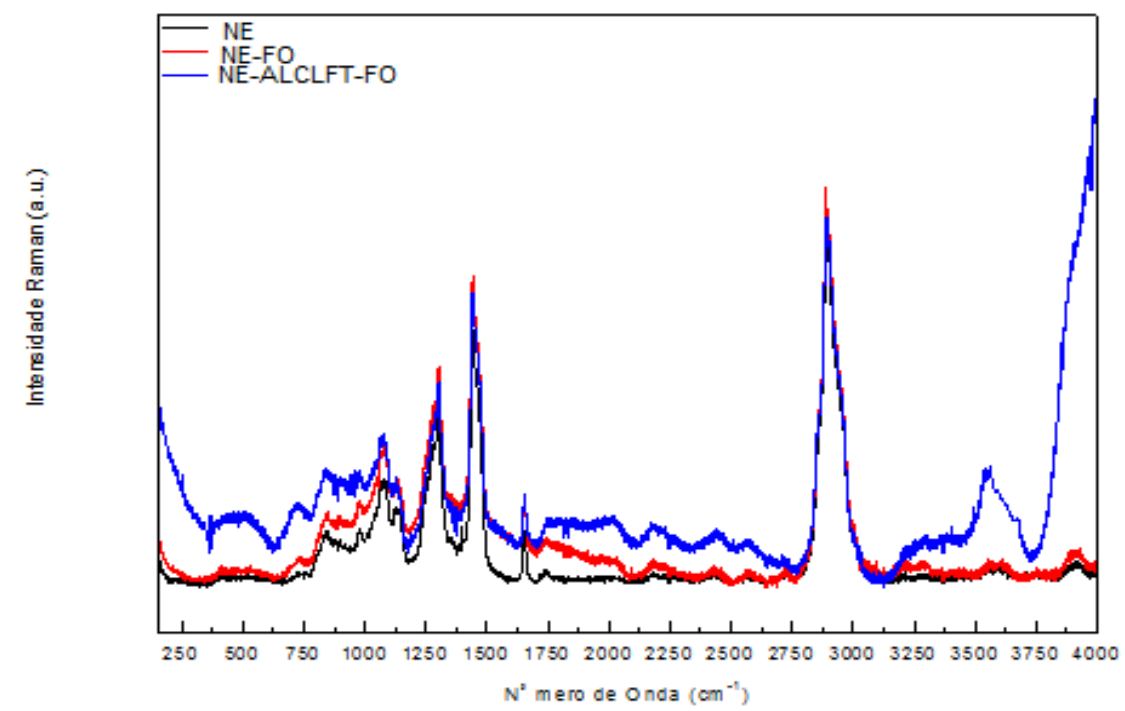

Figura 22. Análise de RAMAN.Os espectros caracterizam os compostos nanoemulsão sem ácido fólico e sem fotossensibilizador (linha em preto), a nanoemuslão com o ácido fólico e sem o fotossensibilizador (linha em vermelho) e a nanoemulsão com o ácido fólico e com o fotossensibilizador (linha em azul).

\subsection{Determinação dos valores coloidais das nanoformulações}

Determinação do Diâmetro Hidrodinâmico (DH), do Índice de Polidispersão (PDI) e do Potencial Zeta (PZ).

Após 24 horas da síntese das nanoemulsões de ftalocianina de cloro-alumínio (NE$\mathrm{AlClFt}$ ) e das nanoemulsões sem o fotossensibilizador (NE) foi realizada a caracterização das nanoemulsões por Espalhamento de Luz Dinâmico (DLS), sendo obtidos a média aritmética e o desvio padrão das soluções em triplicatas.

Constatou-se que a média aritmética do diâmetro hidrodinâmico das NE-ALCLFT em $37^{\circ} \mathrm{C}$ foi de $36.01 \mathrm{~nm}$, com PDI de 0,2 e potencial zeta de $-3,133$. Em $4^{\circ} \mathrm{C}$, tais nanoformulações apresentaram um diâmetro médio de 33,48nm, com PDI a 0,13 e potencial zeta a -2,6. Em meio de cultivo DMEM, o diâmetro hidrodinâmico da nanoemulsão foi de $30.61 \mathrm{~nm}$, com PDI a 0,13 e potencial zeta a 3,84 .

As nanoemulsões sem o fotossensibilizador (NE) apresentaram a $37^{\circ} \mathrm{C}$ o diâmetro de $38,77 \mathrm{~nm}$, com PDI a 0,20 e potencial zeta a $-3,2$. Em $4^{\circ} \mathrm{C}$ o diâmetro foi de 43,24, com PDI a 0,22 e potencial zeta de -3,44. Em meio de cultivo DMEM o diâmetro hidrodinâmico foi de $37,71 \mathrm{~nm}$, com PDI a 0,19 e potencial zeta de 2,55. 
Assim, tais resultados indicam que a carga superficial das NE-ALCLFT e das NE, são predominantemente negativas. Além disso, elas apresentam em geral PDI abaixo de 0,23, o que sugere que a faixa de distribuição do diâmetro hidrodinâmico se caracteriza de forma homogênea em suspensão, apresentando partículas monodispersas. E por fim, os parâmetros do diâmetro hidrodinâmico das nanoemulsões permitiu observar que segundo o teste de Kruskal-Wall com pós-teste de Dunn $(\mathrm{p}<0,05)$ não houve influência estatisticamente significante em nenhum dos fatores avaliados após o preparo (como a temperatura em $37^{\circ} \mathrm{C}$ e a $4^{\circ} \mathrm{C}$, o dispersante e presença do fotossensibilizador), apresentando uma média geral dos elementos com DH de 36,04 nm.

Tais dados relacionados à NE-ALCLFT, podem ser visualizados na tabela 5.

Tabela 5. Determinação do diâmetro hidrodinâmico, do índice de polidispersão e do potencial zeta da nanoemulsão (NE) e da nanoemulsão de ftalocianina de cloroalumínio (NE-ALCLFT).

\begin{tabular}{|c|ccc|}
\hline $\begin{array}{l}\text { Nanoemulsão } \\
\text { /Dispersante }\end{array}$ & $\begin{array}{c}\text { Diâmetro } \\
\text { Hidrodinâmico (nm) }\end{array}$ & PDI & Potencial Zeta (mV) \\
\hline $\begin{array}{c}\text { NE-ALCLFT à } 37^{\circ} \mathrm{C} \\
\text { Água Deionizada }\end{array}$ & $36.01 \pm 0.4199$ & $0.2253 \pm 0.007963$ & $-3.133 \pm 0.2467$ \\
$\begin{array}{c}\text { NE-ALCLFT à } 4^{\circ} \mathrm{C} \\
\text { Água Deionizada }\end{array}$ & $33.48 \pm 0.1896$ & $0.1389 \pm 0.003737$ & $-2.602 \pm 0.1007$ \\
$\begin{array}{c}\text { NE-ALCLFT } \\
\text { Meio de cultivo (DMEM) }\end{array}$ & $30.61 \pm 0.1002$ & $0.134 \pm 0.008$ & $-3.84 \pm 5.17$ \\
$\quad \begin{array}{c}\text { NE à } 37^{\circ} \mathrm{C} \\
\text { Água Deionizada } \\
\text { NE à } 4^{\circ} \mathrm{C}\end{array}$ & $38.77 \pm 0.7745$ & $0.2038 \pm 0.008550$ & $-3.259 \pm 0.2253$ \\
$\begin{array}{c}\text { Água Deionizada } \\
\text { NE }\end{array}$ & $33.24 \pm 0.1552$ & $0.2225 \pm 0.002838$ & $-3.442 \pm 0.04769$ \\
$\begin{array}{c}\text { Meio de cultivo (DMEM) } \\
\text { (DM }\end{array}$ & $37.71 \pm 0.2893$ & $0.19 \pm 0.017$ & $-2.55 \pm 2.27$ \\
\hline
\end{tabular}

Já média aritmética do diâmetro hidrodinâmico das NE-ALCLFT-FO em $37^{\circ} \mathrm{C}$ foi de $65.63 \mathrm{~nm}$, com PDI de 0,21 e potencial zeta de $-2,14$. Em $4^{\circ} \mathrm{C}$, tais nanoformulações apresentaram um diâmetro médio de 65,45nm, com PDI a 0,207 e potencial zeta a -1,79. Em meio de cultivo DMEM, o diâmetro da nanoemulsão foi de 62.32nm, com PDI a 0,29 e potencial zeta a -2.89 .

As nanoemulsões com ácido fólico sem o fotossensibilizador (NE-FO) apresentaram a $37^{\circ} \mathrm{C}$ o diâmetro de $60.58 \mathrm{~nm}$, com PDI a 0,20 e potencial zeta a $-3,2$. Em $4^{\circ} \mathrm{C}$ o diâmetro foi de $43,24 \mathrm{~nm}$, com PDI a 0.224 e potencial zeta de -2.65 . Em meio 
de cultivo DMEM o diâmetro hidrodinâmico foi de $64.72 \mathrm{~nm}$, com PDI a 0.232 e potencial zeta de -2.698 .

Tais dados relacionados à NE-ALCLFT-FO, encontram-se resumidos na Tabela 6.

Tabela 6. Determinação do diâmetro hidrodinâmico, do índice de polidispersão e do potencial zeta da nanoemulsão com ácido fólico (NE-FO) e da nanoemulsão contendo ácido fólico com ftalocianina de cloro-alumínio (NE-ALCLFT-FO).

\begin{tabular}{|c|c|c|c|}
\hline $\begin{array}{c}\text { Nanoemulsão } \\
\text { /Dispersante }\end{array}$ & $\begin{array}{c}\text { Diâmetro } \\
\text { Hidrodinâmico (nm) }\end{array}$ & $\begin{array}{c}\text { PDI } \\
(\mathbf{m V})\end{array}$ \\
\hline $\begin{array}{c}\text { NE-ALCLFT-FO à } 37^{\circ} \mathrm{C} \\
\text { Água Deionizada }\end{array}$ & $65.63 \pm 0.330051$ & $0.21 \pm 0.004933$ & $-2.14 \pm 0.562168$ \\
\hline $\begin{array}{c}\text { NE-ALCLFT-FO à } 4^{\circ} \mathrm{C} \\
\text { Água Deionizada }\end{array}$ & $65.45 \pm 0.329596$ & $0.207 \pm 0.00781$ & $-1.79 \pm 0.47629$ \\
\hline $\begin{array}{c}\text { NE-ALCLFT-FO } \\
\text { Meio de cultivo (DMEM) }\end{array}$ & $62.32 \pm 0.2983$ & $0.29 \pm 0.05622$ & $-2.89 \pm 0.832092$ \\
\hline $\begin{array}{c}\text { NE-FO à } 37^{\circ} \mathrm{C} \\
\text { Água Deionizada }\end{array}$ & $60.58 \pm 0.421$ & $0.224 \pm 0.00652$ & $-2.65 \pm 0.4362$ \\
\hline $\begin{array}{c}\text { NE-FO à } 4^{\circ} \mathrm{C} \\
\text { Água Deionizada }\end{array}$ & $61.63 \pm 0.330051$ & $0.243 \pm 0.00239$ & $-2.23 \pm 0.2131$ \\
\hline $\begin{array}{c}\text { NE-FO } \\
\text { Meio de cultivo (DMEM) }\end{array}$ & $64.72 \pm 0.2341$ & $0.232 \pm 0.00311$ & $-2.698 \pm 0.6334$ \\
\hline
\end{tabular}

Quanto à formulação MIC-FO-ALCLFT, a média aritmética do diâmetro em $37^{\circ} \mathrm{C}$ foi de $164.4 \mathrm{~nm}$, com PDI de 0.353 e potencial zeta de -0.184 . Em $4^{\circ} \mathrm{C}$, tais nanoformulações apresentaram um diâmetro médio de $165.4 \mathrm{~nm}$, com PDI a 0.259 e potencial zeta a -0.342. Em meio de cultivo DMEM, o diâmetro da nanoemulsão foi de $172.4 \mathrm{~nm}$, com PDI a 0.305 e potencial zeta a -0.175 .

As micelas de ácido fólico sem o fotossensibilizador (MIC-FO) apresentaram a $37^{\circ} \mathrm{C}$ o diâmetro de $160,6 \mathrm{~nm}$, com PDI a 0,276 e potencial zeta a $-0,211$. Em $4^{\circ} \mathrm{C}$ o diâmetro foi de $165,4 \mathrm{~nm}$ com PDI a 0.236 e potencial zeta de -0.245 . Em meio de cultivo DMEM o diâmetro hidrodinâmico foi de $167.6 \mathrm{~nm}$, com PDI a 0.243 e potencial zeta de -0.265 .

Tais dados relacionados à MIC-FO-ALCLF, encontram-se resumidos na Tabela 7. 
Tabela 7. Determinação do diâmetro hidrodinâmico, do índice de polidispersão e do potencial zeta da micela de ácido fólico (MIC-FO) e da micela de ácido fólico com ftalocianina de cloro-alumínio (MIC-FO-ALCLFT).

\begin{tabular}{|c|c|c|c|}
\hline $\begin{array}{l}\text { Nanoemulsão } \\
\text { /Dispersante }\end{array}$ & \multicolumn{1}{|c}{$\begin{array}{c}\text { Diâmetro } \\
\text { Hidrodinâmico (nm) }\end{array}$} & Potencial Zeta (mV) \\
\hline $\begin{array}{c}\text { MIC-FO-ALCLFT à } 37^{\circ} \mathrm{C} \\
\text { Água Deionizada }\end{array}$ & $164.4 \pm 26.37695$ & $0.353 \pm 0.063406$ & $-0.184 \pm 0.888882$ \\
\hline $\begin{array}{c}\text { MIC-FO-ALCLFT à } 4^{\circ} \mathrm{C} \\
\text { Água Deionizada }\end{array}$ & $158.6 \pm 16.6538$ & $0.259 \pm 0.0987$ & $-0.342 \pm 0.83797$ \\
\hline $\begin{array}{c}\text { MIC-FO-ALCLFT } \\
\text { Meio de cultivo (DMEM) }\end{array}$ & $172.4 \pm 13.2311$ & $0.305 \pm 0.0089$ & $-0.175 \pm 0.2342$ \\
\hline $\begin{array}{c}\text { MIC-FO à } 37^{\circ} \mathrm{C} \\
\text { Água Deionizada }\end{array}$ & $160.6 \pm 8.6538$ & $0.276 \pm 0.0381$ & $-0.211 \pm 0.566$ \\
\hline $\begin{array}{c}\text { MIC-FO à } 4^{\circ} \mathrm{C} \\
\text { Água Deionizada }\end{array}$ & $165.4 \pm 9.11354$ & $0.236 \pm 0.0473$ & $-0.245 \pm 0.6447$ \\
\hline $\begin{array}{c}\text { MIC-FO } \\
\text { Meio de cultivo (DMEM) }\end{array}$ & $167.6 \pm 13.1239$ & $0.243 \pm 0.0345$ & $-0.265 \pm 0.7329$ \\
\hline
\end{tabular}

\subsection{Avaliação da estabilidade das Nanoformulações}

As análises relacionadas ao estudo de estabilidade da nanoformulações foram baseadas na avaliação quantitativa das amostras quanto ao seu diâmetro hidrodinâmico, o índice de polidispersão, carga superficial da partícula e o potencial hidrogeniônico (pH), por um período de 300 dias.

As estatísticas realizadas segundo o método de regressão linear mostraram a estabilidade das nanoformulações (NE-ALCLFT, NE-ALCLFT-FO e MIC-ALCLFTFO) durante todo o período analisado, observando a temperatura à $37^{\circ} \mathrm{C}$. Além disso, o $\mathrm{pH}$ se mostrou constante num valor próximo a 7.

Os dados podem ser visualizados na figura 24 (A,B,C e D). 
A

\section{Estabilidade à $37^{\circ} \mathrm{C}$}

NE e NE-ALCLFT- (DH/PDI)

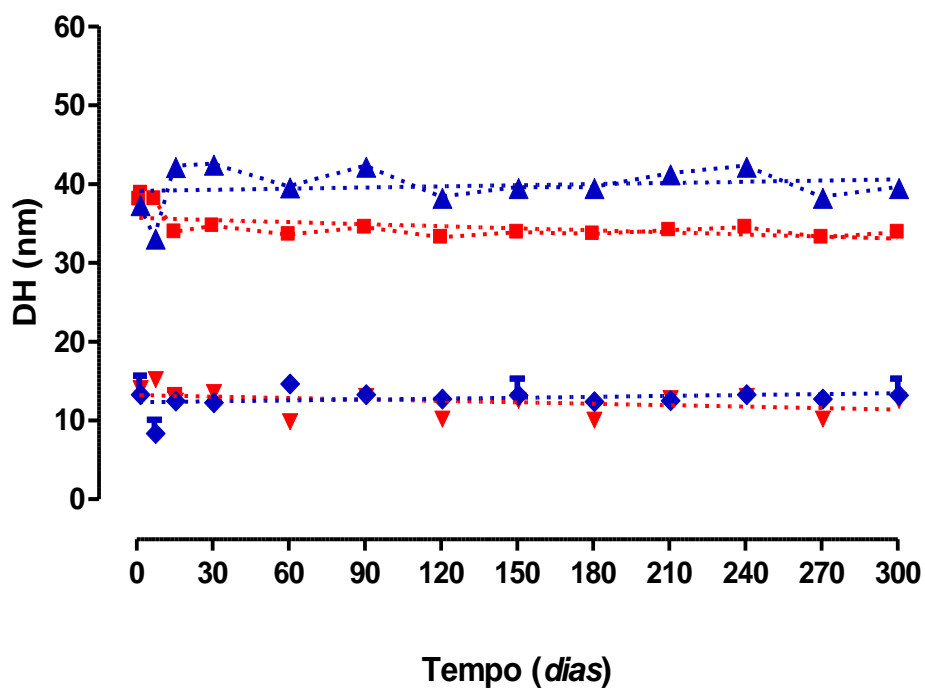

B.

Estabilidade à $37^{\circ} \mathrm{C}$

NE- FO e NE-ALCLFT-FO - (DH/PDI)

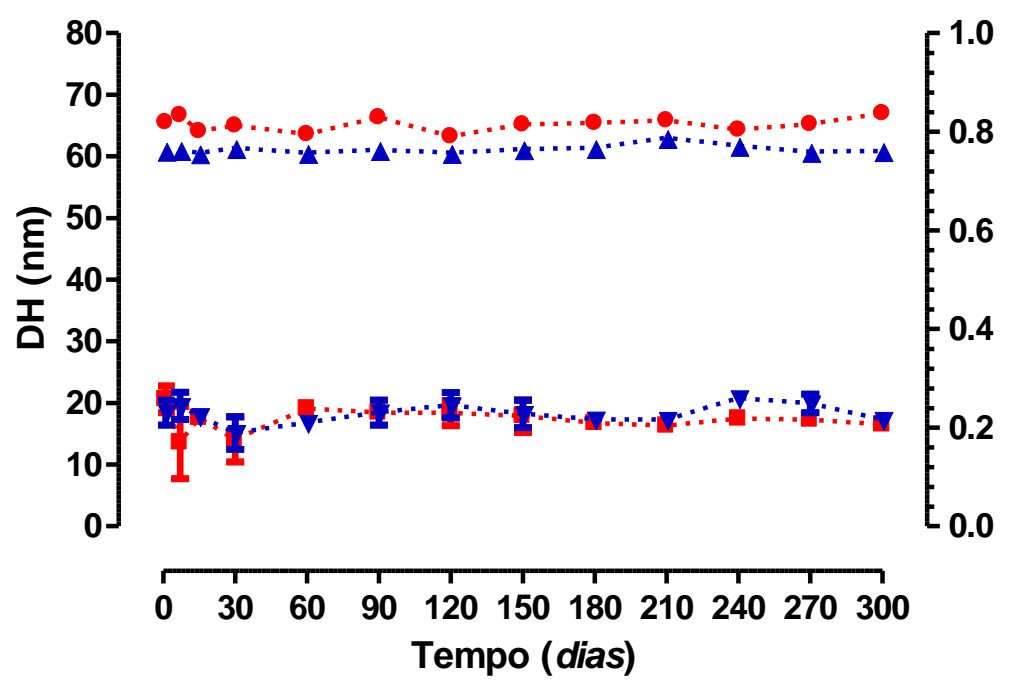

C.

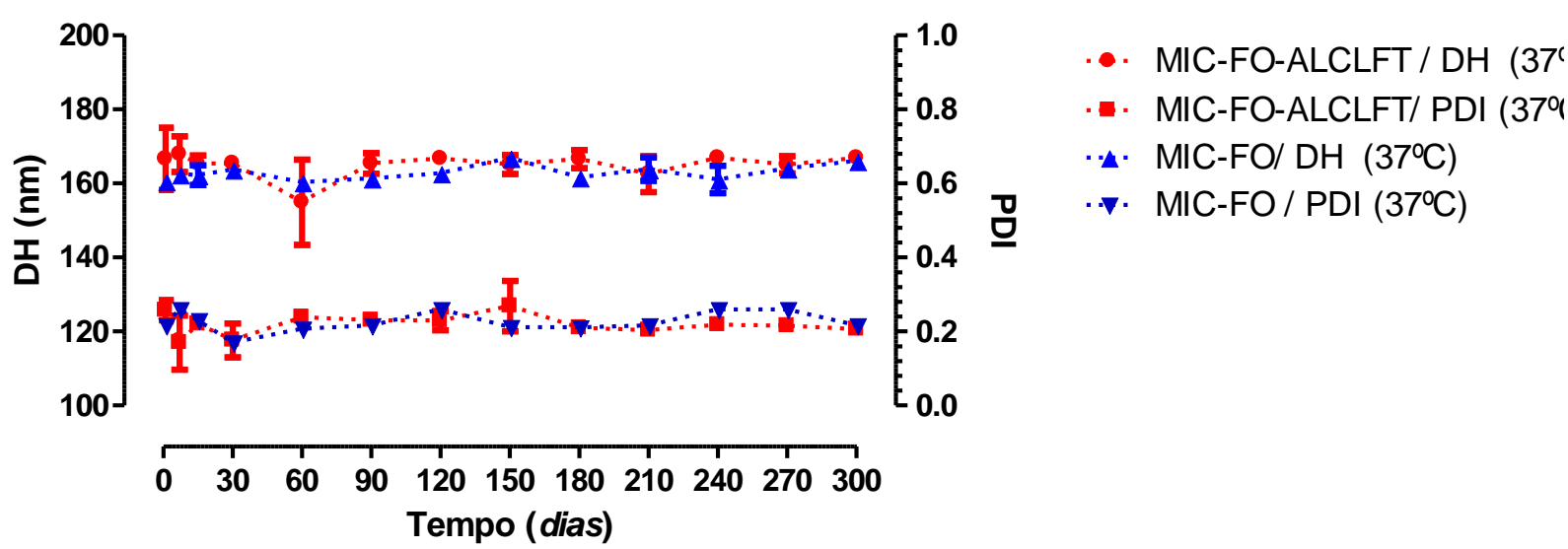

\section{- . NE - ALCLFT -FO / DH (37 \\ - NE - ALCLFT -FO / PDI (3i

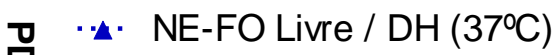 \\ 므 ... N. NE-FO Livre / PDI (37으)}

Estabilidade à 37으
MIC-FO e MIC-FO-ALCLFT - (DH/PDI)

Estabilidade à 37으
MIC-FO e MIC-FO-ALCLFT - (DH/PDI)

Tempo (dias)
- $\mathrm{NE}-\mathrm{AlClFt} / \mathrm{DH}$

-A. NE - DH

. $\mathrm{NE}-\mathrm{AlClFt} / \mathrm{PDI}$

NE - PDI 
D.

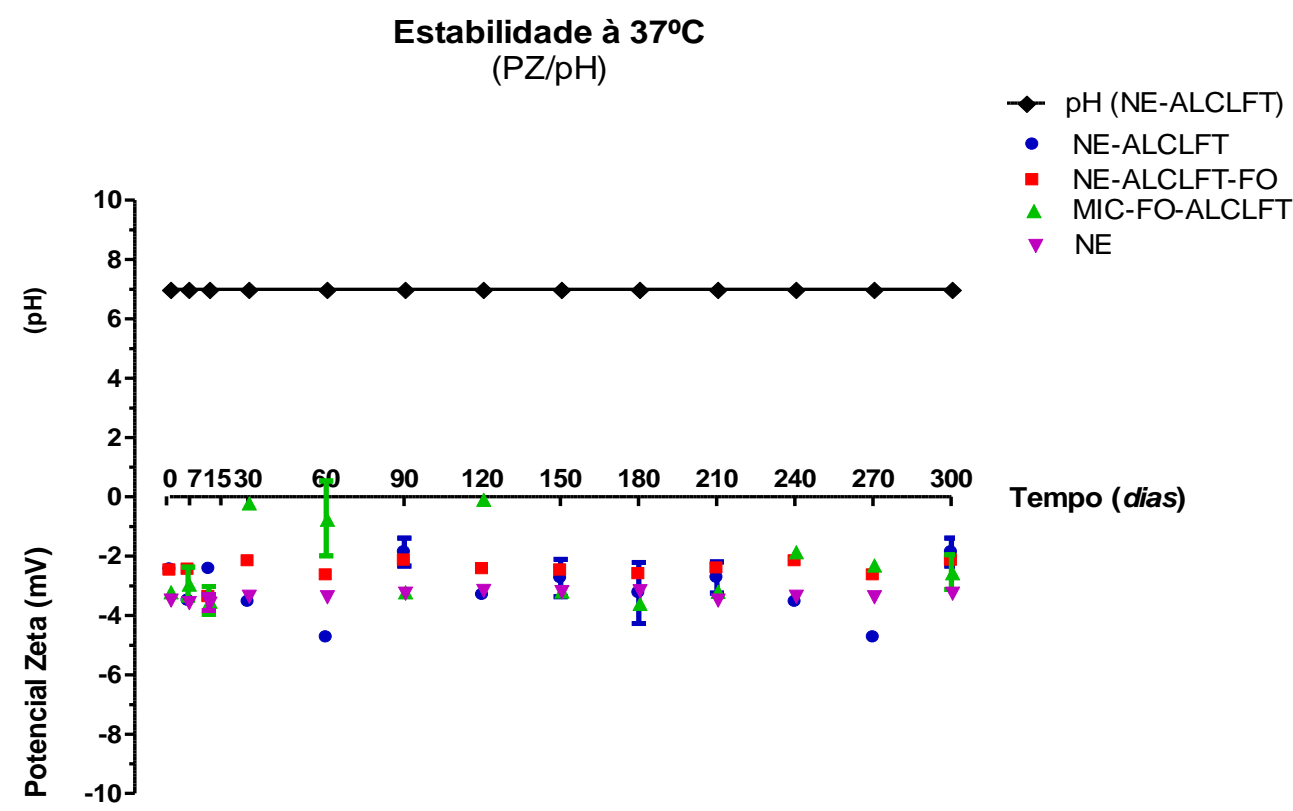

Figura 23. Avaliação da estabilidade física das nanoformulações ao longo de 300 dias. (A) Análise do diâmetro hidrodinâmico (DH) e do índice de polidispersão (PDI) da NEALCLFT. (B) Análise do DH e do PDI da NE-ALCLFT-FO. (C) Análise do DH e do PDI da MIC-FO-ALCLFT. (D) Análise do potencial zeta (PZ) e do potencial hidrogeniônico $(\mathrm{pH})$ à temperatura de $37^{\circ} \mathrm{C}$ da nanoformulações. Os dados mostram que os valores de DH, PDI, PZ e pH, sugerem estabilidade física das nanoformulações em relação ao tempo analisado. Na figura, apenas a linha do $\mathrm{pH}$ da nanoformulação NEALCLFT, foi apresentado, pois as demais formulações apresentaram os mesmos parâmetros.

\subsection{Avaliação das propriedades Fotofísicas: Espectros de Absorbância e Fluorescência}

Os resultados mostraram que a maior intensidade de fluorescência da NE-ALCLFT está situado no comprimento de emissão no intervalo de $680 \mathrm{~nm}$ à $800 \mathrm{~nm}$, com comprimento de excitação no intervalo de 600nm à 700nm, Figura 25. Este mesmo espectro foi igual para as nanoformulações NE-ALCLFT-FO e MIC-FO-ALCLFT, e, portanto às imagens não foram apresentadas. Também é observada uma pequena intensidade, nos comprimentos de excitação entre 360nm à 400nm. 
A.

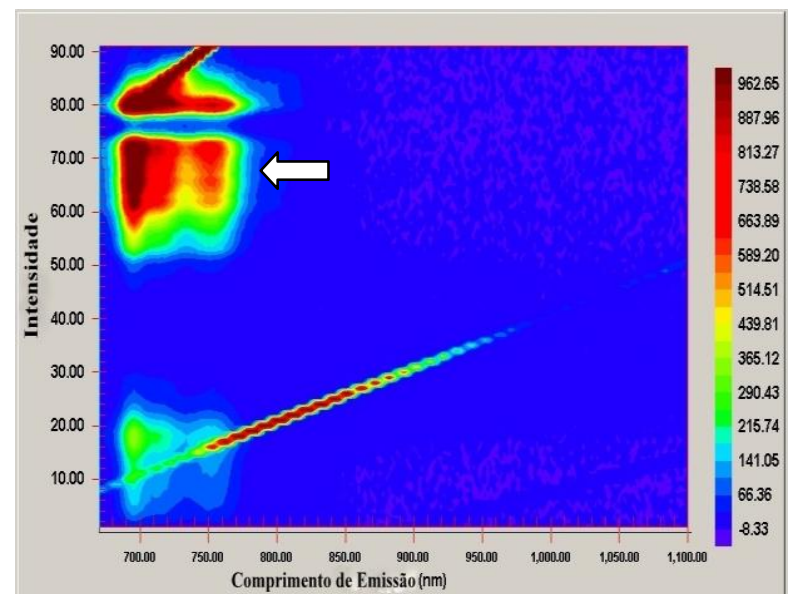

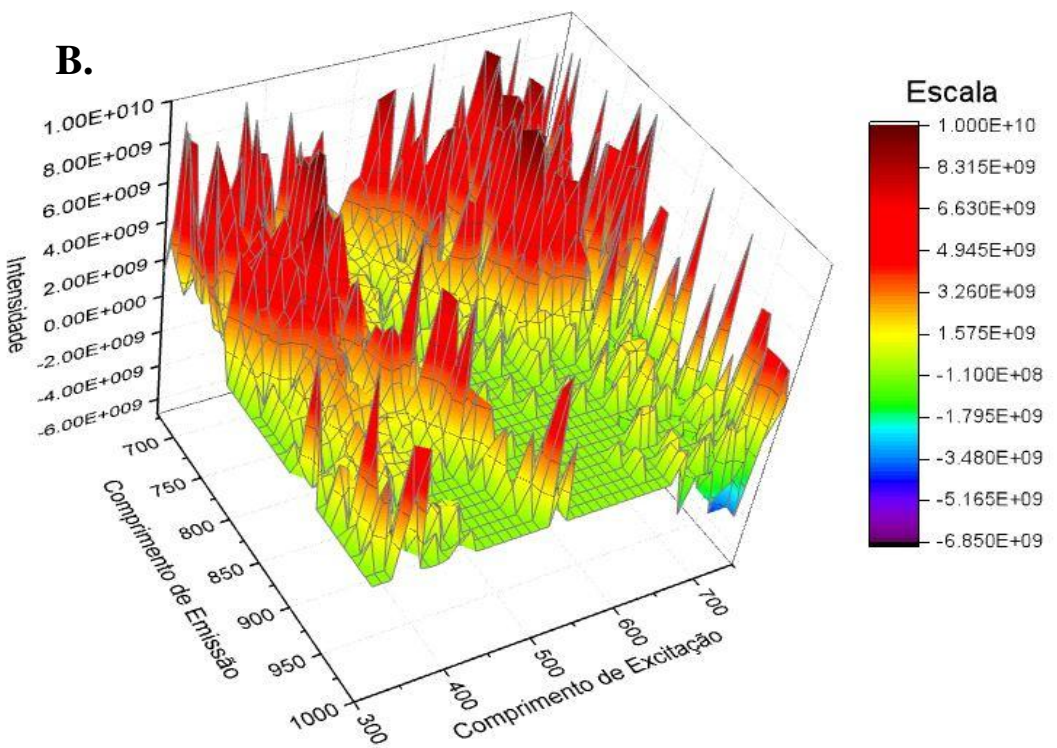

Figura 24. Análise estatística do espectrofluorímetro para quantificar a intensidade de fluorescência emitida pela NE-ALCLFT. (A) Mapeamento colorimétrico da intensidade produzida em relação a região de excitação e emissão. (B) A quantificação gráfica do mapeamento colorimétrico de intensidade de fluorescência. Os dados mostram que os melhores comprimentos de ondas estão situados no comprimento de emissão no intervalo de $680 \mathrm{~nm}$ à $800 \mathrm{~nm}$, com comprimento de excitação no intervalo de $600 \mathrm{~nm}$ à 700nm. A análise mostra o intervalo com maior intensidade de fluorescência emitida pela nanopartícula (região apontada pela seta).

\section{EXPERIMENTOS IN VITRO}

\subsection{Análise do perfil de incorporação das nanoformulações}

Para a análise semi-quantitativa do tempo de incorporação das nanoformulações nas células, foram feitos ensaios utilizando o equipamento IVIS LUMINA. Neste método foi avaliada a bioluminescência, a qual se correlaciona com a quantidade de células 4T1-luciferase por poço, e também, a fluorescência a qual se relaciona com a captação de fótons expressos pela fluorescência presente no fotossensibilizador (ALCLFT) das nanoformulações. 
Após cada tempo de incubação, o estudo das análises foi realizado de forma a comparar a quantidade de células por poço e a intensidade de fluorescência presente. Assim, pôde-se constatar que para todas as formulações (NE-ALCLFT, NE-ALCLFTFO e MIC-FO-ALCLFT) eram suficientes 15 minutos de incubação para que as células captassem as nanoestruturas em alta percentagem (Figura 27. A, B, C, D, E e F). Além disso, foi observado que as formulações NE-ALCLFT e NE-ALCLFT-FO apresentaram maior quantidade na taxa de fluorescência calculada pelo ROI (Region of interest) comparada a MIC-FO-ALCLFT, o que pode corresponder a maior eficácia de incorporação nas células.

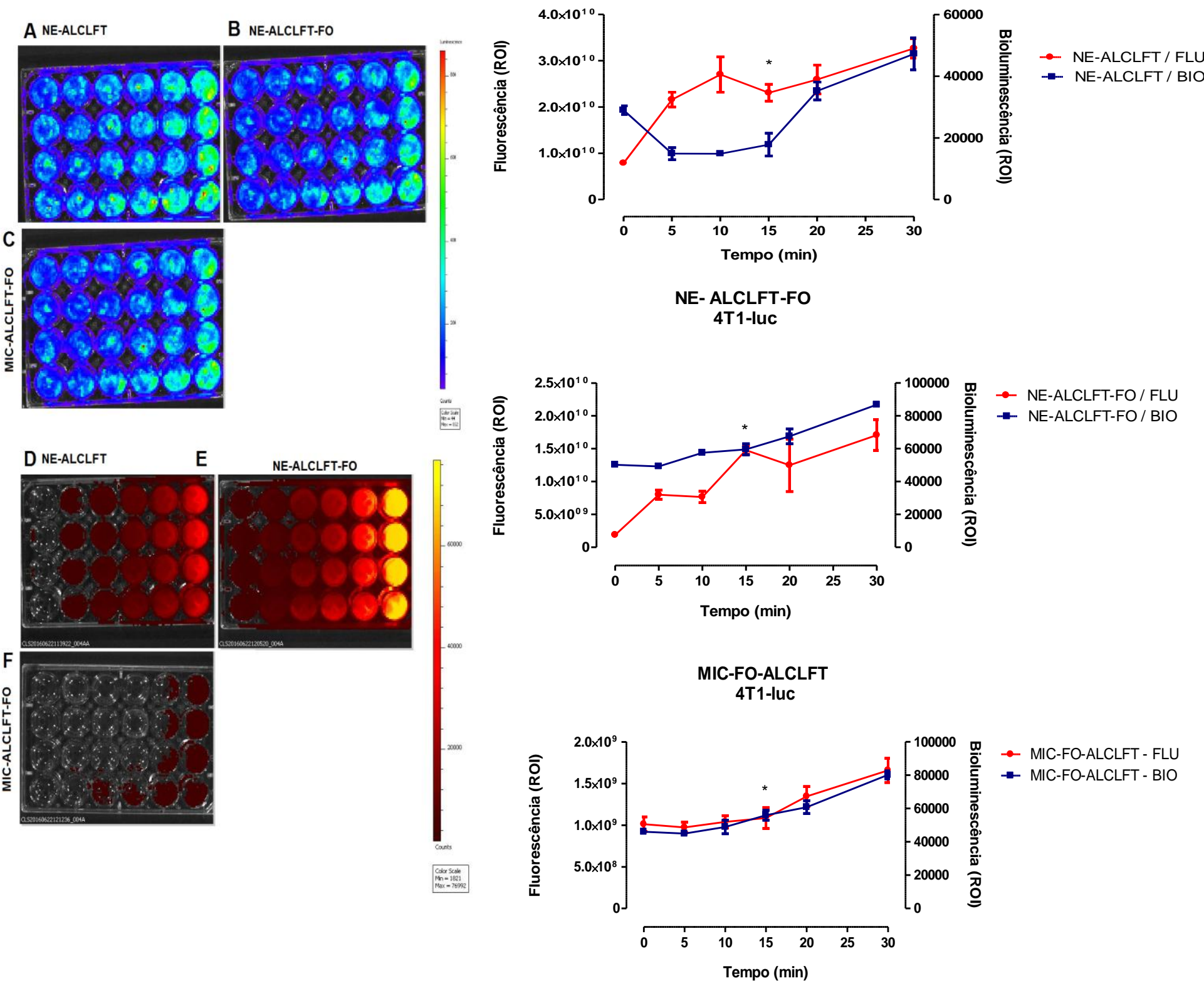


Figura 25. Análise do tempo de incubação das nanoformulações pelo equipamento IVIS LUMINA.Em A, B e C, mostra a imagem de bioluminescência obtida, tendo a escala colorimétrica de intensidade crescente de azul a vermelho. Em D, E e F, tem a imagem de fluorescência, tendo a escala colorimétrica de intensidade crescente de vermelho a amarelo. Ao lado das imagens, são fornecidos os gráficos obtidos pelas imagens, que expressa à quantificação de fluorescência e bioluminescência calculada pelo ROI (Region of interest) no software do equipamento, o que permite comparar a intensidade de fluorescência de cada nanopartícula.

\subsection{Análise da citotoxicidade no escuro das nanoformulações pelo ensaio de MTT}

Os estudos da toxicidade celular causada pelas nanoformulações foram feitas com base nos ensaios de MTT, nas células de fibroblastos murinos (NIH/3T3) e adenocardinoma mamário murino (4T1) conforme já descrito. Foram a analisadas as diferentes concentrações seriadas de formulações sem o fotossensibilizador ALCLFT, sendo: nanoemulsão (NE), nanoemulsão com ácido fólico (NE-FO) e a micela de ácido fólico (MIC-FO).

Para as células de fibroblastos as análises mostram que a formulação NE apresenta diminuição significativa $(\mathrm{p}<0,05)$ da viabilidade celular a partir da concentração $0,625 \mu \mathrm{M}$, tendo $50 \%$ de morte celular na concentração de $20 \mu \mathrm{M}$ (Fig.28 A) comparando com o controle. Já as nanoformulações NE-FO e MIC-FO (Fig.28 B,C), apresentam significativa $(\mathrm{p}>0,05)$ toxicidade celular a partir da concentração de 2,5 $\mu \mathrm{M}$, tendo também $50 \%$ de morte na concentração de $20 \mu \mathrm{M}$.

Para as células de adenocarcinoma mamário, os dados estatísticos mostram que em todas as formulações (NE, NE-FO e MIC-FO), apresentaram toxicidade significativa $(\mathrm{p}<0,05)$ a partir da concentração 0,009 $\mu \mathrm{M}$ (Fig.28 D, E, F). Além disso, constatou-se que a viabilidade celular de $50 \%$ das células foi na concentração de $20 \mu \mathrm{M}$, tanto para as formulações NE como para NE-FO. Para a formulação MIC-FO, a concentração de $20 \mu \mathrm{M}$, foi para $62 \%$. 
(A)

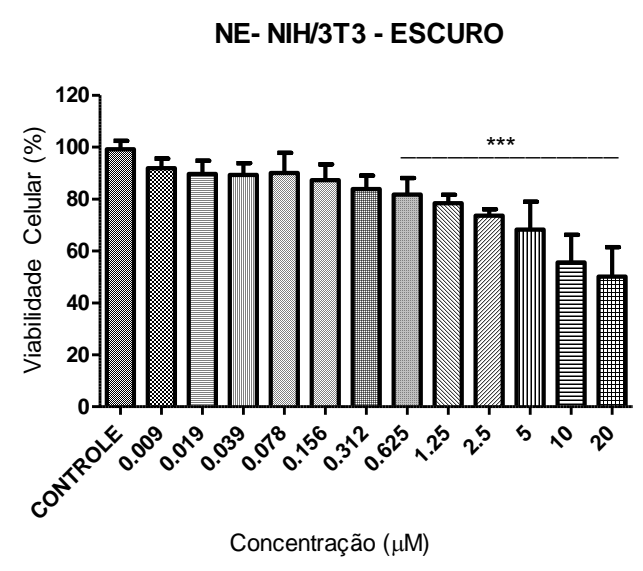

(D)

NE - 4T1 - ESCURO

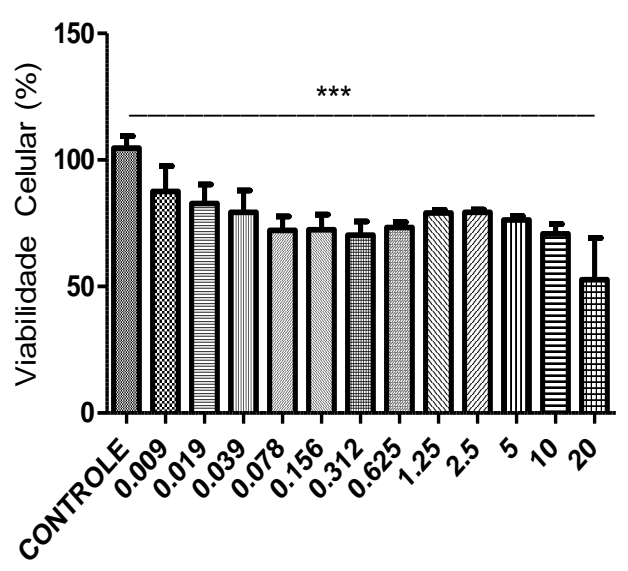

Concentração $(\mu \mathrm{M})$
(B)

NE-FO- NIH/3T3 - ESCURO

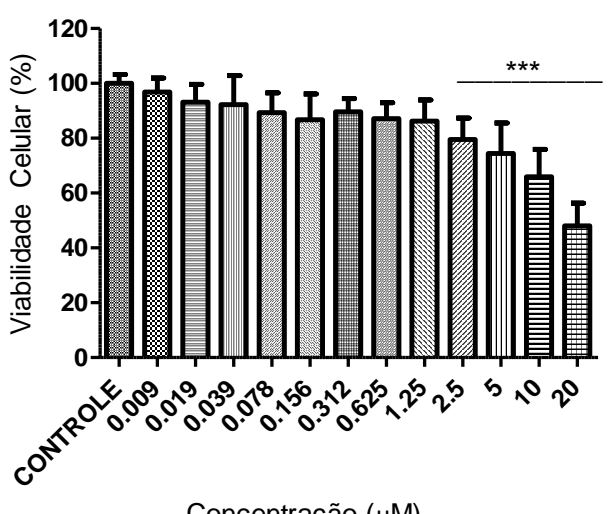

Concentração $(\mu \mathrm{M})$

(E)

NE-FO - 4T1 - ESCURO

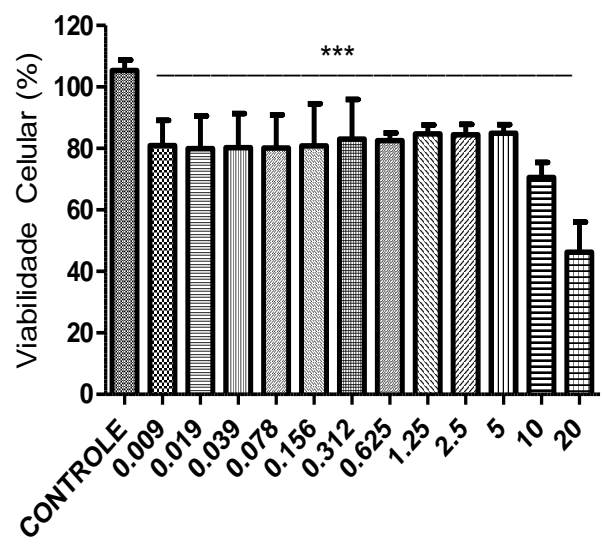

Concentração $(\mu \mathrm{M})$
(F)

MIC-FO - 4T1 - ESCURO

MIC-FO- NIH/3T3 - ESCURO

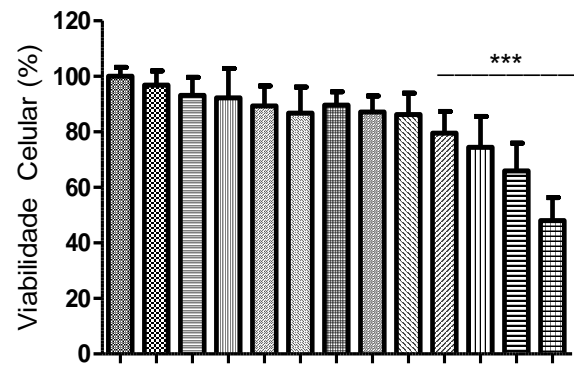

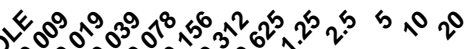

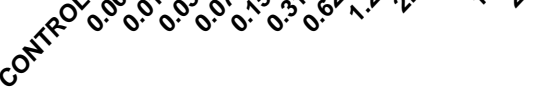

Concentração $(\mu \mathrm{M})$

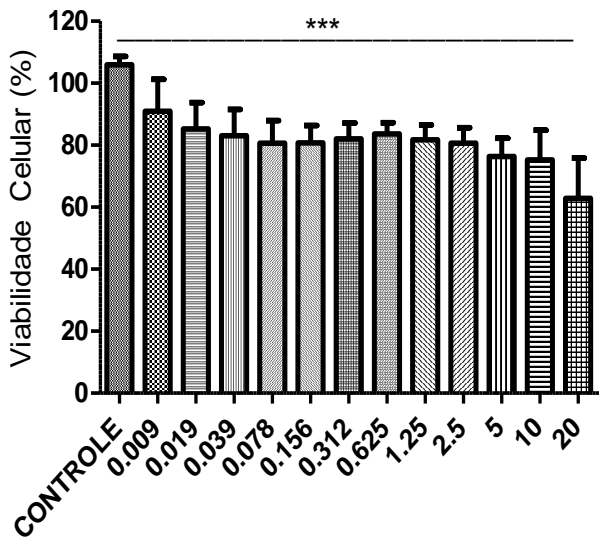

Concentração $(\mu \mathrm{M})$

Figura 26. Viabilidade celular após a exposição das nanoformulações (NE, NE-FO e MIC-FO), nas células de fibroblastos murino (NIH/3T3 - A, B e C) e adenocarcinoma murino (4T1 - D, E e F).Os testes foram realizados sem a presença do fotossensibilizador, em concentrações seriadas (de $0,009 \mu \mathrm{M}$ à $20 \mu \mathrm{M})$, com um período de incubação de 15 minutos para as formulações NE, NE-FO e MIC-FO. Análise estatística: ANOVA em duas vias e teste de múltiplas comparações de Bonferroni. 
Também foram feitas análises das nanoformulações para avaliar o efeito citotóxico com a presença do fotossensibilizador, sem a irradiação do LED, nas células de fibroblasto (NIH/3T3) e adenocarcinoma mamário (4T1). O estudo foi realizado nas seguintes formulações: nanoemulsões com ALCLFT (NE-ALCLFT), nanoemulsões com ácido fólico e ALCLFT (NE-FO-ALCLFT) e a micela de ácido fólico com ALCLFT (MIC-FO-ALCLFT).

Nas células de fibroblasto murino (NIH/3T3), foi constatada apenas uma redução significativa $(\mathrm{p}<0,05)$ de $87 \%$ e $85 \%$ da viabilidade celular a partir da concentração de $10 \mu \mathrm{M}$, para as nanoformulações NE-ALCLFT e MIC-FO-ALCLFT respectivamente (Fig.29 A, C). Na formulação NE-FO-ALCLFT, a redução da viabilidade celular, foi significativa $(\mathrm{p}<0,05)$ a partir da concentração de $5 \mu \mathrm{M}$ para $86 \%$ e $76 \%$ na concentração de $10 \mu \mathrm{M}$ (Fig.29 B).

Nas células de adenocarcinoma mamário (4T1), apenas foi analisado a redução significativa $(\mathrm{p}<0,05)$ para $79 \%$ da viabilidade celular na formulação NE-FO-ALCLFT, comparada ao controle (Fig.29 E). As análises estatísticas não mostraram variância significativa nas formulações NE-ALCLFT e MIC-FO-ALCLFT (Fig. 29 D, F).

Os dados supracitados podem ressaltar que as formulações apresentam baixa toxicidade nestas células, quando não foram irradiadas, em tais circunstâncias estabelecidas.

(A)

NE-ALCLFT - NIH-3T3

o̊
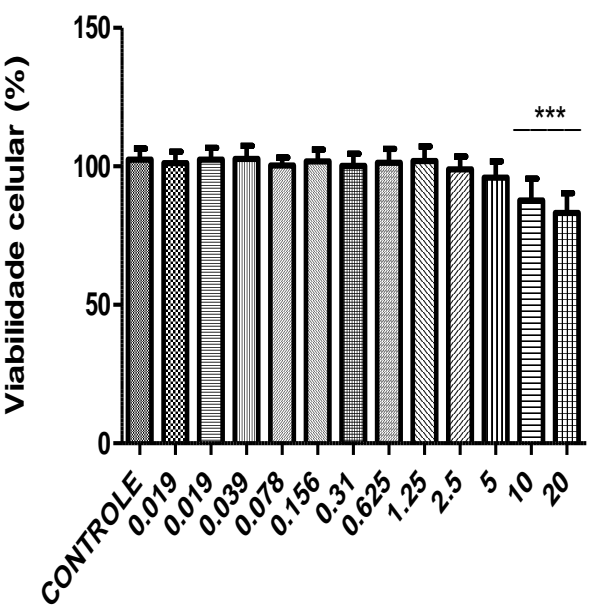

Concentração $\mu \mathrm{M}$
(B)

NE- FO - ALCLFT - NIH-3T3

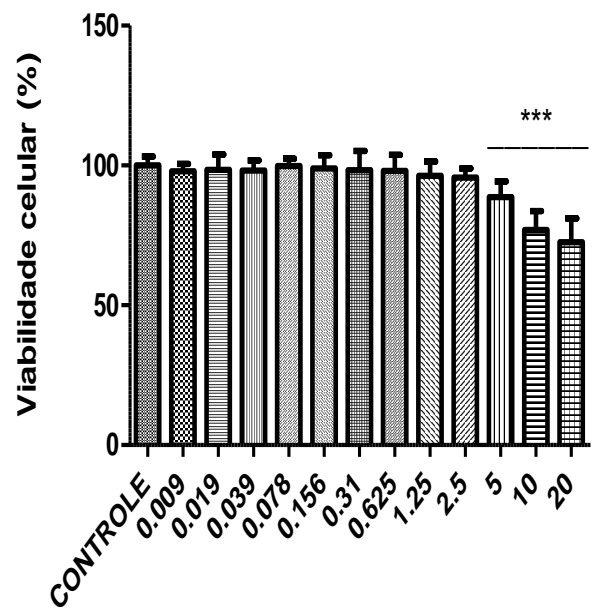

Concentração $\mu \mathrm{M}$
(C)

MIC-FO-ALCLFT - NIH-3T3

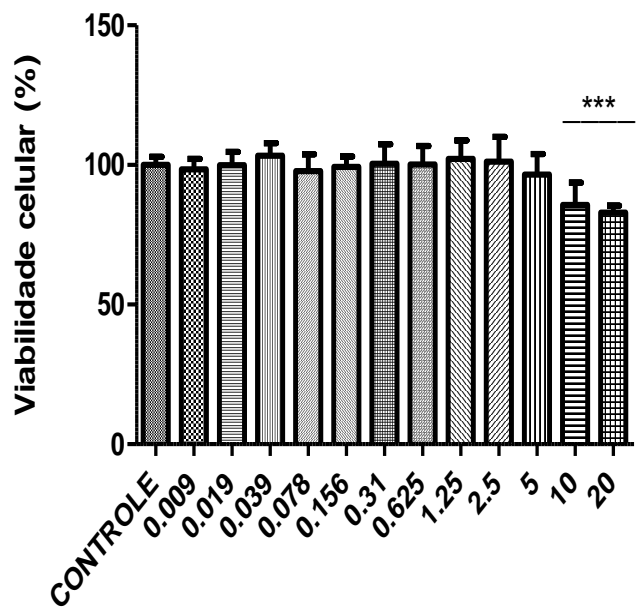

Concentração $\mu \mathrm{M}$ 
(D)

NE-ALCLFT - 4T1

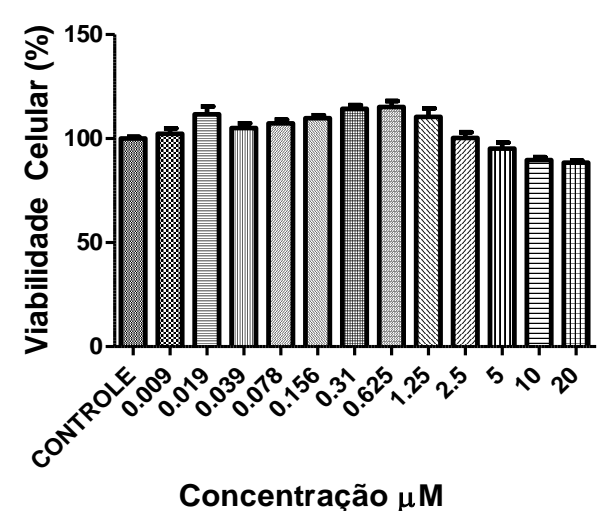

(E)

NE- FO- ALCLFT- 4T1

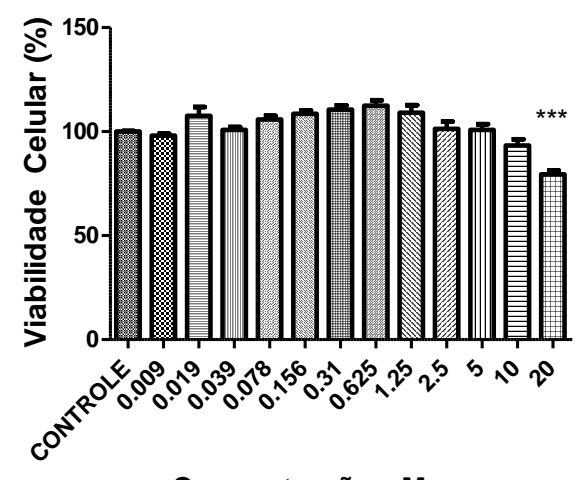

(F)

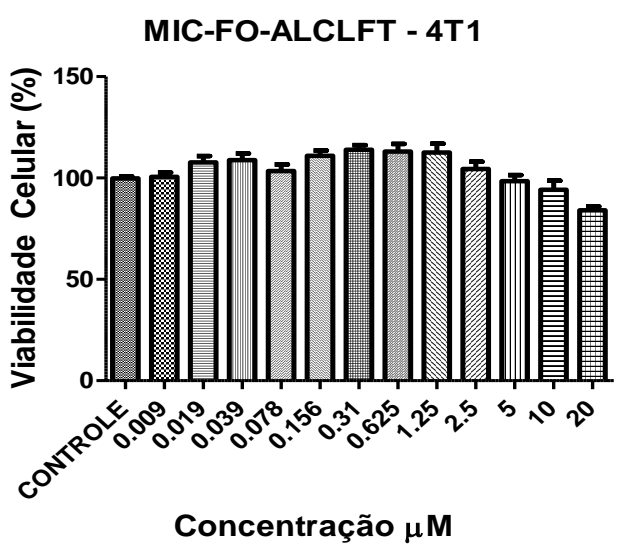

Figura 27. Viabilidade celular após a exposição das nanoformulações (NE-ALCLFT, NE-FO-ALCLFT e MIC-FO-ALCLFT), nas células de fibroblastos murino (NIH/3T3 A, B e C) e adenocarcinoma murino (4T1 - D, E e F). Os testes foram realizados com a presença do fotossensibilizador (Ftalocianina de Cloro Alumínio - ALCLFT), em concentrações seriadas (de $0,009 \mu \mathrm{M}$ à $20 \mu \mathrm{M})$, com um período de incubação de 15 minutos para todas as formulações. Análise estatística: ANOVA em duas vias e teste de múltiplas comparações de Bonferroni.

\subsection{Análise da viabilidade celular das nanoformulações pelo ensaio de MTT, utilizando LED com potências de $10 \mathrm{~mW} / \mathrm{cm}^{2}, 50 \mathrm{~mW} / \mathrm{cm}^{2}$ e $100 \mathrm{~mW} / \mathrm{cm}^{2}$.}

Os ensaios de viabilidade celular tiveram como objetivo analisar a citotoxicidade das nanoformulações nas células de fibroblastos murinos (NIH/3T3) e adenocarcinoma mamário (4T1), avaliando a porcentagem de morte celular causada pelo tratamento com a TFD in vitro. Para isso, foi utilizado seis concentrações $(0,009 \mu \mathrm{M}, 0,019 \mu \mathrm{M}$, $0,039 \mu \mathrm{M}, 0,078 \mu \mathrm{M}, 0,156 \mu \mathrm{M}$ e $0,312 \mu \mathrm{M}$ ) de cada nanoformulação (NE-ALCLFT, NEALCLFT-FO e MIC-FO-ALCLFT). Estas concentrações foram escolhidas com base nos estudos prévios nos ensaios sem a irradiação do LED, de forma a utilizar aquelas que apresentaram menor toxicidade possível no escuro. Além disso, foi possível analisar o efeito do LED sem a presença das nanoformulações, três diferentes potências $\left(10 \mathrm{~mW} / \mathrm{cm}^{2}, 50 \mathrm{~mW} / \mathrm{cm}^{2}\right.$ e $\left.100 \mathrm{~mW} / \mathrm{cm}^{2}\right)($ Fig. 30). 
$10 \mathrm{~mW} / \mathrm{cm}^{2}$

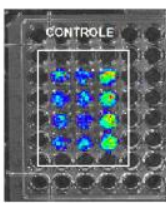

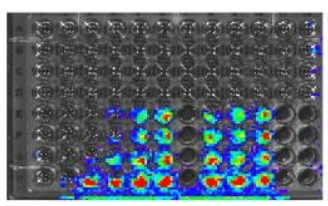

$50 \mathrm{~mW} / \mathrm{cm}^{2}$

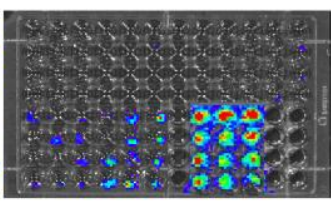

$100 \mathrm{~mW} / \mathrm{cm}^{2}$

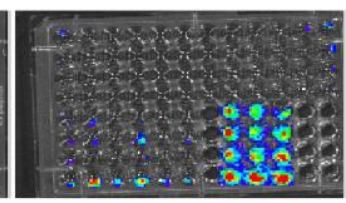

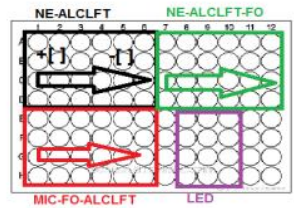

Figura 28. Caracterização bioluminescente do tratamentos com TFD. Imagem representativa observada no equipamento IVIS LUMINA após os tratamentos usando as nanoformulações e as diferentes potências.

Os ensaios in vitro utilizando a potência de $10 \mathrm{~mW} / \mathrm{cm}^{2}$ (com ou sem a presençade fotossensibilizador) por 10 minutos, mostraram significativa redução ( $<<0,001)$ na viabilidade celular das células de adenocarcinoma mamário (Fig. 31, A) fibroblastos (Fig. 31, B). Observou-se que com apenas o uso do LED, houve diminuição para $73 \%$ nas linhagens $4 \mathrm{~T} 1$, e $60 \%$ para as linhagens NIH/3T3. Com o uso das nanoformulações NE-ALCLFT e NE-ALCLFT-FO, a porcentagem de morte celular das células de adenocarcinoma mamário (4T1) foi para taxas inferiores a 20\%, nas concentrações de $0,078 \mu \mathrm{M}, 0,156 \mu \mathrm{M}$ e 0,312 $\mu \mathrm{M}$. Já a nanoformulação MIC-FOALCLFT, mostrou-se menos eficaz nesta mesma linhagem celular (4T1), diminuindo a viabilidade celular para $33 \%$ na maior concentração testada $(0,312 \mu \mathrm{M})$ e entre $55 \%$ a $73 \%$ nas demais concentrações. Nas células de fibroblastos, esses mesmos aspectos foram observados nas formulações de NE-ALCLFT e NE-ALCLFT-FO, mas, para a formulação MIC-FO-ALCLFT, a morte celular foi de $23 \%$ na concentração $0,312 \mu \mathrm{M}$, ou seja, $10 \%$ a mais obervada nas células tumorais, quando irradiadas. 

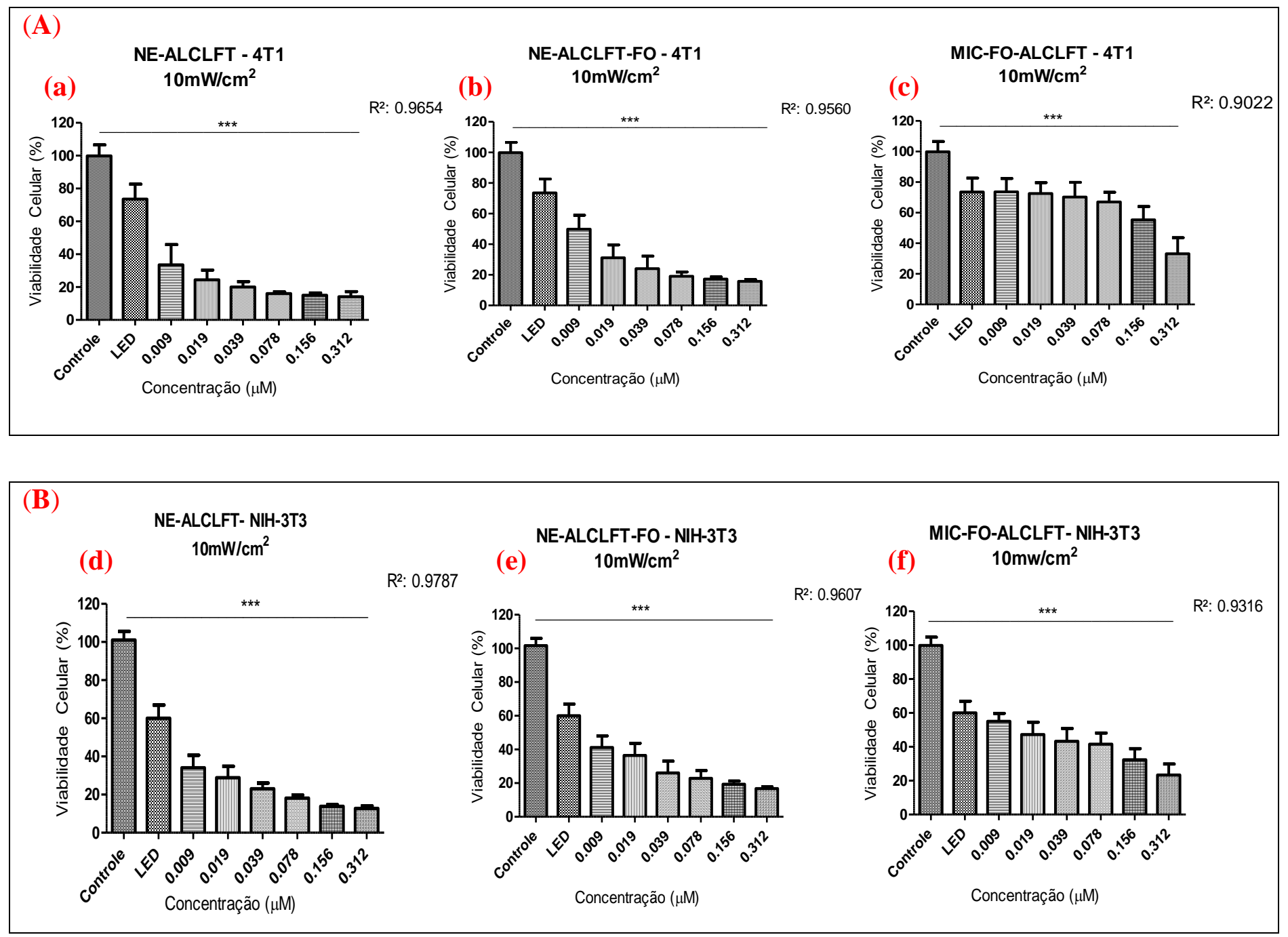

Figura 29. Gráficos representando o percentual de viabilidade celular após incubação por 15 minutos e aplicação da TFD. Dez minutos de exposição ao LED com a potência de $10 \mathrm{~mW} / \mathrm{cm}^{2}$. (A) Linhagem de adenocarcinoma mamário (4T1) (B) Linhagem de fibroblastos (NIH/3T3). Concentrações utilizadas $(0,009 \mu \mathrm{M}, 0,019 \mu \mathrm{M}, 0,039 \mu \mathrm{M}$, $0,078 \mu \mathrm{M}, 0,156 \mu \mathrm{M}$ e $0,312 \mu \mathrm{M})$ de (a,d) NE-ALCLFT, (b,e) NE-ALCLFT-FO e (c,f) MIC-FO-ALCLFT. Em ambos, utilizou-se o método colorimétrico de detecção por MTT. Estatística realizada por ANOVA, com pós-teste Bonferroni, p <0,001.

Nos ensaios de TFD utilizando a potência de $50 \mathrm{~mW} / \mathrm{cm}^{2}$, a porcentagem de morte celular foi significativamente maior comparada à potência de $10 \mathrm{~mW} / \mathrm{cm}^{2}$, especialmente nas células de adenocarcinoma mamário (4T1).

Nas células de adenocarcinoma (Fig. 32, A), o uso apenas do LED ocasionou a redução da viabilidade para $73 \%$. No entanto, com o uso das nanoformulações NE- 
ALCLFT e NE-ALCLFT-FO, a viabilidade celular foi reduzida para 5\% $(0,039 \mu \mathrm{M}$, $0,078 \mu \mathrm{M}, 0,156 \mu \mathrm{M}$ e $0,312 \mu \mathrm{M})$. Já a formulação MIC-FO-ALCLFT, apresentou uma redução gradativa com o aumento das concentrações, resultando na viabilidade celular para $7 \%$ na concentração $0,312 \mu \mathrm{M}$.

Nas células de fibroblastos (Fig. 32, B), os resultados apresentaram aspectos diferentes. Observou-se o aumento de $7 \%$ na quantidade de células, comparado ao controle, quando utilizado apenas a irradiação do LED. Pôde-se notar também, que quando utilizado as nanoformulações NE-ALCLFT e NE-ALCLFT-FO a porcentagem da viabilidade celular foi de $42 \%$ em todas as concentrações testadas, ou seja, ocorreu menos morte celular quando comparada às células de adenocarcinoma mamário. Para a formulação MIC-FO-ALCLFT, os resultados foram similares à resposta das células tumorais, visto que a viabilidade celular dependia do aumento das concentrações, porem, ainda sim a viabilidade manteve-se maior (47\%) nas células de fibroblastos comparadas às células tumorais.

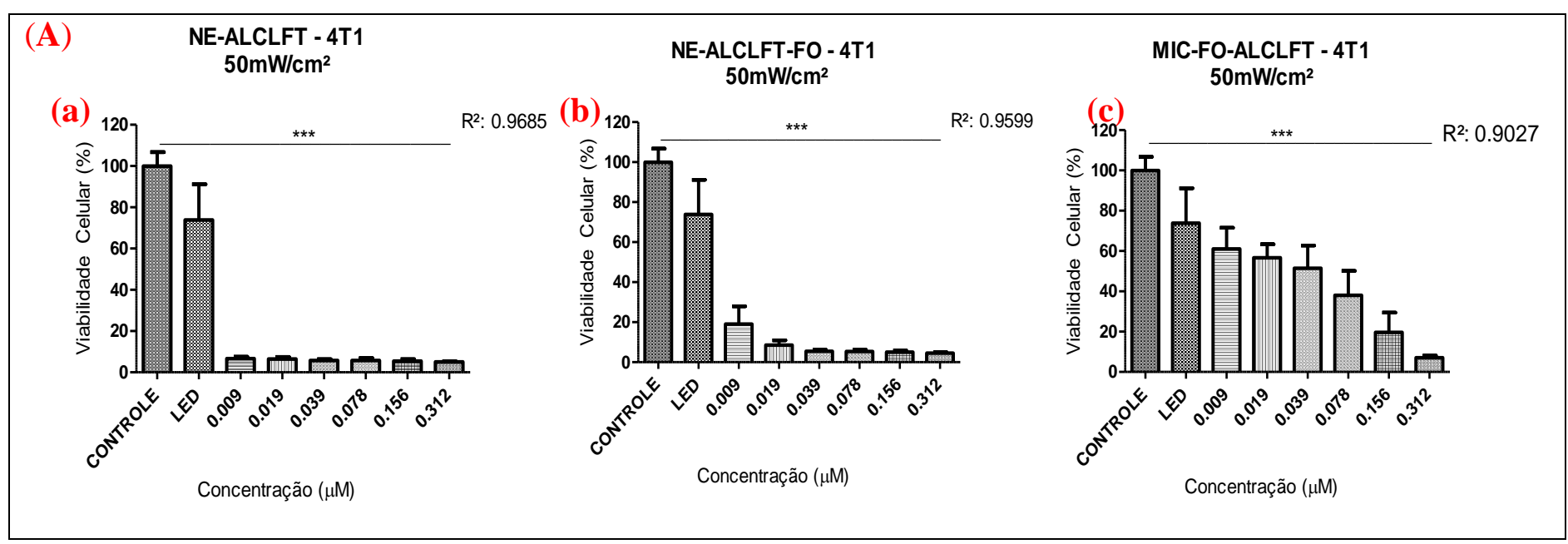


(B)

(d) NE-ALCLFT - NIH/3T3

$50 \mathrm{~mW} / \mathrm{cm}^{2}$

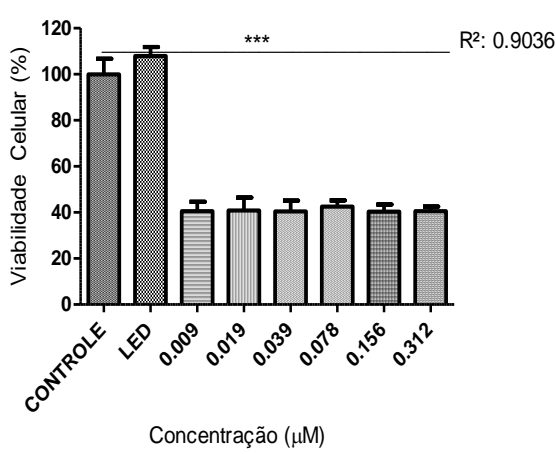

(e) NE-ALCLFT-FO - NIH/3T3

$50 \mathrm{~mW} / \mathrm{cm}^{2}$

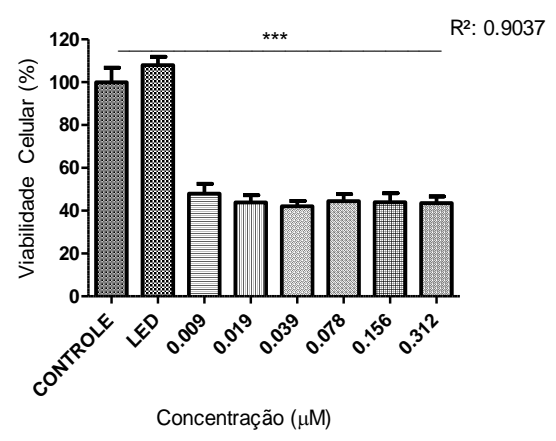

(f) MIC-FO-ALCLFT - NIH/3T3

$50 \mathrm{~mW} / \mathrm{cm}^{2}$
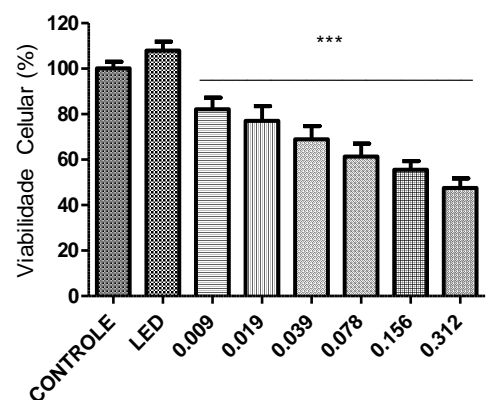

Concentração $(\mu \mathrm{M})$

Figura 30. Gráficos representando o percentual de viabilidade celular após incubação por 15 minutos e aplicação da TFD. Dez minutos de exposição ao LED com a potência de $50 \mathrm{~mW} / \mathrm{cm}^{2}$. (C) Linhagem de adenocarcinoma mamário (4T1) (D) Linhagem de fibroblastos (NIH/3T3). Concentrações utilizadas $(0,009 \mu \mathrm{M}, 0,019 \mu \mathrm{M}, 0,039 \mu \mathrm{M}$, $0,078 \mu \mathrm{M}, 0,156 \mu \mathrm{M}$ e $0,312 \mu \mathrm{M})$ de $(\mathrm{a}, \mathrm{d})$ NE-ALCLFT, $(\mathrm{b}, \mathrm{e})$ NE-ALCLFT-FO e $(\mathrm{c}, \mathrm{f})$ MIC-FO-ALCLFT. Em ambos, utilizou-se o método colorimétrico de detecção por MTT. Estatística realizada por ANOVA, com pós-teste Bonferroni, p <0,001.

Nos experimentos de TFD utilizando a potência de $100 \mathrm{~mW} / \mathrm{cm}^{2}$, a porcentagem de morte celular foi significativamente $(\mathrm{p}<0,001)$ maior comparada à potência de $10 \mathrm{~mW} / \mathrm{cm}^{2}$ e menor $(\mathrm{p}<0,001)$ comparada a $50 \mathrm{~mW} / \mathrm{cm}^{2}$ nas células de adenocarcinoma mamário. Para as células de fibroblasto, a viabilidade celular foi reduzida comparada às demais potências estudadas.

Nas células de adenocarcinoma (Fig. 33,A), a viabilidade celular foi reduzida para $61 \%$, quando se utilizou apenas a irradiação do LED. No entanto, ao aplicar os tratamentos com as formulações NE-ALCLFT e NE-ALCLFT-FO, a viabilidade celular foi reduzida para $18 \%$ em todas as concentrações testadas. Já para a formulação MICFO-ALCLFT, a menor viabilidade encontrada foi de $25 \%$, na concentração $0,312 \mu \mathrm{M}$.

Nas células de fibroblastos (Fig. 33,B), a porcentagem da viabilidade celular foi para 77\% quando utilizado apenas o LED. Para as formulações NE-ALCLFT e NEALCLF-FO, a redução foi para $15 \%$, em todas as concentrações analisadas. Já a formulação MIC-FO-ALCLFT a viabilidade celular manteve-se entre $18 \%$ a $23 \%$ nas concentrações estudadas. 


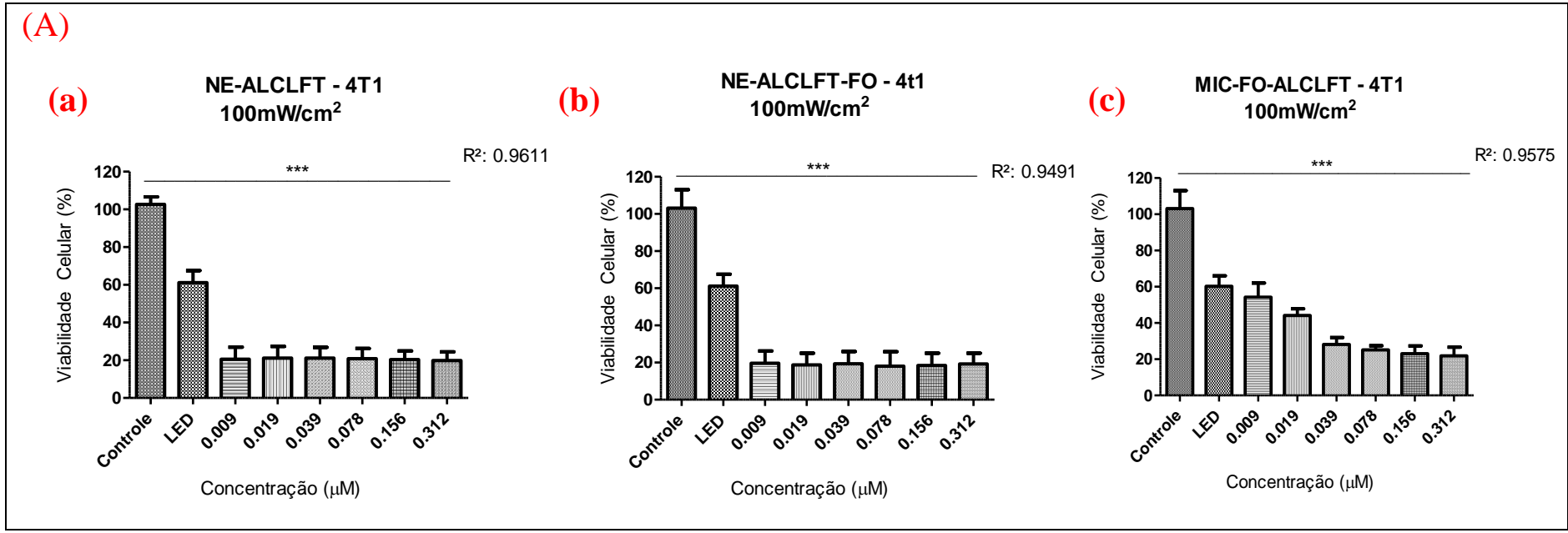

(B)

(d)

$$
\begin{aligned}
& \text { NE-ALCLFT- NIH-3T3 } \\
& 100 \mathrm{~mW} / \mathrm{cm}^{2}
\end{aligned}
$$

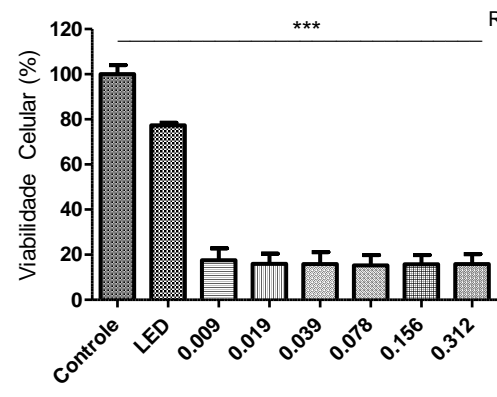

(e) NE-ALCLFT-FO - NIH-3T3 $100 \mathrm{~mW} / \mathrm{cm}^{2}$ $R^{2}: 0.9833$

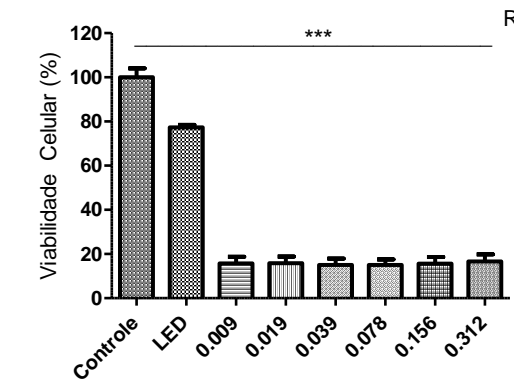

Concentração $(\mu \mathrm{M})$ (f)

MIC-FO-ALCLFT - NIH-3T3 $100 \mathrm{~mW} / \mathrm{cm}^{2}$

$R^{2}: 0.9924$

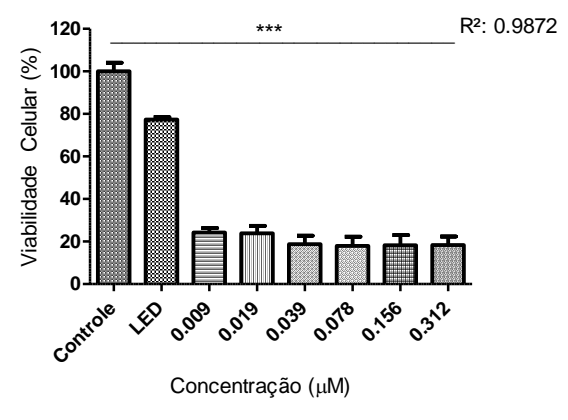

Figura 31. Gráficos representando o percentual de viabilidade celular após incubação por 15 minutos e aplicação da TFD.Dez minutos de exposição ao LED com a potência de $100 \mathrm{~mW} / \mathrm{cm}^{2}$. (E) Linhagem de adenocarcinoma mamário (4T1) (F) Linhagem de fibroblastos (NIH/3T3). Concentrações utilizadas $(0,009 \mu \mathrm{M}, 0,019 \mu \mathrm{M}, 0,039 \mu \mathrm{M}$, $0,078 \mu \mathrm{M}, 0,156 \mu \mathrm{M}$ e $0,312 \mu \mathrm{M})$ de $(\mathrm{a}, \mathrm{d})$ NE-ALCLFT, (b,e) NE-ALCLFT-FO e (c,f) MIC-FO-ALCLFT. Em ambos, utilizou-se o método colorimétrico de detecção por MTT. Estatística realizada por ANOVA, com pós-teste Bonferroni, p <0,001.

Portanto, segundo as análises dos resultados dos ensaios de MTT, foi possível observar que o tratamento utilizando as nanoformulações NE-ALCLFT e NE-ALCLFTFO, provoca maior redução na viabilidade celular, comparada à formulação MIC-FOALCLFT. Além disso, foi constatado que a variação da potência utilizada pelo LED, influência nas porcentagens de morte celular. Outro fator relevante, é que o comportamento da viabilidade celular é diferente para as células tumorais e as células 
não-tumorais de acordo com a potência utilizada para a realização dos tratamentos com a TFD.

\subsection{Análise microscópica da morfologia das células de adenocarcinoma mamário (4T1) e fibroblastos (NIH/3T3), após os tratamentos com TFD}

As fotomicrografias obtidas por microscopia de contraste de fase da linhagem de adenocarcinoma murino (4T1-luc)(Fig. 34) mostram que as células do grupo controle (sem tratamento) apresentaram morfologia típico desta, contendo características como presença de várias projeções da membrana citoplasmática, com núcleos e nucléolos bem evidentes e formato fusiforme. Ainda, observou-se que as projeções da membrana entre as células, no campo observado, representam pontos de adesão focal, ou seja, pontos em que há interações entre elas e estes aspectos sugerem demonstrar que o citoesqueleto de actina está íntegro. Além disso, observou-se que as células encontravam-se aderidas à placa de cultura.

Em relação aos grupos que foram tratados com as nanoformulações e a TFD, foi observada menor confluência celular em relação ao controle. Além disso, notou-se vários aspectos diferentes do grupo controle, como, ausência de projeções citoplasmáticas, redução do volume do citoplasma, presença de debris e formato arredondado, o que pode demonstrar que as células perderam a aderência ao substrato (neste caso, a placa), processo que antecede células em processo de morte celular, e que são características peculiares de células com alterações no citoesqueleto de actina. Outra característica precedente de toxicidade celular foi à presença de maior granulosidade em algumas células e isto pode estar relacionado com o aumento do número de vesículas dentro da célula e formação de inúmeros vacúolos, característica que pode indicar alterações que podem induzir a morte celular. Todas essas características foram observadas principalmente com o uso das nanoformulações NE-ALCLFT e NEALCLFT-FO, em todas as potências testadas $\left(10 \mathrm{~mW} / \mathrm{cm}^{2}, 50 \mathrm{~mW} / \mathrm{cm}^{2}\right.$ e $\left.100 \mathrm{~mW} / \mathrm{cm}^{2}\right)$. Já nos tratamentos utilizando a formulação MIC-FO-ALCLFT, observou-se que esses efeitos citotóxicos supracitados foram mais atenuados, visto que as alterações notadas foram principalmente apenas com relação à modificação morfológica para o formato arredondado e algumas alterações no citoesqueleto, no entanto, ainda é possível observar estruturas características desta linhagem celular (Fig. 34, de A à J). 
ADENOCARCINOMA MAMÁRIO MURINO - 4T1-luciferase
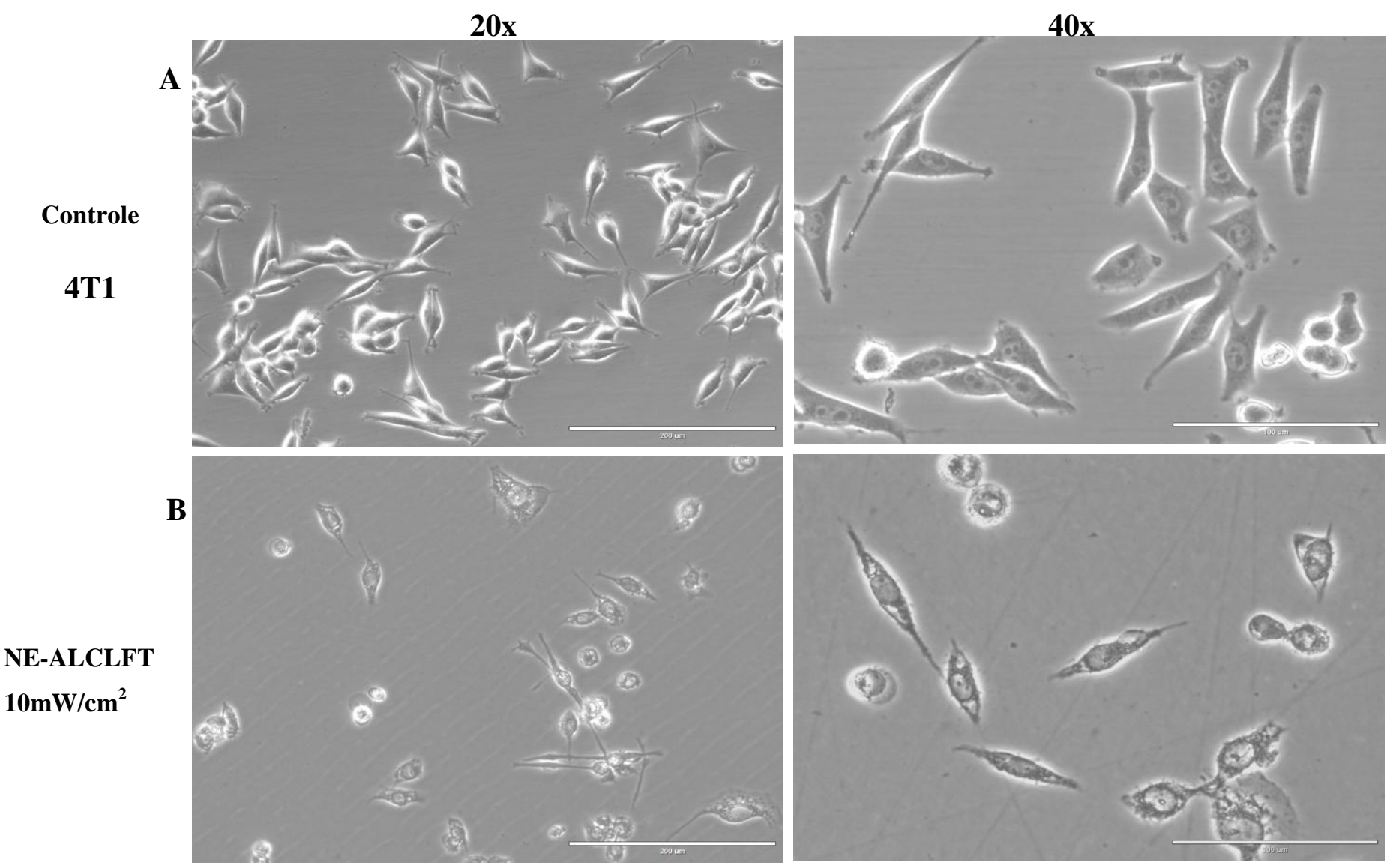

NE-ALCLFT
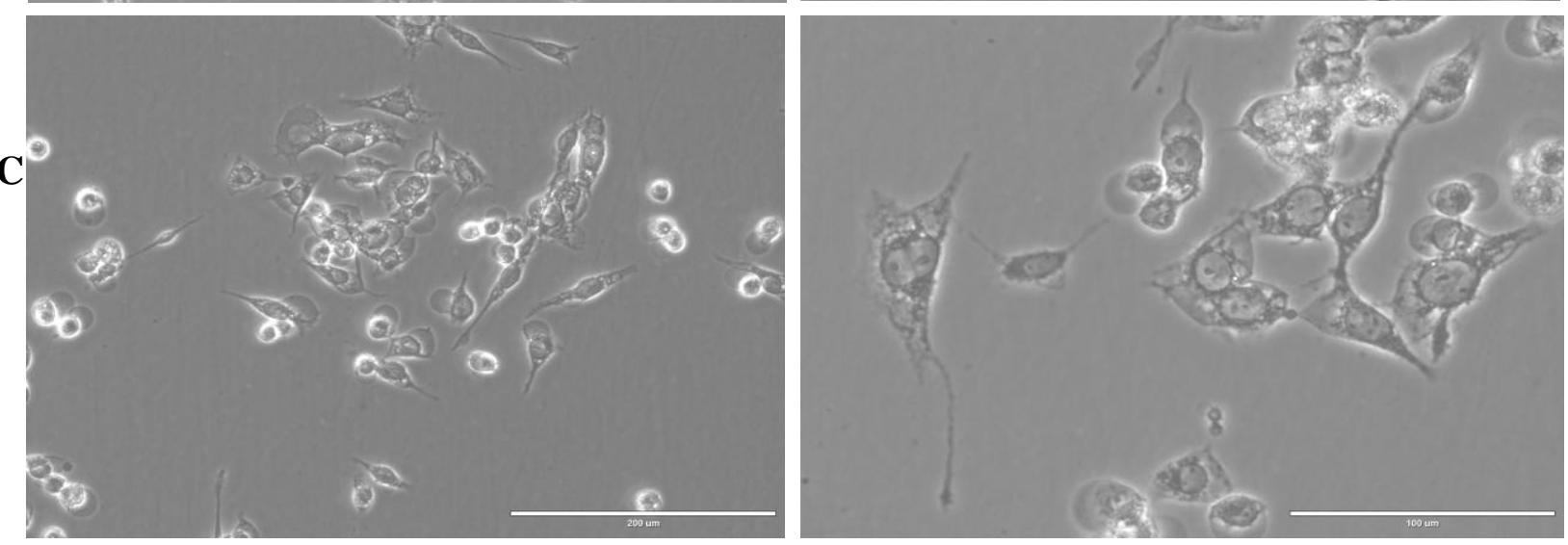

$50 \mathrm{~mW} / \mathrm{cm}^{2}$

NE-ALCLFT
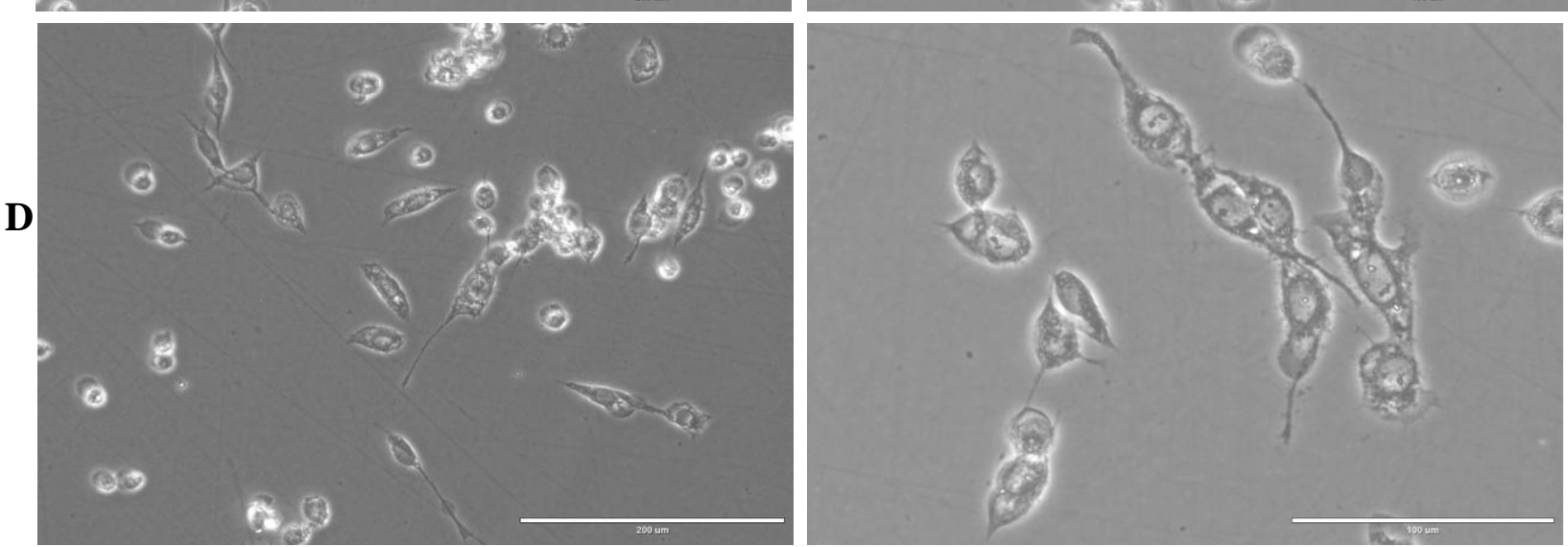


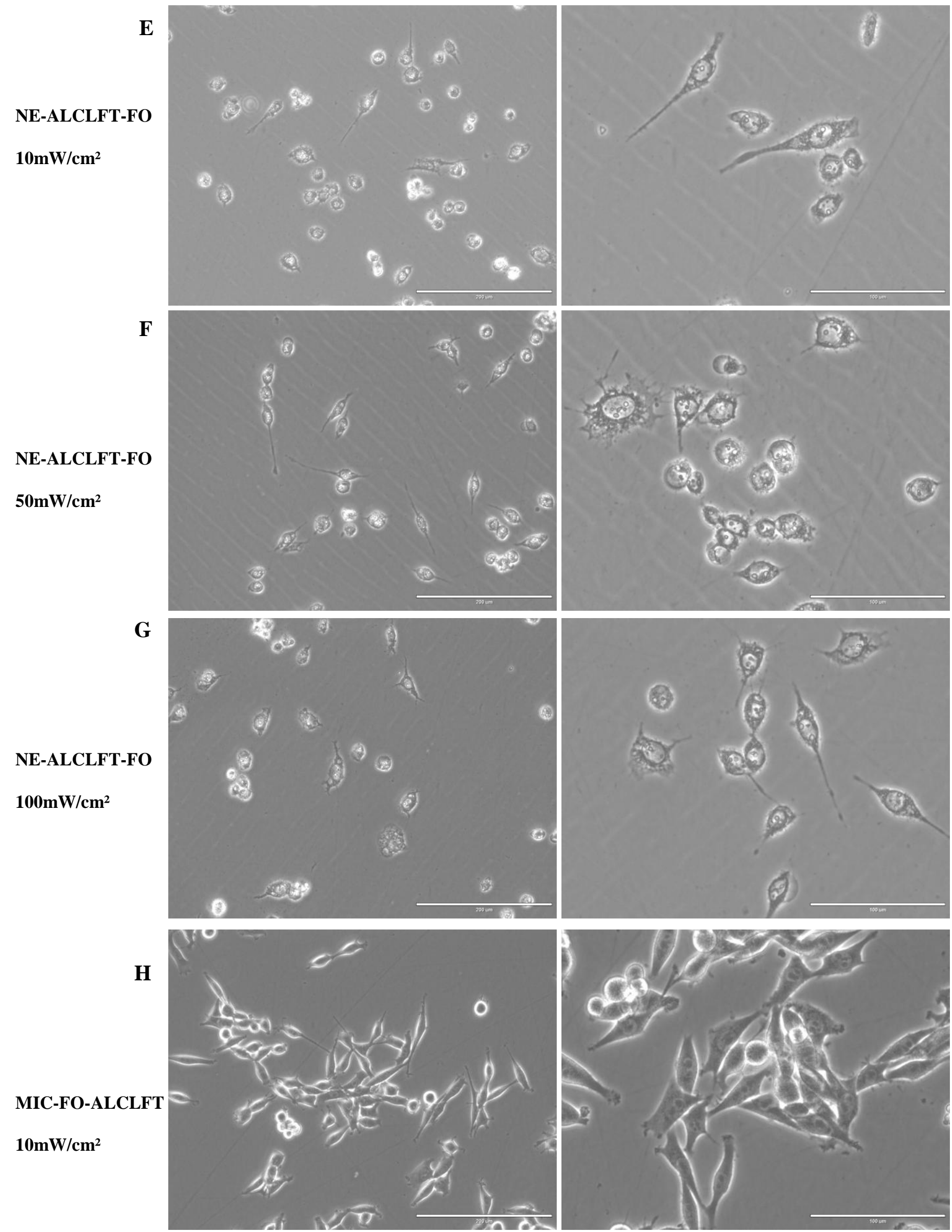




\section{I}

MIC-FO-ALCLFT

$50 \mathrm{~mW} / \mathrm{cm}^{2}$

MIC-FO-ALCLFT

$100 \mathrm{~mW} / \mathrm{cm}$

$\mathbf{J}$
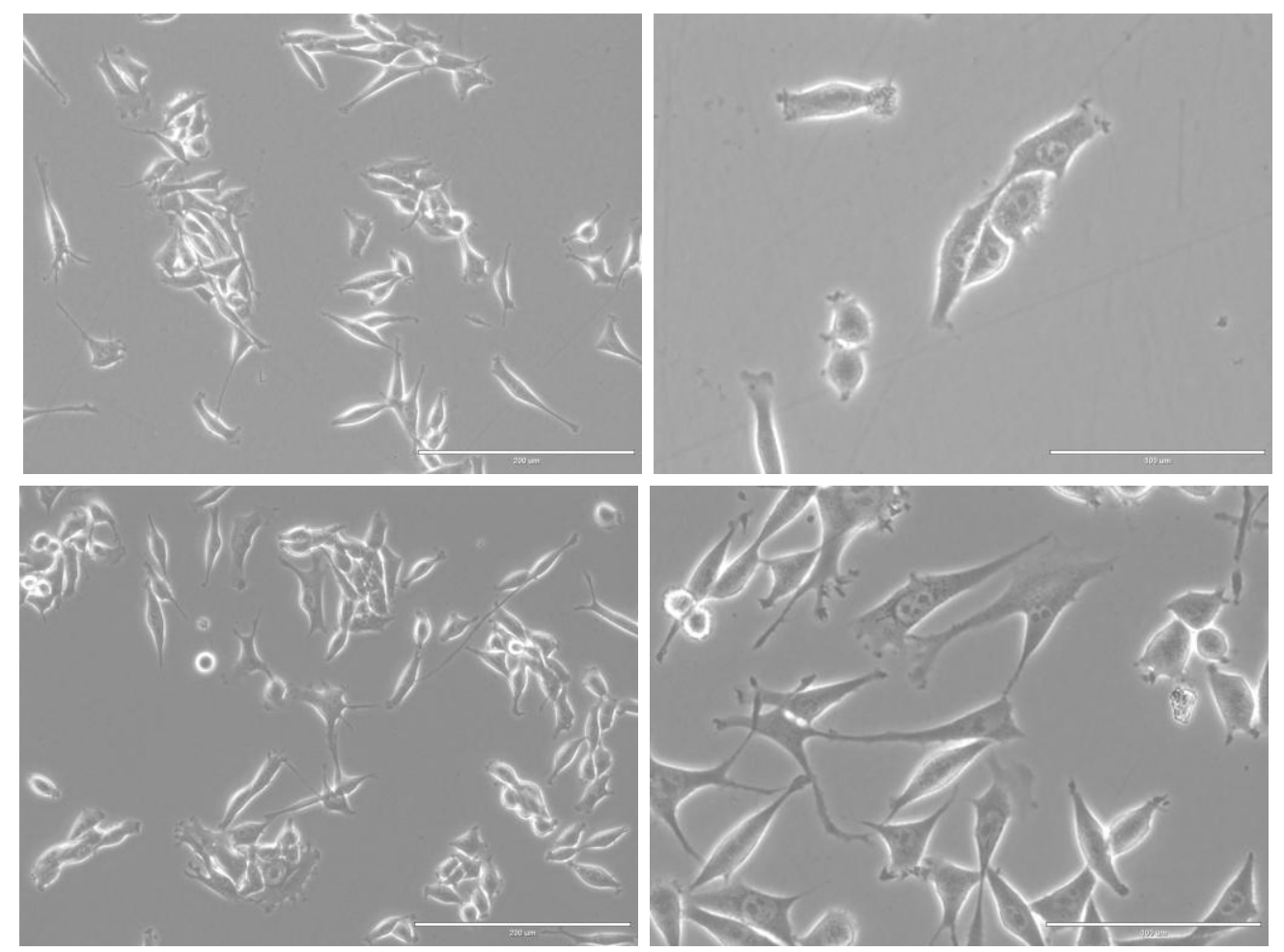

Figura 32. Alterações morfológicas e estruturais induzidas pela TFD utilizando as nanoformulações (NE-ALCLFT, NE-ALCLFT-FO, MIC-FO-ALCLFT) em células de carcinoma mamário (linhagem 4T1).Análise após a incubação por 15 minutos das respectivas nanoformulações na concentração de $0,078 \mu \mathrm{M}$ e posterior aplicação da TFD. Dez minutos de exposição ao LED com as potências de $10 \mathrm{~mW} / \mathrm{cm}^{2}, 50 \mathrm{~mW} / \mathrm{cm}^{2} \mathrm{e}$ $100 \mathrm{~mW} / \mathrm{cm}^{2}$. As imagens foram divididas em duas colunas, sendo a resolução de $20 \mathrm{x}$ (esquerda) e 40x (direita). (A) Controle (células sem tratamento); (B, C, D, E, F, G, H, I, J) Grupos Tratados. Nas células tratadas, é possível notar alterações estruturais, modificação citoplasmática, presença de debris e formas arredondadas.

Também foram avaliados os efeitos morfológicos causados pelos tratamentos nas células de fibroblastos (NIH/3T3) (Fig. 35). No grupo controle (sem tratamento) desta linhagem, se podem observar características peculiares referentes destas células, como formato estrelado, núcleos e nucléolo bem evidentes, presença de grânulos e aspectos aderentes ao substrato (no caso a placa). No entanto, nos grupos onde as células receberam os tratamentos, principalmente nas formulações NE-ALCLFT e NEALCLFT-FO, tais características são modificadas. Nota-se a presença de vacúolos nas células, perda de aderência ao substrato, modificação na estrutura citoplasmática celular e diminuição da confluência nas regiões analisadas, caracterizando aspectoscitotóxicos e de morte celular. Nos tratamentos utilizando MIC-FO-ALCLFT, as estrtuturas apresentaram alterações atenuantes (Fig. 35 de A à J). 
FIBROBLASTO MURINO - NIH/3T3

20X

A

\section{Controle}

NIH/3T3

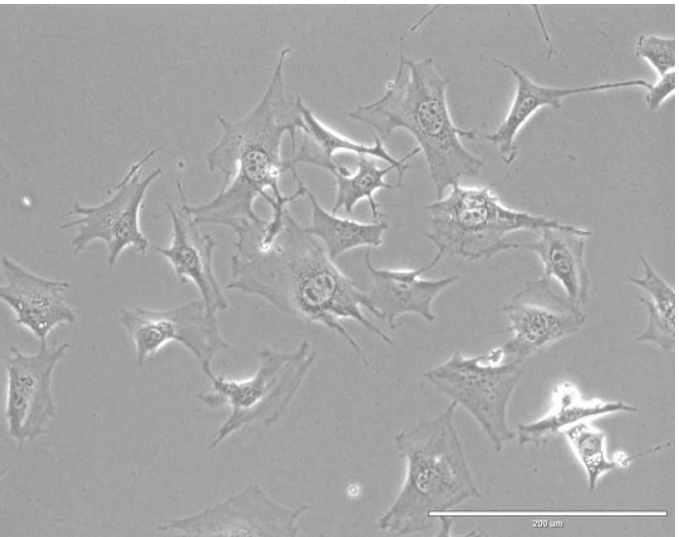

B

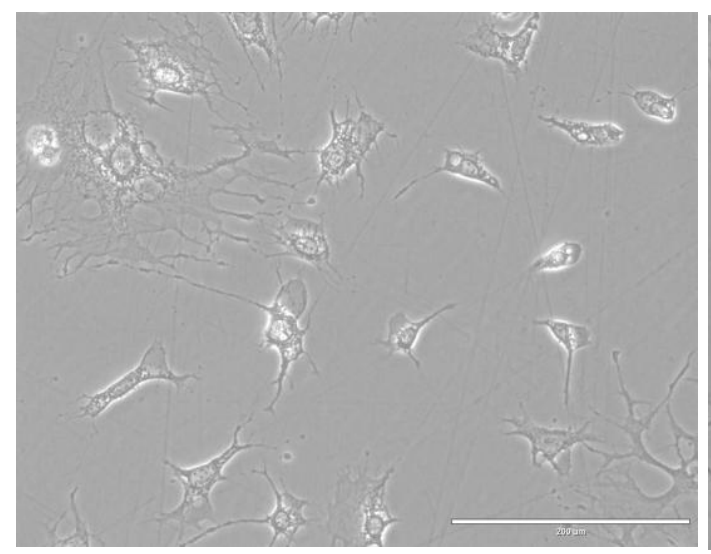

Ne-Alclft

$10 \mathrm{~mW} / \mathrm{cm}^{2}$

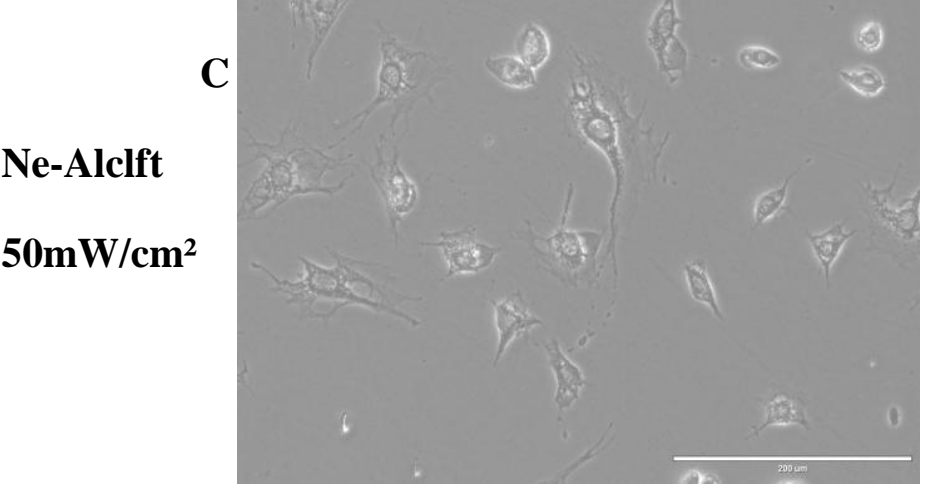

Ne-Alclft

$50 \mathrm{~mW} / \mathrm{cm}^{2}$

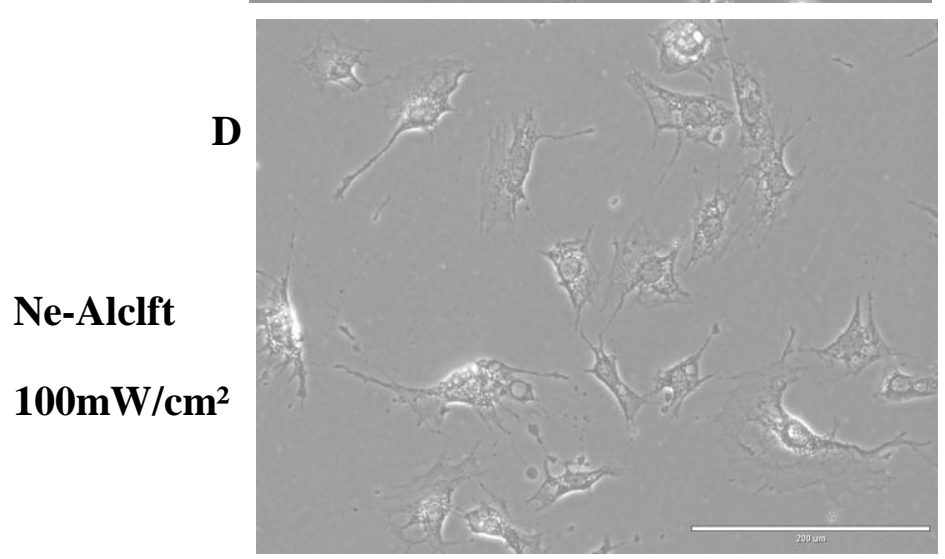

40X
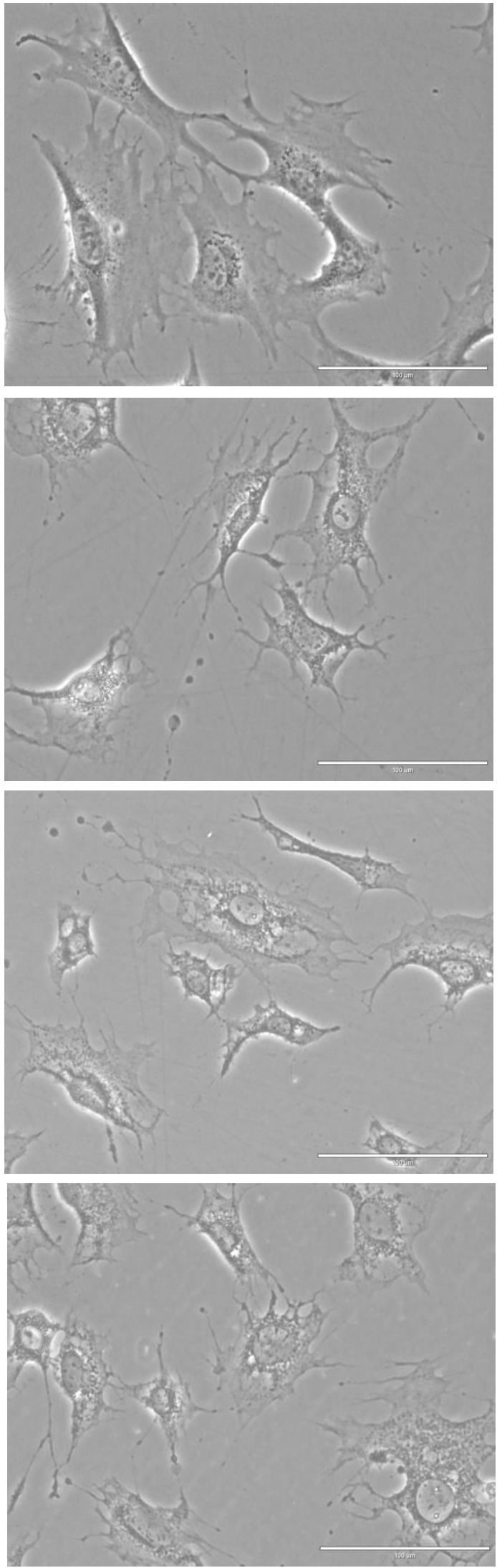


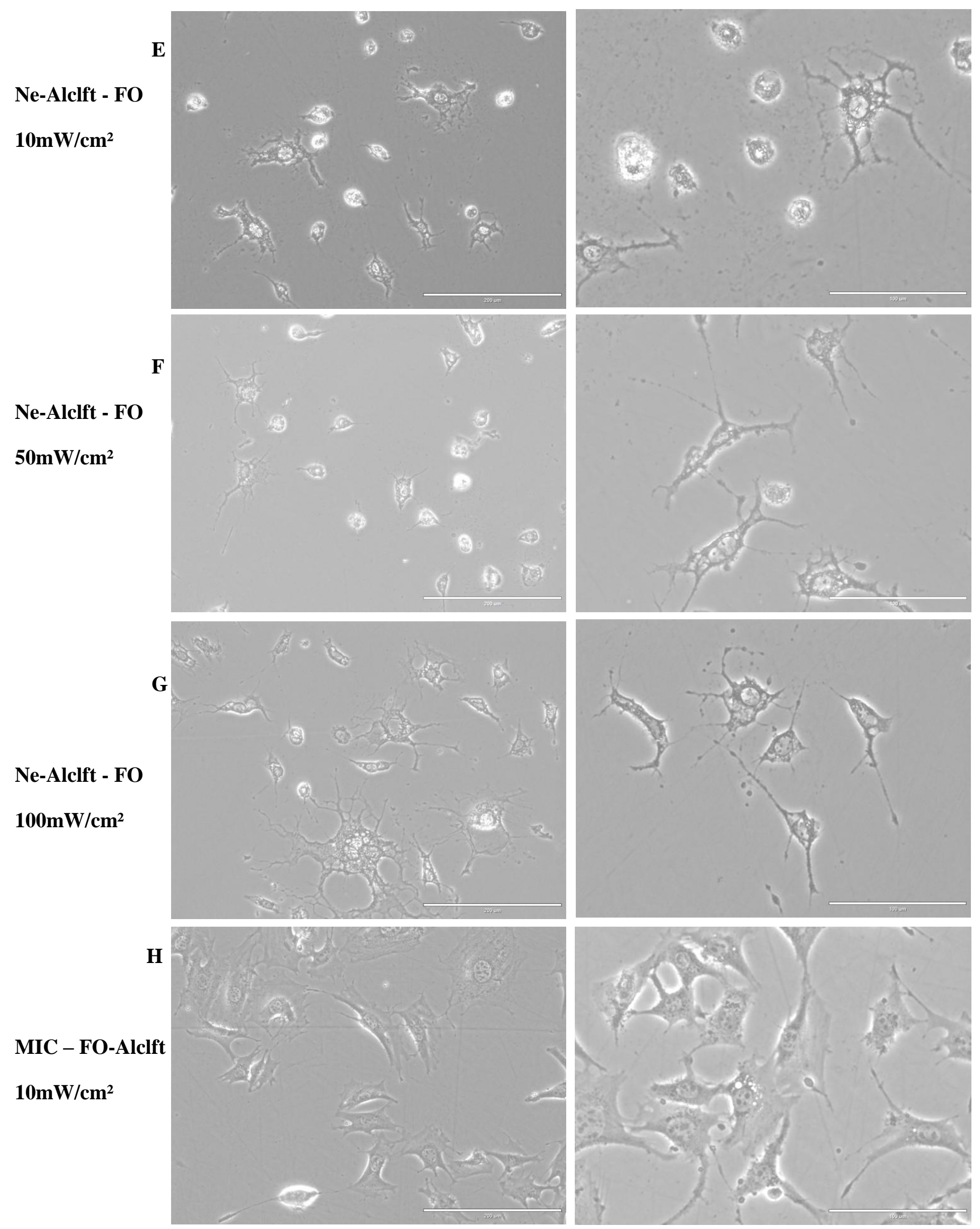


MIC - FO-Alclft

$50 \mathrm{~mW} / \mathrm{cm}^{2}$
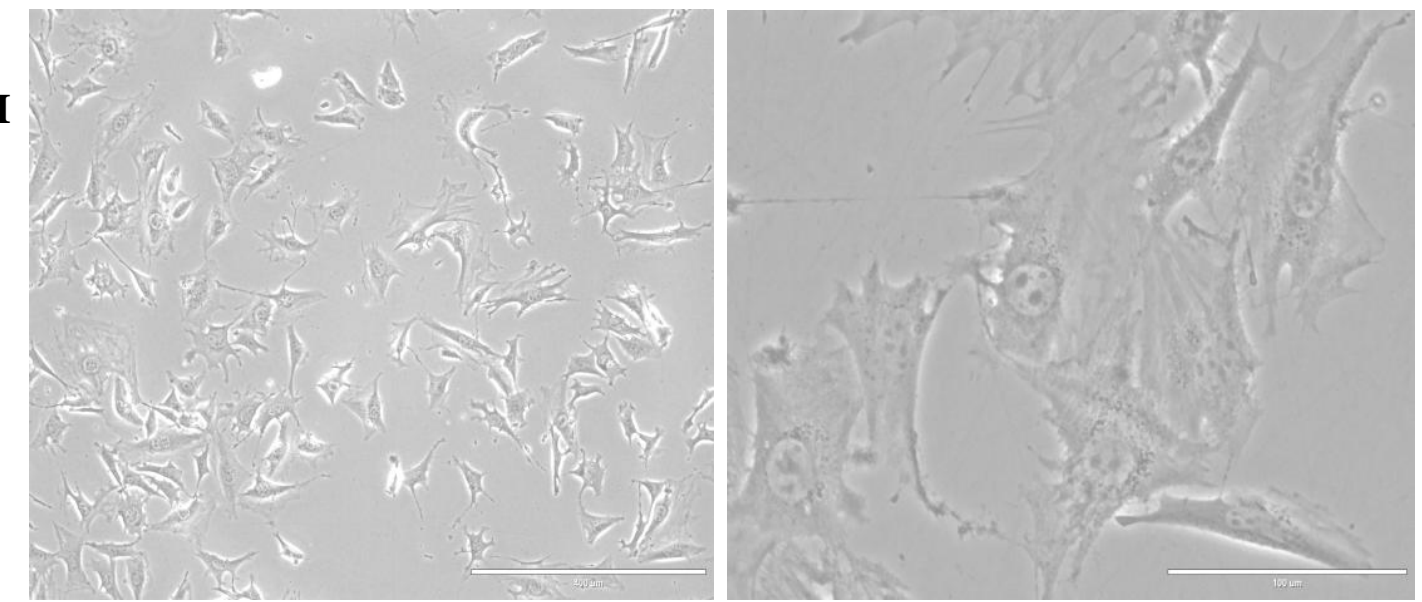

MIC - FO-Alclft

$100 \mathrm{~mW} / \mathrm{cm}^{2}$

\section{$\mathbf{J}$}
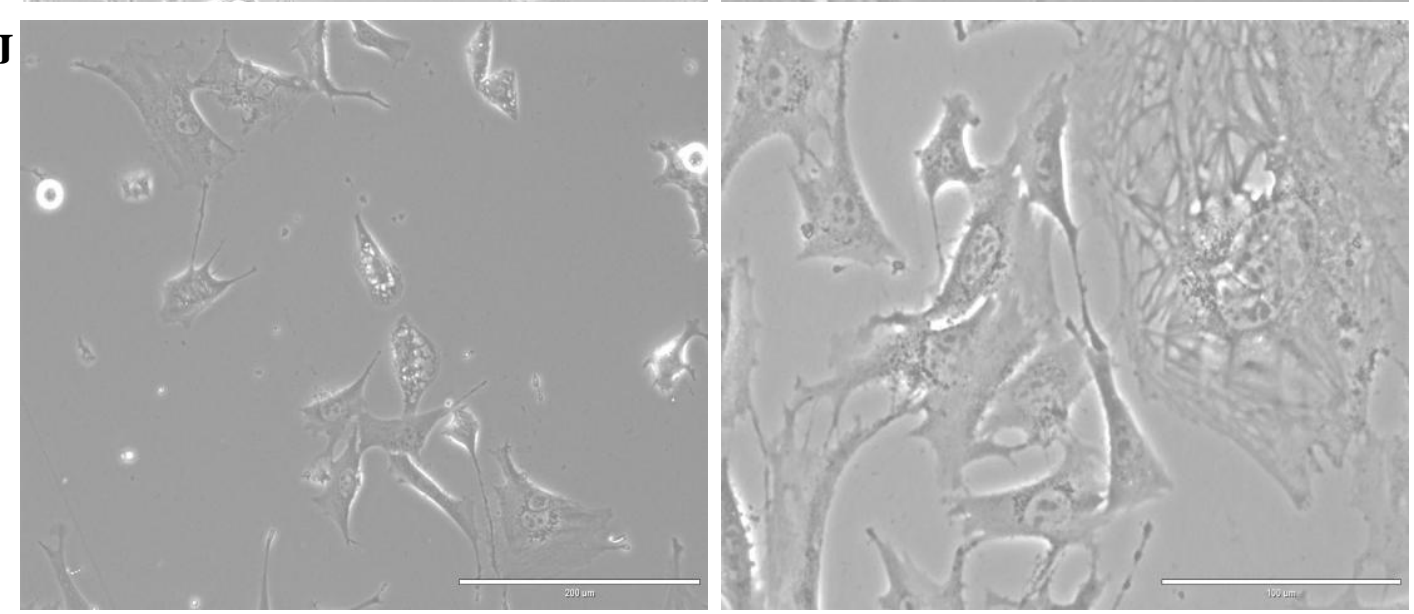

Figura 33. Alterações morfológicas e estruturais induzidas pela TFD utilizando as nanoformulações (NE-ALCLFT, NE-ALCLFT-FO, MIC-FO-ALCLFT) em células de fibroblasto (linhagem NIH/3T3).Análise após a incubação por 15 minutos das respectivas nanoformulações na concentração de $0,078 \mu \mathrm{M}$ e posterior aplicação da TFD. Dez minutos de exposição ao LED com as potências de $10 \mathrm{~mW} / \mathrm{cm}^{2}, 50 \mathrm{~mW} / \mathrm{cm}^{2} \mathrm{e}$ $100 \mathrm{~mW} / \mathrm{cm}^{2}$. As imagens foram divididas em duas colunas, sendo a resolução de $20 \mathrm{x}$ (esquerda) e 40x (direita). (A) Controle (células sem tratamento); (B, C, D, E, F, G, H, I, J) Grupos Tratados. Nas células tratadas, é possível notar alterações estruturais, modificação citoplasmática, presença de debris e estruturas amórficas.

Portanto, conforme as análises realizadas pelas fotomicrografias observou-se que os tratamentos utilizando a TFD, ocasionam alterações relevantes nas estruturas morfológicas das linhagens celulares estudas. Em ambas as células notam-se a presença de vacúolos, modificação citoplasmáticas, perda de aderência no subtrato e consequência morte celular. Além disso, ressalta-se que as alterações são mais evidentes quando utilizada às nanoformulações NE-ALCLFT e NE-ALCLFT-FO, que 
comparadas a MIC-FO-ALCLFT. Esses dados complementam e corroboram os resultados dos testes pelo MTT.

\section{EXPERIMENTOS IN VIVO}

\subsection{Indução Tumoral}

O modelo de indução tumoral foi ortotópico, realizada na quinta mama do camundongo. A Figura 36 mostra a visualização da bioluminescência, avaliada pelo equipamento IVIS Lumina XR, representando a quantidade de bioluminescência expressa pela reação da luciferina com a luciferase, mostrando a quantidade de células na região.
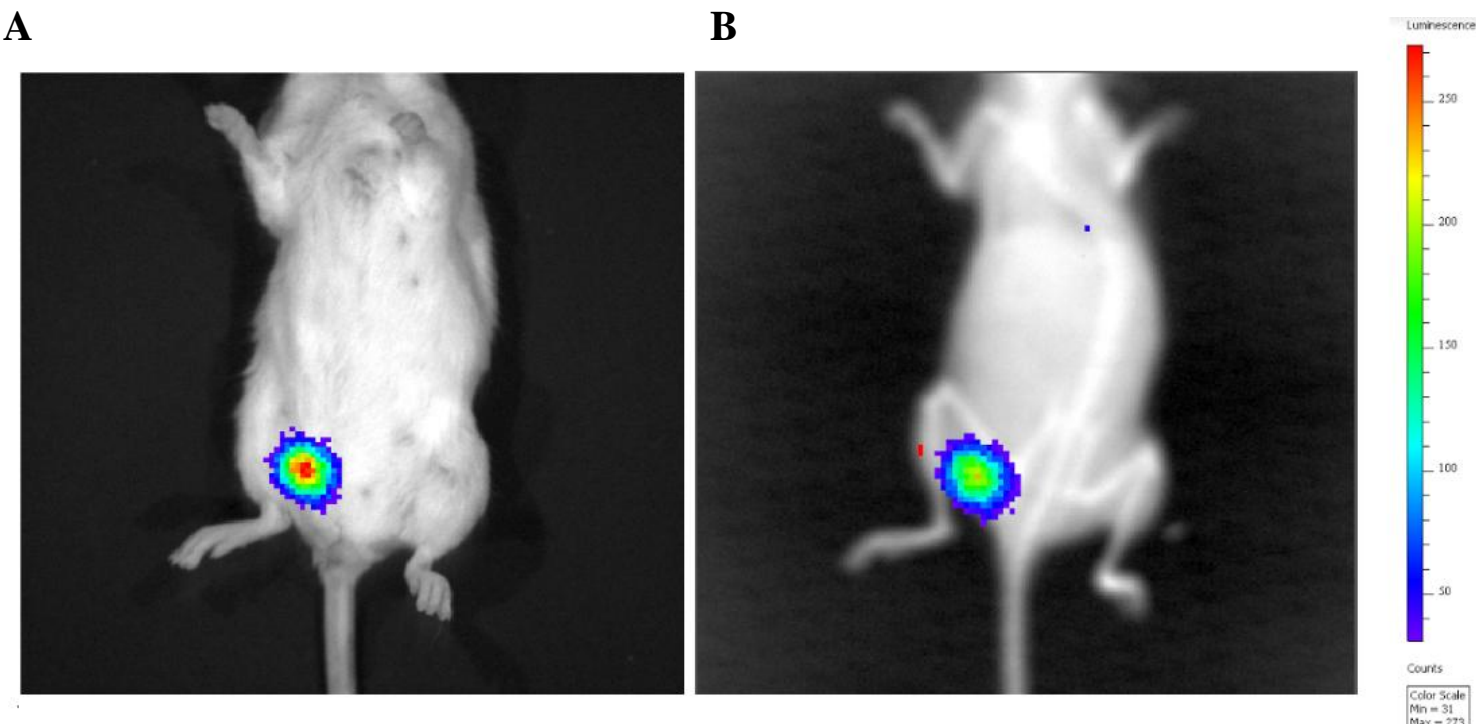

Figura 34. Representação do modelo ortotópico de células tumorais de carcinoma adenocarcinoma mamário mamário (4T1-luciferase) na quinta mama do camundongo. A imagem demonstra a visualização da bioluminescência, visualizada pelo equipamento Ivis Lumina XR. (A). Aquisição de imagem em campo normal. (B) Aquisição de imagem com Raio X.

\subsection{Análises da biodistribuição das nanoformulações (NE-ALCLFT, NE- ALCLFT-FO e MIC-FO-ALCLFT).}

As análises dos testes de biodistribuição in vivo permitiu obervar à circulação endovenosa das nanoformulações utilizadas por imageamento em tempo real no IVIS 
Lumina XR. Tais análises mostram a intensidade de fluorescência nos tempos: 1,2, 4, 6, 8, 10 e 12 horas, para as formulações NE-ALCLFT, NE-ALCLFT-FO e MIC-FOALCLFT.

Nestes intervalos, observa-se que há uma maior intensidade de fluorescência nos tempos de 6horas e 10horas, independente da nanoformulação utilizada. Além disso, as imagens mostram que há um distribuição das formulações por todo o corpo do animal, e maior retenção na cauda, possivelmente devido ao extravasamento das nanoformulações na aplicação. Nota-se que as principais regiões atingidas pelas nanoformulações, foram às regiões dos linfonodos, pulmão, fígado, baço e rins.

A formulação NE-ALCLFT, apresentou maior intensidade na região tumoral. Além disso, pôde-se notar que à partir de 2horas havia uma concentração na região dos linfonodos, rins e fígado. Posteriormente às 4horas, podia-se observar a presença de fluorescência na região torácica (Fig.37, A).

A formulação NE-ALCLFT-FO, apresentou intensidade de fluorescência na região do fígado, linfonodos e rins especialmente nos intervalos de 4, 6, 8, 10 e 12 horas, em uma intensidade menor a comparada à NE-ALCLFT (Fig.37, B).

A formulação MIC-FO-ALCLFT, apresentou alta intensidade de fluorescência na região do fígado e baço, principalmente nos intervalos de 6 horas à 10 horas (Fig.37, C).

Assim, a partir dos dados in vivo decidimos que haveria necessidade de análises ex vivo nos tempos de 6horas e 10 horas, para a melhor quantificação da intensidade de fluorescência nos órgãos analisados.

NE-ALCLFT

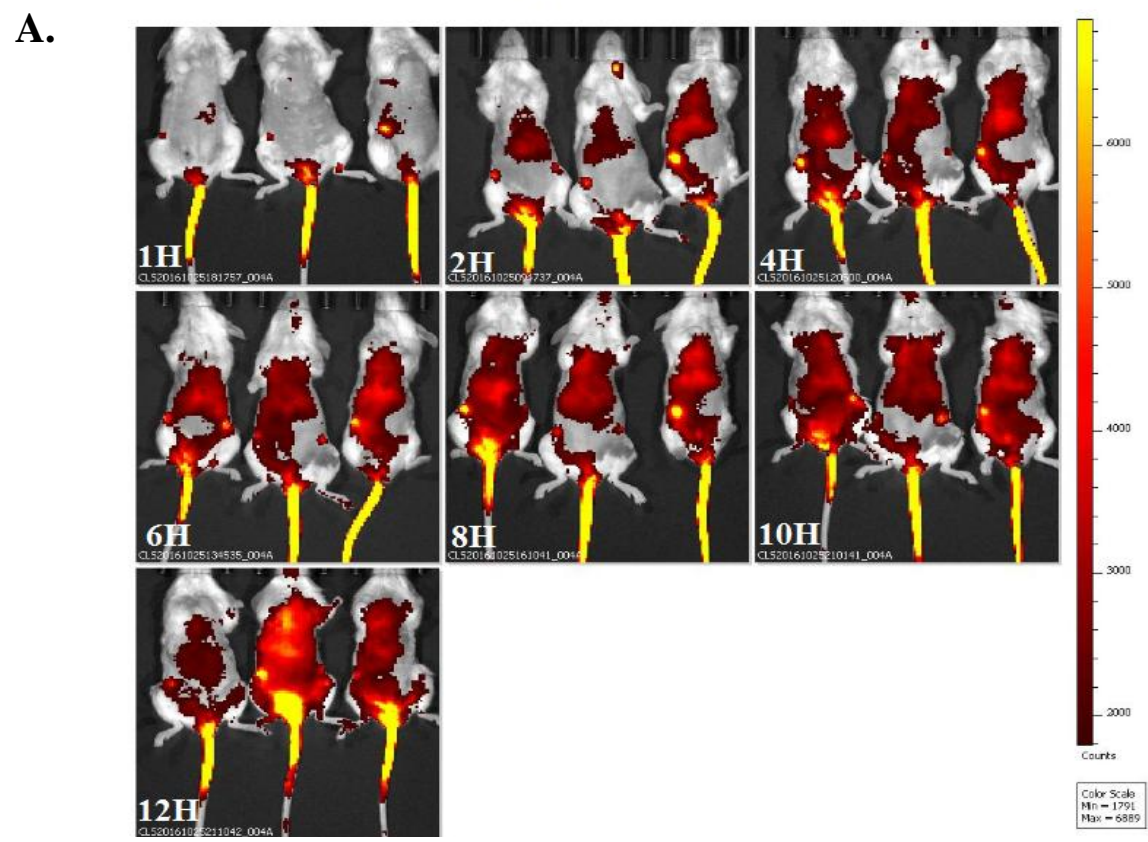


B.

NE-ALCLFT-FO

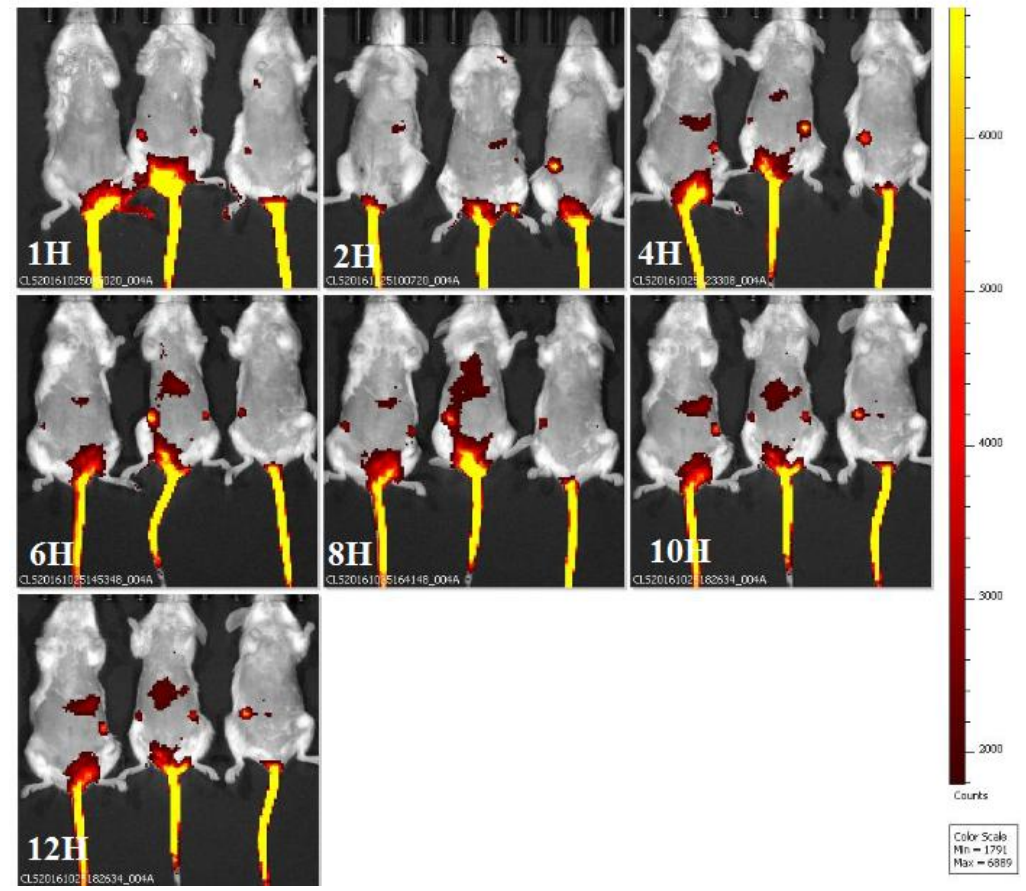

C. MIC-FO-ALCLFT

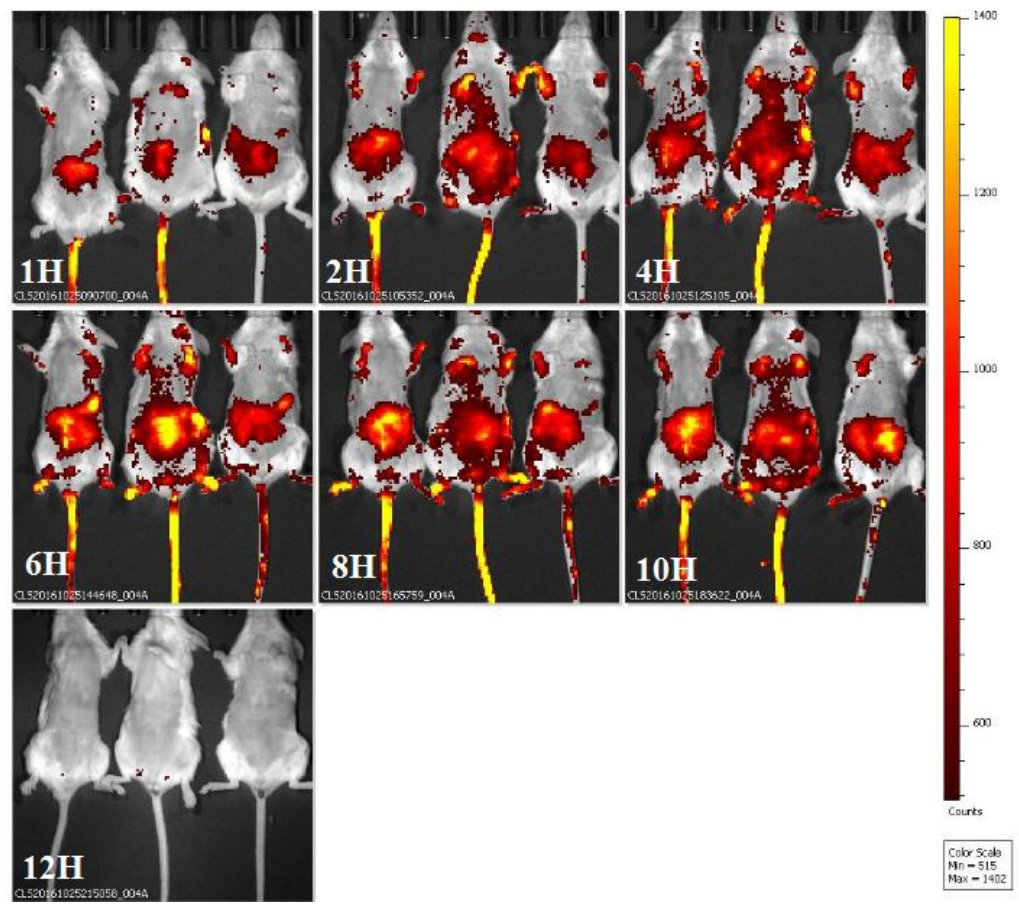

Figura 35. Análise da biodistribuição in vivo pelo equipamento IVIS Lumina XR, medindo a intensidade de fluorescência das nanoformulações. (A) Representa a formulação NE-ALCLFT. (B) Representa a formulação NE-ALCLFT-FO. (C) Representa a formulação MIC-FO-ALCLFT. Foram analisado os intervalos 1, 2, 4, 6, 8, 10 e 12 horas. 


\subsection{Análise EX-VIVO da biodistribuição das nanoformulações em 6 e 10 horas}

As análises realizadas ex vivo permitiram quantificar a intensidade de fluorescência nos órgãos dos animais. Foram observados nos tempos de 6 e 10 horas, os seguintes órgãos: tumor, mama contralateral, linfonodo sentinela, linfonodo contralateral, rins, baço, fígado, coração, cérebro e pulmão.

O grupo controle negativo (com tumor, mas sem a administração de nanoformulações) mostrou uma pequena taxa de fluorescência (autofluorescência) presente naturalmente nos órgãos, principalmente rins, pulmão, fígado e cérebro.

Os dados mostram que a NE-ALCLFT (Fig. 38 A, B), atinge pelo menos uma pequena proporção de todos os órgãos analisados. Essa proporção é aumentada no intervalo de $10 \mathrm{~h}$ comparada à $6 \mathrm{~h}$. Os principais órgãos atingidos por essa formulação são o fígado, baço, o linfonodo sentinela e os rins. Também é observada a presença da intensidade de fluorescência no tumor, a qual permanece constante nos tempos analisados.

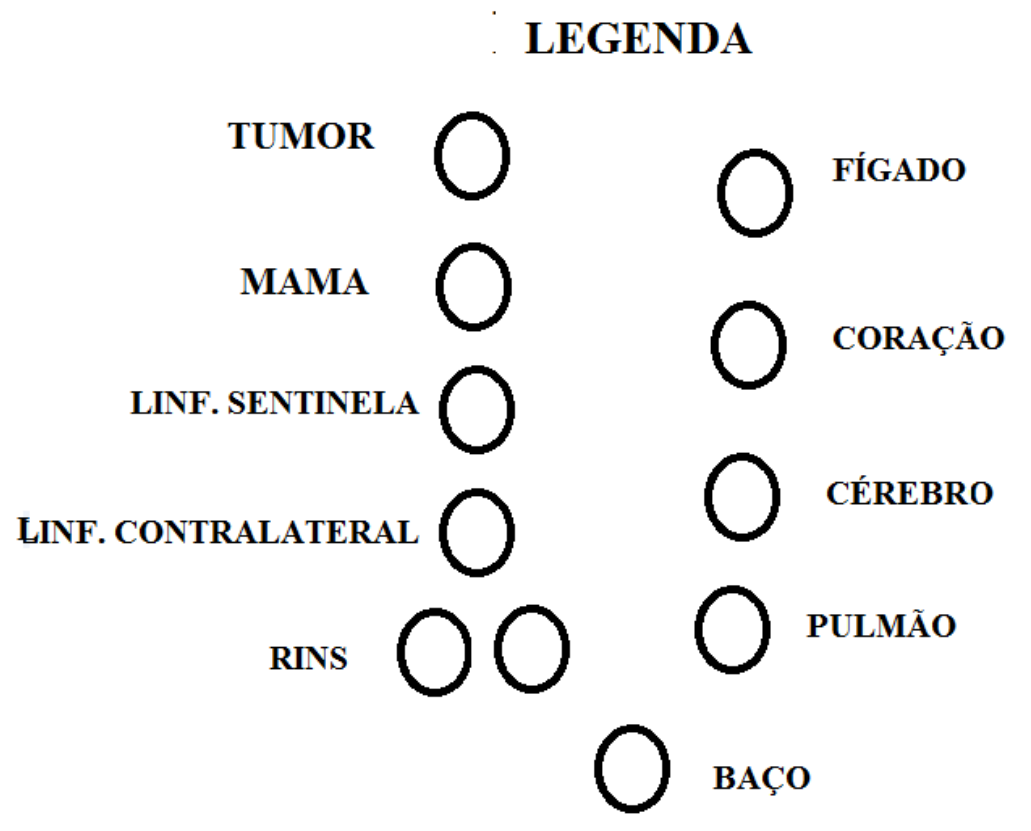


(A)

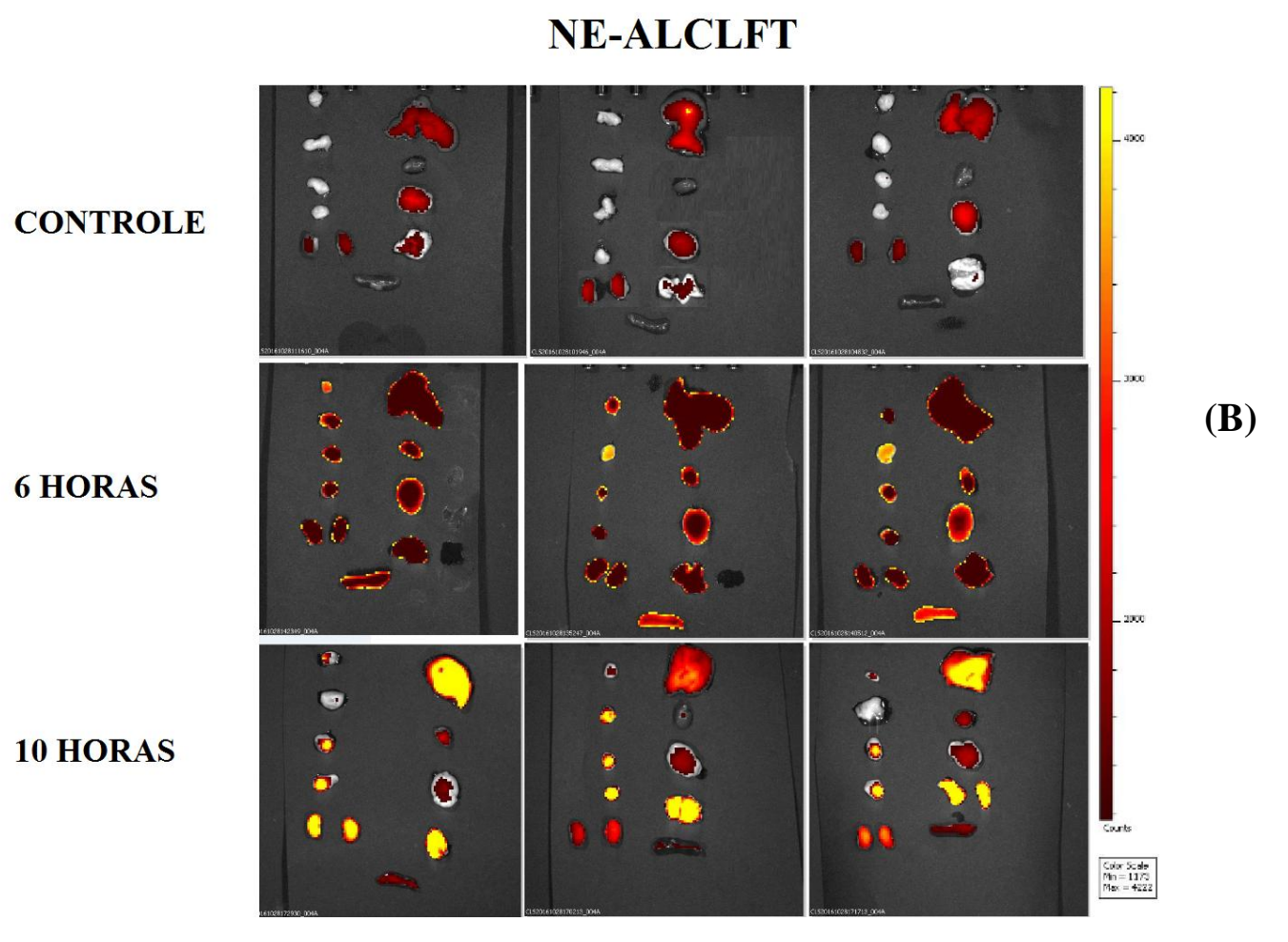

NE-ALCLFT

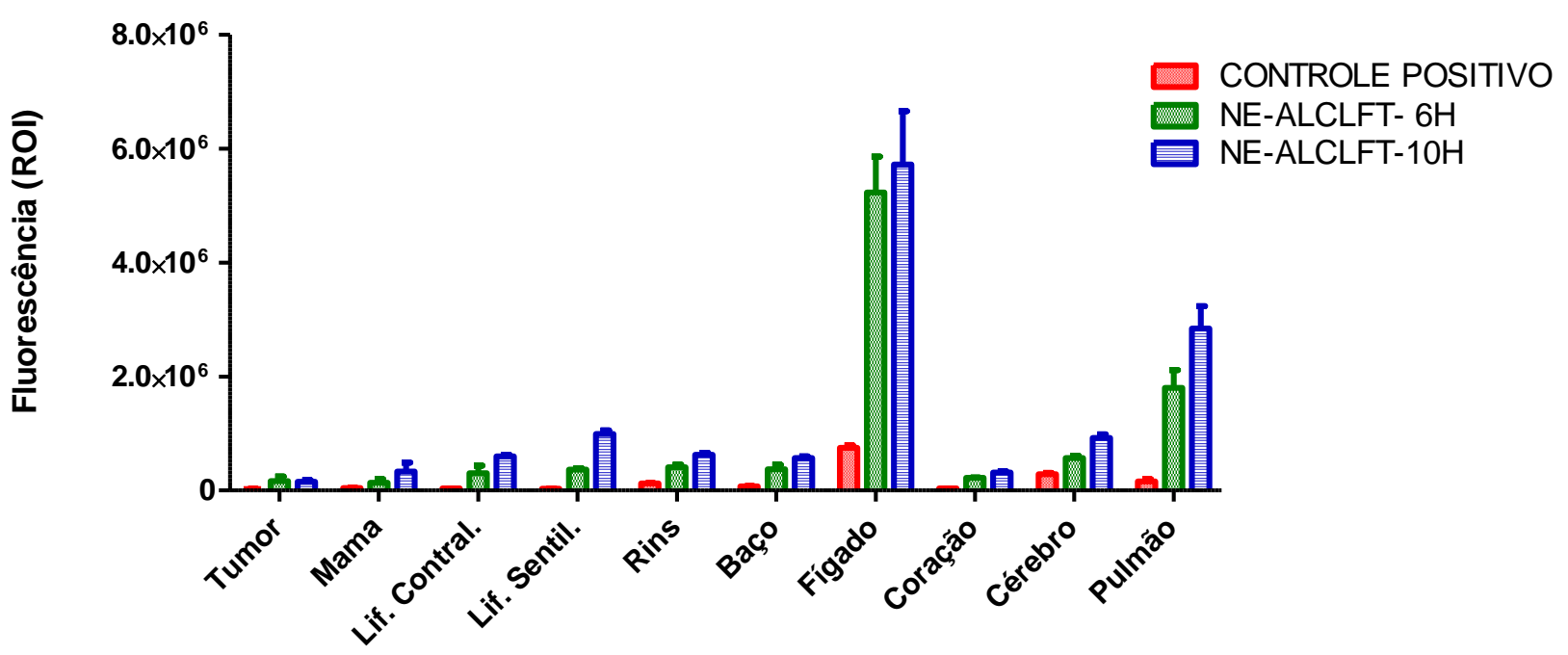

ÓRGÃOS

Figura 36. Imagem da biodistribuição ex vivo da formulação NE-ALCLFT. (A) A imagem dos órgãos contendo a NE-ALCLFT, tendo o grupo controle e os intervalo de 6 e 10 horas. No gráfico (B) é possível observar a alta intensidade de fluorescência 
(quantificada pelo ROI), principalmente no fígado, pulmão e linfonodo sentinela. A medida que o tempo passa ( de 6horas para 10 horas), essa quantidade aumenta, no entanto, mantém-se proporcional na região do tumor.

A nanoformulação NE-ALCLFT-FO, também apresentou intensidade de fluorescência em todos os órgãos analisados, principalmente no fígado, rins e pulmão, com intensidade significativa no cérebro às 6horas. No tumor, o melhor tempo seria às 6 horas (Fig. 39, A, B).

NE-ALCLFT-FO

(A)

CONTROLE

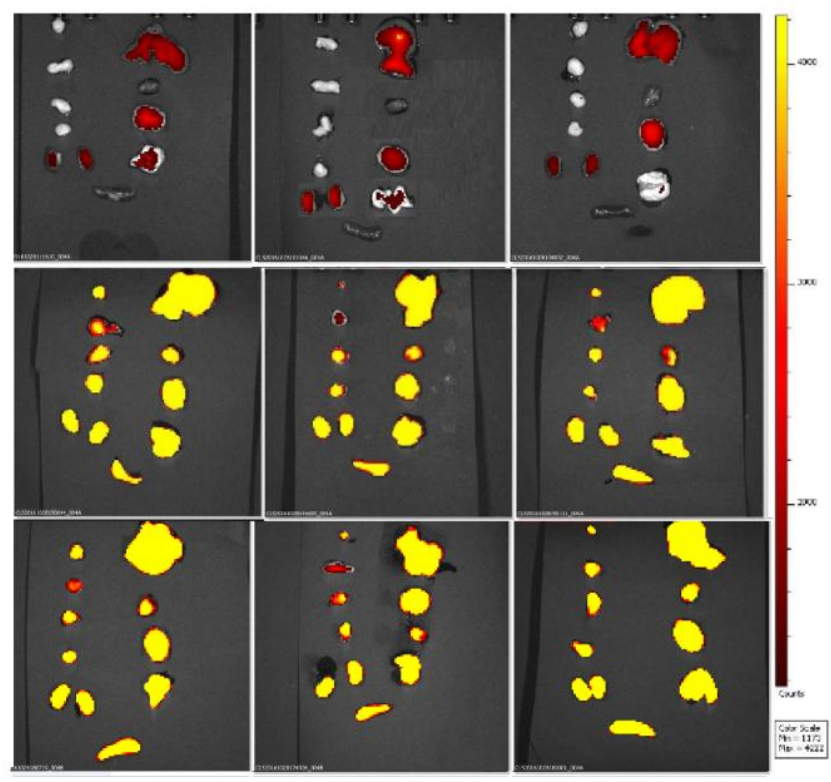

(B)

NE-ALCLFT-FO

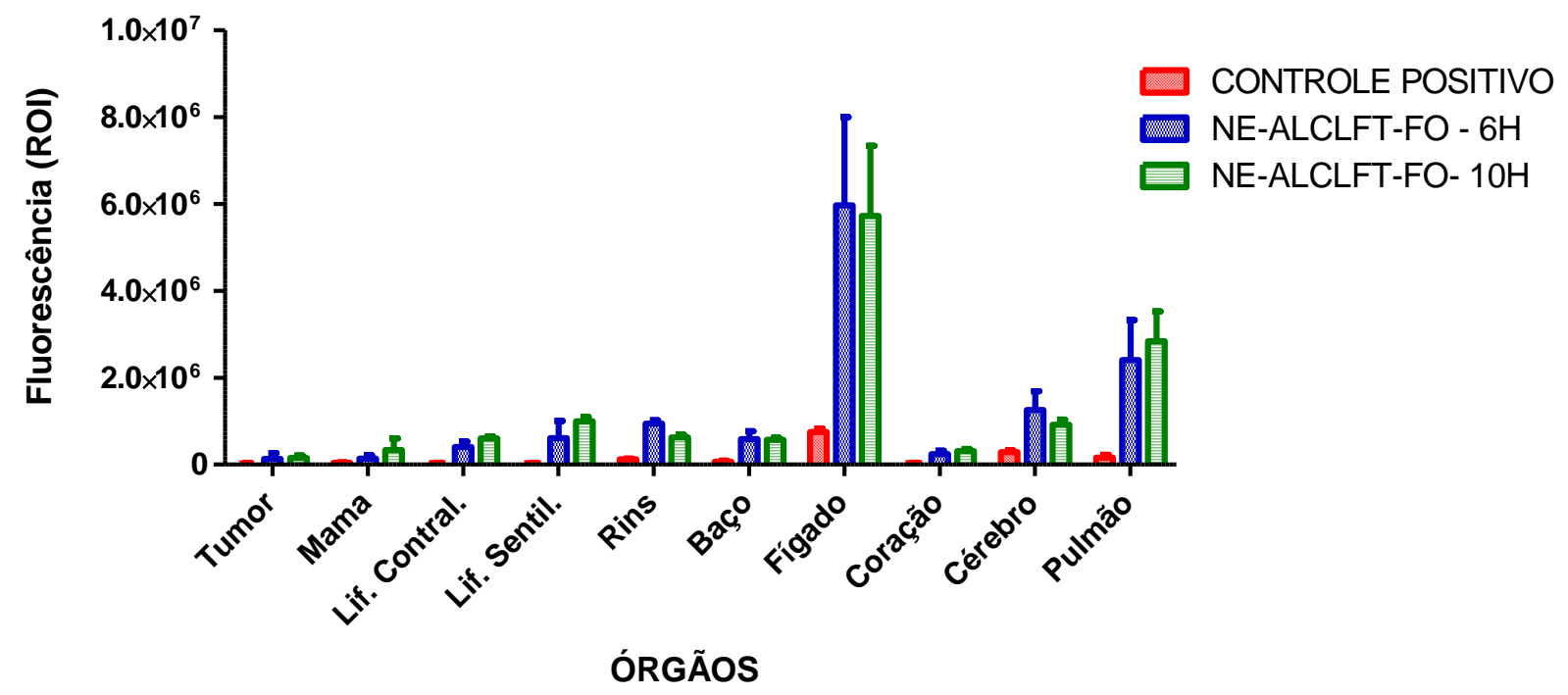


Figura 37. Análise da intensidade de fluorescência da biodistribuição ex vivo da formulação NE-ALCLFT-FO. (A) A imagem dos órgãos contendo a NE-ALCLFT-FO, tendo o grupo controle e os intervalo de 6 e 10 horas. No gráfico (B) é possível observar a alta intensidade de fluorescência (quantificada pelo ROI), principalmente no fígado, pulmão, cérebro e linfonodo sentinela. À medida que o tempo passa (de 6horas para 10 horas), a quantidade de fluorescência decai para alguns órgão (rins, fígado e cérebro) e aumenta em outros (linfonodo sentinela e pulmão). Mantém-se proporcional na região do tumor.

As análises da formulação MIC-FO-ALCLFT foi a que apresentou menor intensidade de fluorescência nos órgãos analisados, comparando-se às outras nanoformulações. Os principais órgãos atingidos foram fígado, rins e pulmão. A presença da nanoformulção no tumor, não foi significativa (Fig. 40 A, B).

(C)

MIC-FO-ALCLFT

CONTROLE

6 HORAS

10 HORAS

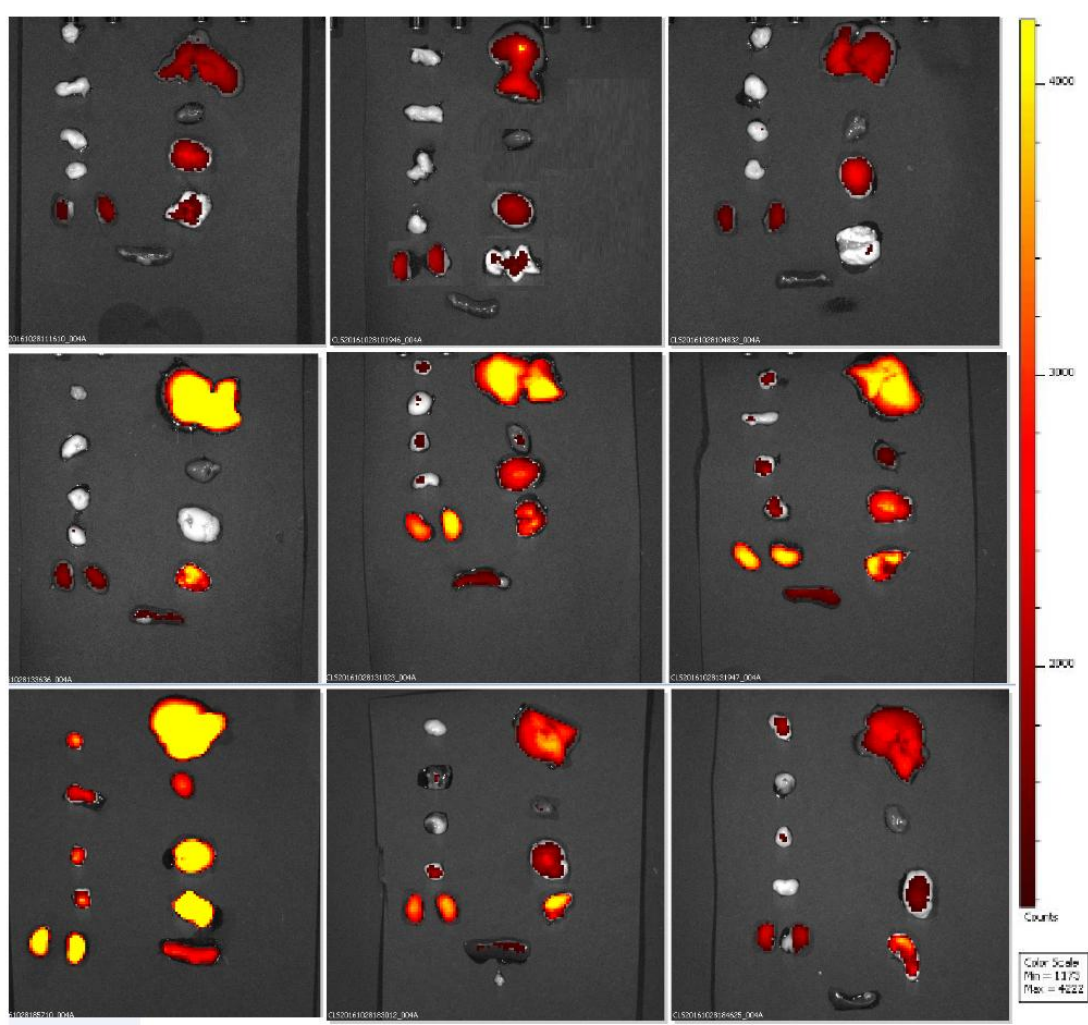

(B) 


\section{MIC-FO-ALCLFT}

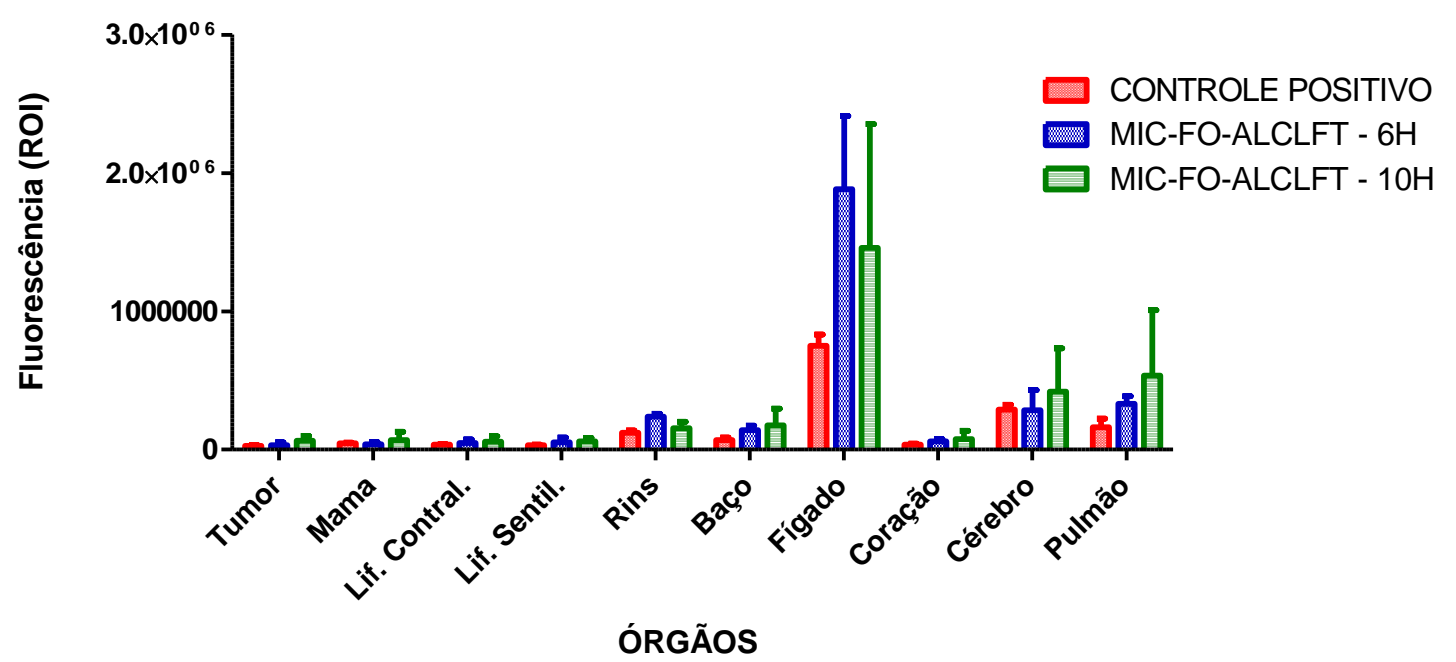

Figura 38. Análise da biodistribuição ex vivo da formulação MIC-FO-ALCLFT. (A) A imagem dos órgãos contendo a MIC-FO-ALCLFT, tendo o grupo controle e os intervalo de 6 e 10 horas. No gráfico (B) é possível observar a alta intensidade de fluorescência (quantificada pelo ROI), principalmente no fígado e pulmão.

\subsubsection{Análise da relação entre o número de células tumorais e a quantidade de} fluorescência presente das nanoformulações.

A bioluminescência representa a presença de células tumorais em uma determinada região, devido à reação entre a luciferina e a enzima luciferase trasfectada na célula 4T1, conforme já descrito, permitindo semi-quantificar a intensidade desta reação, e assim mensurar a quantidade de células vivas.

Assim, foi feita a relação da quantidade expressa de bioluminescência (células vivas na região tumoral), com a presença de fluorescência (dada pelas nanoformulações) relacionadas ao tumor, a fim de avaliar a intensidade de fluorescência das nanoformulações por quantidade de células tumorais, nos tempo 6 e 10 horas.

Com isso, pôde-se observar que não houve variações significativas $(\mathrm{p}<0.05)$ na quantidade de bioluminescência entre as regiões tumorais analisadas (Fig. 41, A). Isso mostra que a quantidade de fluorescência na região analisada, não é influenciada pelo tamanho tumoral, podendo dar informações mais concisas quanto à presença da intensidade de fluorescência presente das nanoformulações (Fig. 41, B).

(A)

(B) 

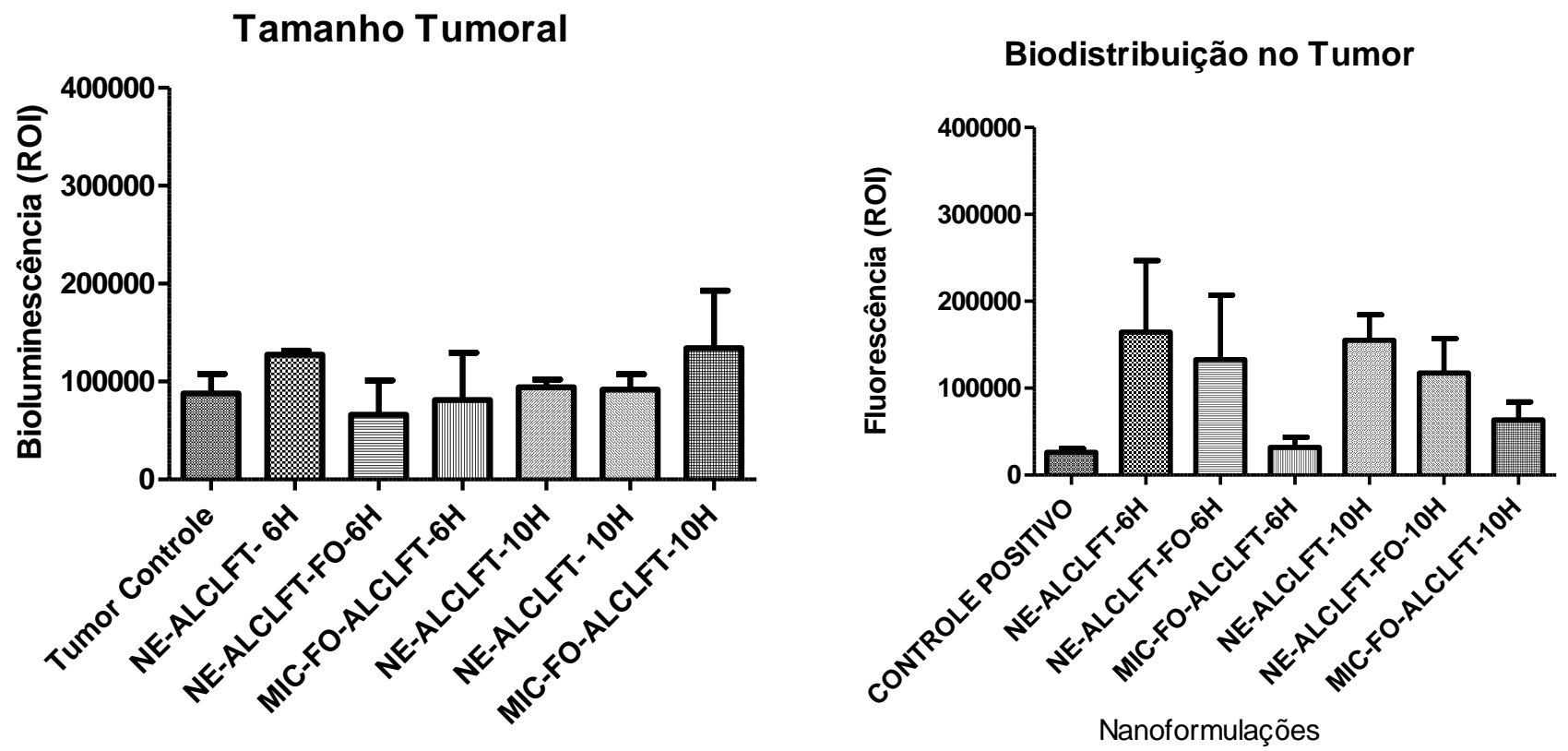

Figura 39. Análise de bioluminescência e fluorescência pelas nanoformulações nos intervalos de $6 \mathrm{~h}$ e $10 \mathrm{~h}$. (A) Análise da bioluminescência do tumor, a qual representa o tamanho tumoral avaliado pela quantidade de bioluminescência presente na região. (B) Análise da intensidade de fluorescência das nanoformulações, quantificada em cada tumor nos tempos de 6h e 10h. Estatística OneWay-ANOVA, p<0.05.

\subsubsection{Relação entre o peso dos órgãos e da intensidade de fluorescência expressa pelas nanoformulações.}

A fim de se ter a proporção do tamanho dos órgãos analisados e uma comparação mais minuciosa, todos os órgãos dos animais em análise foram pesados.

Pôde-se concluir que não houve diferenças significativas quanto ao peso dos órgãos entre os grupos analisados (Controle, NE-ALCLFT, NE-ALCLFT-FO e MICFO-ALCLFT), tanto para o tempo de 6h (Fig. 42,A) como de 10h (Fig. 42, B).

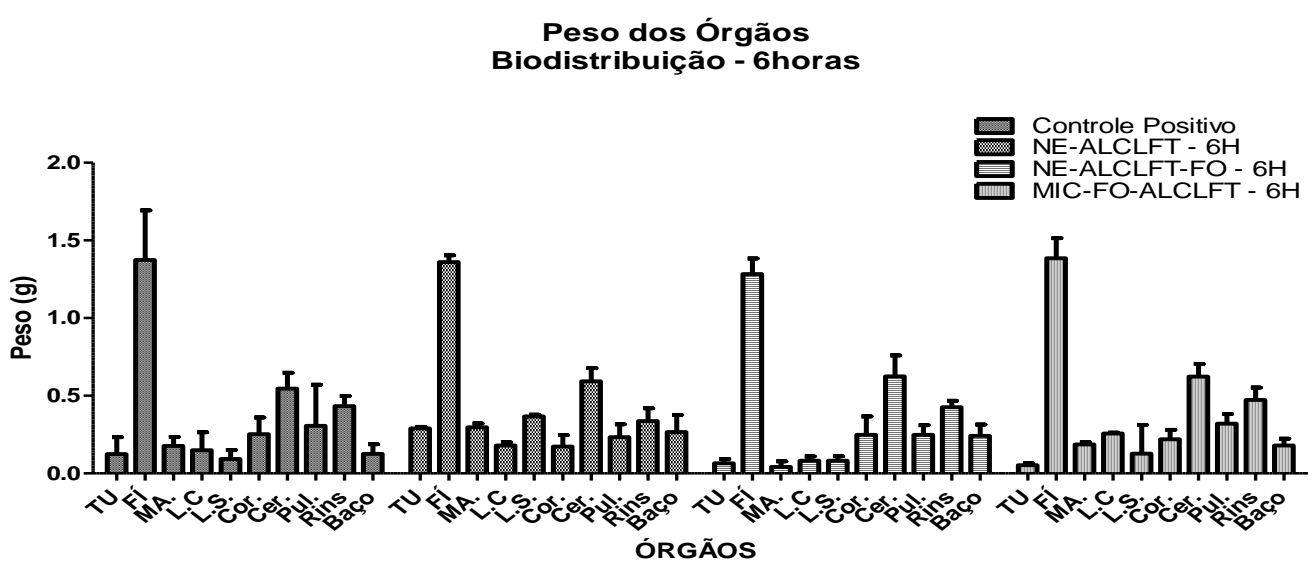


Peso dos Órgãos

(B)

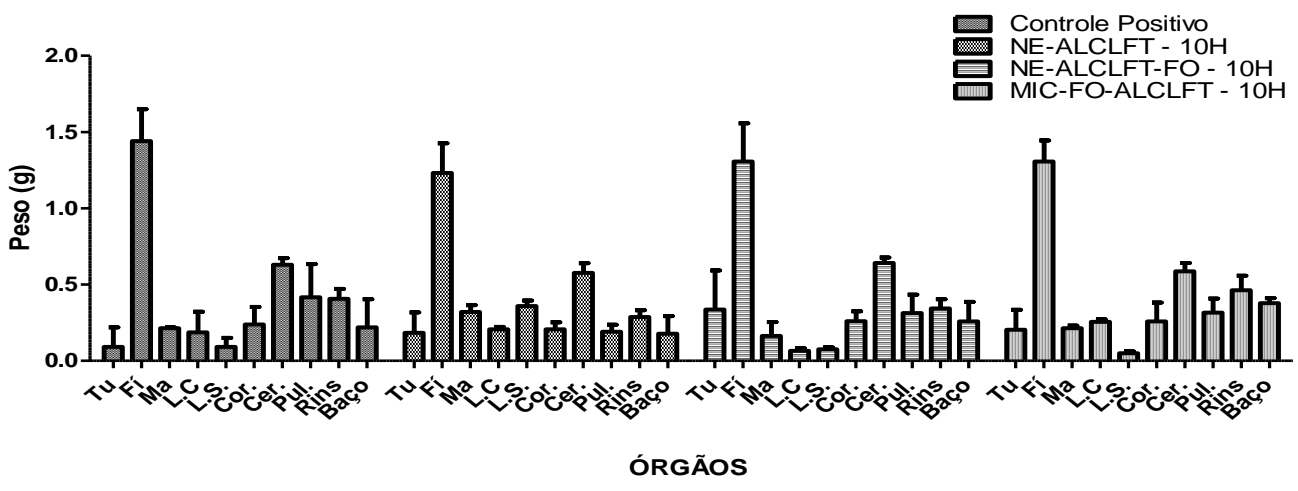

Figura 40. Avaliação do peso dos órgãos segundo as análises de biodistribuição ex vivo das nanoformulações. (A) Representa os órgãos do intervalo de 6horas. (B) Representa os órgãos do intervalo de 10horas.

Com base nos pesos dos órgãos e a intensidade de fluorescência em cada um deles, foi feita a relação entre a proporção de fluorescência pelo peso. Concluiu-se que apesar do fígado ter massa maior, comparada ao tumor, a nanoformulação NE-ALCLFT (6 horas), se manteve em maior proporção no tumor (Fig. 43, A). Já as formulações NEALCLFT-FO e MIC-FO-ALCLFT (6 horas) a relação da fluorescência presente no fígado é proporcionalmente maior (Fig. 43, A).

No tempo de 10horas, a proporção de intensidade de fluorescência no fígado diminui, e as formulações NE-ALCLFT-FO e MIC-FO-ALCLFT, aumenta no tumor (Fig. 43, B).

A.

PESO x FLUORESCÊNCIA

6HORAS

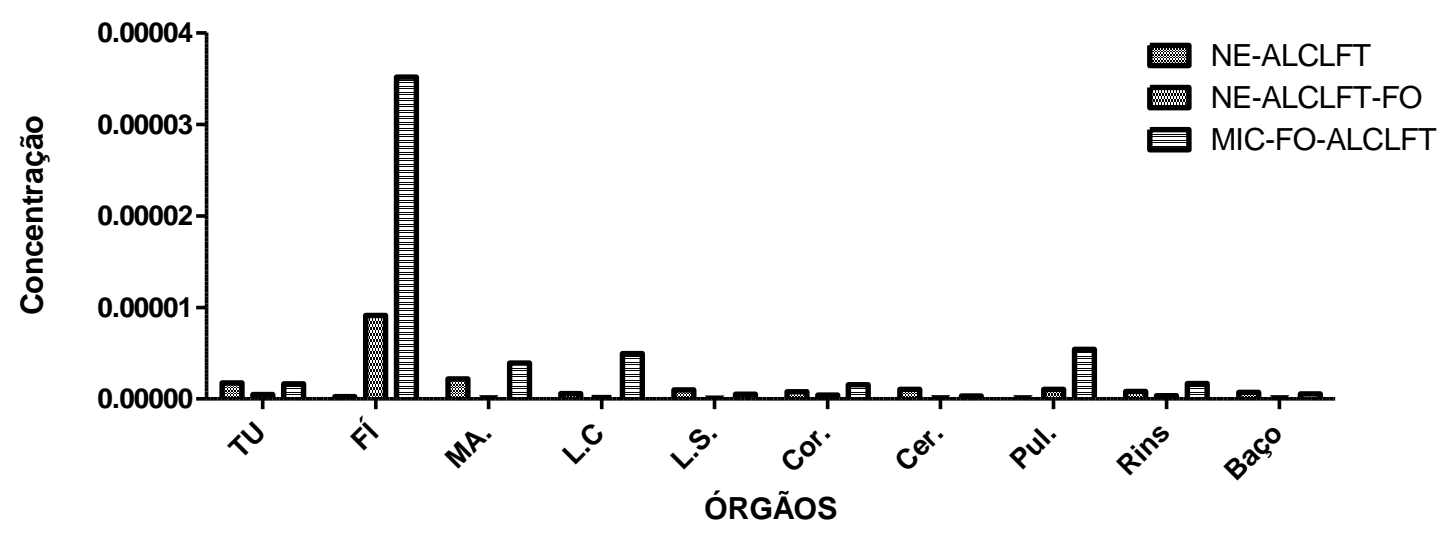




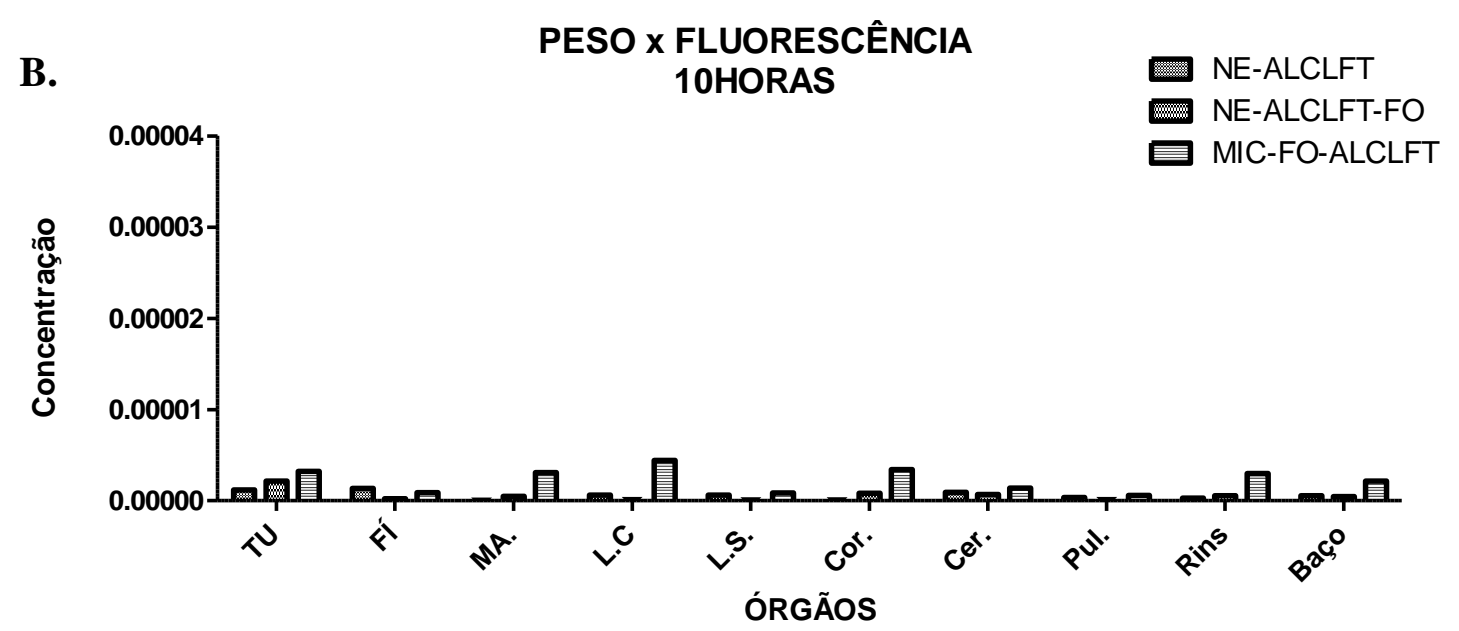

Figura 41. Relação entre o peso dos órgãos e a intensidade de fluorescência presente em cada órgão. (A) Análise às 6h. (B) Análise às $10 \mathrm{~h}$.

\subsubsection{Análise clínica da presença das nanoemulsões no linfonodo sentinela}

No ato da eutanásia dos animais, foi observado o acúmulo da nanoformulação de NE-ALCLFT e da NE-ALCLFT-FO, no linfonodo sentinela dos animas. Essas análises podem ser visualizadas na imagem da Figura 44 (A,B).

A.

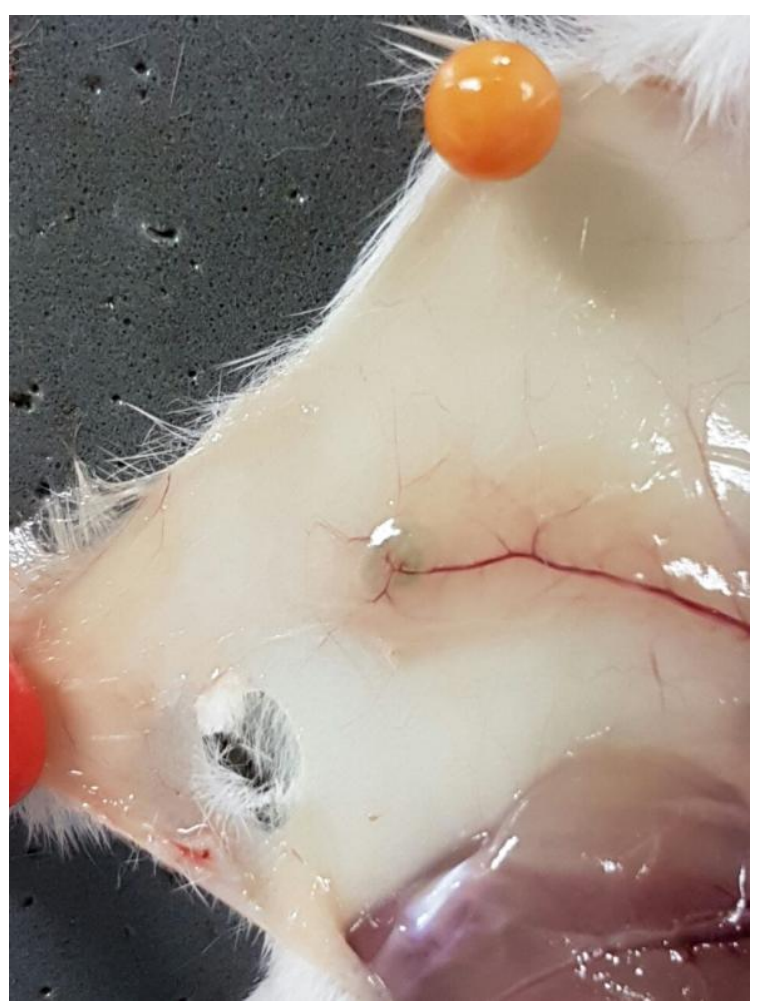

B.

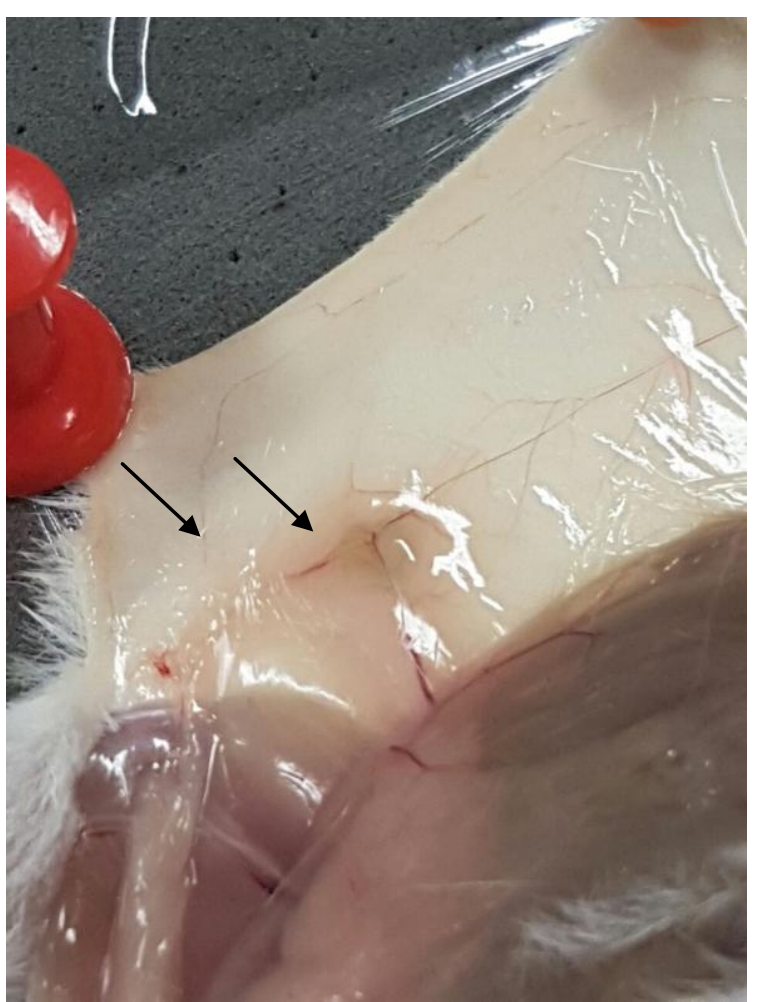


Figura 42. Fotografia da região do linfonodo sentinela. (A) Animal que recebeu a NEALCLFT. (B) Animal que recebeu a NE-ALCLFT-FO. Note a coloração mais escura ocasionada possivelmente pelo acumulo das nanoformulações nesta região (setas).

\subsection{Análise do volume tumoral no decorrer dos tratamentos}

A comparação do volume tumoral foi feita com base nas medidas realizadas com auxílio de um paquímetro durante todo o tratamento realizado (6 semanas). Os dados mostram que inicialmente todos os grupos apresentaram em média volume tumoral de $25 \mathrm{~mm}^{3}$.

O grupo controle positivo (animais com tumor e não tratados) e daqueles que receberam NE-ALCLFT (sem a aplicação de TFD), e com a aplicação apenas do LED (sem a nanoemulsão), apresentaram aumento crescente no volume tumoral (Fig. 46 A).

O grupo dos animais que receberam apenas o LED teve o aumento exponencial do volume tumoral, chegando a apresentar na última semana $895 \mathrm{~mm}^{3}$, sendo o grupo que apresentou maior aumento do tumor comparado aos demais grupos.

Os grupos do controle positivo e da NE-ALCLFT (sem a TFD), apresentaram taxa de crescimento linear, semelhante entre si, tendo o maior volume apresentado na última semana.

Já os animais que foram tratados com a aplicação da TFD (Tratamento Sistêmico (endovenoso, irradiação sistêmica), Parcialmente Sistêmico (endovenoso, irradiação local) e Local (intratumoral, com irradiação sistêmica) apresentaram regressão do volume tumoral em todos os grupos, comparado aos grupos não tratados com a TFD (Fig. 46, B).

O grupo com Tratamento Sistêmico, apresentou regressão do volume tumoral para $9 \mathrm{~mm}^{3}$ na última semana de tratamento com a TFD.

O grupo Parcialmente Sistêmico apresentou redução para $0,42 \mathrm{~mm}^{3}$ do volume tumoral na última sessão de tratamento com a TFD, apresentando a melhor forma de tratamento. Este grupo teve $80 \%$ na eficiência do tratamento, visto que 4 animais tiveram a redução total do tumor $(n=5)$.

O grupo Tratamento Local, apresentou redução do volume tumoral para $37 \mathrm{~mm}^{3}$ na última sessão de tratamento com a TFD. 


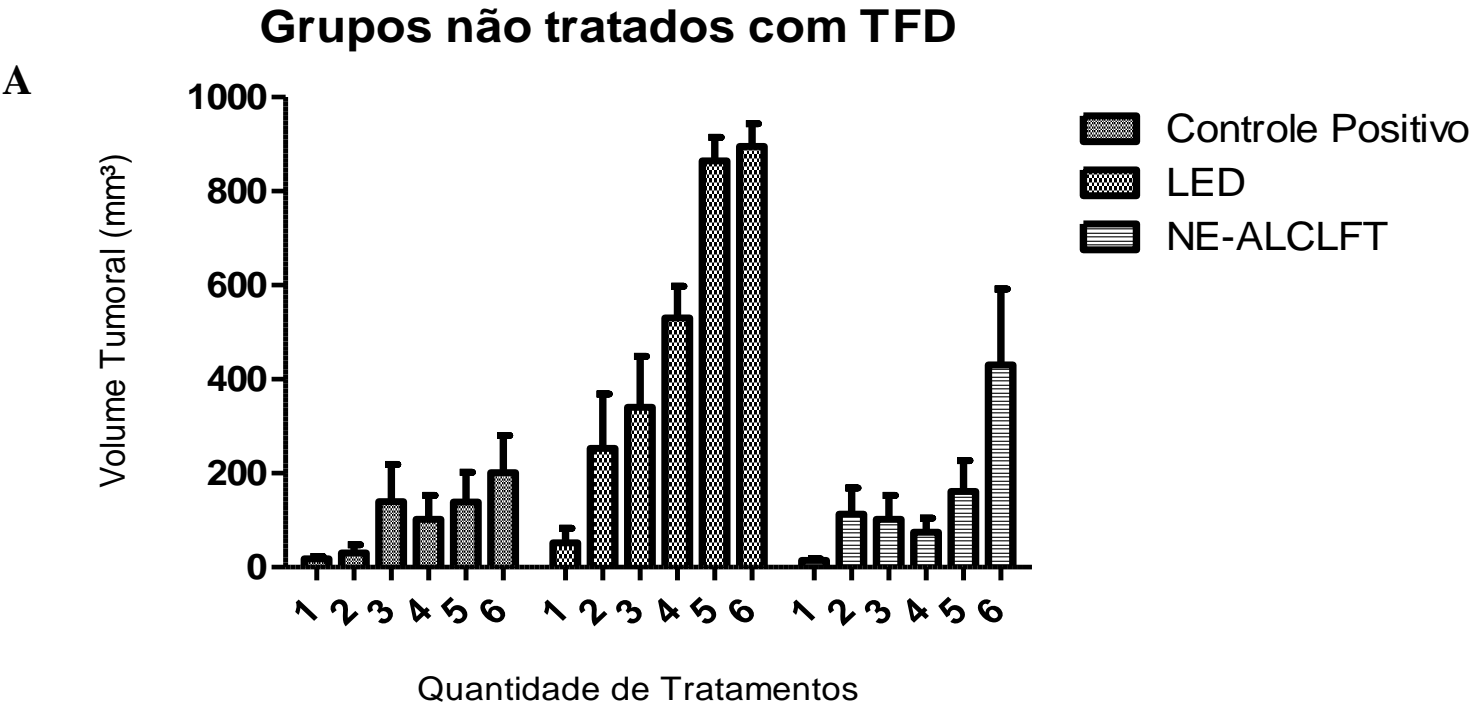

B

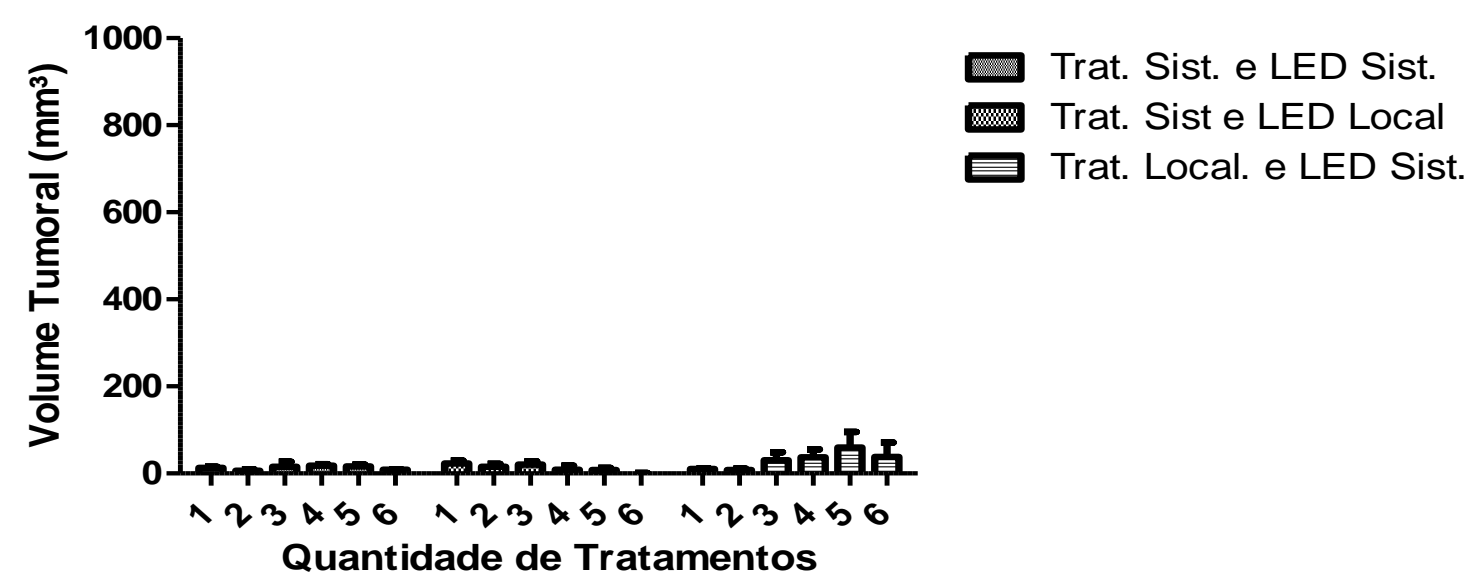

Figura 43. Análise do volume tumoral dos grupos nnão tratados com TFD (A) e dos grupos tratados com TFD (B). Variação do volume tumoral no decorrer das semanas de tratamento, sendo no total 6 sessões. Volume calculado segundo a fórmula: (Comprimento) x (largura) ${ }^{2}$ x 0,5. (A) Note que no gráfico dos grupos não tratados com a TFD, a escala do eixo Y é de 0 a $1000 \mathrm{~mm}^{3}$, e no gráfico dos grupos tratadas com TFD (B) a escala é de 0 a $100 \mathrm{~mm}^{3}$. Este aspecto é para a melhor visualização da análise de regressão do volume tumoral, comparando os grupos tratados e não tratados com a aplicação da TFD. 
Ressalta-se que, após as sessões de tratamentos, já podia se perceber aspectos clínicos, como presença de necrose, após a irradiação da terapia fotodinâmica (Fig. 47).

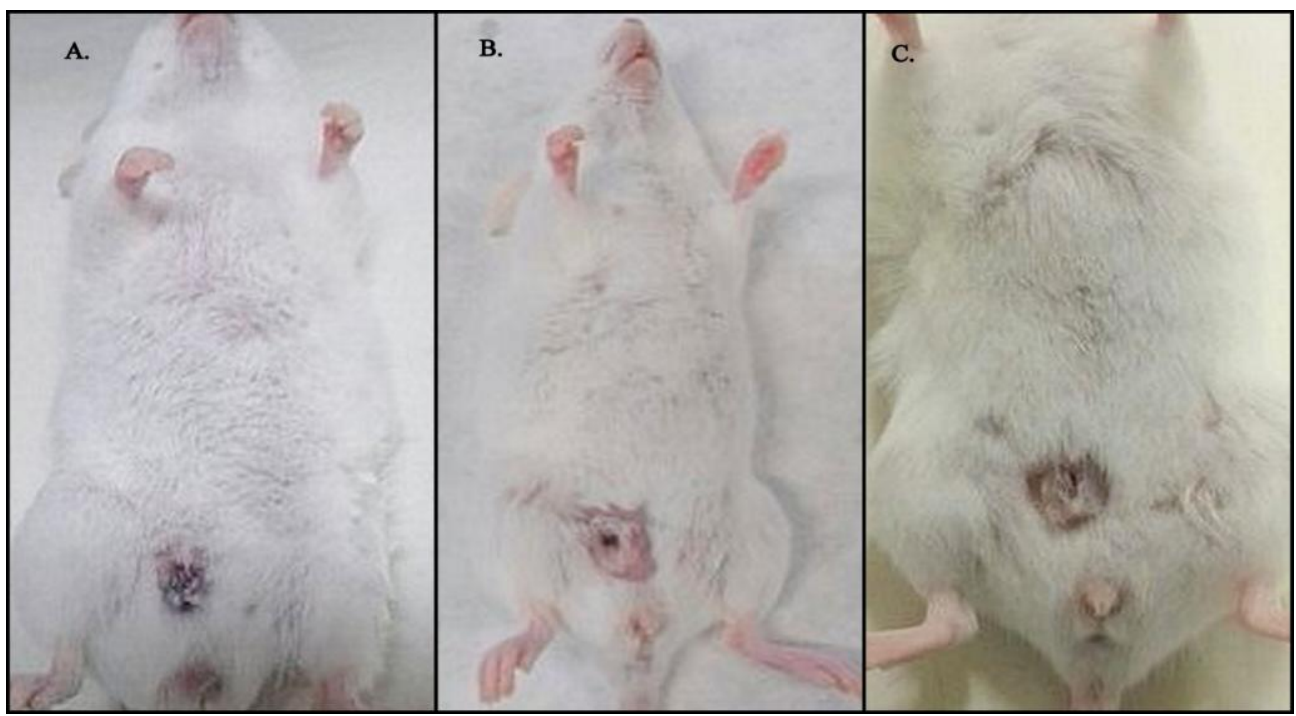

Figura 44. Imagens após terceira sessão de tratamentos com aplicação da TFD. (A) Tratamento sistêmico (endovenoso) com irradiação sistêmica. (B) Tratamento local (intratumoral) com irradiação sistêmica. (C). Tratamento endovenoso com Irradiação local.

\subsection{Taxa de sobrevivência após tratamentos}

Ao final dos tratamentos houve diferença na quantidade de animais que sobreviveram após os tratamentos, ressaltando que o grupo inicialmente era constituído de $n=5$. Os grupos controle negativo, NE-ALCLFT (só a nanoformulação) e parcial sistêmico (administração endovenosa com irradiação sistêmica), apresentaram taxa de $100 \%$ de sobrevivência, visto que nenhum animal morreu durante os tratamentos. O controle positivo (com tumor e sem tratamento) e o tratamento LOCAL (administração intratumoral e irradiação sistêmica) apresentaram $80 \%$ de sobrevivência, visto que 1 animais de cada grupo foi encontrado morto. Já o grupo sistêmico (administração endovenosa com irradiação sistêmica) apresentou $60 \%$ de sobrevivência, onde 2 animais morreram após a administração do anestésico e da nanoformulação. Os dados são representados na Figura 


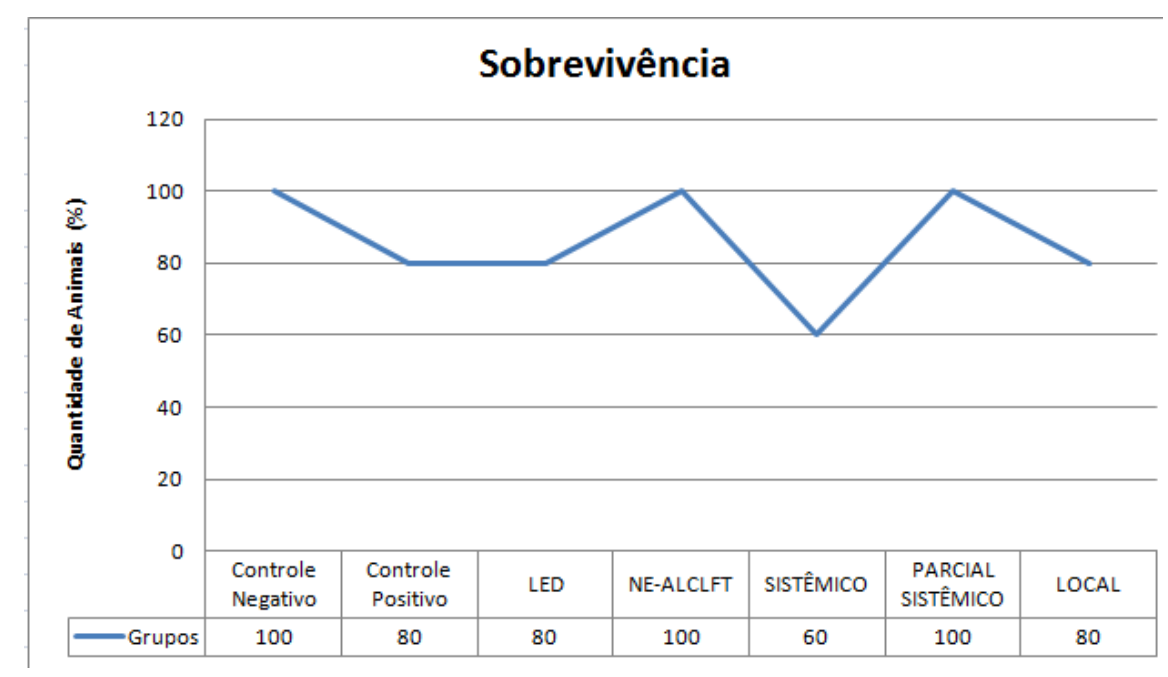

Figura 45. Quantidade de animais (em porcentagem) que sobreviveram após todos os tratamentos.

\subsection{Análise por Tomografia Computadorizada}

As análises por tomografia computadorizada realizadas no PET/SPECT permitiram analisar o volume pulmonar e ósseo dos grupos. Esses dados ajudam a avaliar a presença de possíveis focos metastáticos, com base na avaliação e quantificação do volume desses órgãos, comparando os grupos controle negativo (saudáveis), controle positivo (com tumor e não tratados), e os demais grupos. As imagens foram feitas em corte transversal, sagital e frontal (Figura 48. A, B). Além disso, fez-se uma imagem representativa avaliando a estrutura óssea e o pulmão, a qual se encontra na Figura 49.

Foi possível analisar, que não houve alterações significativas no volume ósseo dos grupos analisados (Figura 50, A). Já o volume pulmonar, apresentou redução nos grupos utilizando apenas o LED, e no grupo do tratamento local (por administração intratumoral) (Figura 50, B). Essa redução pode ser indícios da presença de focos metastáticos, mas que foram corroboradas com as análises histopatológicas. 
A

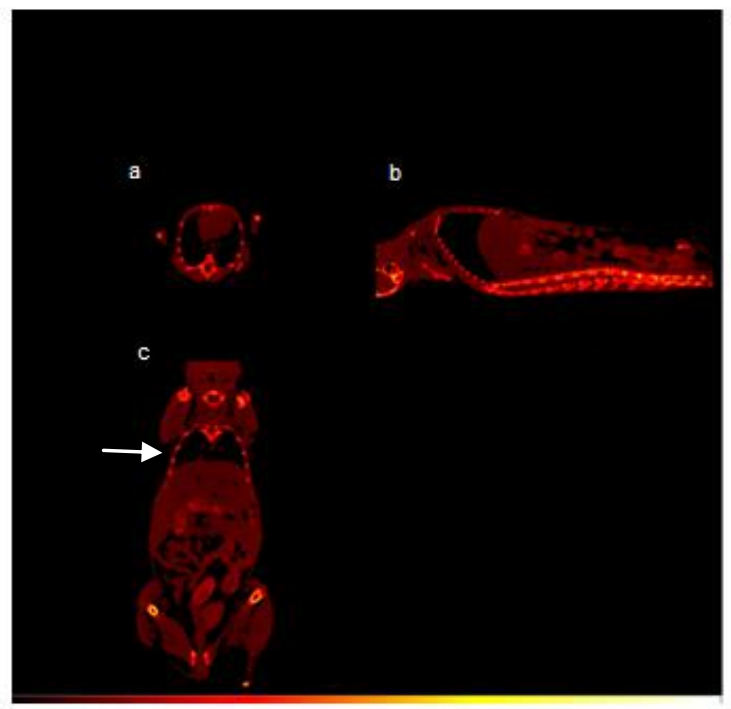

B

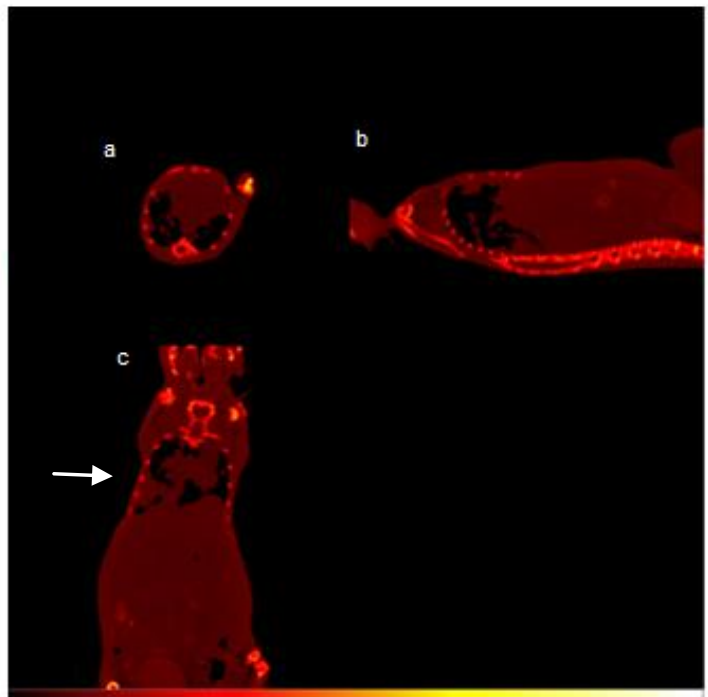

Figura 46. Imagens de tomografia computadorizada dos animais do grupo controle negativo (A) e controle positivo (B). As imagens apresentam corte transverso (a), sagital (b) e frontal (c). Note que o pulmão do grupo controle negativo, visualizado no corte frontal, apresenta coloração preta, a qual é indício da presença de ar no pulmão. Já o pulmão do grupo controle positivo, no corte frontal, não apresenta este mesmo aspecto. Setas ressaltando os pulmões.

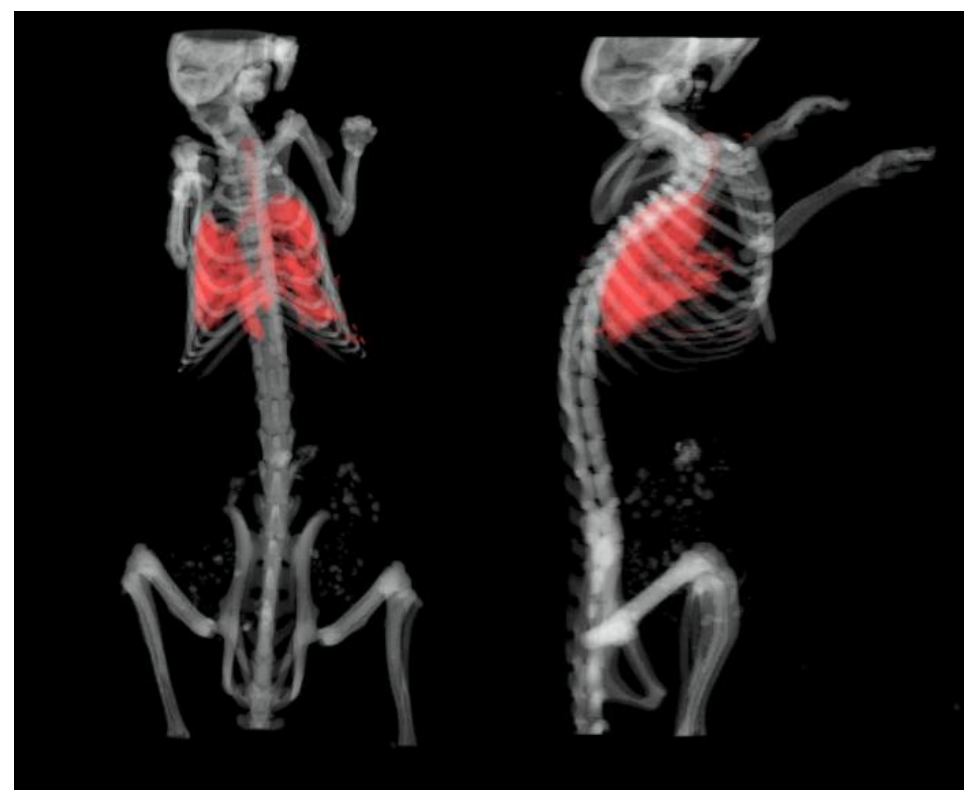

Figura 47. Imagem tridimensional do animal do grupo controle positivo. Posição frontal em (direita) e sagital (esquerda). Ressalta-se a estrutura pulmonar e óssea do animal. 
(A)

Osso

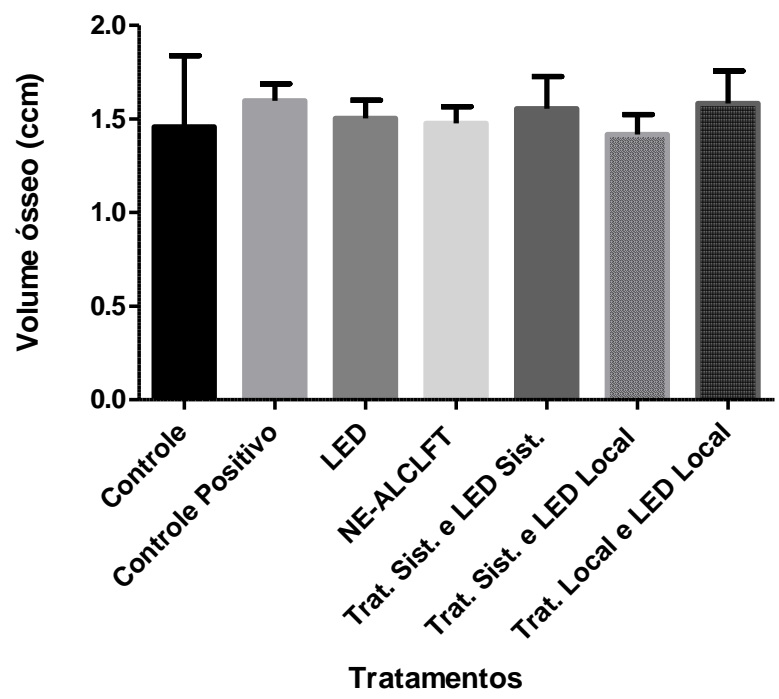

(B)

Pulmão

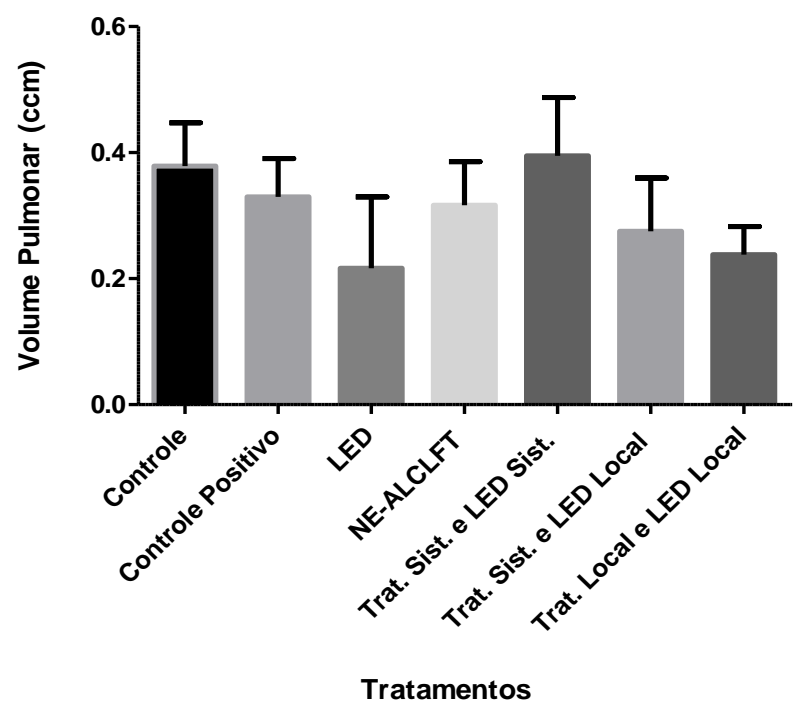

Figura 48. Análise do volume ósseo (A) e pulmonar (B), dos grupos após os tratamentos.

\subsection{Análise do peso do fígado, baço e tumor, após a excisão cirúrgica}

A fim de identificar se houve alterações no tamanho dos órgãos fígado, baço e tumor, foi realizada a análise do peso destes órgãos (Figura 51).

Pôde-se observar o aumento significativo (p<0,05) nos órgãos do fígado (Fig. 51, A) baço (Fig. 51, B) e tumor (Fig. 51, C) do grupo utilizando apenas o LED em relação ao controle positivo (Fig. 46). Este aspecto pode ressaltar características como hepatomegalia e esplenomegalia, as quais são alterações no aumento do volume nestes órgãos.

Nos demais grupo não foi apresentado alterações significativas com relação ao peso.

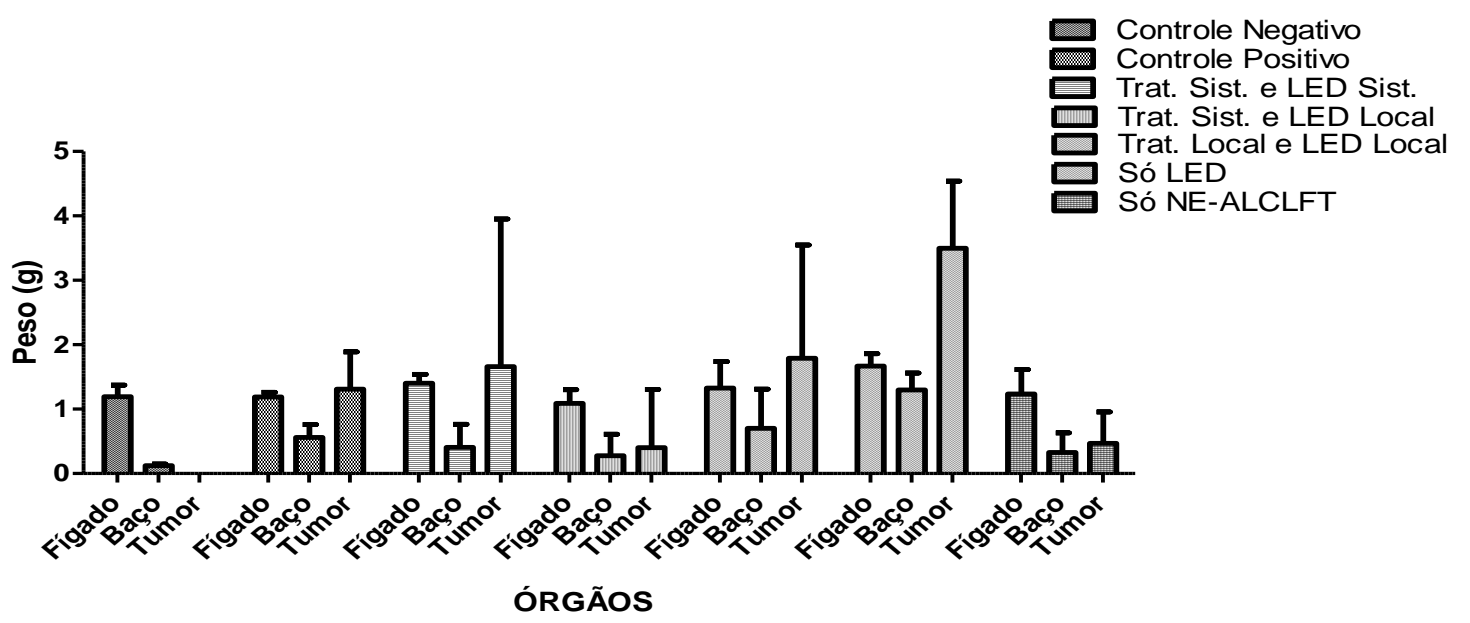


A

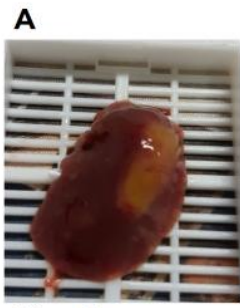

Fígado

Lóbulo Maior
B

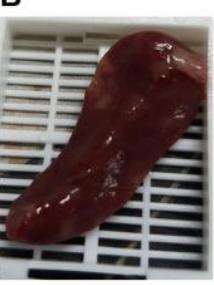

Baço

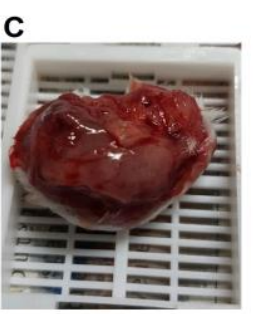

Tumor

Figura 49. Peso dos órgãos (fígado, baço e tumor) no dia da eutanásia dos animais. As análises estatísticas foram feitas utilizando Two-WayANOVA, com pós-teste de Bonferroni $(\mathrm{p}<0,05)$. Abaixo do gráfico, têm-se imagens de fotos mostrando o (A) Fígado (porção do lóbulo maior), (B) Baço e (C) Tumor do grupo LED, evidenciamento o aumento destes órgãos.

\subsection{Análise do poso corporal dos animais}

No início dos tratamentos a massa corporal dos animais estava em torno de $23 \mathrm{~g}$ a 25g. Durante o decorrer dos tratamentos as variações do peso mais relevantes, observadas foram: Na segunda semana houve o aumento de peso para $27 \mathrm{~g}$, do grupo Sistêmico (endovenoso e irradiação sistêmica) (Fig. 45), e diminuição de peso para $22 \mathrm{~g}$ no grupo parcialmente sistêmico (endovenoso, e irradiação local). Entre a terceira e a quarta semana de tratamentos, o grupo "só LED” apresentou aumento de peso para uma média de $27 \mathrm{~g}$.

Os demais grupos (controle negativo (sem tumor), controle positivo (com tumor e sem tratamento), tratamento local (intratumoral e LED sistêmico), e apenas a nanoemulsão (só NE-ALCLFT)) não apresentaram variações significativas na massa corporal durante os tratamentos. 


\section{Peso dos Animais}

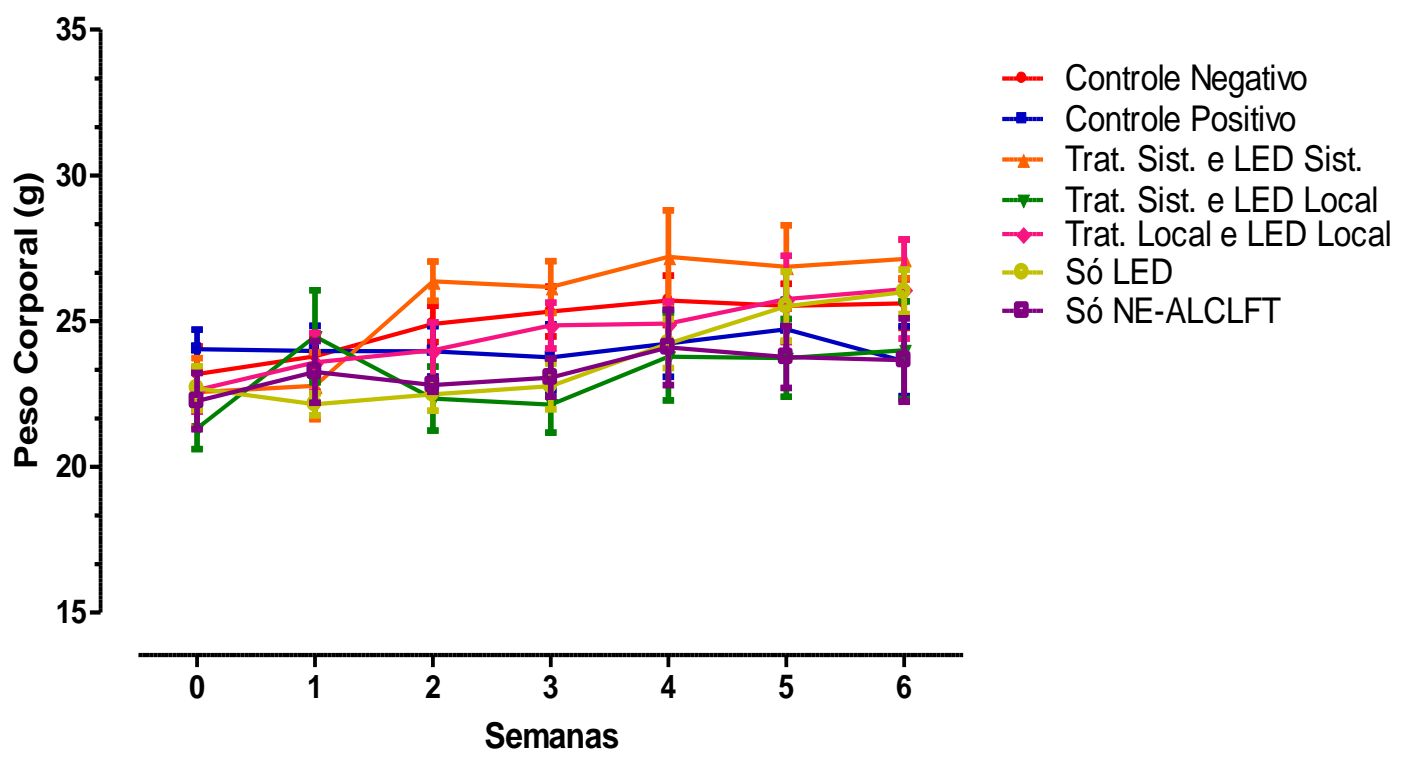

Figura 50. Peso corporal monitorado por 6 semanas (1 vez por semana) durante o período de tratamento por TFD em camundongos Balb/c portando tumores da linhagem 4T1-luc.

\subsection{Análises clínicas}

\subsubsection{Hemograma}

Para as análises do hemograma, foram avaliadas as taxas dos seguintes elementos: glóbulos brancos, eritrócitos, hemoglobina, hematócrito, hemoglobina corpuscular média (HCM), concentração de hemoglobina corpuscular média (CHCM) e plaquetas.

Nestes parâmetros, foram observados em todos os grupos, significativas alterações nas taxas de glóbulos brancos e trombocitose (aumento de plaquetas no sangue), em relação ao grupo controle negativo (saudável). O grupo tratado com apenas o LED, apresentou redução nas taxas de eritrócitos, hemoglobina e hematócrito. Os demais parâmetros apresentaram valores normais.

Os dados podem ser observados na Tabela 8 . 
Tabela 8. Análise hemograma após tratamentos.

\begin{tabular}{|c|c|c|c|c|c|c|c|c|}
\hline GRUPOS & $\begin{array}{c}\text { Glóbulos } \\
\text { Brancos (WBC) } \\
(103 / \mathrm{uL})\end{array}$ & $\begin{array}{c}\text { Eritrócitos } \\
\text { (RBC) } \\
(106 / \mathrm{uL})\end{array}$ & $\begin{array}{l}\text { Hemoglobina } \\
\text { (HGB) } \\
\text { (g/dL) }\end{array}$ & $\begin{array}{l}\text { Hematócrito } \\
\text { (HCT) }(\%)\end{array}$ & MCV (fL) & $\mathrm{HCM}(\mathrm{pg})$ & $\mathrm{CHCM}(\mathrm{g} / \mathrm{dL})$ & $\begin{array}{l}\text { Plaquetas } \\
\text { (x103/uL) }\end{array}$ \\
\hline $\begin{array}{l}\text { Controle } \\
\text { Negativo }\end{array}$ & $3.2 \pm 1.16$ & $9.05 \pm 1.00$ & $13.15 \pm 1.57$ & $32.23 \pm 3.85$ & $35.55 \pm 0.45$ & $14.5 \pm 0.26$ & $40.8 \pm 0.37$ & $728.5 \pm 389$ \\
\hline $\begin{array}{l}\text { Controle } \\
\text { Positivo }\end{array}$ & $40.82 \pm 50.11$ & $9.44 \pm 1.43$ & $13.48 \pm 1.84$ & $33.6 \pm 4.70$ & $35.68 \pm 0.55$ & $14.32 \pm 0.33$ & $40.12 \pm 0.52$ & $\begin{array}{c}1030.8= \\
407.4\end{array}$ \\
\hline Só LED & $106.7 \pm 66.44$ & $6.09 \pm 3.66$ & $8.85 \pm 5.26$ & $21.75 \pm 11.16$ & $36.15 \pm 1.06$ & $14.7 \pm 0.63$ & $40.67 \pm 0.97$ & $631 \pm 465$ \\
\hline Só ALCLFT & $31.1 \pm 47.8$ & $9.2 \pm 0.88$ & $13.3 . \pm 1.15$ & $32.8 \pm 3.17$ & $35.54 \pm 0.45$ & $14.4 \pm 0.39$ & $40.6 \pm 0.68$ & $\begin{array}{c}1071.68 \pm \\
471\end{array}$ \\
\hline $\begin{array}{c}\text { Trat. } \\
\text { Sistêmico } \\
\text { Total }\end{array}$ & $29.5 \pm 44.71$ & $9.81 \pm 0.83$ & $13.16 \pm 1.15$ & $33.4 \pm 2.92$ & $34.03 \pm 0.66$ & $13.25 \pm 0.55$ & $39.43 \pm 0.80$ & $1208 \pm 473$ \\
\hline $\begin{array}{c}\text { Trat. } \\
\text { Sistêmico e } \\
\text { LED local }\end{array}$ & $18.82 \pm 32.23$ & $9.48 \pm 0.92$ & $13.06 \pm 1.32$ & $32.94 \pm 3.44$ & $34.68=0.40$ & $13.76=0.23$ & $39.66 \pm 0.55$ & $1131.6 \pm 312$ \\
\hline Trat. Local & $142.3 \pm 161$ & $9.09 \pm 1.06$ & $13.12=1.27$ & $31.85 \pm 3.09$ & $35.05 \pm 0.36$ & $14.45=0.46$ & $41.3 \pm 1.31$ & $1229 \pm 180$ \\
\hline
\end{tabular}

\subsubsection{Bioquímico}

Foram feitas avaliações bioquímica dos analitos, ALT, AST, CK-MB, ferro e ureia. Ressalta-se que as enzimas ALT e AST, são importantes substâncias que indicam possíveis disfunções hepática, enquanto que a isoenzima CK-MB avalia possível dano cardíaco, e a ureia, a função renal.

Segundo a análise estatística realizada pelo teste Two-Way-ANOVA, com pós teste Bonferroni com $\mathrm{p}<0,05$, os valores para todos os grupos apresentaram normais, com relação ao grupo controle negativo (saudáveis), para os analitos ALT, AST, ferro e ureia, o que indica que mesmo com os tratamentos utilizando a TFD, não houve alterações permanentes destas enzimas no fígado e rins (Fig. 52). 


\section{Bioquímico}

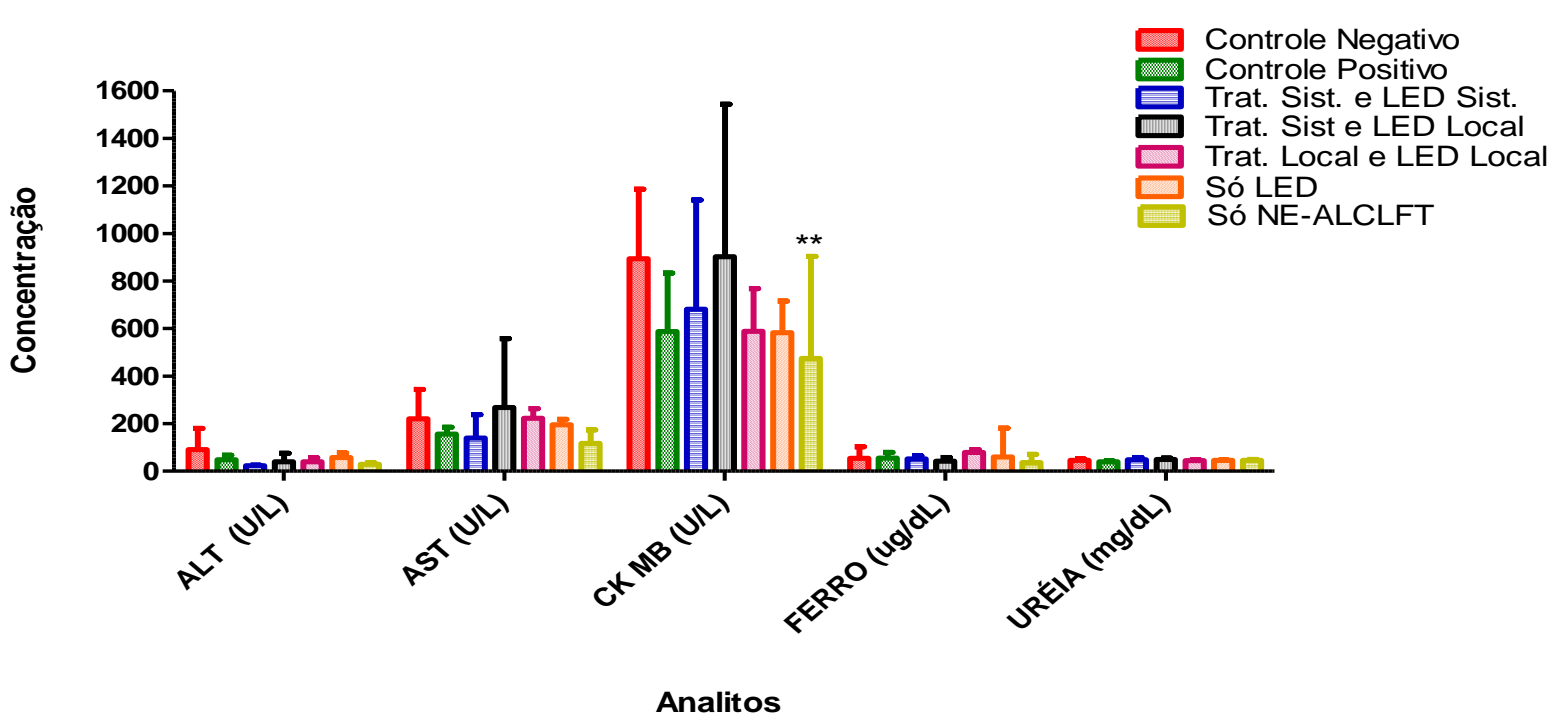

Figura 51. Análise bioquímica dos analitos alanina transaminase (ALT), aspartato transaminase (AST), isoenzima CK-MB, ferro e ureia. Esses analitos, visam as análises complementares das funções hepáticas (ALT eAST), renais (Ureia), cardíacas (CK-MB) e disfunções relacionadas ao ferro. Os testes foram feitos com base na análise estatísticas por Two-Way-ANOVA, com pós-teste Bonferrone, considerando $\mathrm{p}<0,05$.

\subsection{Histopatologia}

Dentro dos parâmetros histológicos considerados como resposta do tumor à terapia temos: necrose; redução do tamanho em relação ao inicial; infiltrado inflamatório; fibroplasia estromal (4 critérios). Existem outros parâmetros, mas estes são os principais que foram avaliados neste trabalho.

Sabe-se que a resposta à terapia pode ser parcial, onde apenas uma parte do tumor morre, ou completa, quando não há mais vestígios da presença do tumor. Tumores que crescem muito rápido podem sofrer necrose de forma espontânea, e este fator, acontece porque a massa tumoral cresce em uma velocidade maior que a vascularização consegue acompanhar. Esta necrose ocorre geralmente no centro do tumor, mas de forma geral não é possível distinguir a necrose espontânea da necrose induzida pela terapia. 
Entretanto, a necrose induzida por terapêutica costuma ser maior e mais difusa que a necrose espontânea, conforme analisado neste trabalho.

Outro fator, é a presença de infiltrado inflamatório, o qual ocorre tanto pela presença do tumor em si quanto por uma resposta à terapia, visto que, quando ocorre à morte celular, temos a liberação de conteúdo das células mortas no estroma e indução da resposta inflamatória.

A fibroplasia estromal é uma resposta estereotipada do organismo contra uma agressão. O tecido conjuntivo perilesional reage formando fibrose (cicatriz). Ela também é um marcador de resposta à terapia antitumoral. O tumor morre em decorrência da terapia e o espaço que antes era ocupado por ele é preenchido por fibrose.

O carcinoma mamário apresenta vários tipos histológicos (tubular, cribriforme, sólido, comedo e papilar) e diversos graus histológicos (baixo grau e alto grau). Contudo, a indução tumoral nestes camundongos produziu geralmente o carcinoma sólido de alto grau.

Portanto, com base nas análises histopatológicas, de forma geral, de $100 \%$ de todos os grupos analisados (com exceção do grupo controle negativo), 60\% apresentaram carcinoma mamário nos cortes histológicos. Nestes, também foi possível perceber a presença de necrose e infiltrados inflamatórios. Dos $40 \%$ restantes, foi possível encontrar indícios histológicos da presença prévia de neoplasia no leito tumoral (TU) na forma de fibrose estromal e/ou infiltrado inflamatório, sendo que 4 animais, eram pertencentes ao grupo do tratamento sistêmico endovenoso com irradiação no local do tumor, podendo corresponder a resposta completa à terapia. Portanto, neste grupo em específico, apresentou eficácia de $80 \%$ no tratamento realizado $(\mathrm{n}=5)$.

\subsubsection{Sumarização dos achados histológicos (descrição completa em Apêndice I):}

Para facilitar as análises histopatológicas, foram reunidas informações gerais de acordo com cada grupo de tratamento. Essas análises são dadas a seguir.

- Grupo controle negativo.
- Animal 1
- Lâminas com aspecto histológico habitual.
○ Animal 2
- Lâminas com aspecto histológico habitual.
○ Animal 3 
- Lâminas com aspecto histológico habitual.

○ Animal 4

- Lâminas com aspecto histológico habitual.

○ Animal 5

- Lâminas com aspecto histológico habitual.

- Grupo controle positivo (com indução tumoral e sem tratamentos)

○ Animal 1

- Lâminas com aspecto histológico habitual, indicando possível regressão tumoral espontânea.

- Animal 2

- Carcinoma mamário padrão sólido em tumor, medindo $11,0 \mathrm{~mm}$ de diâmetro, com $20 \%$ de necrose, leve infiltrado inflamatório misto, sem fibrose estromal.

- Metástase em pulmão.

- Animal 3

- Carcinoma mamário padrão sólido em tumor

- Metástases de carcinoma mamário em pulmão, linfonodo sentinela e na glândula adrenal em rins.

- Presença de leve hepatite neutrofílica periportal, sem necrose, em fígado

- Animal 4

- Carcinoma mamário padrão sólido em tumor

- Presença de hiperplasia linfóide reacional em linfonodos de pulmão.

- Presença de moderado infiltrado inflamatório linfocítico em mama contralateral.

Observação: Um dos animais deste grupo, morreu durante os tratamentos.

- Grupo de Tratamento sistêmico (endovenoso) com irradiação sistêmica (corpo inteiro do animal)

- Animal1

- Carcinoma mamário padrão sólido na mama contralateral, medindo $11,0 \mathrm{~mm}$ de diâmetro, com $20 \%$ de necrose, leve infiltrado inflamatório misto, sem fibrose estromal.

- Metástases em pulmão e linfonodo sentinela.

○ Animal 2

- Presença de leve fibrose estromal no tumor.

○ Animal 3

- Carcinoma mamário padrão sólido no tumor, medindo $15,0 \mathrm{~mm}$ de diâmetro, sem necrose. Presença de moderado infiltrado inflamatório linfocítico e leve fibrose estromal.

Observação: Neste tratamento, dois animais morreram durante os experimentos.

- Grupo de tratamento sistêmico (endovenoso) com irradiação local

○ Animal 1

- Lâminas com aspecto histológico habitual. 
- Animal 2

- Lâminas com aspecto histológico habitual.

○ Animal 3

- Lâminas com aspecto histológico habitual.

○ Animal 4

- Carcinoma mamário padrão sólido em tumor, medindo 30,0 mm de diâmetro, com $15 \%$ de necrose, leve infiltrado inflamatório misto, sem fibrose estromal.

- Metástases em pulmão, fígado e baço.

- Mama contralateral com hemorragia tecidual.

- Animal 5

- Presença de leve fibrose estromal em lâmina de tumor.

- Grupo com tratamento local (intratumoral) e irradiação sistêmica

○ Animal 1

- Presença de leve fibrose estromal e leve infiltrado inflamatório linfocítico em tumor.

○ Animal 2

- Carcinoma mamário padrão sólido em tumor, medindo 21,0 mm de diâmetro, com $60 \%$ de necrose, leve infiltrado inflamatório misto, sem fibrose estromal.

- Metástase em pulmão.

○ Animal 3

- Carcinoma mamário padrão sólido em tumor, medindo $28,0 \mathrm{~mm}$ de diâmetro, com $15 \%$ de necrose, leve infiltrado inflamatório misto, sem fibrose estromal.

- Metástases em pulmão, fígado, baço, linfonodo sentinela e linfonodo contralateral.

- Presença de trombo cardíaco intraventrículo direito no coração.

- Presença de moderado infiltrado inflamatório linfocítico na mama contralateral.

- Animal 4

- Metástase de carcinoma mamário padrão sólido em pulmão.

Observação: durante os tratamentos, um animal morreu.

- Grupo com tratamento apenas utilizando NE-ALCLFT

○ Animal 1

- Carcinoma mamário padrão sólido em tumor, medindo 19,0 mm de diâmetro, com $40 \%$ de necrose, leve infiltrado inflamatório misto, sem fibrose estromal.

- Metástases em pulmão, fígado e baço.

○ Animal 2

- Lâminas com aspecto histológico habitual.

- Animal 3

- Carcinoma mamário padrão sólido em tumor, medindo 9,0 mm de diâmetro, com $20 \%$ de necrose, leve infiltrado inflamatório misto, sem fibrose estromal.

- Presença de foco hemorrágico em pulmão. 
- Presença de depósito de substância exógena em linfonodo sentinela.

- Animal 4

- Carcinoma mamário padrão sólido em tumor

- Presença de leve fibrose estromal e leve infiltrado inflamatório linfocítico em tumor.

- Animal 5

- Carcinoma mamário padrão sólido em tumor, medindo 9,0 mm de diâmetro, com $60 \%$ de necrose, leve infiltrado inflamatório misto, sem fibrose estromal.

- Metástase em linfonodo sentinela.

- Grupo apenas LED

○ Animal 1

- Carcinoma mamário padrão sólido em tumor, medindo 21,0 mm de diâmetro, com $40 \%$ de necrose, leve infiltrado inflamatório misto, sem fibrose estromal.

- Metástases em pulmão, fígado, baço, linfonodo sentinela, e glândula adrenal em rins.

- Animal 2

- Carcinoma mamário padrão sólido em tumor,

- Metástases em pulmão, fígado e linfonodo contralateral

- Presença de moderada fibrose estromal e infiltrado inflamatório linfocítico em mama contralateral.

- Animal 3

- Carcinoma mamário padrão sólido em tumor, medindo 22,0 mm de diâmetro, com $60 \%$ de necrose, moderado infiltrado inflamatório misto, sem fibrose estromal.

- Metástases em coração, pulmão, fígado e linfonodo sentinela..

○ Animal 4

- Metástases empulmão, linfonodo sentinela e mama contralateral.

- Presença de leve hepatite neutrofílica periportal, sem necrose, em fígado.

Observação: Um do animal deste grupo morreu durante os tratamentos.

Outros achados importantes nos tratamentos foram:

. Em apenas um caso do grupo controle positivo (animais com tumor e sem tratamentos), foi verificada fibrose adjacente ao tumor principal.

. Em um dos animais do grupo sistêmico (endovenoso) com irradiação local, pôde-se perceber a presença de hemorragia recente intraparenquimatosa em tecido mamário em na região da mama contralateral, mas que pode ser apenas um artefato técnico e não relacionado ao trabalho, mas ao método de eutanásia. 
- Um dos animais do grupo controle positivo, apresentou hiperplasia linfoide reacional bem exuberante. O que pode ser indício da resposta do sistema imune contra o tumor em si.

Não foi possível comprovar aspectos de infiltração vascular e linfática, visto que tais análises apresentam características por vezes difíceis de avaliar na histologia. É necessária a presença de êmbolos tumorais aderidos à parede vascular, o que não foi possível visualizar nestes cortes histológicos, apesar de que a presença de metástases a distância ser um marcador óbvio da presença da infiltração vascular e linfática.

Algumas características dos dados histológicos, especialmente células neoplásicas, fibrose e infiltrados inflamatórios, podem ser visualizados nas imagens da Figura 53, $54,55,56$ e 57. 
BAÇO

CONTROL .

CONTROL +

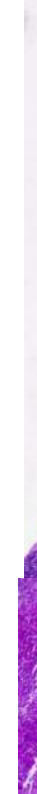

FÍGADO

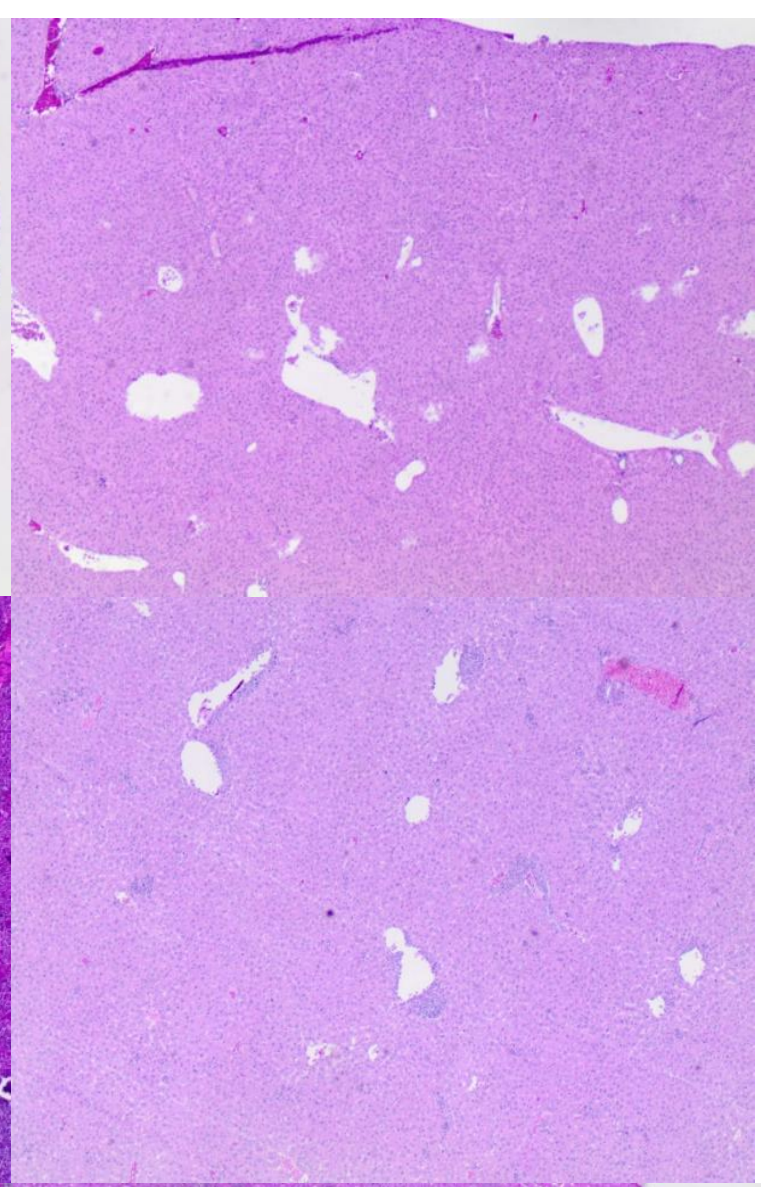

LED

NE-ALCLFT
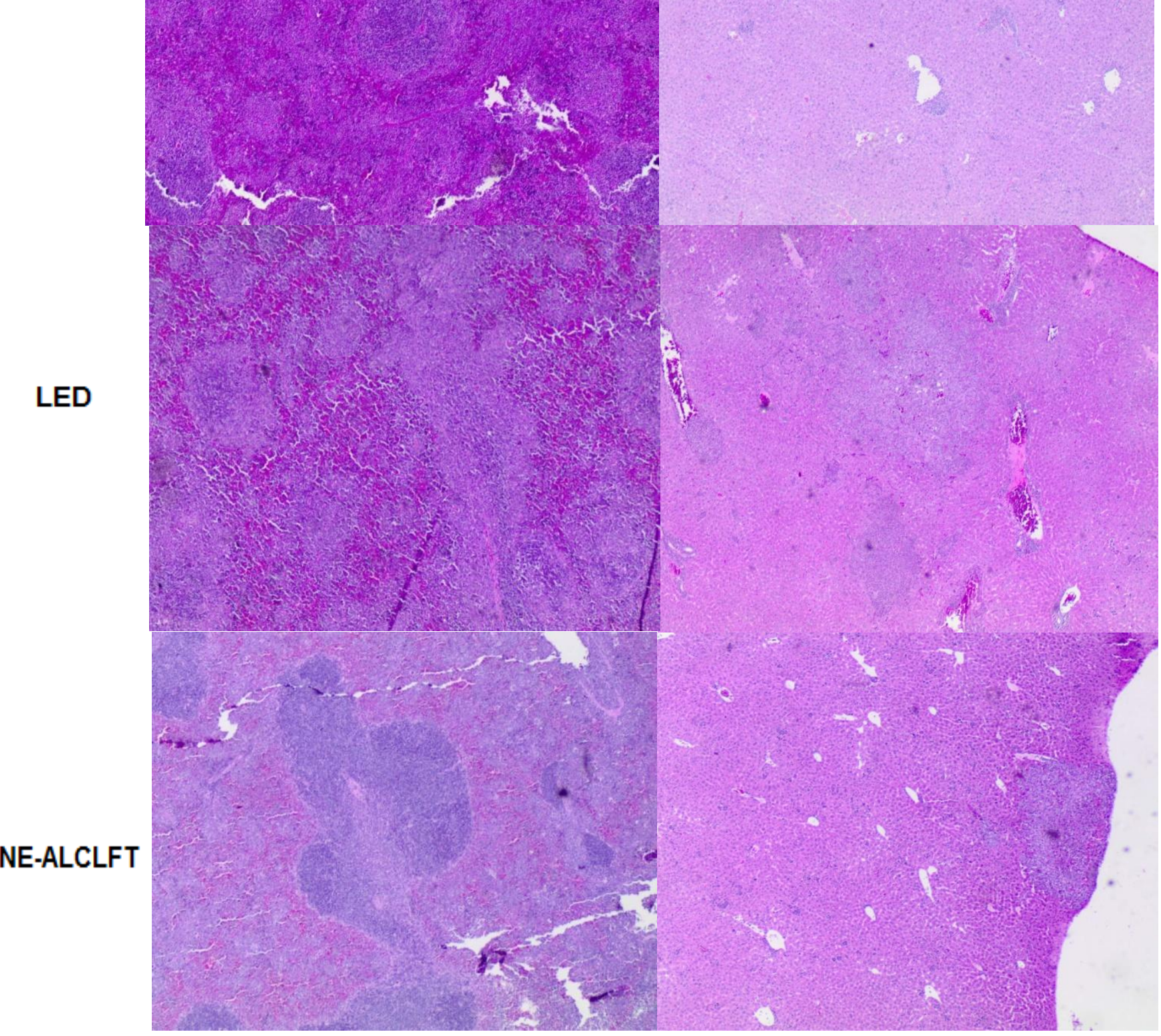


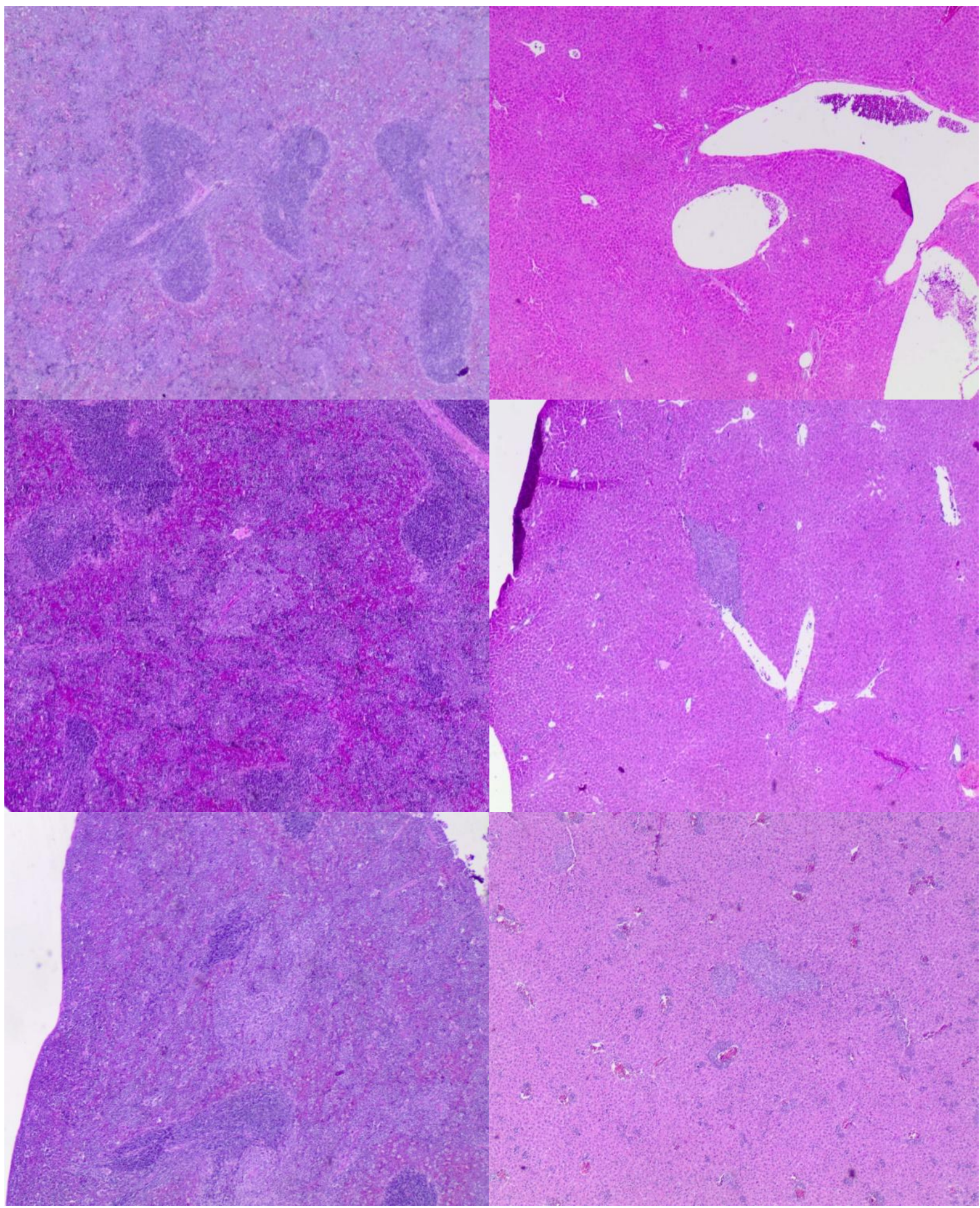

Figura 52. Prancha histológica retratando o baço e o fígado. Os grupos CONTROLE NEGATIVO, POSITIVO, E SISTÊMICO, apresentam aspectos habituais dos tecidos. No grupo LED, NE-ALCLFT, SISTEMICO-LOCAL e LOCAL apresentam focos neoplásicos. Todas fotomicrografias foram registradas em objetiva de 40x. Coloração por H\&E. 
CÉREBRO

CONTROL -

CONTROL +

LED

NE-ALCLFT
CORAÇÃO
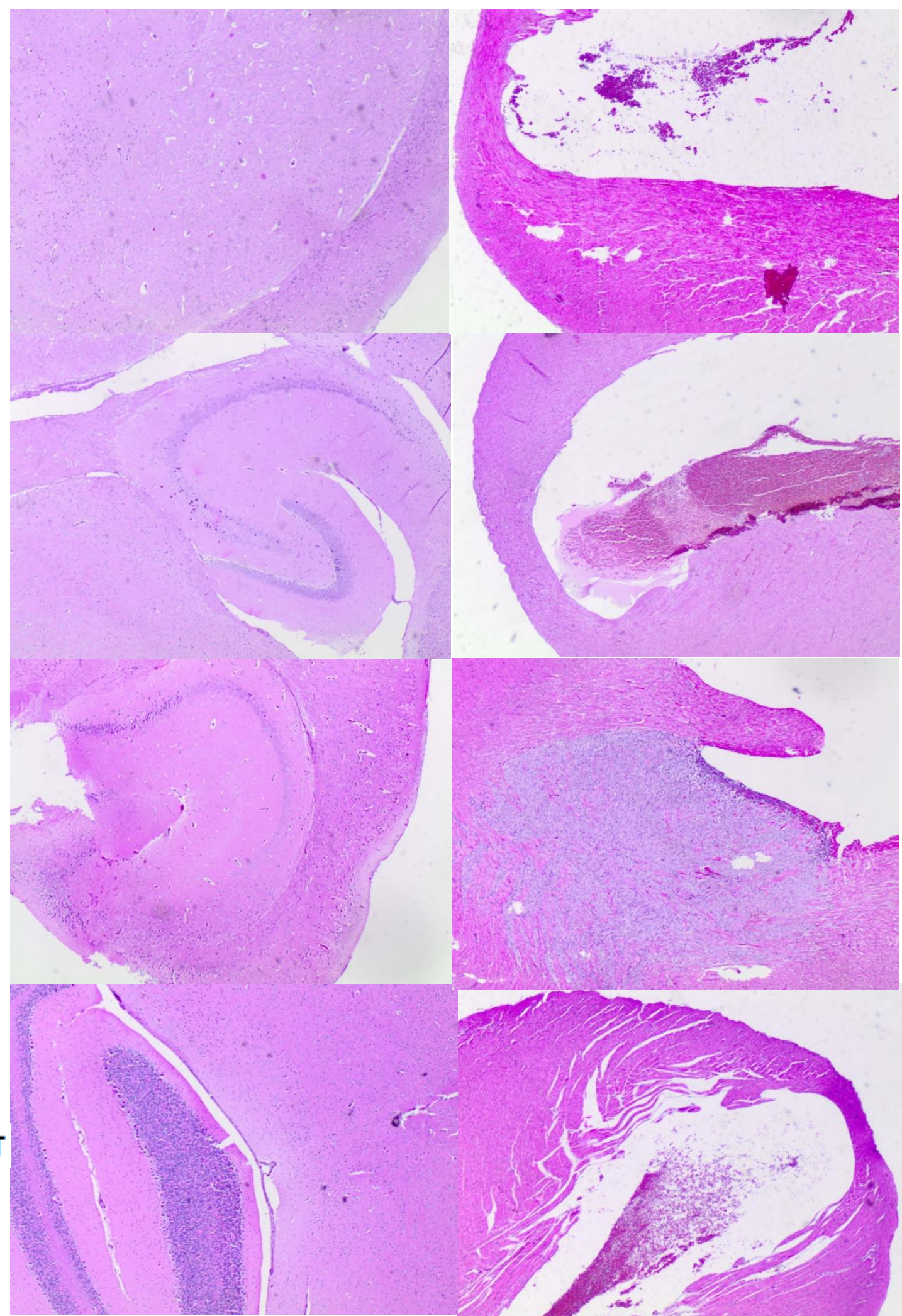


\section{CÉREBRO} CORAÇÃO

SISTÊMICO

SIST-LOC

LOCAL

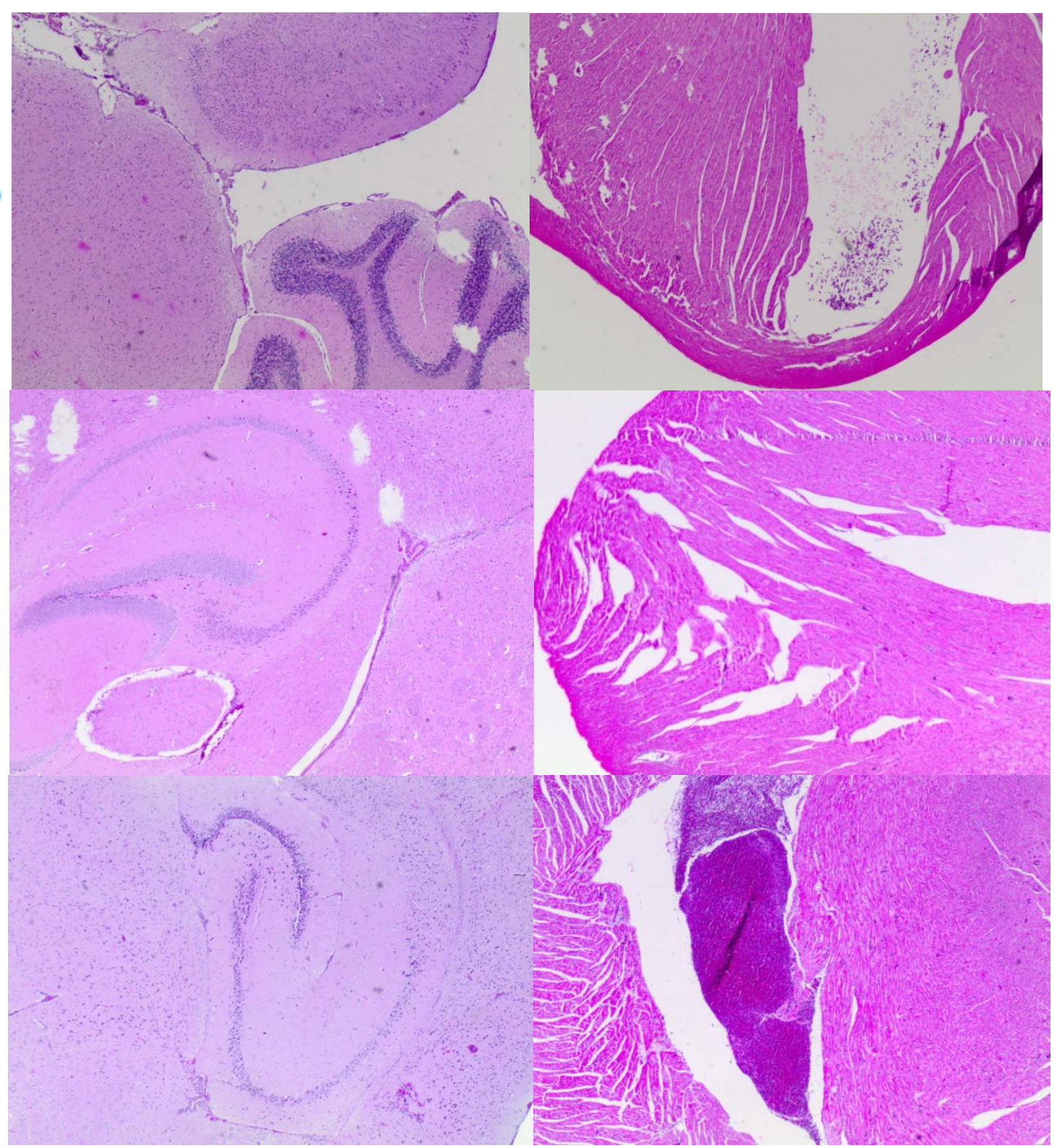

Figura 53. Prancha histológica retratando o cérebro e o coração. Em todos os grupos o cérebro retrata aspectos habituais do tecido. Já o coração, apresenta focos neoplásicos no grupo LED e trombos no grupo LOCAL, apresentando estruturas habituais nos demais grupos. Todas fotomicrografias foram registradas em objetiva de 40x. Coloração por H\&E. 


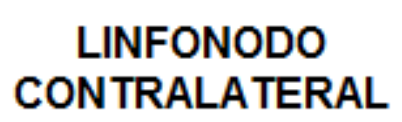

LINFONODO

SENTINELA

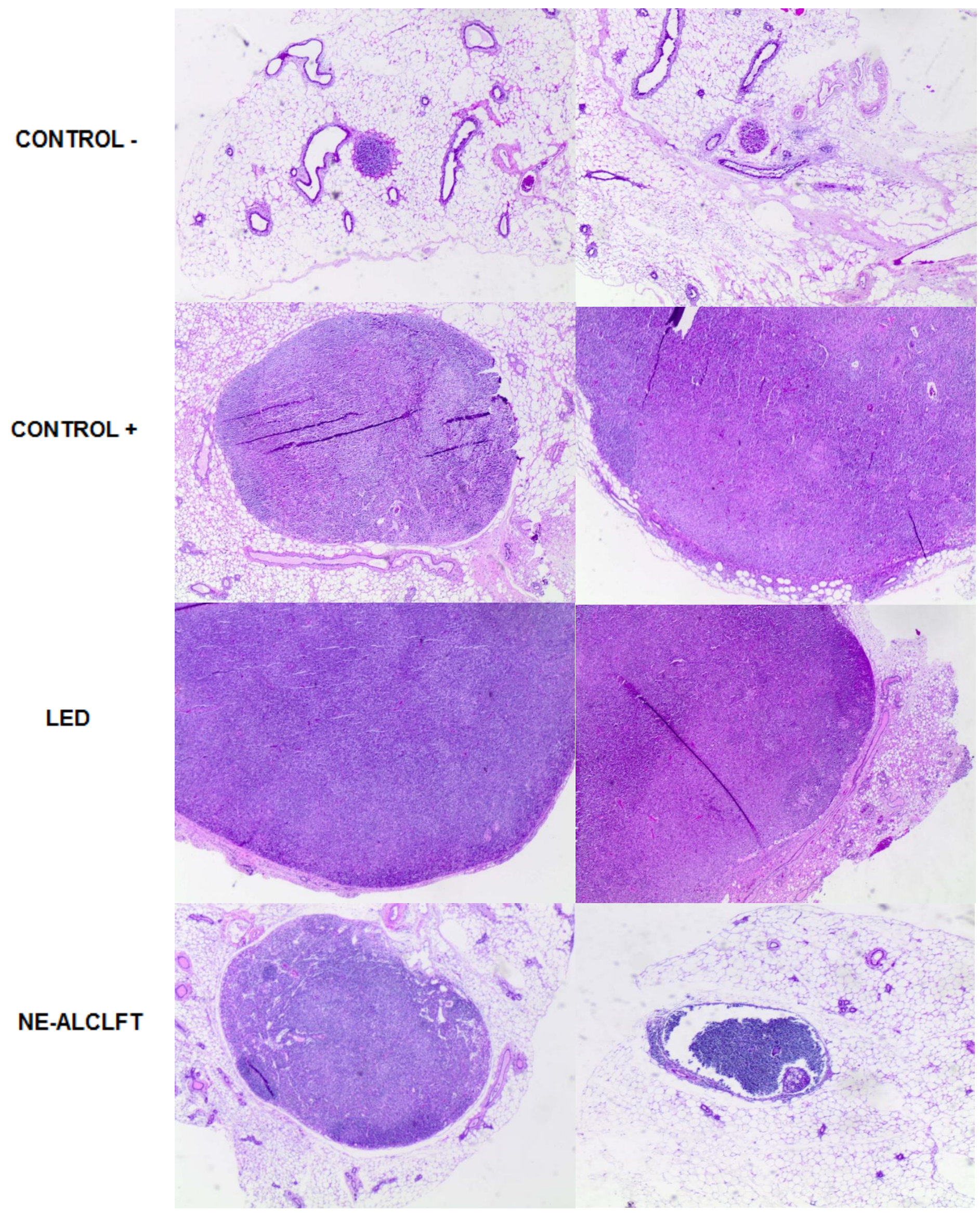




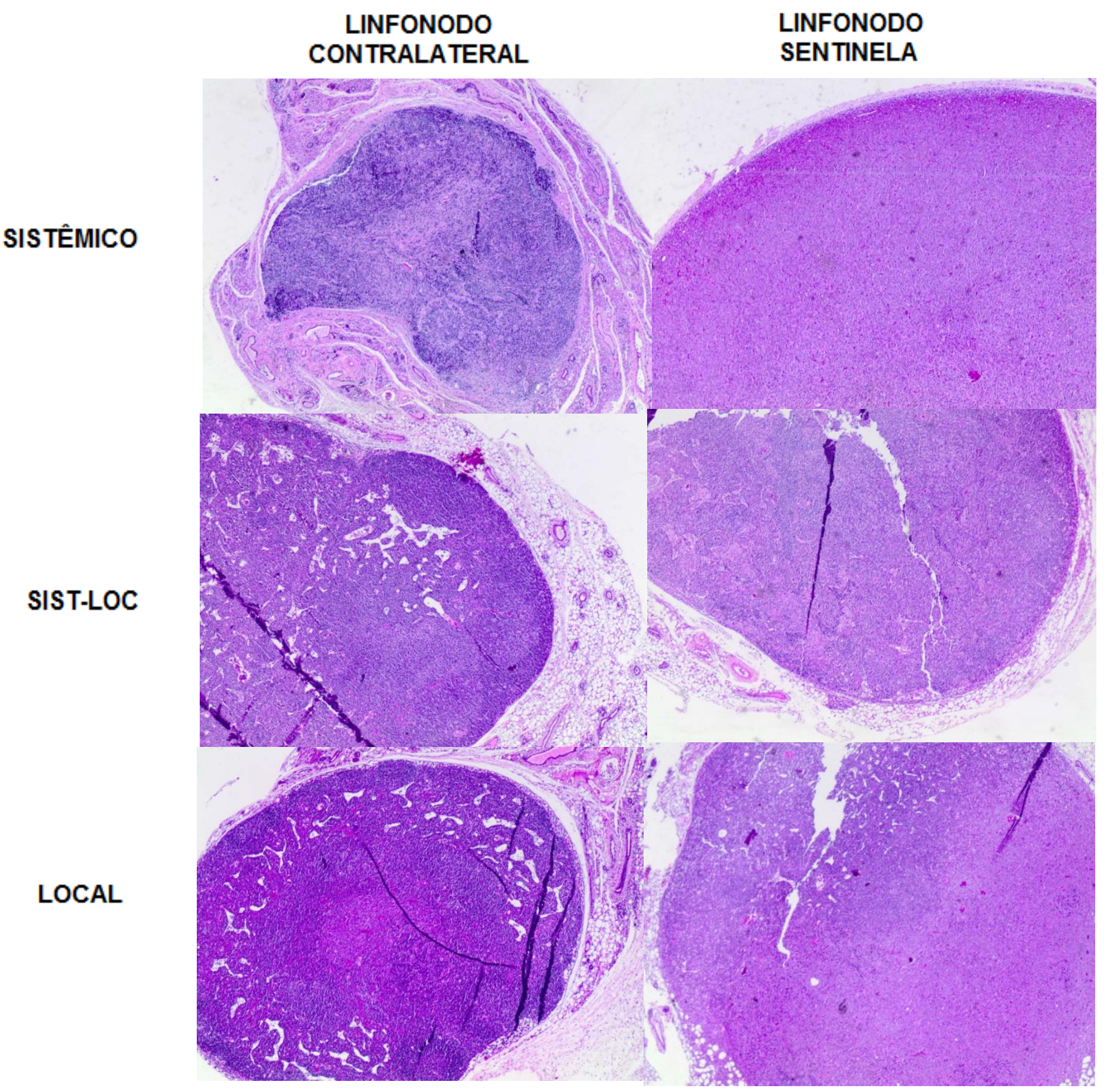

Figura 54. Prancha histológica retratando o linfonodo contralateral e o linfonodo sentinela. Nos grupos do CONTROLE NEGATIVO, POSITIVO, LED, NE-ALCLFT, SISTÊMICO e SISTÊMICO LOCAL, está mostrando tecidos habituais deste órgão, já o grupo LOCAL, apresenta focos neoplásicos. Quanto ao linfonodo sentinela, tem aspectos neoplásicos nos grupos POSITIVO, LED, LOCAL e SISTÊMICO, tendo aspectos habituais nos demais grupos. Todas fotomicrografias foram registradas em objetiva de 40x. Coloração por H\&E. 
MAMA

CONTRALATERAL

REGIÃO TUMORAL

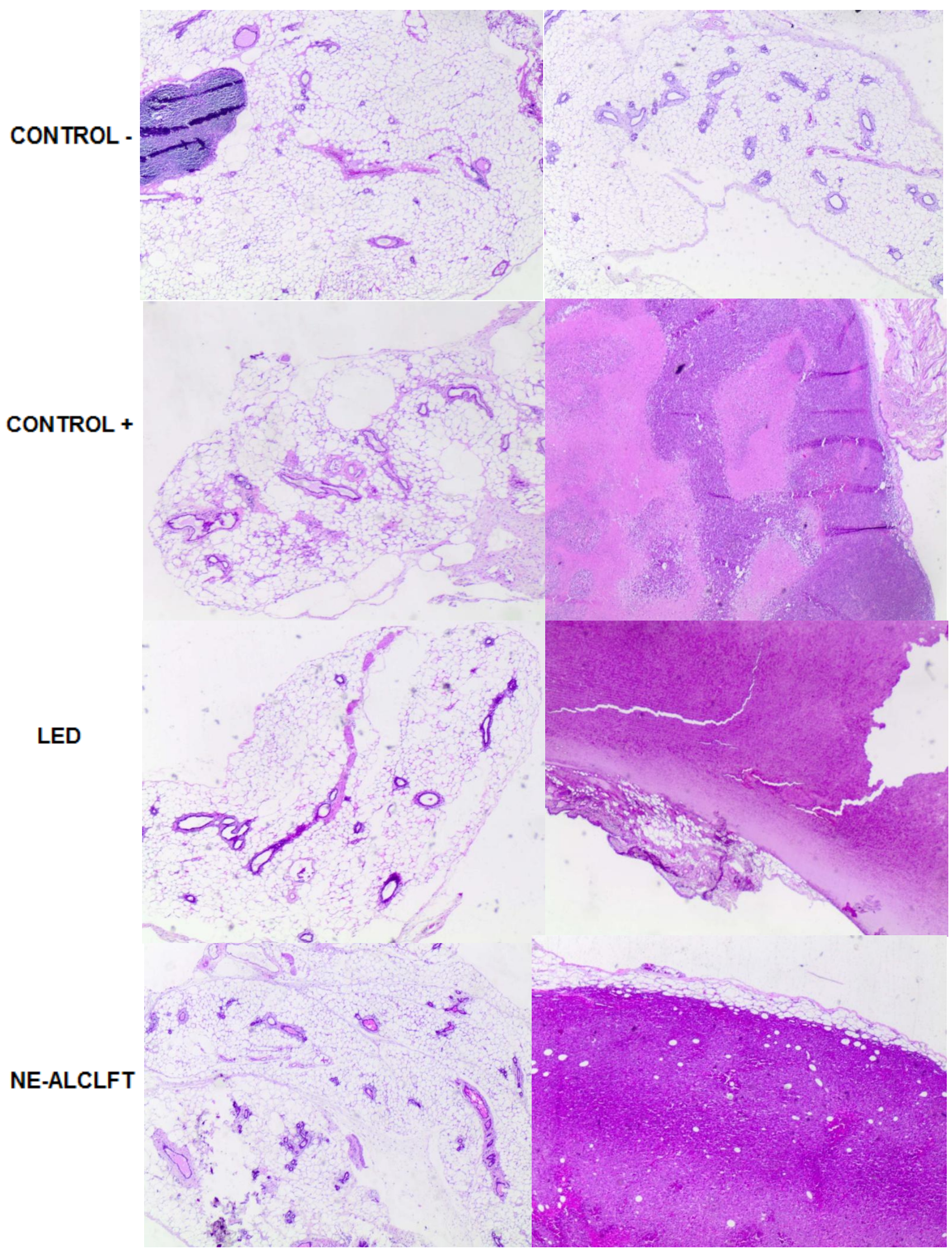




\section{MAMA \\ CONTRALATERAL \\ REGIÃO TUMORAL}

SISTÊMICO

SIST-LOC

LOCAL

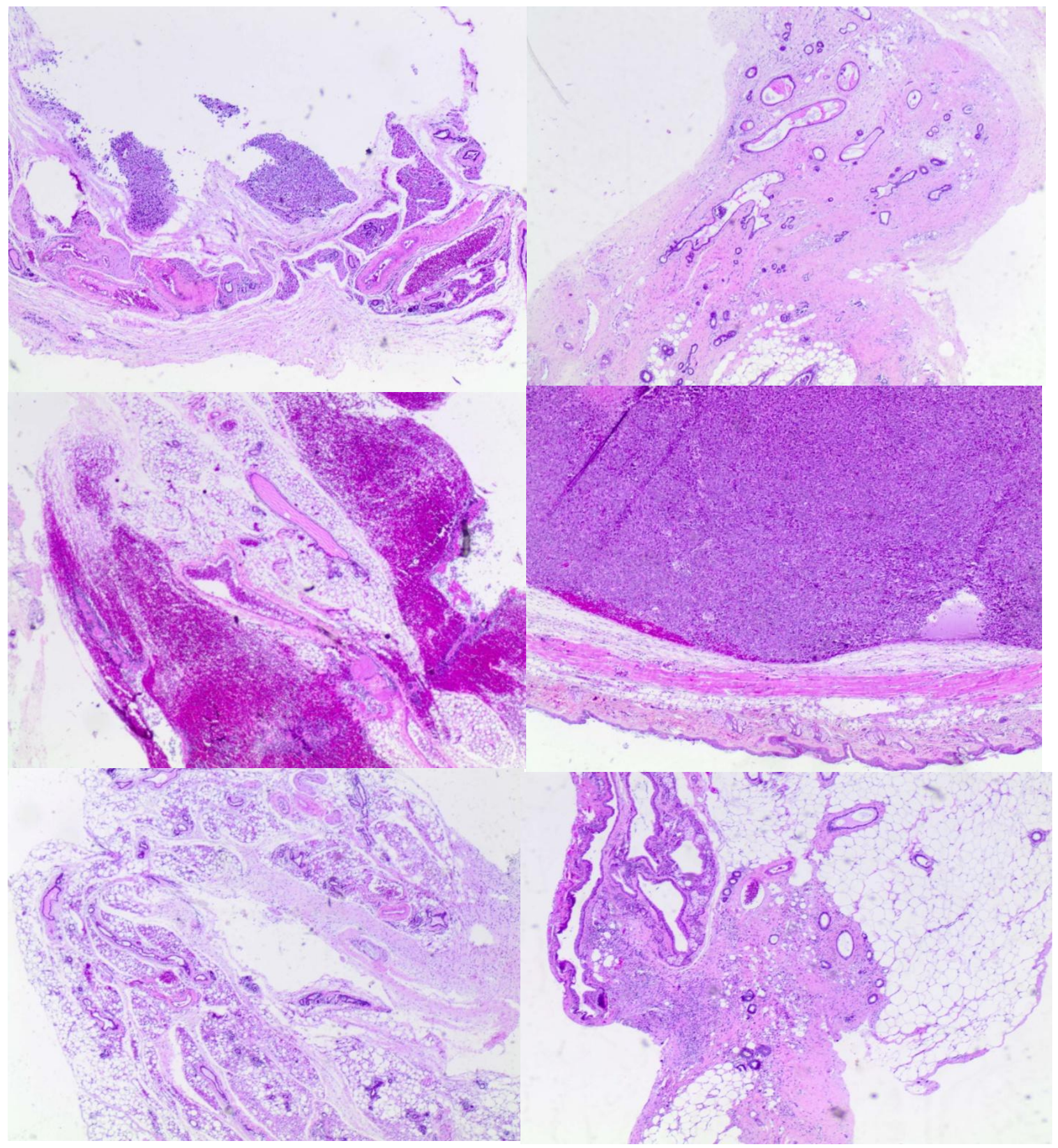

Figura 55. Prancha histológica retratando a mama contralateral e a região tumoral. Em todas as regiões tumorais de todos os grupos, com exceção do CONTROLE NEGATIVO e DO SISTÊMICO-LOCAL, apresentam áreas neoplásicas. O controle negativo mostra aspecto habituais do tecido. O grupo SISTÊMICO-LOCAL, apresenta áreas com fibrose. Já a mama contralateral, apresenta tecidos normais no grupo CONTROLE NEGATIVO, POSITIVO, LED, NE-ALCLFT, enquanto que no grupo LOCAL, apresenta uma área acentuada de infiltrado inflamatório, e no grupo SISTÊMICO, apresenta focos neoplásicos. No grupo SISTÊMICO-LOCAL, evidencia uma região hemorrágica. Todas fotomicrografias foram registradas em objetiva de 40x. Coloração por H\&E. 
CONTROL -

CONTROL +

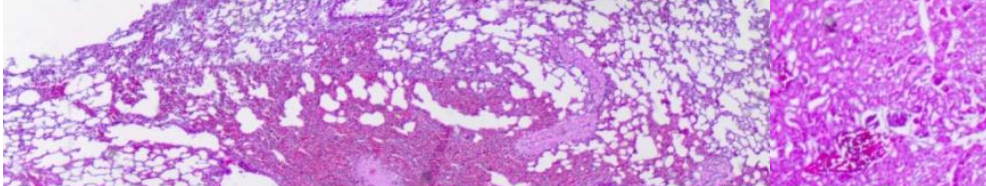

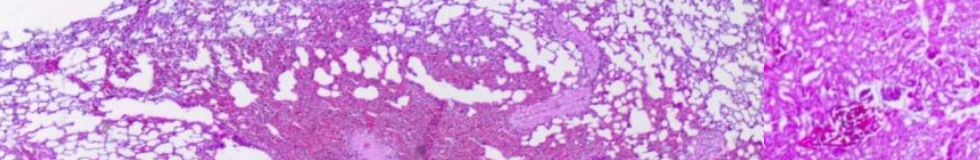
Co 5 ,
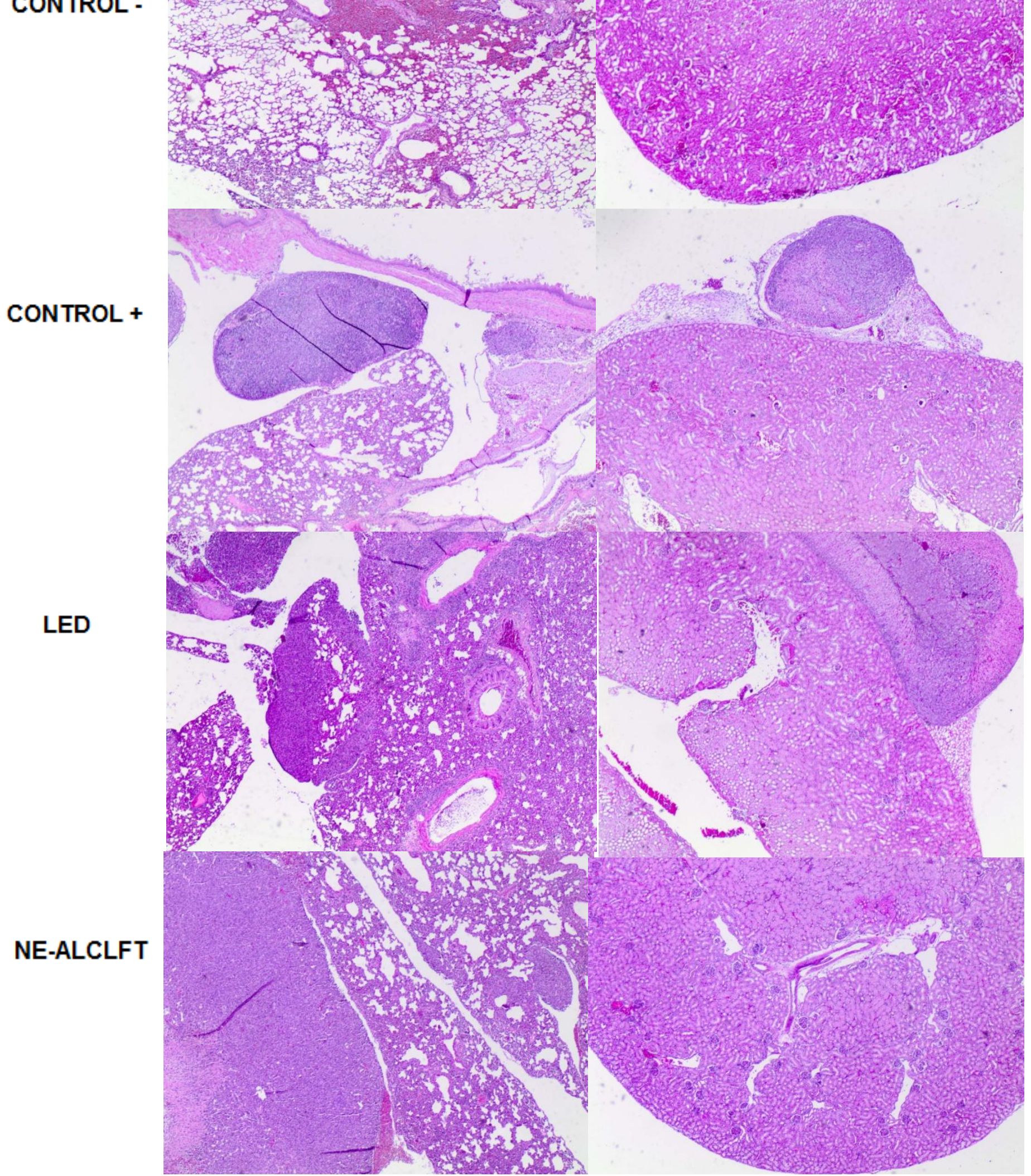


\section{PULMÃO}

\section{SISTÊMICO}

SIST-LOC

LOCAL

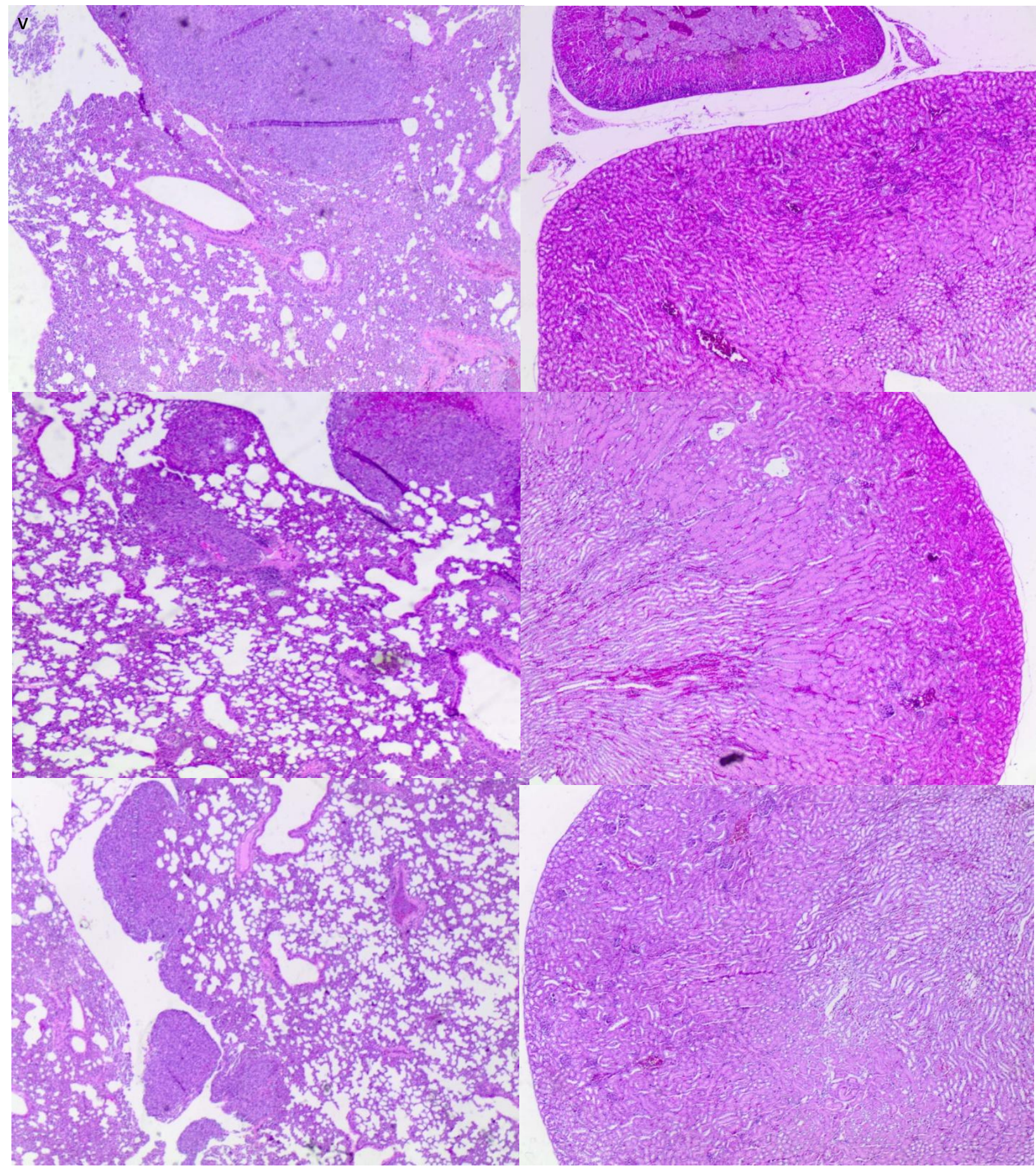

Figura 56. Prancha histológica retratando o pulmão e os rins. Em todos os grupos, houve focos de células neoplásicas no pulmão em pelo menos um dos animais de cada grupo, com exceção do grupo CONTROLE NEGATIVO. Quanto às análises histológicas dos rins, há a presença de células neoplásicas no grupo CONTROLE POSITIVO, apresentando aspectos normais para os demais grupos. Todas fotomicrografias foram registradas em objetiva de 40x. Coloração por H\&E. 
DISCUSSÕES 
Com o avanço do uso da terapia fotodinâmica (TFD) com a combinação da nanobiotecnologia no tratamento de modelos tumorais, novas formas de terapias tem sido alvo de pesquisas científicas. Assim, neste trabalho, foi realizado o estudo de duas nanoemulsões e uma micela com a aplicação da Terapia Fotodinâmica para o tratamento do câncer de mama.

As nanoemulsões são um sistema de partículas coloidais na gama de tamanhos na nanoescala, que podem ser usadas como veículos de moléculas de fármaco (Jaiswal; DudheSharma, 2014). Segundo Gasto e colaboradores (1991), os principais componentes das nanoemulsões é a presença de óleo, agentes emulsificantes e uma fase aquosa, os quais foram utilizados nesteestudo, o óleo de rícino, o cremophor e o tampão de PBS como sendo a fase aquosa. Uma mistura de óleo e água pode produzir uma emulsão temporária bruta, a qual se separará em duas fases distintas devido à coalescência dos glóbulos dispersos (Jaiswal; DudheSharma, 2014). Agentes emulsificantes, amplamente classificados como tensoativos, podem conferir estabilidade a tais sistemas (Jaiswal; DudheSharma, 2014), como o caso do Cremophor.

Estes transportadores podem ser esféricas e a sua superfície é amorfa e lipofílica com uma carga negativa, e o seu tamanho pode variar de 10 a $1.000 \mathrm{~nm}$ (Jaiswal; DudheSharma, 2014). Estas características puderam ser observadas nas nanoemulsões sintetizadas neste trabalho, visto que as nanoemulsões de ftalocianina de cloro alumínio (NE-ALCLFT) apresentaram tamanho hidrodinâmico de 36nm, com carga superficial de $-3,133 m V$ (Tabela 5), enquanto que a nanoemulsão com ácido fólico contendo a ftalocianina de cloro alumínio (NE-ALCLFT-FO), apresentou diâmetro hidrodinâmico de $65,63 \mathrm{~nm}$ e carga superficial de $-2,14 \mathrm{mV}$ (Tabela 6), ambas tendo populações monodispersas (PDI com índice em média de 0,2), morfologia esférica (Figura 19, 20) e estrutura sólida. Tais caracterizações, também puderam ser observadas no trabalho de Muehlmann e colaboradores (2015), o qual utilizou NE-ALCLFT, para a avaliação in vitro de células de adenocarcionama mamário com a aplicação da TFD.

Propriedades fotofísicas e fotoquímicas, como a geração e a vida útil de oxigênio singleto e triplete, o rendimento quântico de oxigênio $(\Phi \Delta)$, o rendimentos quânticos de fluorescência ( $\Phi$ f), são parâmetros que interferem diretamente na eficiência da Terapia Fotodinâmica. No caso da ftalocianina de cloro-alumínio, De Paula e colaboradores (2013), mostram que a propriedade fotoquímica deste 
fotossensibilizador pode ser aumentada quando nanoencapsulado, tendo o tempo de vida útil da geração de ROS, prolongado.

Outra nanoformulação que apresenta uma plataforma versátil na nanomedicina são as micelas, as quais são constituídas de polímero, apresentando a biodistribuição dos fármacos melhorados e também, a resposta para o tratamento do câncer (Sutton et al., 2007). A estrutura núcleo-casca das micelas proporciona várias vantagens para aplicações de administração de fármacos. Primeiramente, o encapsulamento de fármacos dentro do núcleo da micela permite a solubilização de fármacos pouco solúveis em água (Sutton et al., 2007), como o caso dos fotossensibilizadores ftalocianinas, no caso a utilizado, a ftalocianina de cloro-alumínio (ALCLFT).

A micela de ácido fólico com ALCLFT (MIC-FO-ALCLFT) sintetizada, apresentou propriedades coloidais tais como, tamanho hidrodinâmico de 164,4nm, carga superficial negativa de $-0,184 \mathrm{mV}$, e índice populacional polidisperso de 0,3 (Tabela 7). Em teoria as micelas possuem uma elevada estabilidade tanto in vitro como in vivo e uma boa biocompatibilidade (Mahmud et al., 2017). Estas características puderam ser corroboradas nos ensaios de estabilidade, realizado neste trabalho.

A utilização do composto ácido fólico para a síntese da NE-ALCLFT-FO e da MIC-FO-ALCLFT, foi feita com base em estudos que utilizam este composto como ligante funcional de direcionamento (Dixit et al., 2006; LuLow, 2012; Chauhan et al., 2017 ). O ácido fólico tem sido ligado tanto a fármacos de baixo peso molecular como a complexos macromoleculares como meio de direcionar as moléculas ligadas a células malignas. O estudo de Yoo e Park (2004), e Park e colaboradores (2005) verificaram que a conjugação de ácido fólico com macromoléculas aumenta a sua distribuição para células tumorais que expressam receptores de folato in vitro em quase todas as situações testadas, como ocorre em cânceres de mama.

Além disso, a densidade do receptor de folato parece aumentar à medida que o estágio / grau do câncer piora. Em tese, os cânceres que são mais difíceis de tratar pelos métodos clássicos, poderiam ser mais facilmente direcionados para terapêuticas ligadas ao folato.

No entanto, neste trabalho, a presença do ácido fólico nas nanoemulsões e na micela, não apresentou diferenças significativas na internalização das nanoformulações, conforme nos testes de incorporação das nanoformulações (Figura 26), e nos estudo da biodistribuição in vivo. Este fator pode ser discutido conforme os estudos de Lu e Low 
(2012), os quais ressaltam à respeito da quantidade de receptores expressos em diferentes tipos de neoplasias, e a limitação desta funcionalização, devido a baixa penetração em tumores sólidos. Mais estudos de internalização e da presença de receptores das linhagens utilizadas, devem ser feitos para o entendimento destes fatores.

Os ensaios in vitro, mostraram a atividade citotóxica nas células tanto de adenocarcinoma mamário (4T1), como de fibroblastos (NIH/3T3). Tais efeitos são provenientes da aplicação da terapia fotodinâmica, com a consequente produção de espécies reativas de oxigênio (ROS) na ativação do fotossensibilizador. Excessivas concentrações de ROS podem danificar lipídios, proteínas e DNA, bem como causar disfunção mitocondrial, desregular o balanço iônico, e causar perda de integridade da membrana (Khaitlina, 2001; Wang et al, 2015).

Além disso, os ensaios mostraram que os tratamentos apresentam eficiência com dependência de luz-dose, onde quanto maior a potência utilizada, menor a viabilidade das células, principalmente às de linhagens tumorais. Este mesmo aspecto foi observado no trabalho de Wang e colaboradores (2015), onde avaliaram os efeitos da terapia fotodinâmica no câncer de mama, com linhagens 4T1.

O estudo da biodistribuição das nanoformulações, in vivo, mostrou que embora haja a acumulação passiva dentro de tumores com alta vascularização, a maioria das nanopartículas ainda são absorvidas pelo sistema reticulo endotelial (sistema mononuclear fagocitário), resultando meias-vidas curtas e deposição indesejada de micelas em órgãos como fígado e baço, conforme já descrito na literatura.

Wilhelm e colaboradores (2016) reuniram informações importantes dos últimos 10 anos, mostrando que apenas $0,7 \%$ (mediana) da dose de nanopartículas administrada são encontradas nos tumores sólidos. Eles ressaltam que o fígado é o órgão primário do sistema fagocitário mononuclear que aprisiona a maioria da dose de nanopartículas. Este conceito pode ser uma das explicações, para podermos ter quantificado a maior concentração da NE-ALCLFT, no fígado. Além disso, outros órgãos importantes que estão envolvidos na remoção de nanopartículas da corrente sanguínea incluem o baço, os gânglios linfáticos e a pele, os quais também foram órgãos que obtiveram taxas da nanoemulsão. Portanto, é importante o estudo de estratégias que visam solucionar este problema.

Por isso, neste trabalho, utilizou-se do estudo da biodistribuição da NEALCLFT, como estratégia para diminuir os efeitos tóxicos na aplicação da TFD. 
Sabendo que da possibilidade da nanopartícula ser acumulada em outros órgãos, foi de suma importância analisar a biodistribuição da mesma, e também averiguar em qual seria o tempo ideal para a aplicação da terapia fotodinâmica, de forma a utilizar as melhores condições fisiológicas, onde a nanoestrutura se concentrasse em maior porção no tumor, e em menor concentração nos demais órgãos.

Este fator foi crucial para o sucesso da terapia, visto que possibilitou a diminuição da toxicidade dos tratamentos com a aplicação da TFD, e também possíveis focos inflamatórios que poderiam ser ocasionadas caso houvesse grande quantidade de NE-ALCLFT em outras partes do organismo, devido ao fato, das terapias serem realizadas de forma sistêmica. Também para diminuir tais inconvenientes, as sessões de TFD foram realizadas em intervalos maiores de tempo (entre 3 a 4 dias), para que o organismo pudesse se restabelecer, de possíveis danos adversos causados pela TFD sistêmica.

Um fato relevante a se observar no estudo da biodistribuição foi o fato que no decorrer das análises de tempo, a nanoemulsão permaneceu constante na região do tumor, enquanto que nos outros órgãos a sua taxa foi alterada. Isto mostra o efeito de permeabilidade e retenção (EPR) característico das nanopartículas, devido à morfologia da capilaridade nos vasos sanguíneos do tumor.

Outro fator importante a se considerar, é a relação dos tamanhos das nanopartículas com a biostribuição no organismo. Blanco e colaboradores (2015), mostraram em seu estudo esta relação, e ressaltam que grandes partículas com diâmetros > $2.000 \mathrm{~nm}$ se acumulam prontamente dentro do baço e do fígado, bem como nos capilares dos pulmões. Nanopartículas na faixa de 100-200 nm têm se mostrado extravasadas através de fenestrações vasculares de tumores (efeito EPR) e são filtradas pelo fígado e baço, conforme foi analisado pelo estudo da nanoformulação MIC-FOALCLFT. À medida que o tamanho aumenta além de $150 \mathrm{~nm}$, mais e mais nanopartículas são aprisionadas dentro do fígado e do baço. Já as pequenas nanopartículas $(<5 \mathrm{~nm})$ são filtradas pelos rins, como mostra esquematizado na Figura 56. 

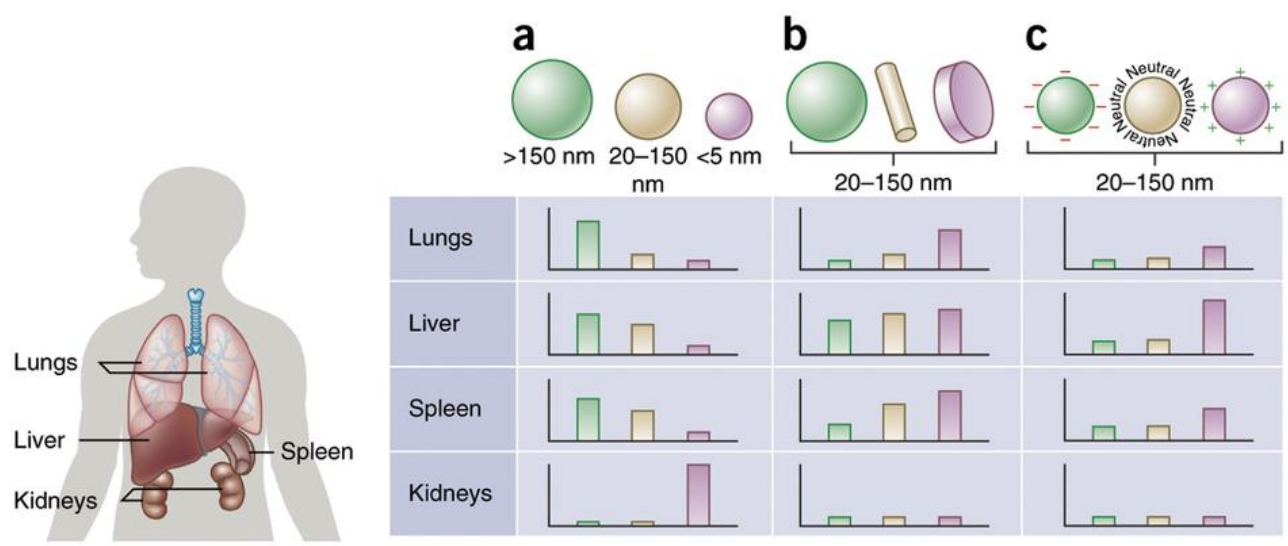

Figura 57. Biodistribuição de nanopartículas de acordo com o seu tamanho.

Fonte: Blanco et al., 2015.

Com relação às análises dos tratamentos realizados, estes visaram analisar os seguintes fatores: a forma de administração dos fármacos (endovenosa e intratumoral) e o modo de irradiação do LED para a realização da TFD (sistêmico, de forma a atingir o corpo todo do animal, e local). Neste aspecto, pôde-se observar que a melhor forma de tratamento, foi quando utilizado a via de administração endovenosa, com a aplicação do LED no local do tumor, mostrando nas condições em que os tratamento foram realizados, a forma de administração endovenosa foi mais eficiente comparada a via de administração intratumoral. Esta resposta contradiz outros estudos (Foster et al., 2010; Hebeda et al., 1998; Zheng et al., 2012), que utilizaram fotossensibilizadores e a aplicação da TFD, e que compararam as vias endovenosa e intratumoral, onde concluíram que devido a maior concentração do fármaco na região do tumor (pela via intratumoral), melhor a eficiência do tratamento tumoral. No entanto, nós colocamos em tese que o fato do estudo da biodistribuição ter sido feito previamente, possibilitou as condições favoráveis para o acúmulo da nanopartícula no tumor. Além disso, o tratamento do tumor primário com a TFD pode ter possibilitado a erradicação de células metastáticas, conforme um estudo realizado por Longo e colaboradores (2016).

No entanto, o tratamento sistêmico (endovenso e irradiação do LED no corpo inteiro do animal), ocasionou alta toxicidade no organismo dos camundongos, com focos inflamatórios nos órgãos dos animais (confirmados nos dados histopatológicos), e a morte de dois camundongos $(n=5)$ durante o tratamento. No entanto, nos demais animais deste grupo foi observado a regressão do volume tumoral. Portanto, novos testes podem ser feitos a fim de analisar a concentração utilizada da NE-ALCLFT, para que se possa ter melhores resultados. 
Além deste tratamento, o resultado do grupo com tratamento intratumoral e irradiação do LED de forma sistêmica, não foi o suficiente para erradicar as células neoplásicas. Este dado pode ser explicado devido o fato das células utilizadas, 4T1, ser de uma linhagem altamente metastática, e por isso seria necessário de tratamentos mais invasivos. Uma forma que poderia melhorar a eficiência deste tratamento, seria diminuir os intervalos de tempo entre as sessões de aplicação da TFD, visto que nestas circunstâncias o tratamento em si é mesmos invasivo.

Muitos focos inflamatórios foram observados pela histopatologia no local da aplicação da TFD. Estes fatores podem ser relacionado, devido a ligação entre a terapia fotodinâmica e o sistema imunológico. Um dos fatores importantes relacionados às análises do tratamento com a aplicação da TFD resulta na resposta inflamatória aguda mediada por neutrófilos, macrófagos e outros componentes celulares, que migram para o local do tumor tratado (Anzengruber et al., 2015). Estudos, como de Banerjee e colaboradores (2017), apontam que a populações de neutrófilos são os primeiro a aumentar, e isto é facilitado pela presença do TNF-alfa (Banerjee et al., 2017; Peng, 2011). Embora os neutrófilos sejam os primeiros a aumentar em migração em resposta à TFD, os macrófagos também têm papel na potenciação dos efeitos mediados pelo sistema imunológico (Banerjee et al., 2017). Assim, seria interessante um estudo complementar relacionado a resposta destes tratamentos, com a avaliação do sistema imunológico na participação da terapia.

Outro dado relevante foi avaliado nos grupos dos animais que recebiam apenas a irradiação do LED, onde se pôde observar o crescimento exponencial do tumor. Estudos, como o de Desmet e colaboradores (2006) apontam uma forma de terapia utilizando a aplicação de luz, comumente referida como "fotobiomodulação", onde é utilizado o comprimento de onda de luz no infravermelho próximo do espectro (630$1000 \mathrm{~nm}$ ) o qual modula numerosas funções celulares, incluindo a aceleração da cicatrização de feridas, recuperação melhorada da lesão isquêmica do coração e atenuação da degeneração dos nervos ópticos lesados, melhorando o metabolismo e a produção de energia mitocondrial, resultando no aumento e produção do metabolismo energético (Desmet et al., 2006). A hipótese é que a irradiação do LED nas células tumorais tenha efeito proliferativo devido o estímulo e modulação fisiológica nas células tumorais. No entanto, avaliações moleculares devem ser analisadas a fim de ter a melhor compreensão deste evento. 
Em suma, pôde-se observar pelas análises clínicas dos exames realizados, que os tratamentos com a aplicação da terapia fotodinâmica, não causaram alterações bioquímicas e hematológicas nos camundongos em longo prazo (após 10 dias decorridos dos tratamentos), mesmo os tratamentos sendo feitos de forma sistêmica.

Portanto, os dados apresentados, ressaltam que o tratamento utilizando a terapia fotodinâmica com a nanoemulsão de ftalocianina de cloro alumínio, possibilitou a regressão neoplásica, sendo uma nova forma para o tratamento de câncer de mama. 
CONCLUSÕES 
Neste trabalho foi possível realizar o estudo de três nanoformulações, sendo elas: Nanoemulsão de Ftalocianina de Cloro-Alumínio, Nanoemulsão com Ácido Fólico contendo Ftalocianina de Cloro-Alumínio e a Micela de Ácido Fólico contendo a Ftalocianina de Cloro-Alumínio. A caracterização, mostrou que essas formulações apresentam diâmetro hidrodinâmico de 35nm, 64nm e 164nm, respectivamente, com carga superficial levemente negativas e populações monodispersas. Além disso, todas as nanoformulações apresentaram estabilidade durante o período analisado de 300 dias, morfologias esféricas, além de possuírem propriedades fotofísicas e fotoquímicas intrínsecas a sua composição, tendo seus comprimentos de onda de excitação e emissão no infravermelho.

Os ensaios in vitro, mostraram que as nanoformulações estudadas neste projeto, apresentaram período suficiente de incubação de 15 minutos, para a realização da Terapia Fotodinâmica (TFD). Além disso, todas apresentaram citotoxicidade nas células de carcinoma adenocarcinoma mamário mamário (4T1) e fibroblastos (NIH/3T3).

Das avaliações de potências utilizadas $\left(10 \mathrm{~mW} / \mathrm{cm}^{2}, 50 \mathrm{~mW} / \mathrm{cm}^{2}\right.$ e $\left.100 \mathrm{~mW} / \mathrm{cm}^{2}\right)$, tem-se que a potência que mais causou diminuição da viabilidade nas células, foi a de $50 \mathrm{~mW} / \mathrm{cm}^{2}$. Outro fator relevante, é que o uso apenas do LED, pode provocar o aumento de células da linhagem fibroblasto.

A análise morfológica das células após os tratamentos com TFD, evidenciam morte celular, com formação de vacúolos, deformações citoplasmáticas, perda de aderência no substrato e perda na matriz.

Os ensaios in vivo relacionados à biodistribuição apontam que os principais órgãos que acumulam as nanoformulações, são o fígado, pulmão, rins e lifonodo sentinela. Além disso, com a realização das análises em tempo real das imagens de florescência, pôde-se concluir que o tempo ideal para a aplicação da TFD, é após 6 horas decorridos da administração endovenosa.

A formulação que apresentou melhor biodistribuição, se concentrando na região do tumor, foi a NE-ALCLFT e a NE-ALCLFT-FO, as quais apresentaram aspectos semelhantes na sua biodistribuição. Para os tratamentos neste trabalho, foram então escolhidas a formulação NE-ALCLFT.

Por fim, os tratamentos in vivo com o uso da TFD, apontam efeitos de necrose tumoral e infiltrados inflamatórios. Além disso, foi possível concluir que a melhor forma de tratamento, dentre as analisadas, foi utilizar a nanoformulação por 
administração endovenosa, e a irradiação do LED no local da região do tumor, onde apresentou $80 \%$ de eficiência do tratamento, com 4 camundongos apresentando todos tecidos normais $(\mathrm{n}=5)$.

Portanto, com este trabalho, foi possível desenvolver um método eficiente para o tratamento do câncer de mama em camundongos Balb/c, utilizando a TFD com uma nanoemulsão de ftalocianina de cloro alumínio, por administração endovenosa. 


\section{REFERÊNCIAS BIBLIOGRÁFICAS}


Agostinis, P. et al. Photodynamic therapy of cancer: An update. CA: A Cancer Journal for Clinicians, v. 61, n. 4, p. 250-281, 2011.

Anzengruber, F. et al. T-cell mediated anti-tumor immunity after photodynamic therapy: why does it not always work and how can we improve it?. Photochem. Photobiol. Sci., v. 14, n. 8, p. 1492-1509, 2015.

Belicha-Villanueva, A. et al. The effect of photodynamic therapy on tumor cell expression of major histocompatibility complex (MHC) class I and MHC class I-related molecules. Lasers Surg. Med., v. 44, n. 1, p. 60-68, 2012.

Bicalho, L. et al. Photodynamic Therapy Leads to Complete Remission of Tongue Tumors and Inhibits Metastases to Regional Lymph Nodes. Journal of Biomedical Nanotechnology, v. 9, n. 5, p. 811-818, 2013.

Blanco, E.; Shen, H.; Ferrari, M. Principles of nanoparticle design for overcoming biological barriers to drug delivery. Nature Biotechnology, v. 33, n. 9, p. 941-951, 2015.

Castano, A.; Mroz, P.; Hamblin, M. Photodynamic therapy and anti-tumour immunity. Nature Reviews Cancer, v. 6, n. 7, p. 535-545, 2006.

Chauhan, G. et al. "Gold nanoparticles composite-folic acid conjugated graphene oxide nanohybrids" for targeted chemo-thermal cancer ablation: In vitro screening and in vivo studies. European Journal of Pharmaceutical Sciences, v. 96, p. 351-361, 2017.

Chiyin Ma, B. Eficácia do Alumínio-Cloro Ftalocianina associado à nanopartículas de Poli (Vinil Metil-Co-Anidrido Maleico) na terapia fotodinâmica contra células tumorais in vitro. Mestre. Universidade de Brasília, 2012.

Christiansen, A.; Detmar, M. Lymphangiogenesis and Cancer. Genes \& Cancer, v. 2, n. 12, p. 1146-1158, 2011.

Desmet, K. et al. Clinical and Experimental Applications of NIR-LED Photobiomodulation. Photomedicine and Laser Surgery, v. 24, n. 2, p. 121-128, 2006.]

Dethlefsen, C.; Hojfeldt, G.; Hojman, P. The role of intratumoral and systemic IL-6 in breast cancer. Breast Cancer Res Treat, v. 138, n. 3, p. 657-664, 2013.

Dixit, V. et al. Synthesis and Grafting of Thioctic Acid-PEG-Folate Conjugates onto $\mathrm{Au}$ Nanoparticles for Selective Targeting of Folate Receptor-Positive Tumor Cells. Bioconjugate Chemistry, v. 17, n. 3, p. 603-609, 2006. 
Dolmans, D.; Fukumura, D.; Jain, R. TIMELINE: Photodynamic therapy for cancer. Nature Reviews Cancer, v. 3, n. 5, p. 380-387, 2003.

Dougherty, et al., .Photoradiation therapy for the treatment of malignant tumors. Cancer Res. 38, 2628 (1978).

Dougherty, et al., .Photoradiation therapy II. Cure of animal tumors with hematoporphyrin and light. J. Natl. Cancer Inst. 55, 115 (1975).

Du, W.; Elemento, O. Cancer systems biology: embracing complexity to develop better anticancer therapeutic strategies. Oncogene, v. 34, n. 25, p. 3215-3225, 2014.

Fertig, E. et al.,. Analysis of gene expression of secreted factors associated with breast cancer metastases in breast cancer subtypes. Sci. Rep., v. 5, p. 12133, 2015.

Foster, T. et al. Intratumor Administration of the Photosensitizer Pc 4 Affords Photodynamic Therapy Efficacy and Selectivity at Short Drug-Light Intervals. Translational Oncology, v. 3, n. 2, p. 135-141, 2010.

França Matias, B. Avaliação da resposta imune mediada por macrófagos, células NK e linfócitos $\mathrm{T}$ citotóxicos em pacientes oncológicos submetidos à Imunoterapia com células dendríticas. Mestre. Universidade Federal do Triângulo Mineiro, 2010.

Garg, A.; Agostinis, P. ER stress, autophagy and immunogenic cell death in photodynamic therapy-induced anti-cancer immune responses. Photochem. Photobiol. Sci., v. 13, n. 3, p. 474, 2014.

Grant, W. et al. Photodynamic therapy of oral cancer: photosensitisation with systemic aminolaevulinic acid. The Lancet, v. 342, n. 8864, p. 147-148, 1993.

Guelcher, S.; Sterling, J. Contribution of Bone Tissue Modulus to Breast Cancer Metastasis 32 to Bone. Cancer Microenvironment, v. 4, n. 3, p. 247-259, 2011.

Hanahan, D.. Hallmarks of cancer: applications to cancer medicine?. European Journal of Cancer, v. 50, p. S21, 2014.

Hanahan, D.; Weinberg, R. Hallmarks of Cancer: The Next Generation. Cell, v. 144, n. 5, p. 646-674, 2011.

Hebeda, K. et al. Damage to Tumour and Brain by Interstitial Photodynamic Therapy in the 9L Rat Tumour Model Comparing Intravenous and Intratumoral Administration of the Photosensitiser. Acta Neurochirurgica, v. 140, n. 5, p. 495-501, 1998. 
Hsu SM, Raine L, Fanger H. Use of avidin-biotin-peroxidase complex (ABC) in immunoperoxidase tecchniques. A comparison between $\mathrm{ABC}$ and unlabeled antibody (PAP) procedures. J Histochem Cytochem.29(4):577-88. 1981.

Hunter, K.; Crawford, N.; Alsarraj, J. Mechanisms of metastasis. Breast Cancer Research, v. 10, n. Suppl 1, p. S2, 2008.

INCA. Outubro Rosa. Disponível em: <http://www.inca.gov.br/wcm/outubrorosa/2015/ cancer-de-mama.asp>. Acesso em: 19 dez. 2010.

Jin,; Mu, P. Targeting Breast Cancer Metastasis. BCBCR, p. 23, 2015.

Kalluri, R. Angiogenesis: Basement membranes: structure, assembly and role in tumour angiogenesis. Nature Reviews Cancer, v. 3, n. 6, p. 422-433, 2003.

Khaitlina SY. Functional specificity of actin isoforms. Int Rev Cytol.; 202: 35-98. 2001

Kim, E. et al. Dietary fat increases solid tumor growth and metastasis of 4T1 murine mammary carcinoma cells and mortality in obesity-resistant BALB/c mice. Breast Cancer Research, v. 13, n. 4, p. R78, 2011.

Kitamura, T.; Qian, B.; Pollard, J. Immune cell promotion of metastasis. Nat Rev Immunol, v. 15, n. 2, p. 73-86, 2015.

Koltun, M. et al. Cancer testis antigens: Searching for novel mechanisms of photodynamic therapy-mediated antitumor immune responses. Photodiagnosis and Photodynamic Therapy, v. 11, n. 4, p. 546-548, 2014.

Korbelik, M.; Hamblin, M. The impact of macrophage-cancer cell interaction on the efficacy of photodynamic therapy. Photochem. Photobiol. Sci., v. 14, n. 8, p. 1403 $1409,2015$.

Krieger, N. Breast bruises and breast cancer. Breast Cancer Research, v. 17, n. 1, 2015.

Lapeš, M.; Petera, J.; Jirsa, M. Photodynamic therapy of cutaneous metastases of breast cancer after local application of meso-tetra-(para-sulphophenyl)-porphin (TPPS4). Journal of Photochemistry and Photobiology B: Biology, v. 36, n. 2, p. 205-207, 1996.

Lee, E. et al. Breast cancer cells condition lymphatic endothelial cells within premetastatic niches to promote metastasis. Nature Communications, v. 5, p. 4715, 2014. $\mathrm{Li}$, B. et al. Apoptotic mechanism of MCF-7 breast cells in vivo and in vitro induced by photodynamic therapy with C-phycocyanin. Acta Biochimica et Biophysica Sinica, v. 42, n. 1, p. 80-89, 2009. 
Lizotte, P. et al. In situ vaccination with cowpea mosaic virus nanoparticles suppresses metastatic cancer. Nature Nanotech, v. 11, n. 3, p. 295-303, 2015.

Loiane Vieira Ramos, K. Avaliação da citotoxicidade da terapia fotodinâmica mediada por nanoemulsão à base de óleo de açaí contra câncer de pele não-melanoma. Mestre[s.l.] Universidade de Brasília, 2014.

Lu, Y.Low, P. Folate-mediated delivery of macromolecular anticancer therapeutic agents. Advanced Drug Delivery Reviews, v. 64, p. 342-352, 2012.

Lucky, S.; Soo, K.; Zhang, Y. Nanoparticles in Photodynamic Therapy. Chemical Reviews, v. 115, n. 4, p. 1990-2042, 2015.

Mahmud, A. et al. Polymeric micelles for drug targeting. . Acesso em: 8 fev. 2017.

Marrache, S., Choi, J., Tundup, S., Zaver, D., Harn, D. and Dhar, S.). Immune stimulating 33 Photoactive hybrid nanoparticles for metastatic breast cancer. Integr. Biol., 5(1), pp.215-223, 2013.

Mason, T. et al. Nanoemulsions: formation, structure, and physical properties. Journal of Physics: Condensed Matter, v. 18, n. 41, p. R635-R666, 2006.

Michell, M. Breast cancer. Traducao . Cambridge: Cambridge University Press, 2010.

Muehlmann, L. Aluminum-Phthalocyanine Chloride-Based Photodynamic Therapy Inhibits PI3K/Akt/Mtorpathway In Oral Squamous Cell Carcinoma Cells In Vitro. Chemotherapy, v. 01, n. 05, 2012.

Muehlmann, L. et al. Aluminium-phthalocyanine chloride nanoemulsions for anticancer photodynamic therapy: Development and in vitro activity against monolayers and spheroids of human mammary adenocarcinoma MCF-7 cells. Journal of Nanobiotechnology, v. 13, n. 1, 2015.

Muehlmann, L. et al. Aluminum\&ndash;phthalocyanine chloride associated to poly(methyl vinyl ether-co-maleic anhydride) nanoparticles as a new third-generation photosensitizer for anticancer photodynamic therapy. International Journal of Nanomedicine, p. 1199, 2014.

Muller, A. et al. Involvement of chemokine receptors in breast cancer metastasis. Nature, v. 410, n. 6824, p. 50-56, 2001. 
Oseroff, A. PDT as a Cytotoxic Agent and Biological Response Modifier: Implications for Cancer Prevention and Treatment in Immunosuppressed and Immunocompetent Patients. Journal of Investigative Dermatology, v. 126, n. 3, p. 542-544, 2006.

Park, E. et al. Folate-conjugated methoxy poly(ethylene glycol)/poly(e-caprolactone) amphiphilic block copolymeric micelles for tumor-targeted drug delivery. Journal of Controlled Release, v. 109, n. 1-3, p. 158-168, 2005.

Peng, Q. Apoptotic induction by photodynamic therapy with porphyrin precursors in tumour cells. Photodiagnosis and Photodynamic Therapy, v. 8, n. 2, p. 148, 2011.

Piette, J. Signalling pathway activation by photodynamic therapy: NF-I ${ }^{\circ} \mathrm{B}$ at the crossroad between oncology and immunology. Photochem. Photobiol. Sci., v. 14, n. 8, p. $1510-1517,2015$.

Pizova, K. et al. Photodynamic therapy for enhancing antitumour immunity. Biomed Pap Med Fac Univ Palacky Olomouc Czech Repub., v. 156, n. 2, p. 93-102, 2012.

Portilho, F. et al. Antitumor activity of photodynamic therapy performed with nanospheres containing zinc-phthalocyanine. Journal of Nanobiotechnology, v. 11, n. 1, p. 41, 2013.

Rabb, C., "Uber die wirkung fluoreszirenden stoffe auf infusoria," Z. Biol. 39, 524, 1900.

Reginato, E. et al. Photodynamic therapy plus regulatory T-cell depletion produces immunity against a mouse tumour that expresses a self-antigen. Br J Cancer, v. 109, n. 8, p. 2167-2174, 2013.

Scully, O. et al. Breast Cancer Metastasis. Proteomics, v. 9, n. 5, p. 311-320, 2012.

Silva C. V. Sistema lipossomal de ftalocianina cloro-alumínio, contendo Ácido Fólico, aplicada a Terapia Fotodinâmica. Mestre. Universidade de São Paulo, 2013.

Skobe, M. et al. Induction of tumor lymphangiogenesis by VEGF-C promotes breast cancer metastasis. Nature Medicine, v. 7, n. 2, p. 192-198, 2001. 34

Sutton, D. et al. Functionalized Micellar Systems for Cancer Targeted Drug Delivery. Pharmaceutical Research, v. 24, n. 6, p. 1029-1046, 2007.

Wang, X. et al. Analysis of the In Vivo and In Vitro Effects of Photodynamic Therapy on Breast Cancer by Using a Sensitizer, Sinoporphyrin Sodium. Theranostics, v. 5, n. 7, p. 772-786, 2015. 
Wang, X. et al. Analysis of the In Vivo and In Vitro Effects of Photodynamic Therapy on Breast Cancer by Using a Sensitizer, Sinoporphyrin Sodium. Theranostics, v. 5, n. 7 , p. 772-786, 2015.

Weiss, A. et al. Angiostatic treatment prior to chemo-or- photodynamic therapy improves anti-tumor efficacy. Sci. Rep., v. 5, p. 8990, 2015.

Winslow, S. et al. Prognostic stromal gene signatures in breast cancer. Breast Cancer Research, v. 17, n. 1, p. 23, 2015.

Yoo, H.Park, T. Folate receptor targeted biodegradable polymeric doxorubicin micelles. Journal of Controlled Release, v. 96, n. 2, p. 273-283, 2004.

Yu, M.; Park, J.; Jon, S. Targeting Strategies for Multifunctional Nanoparticles in Cancer Imaging and Therapy. Theranostics, v. 2, n. 1, p. 3-44, 2012.

Zamarran, A. et al. Isolation and characterization of PDT-resistant cancer cells. Photochem. Photobiol. Sci., v. 14, n. 8, p. 1378-1389, 2015.

Zheng, X. et al. Enhanced Tumor Treatment Using Biofunctional Indocyanine GreenContaining Nanostructure by Intratumoral or Intravenous Injection. Molecular Pharmaceutics, v. 9, n. 3, p. 514-522, 2012. 


\section{APÊNCICE 1}

\section{DESCRIÇÃO DETALHADA DOS ACHADOS HISTOPATOLÓGICOS:}

\section{- GRUPO SISTÊMICO (ENDOVENOSO E IRRADIAÇÃO SISTEMICA)}

○ Animal 1

- MA - Mama: carcinoma mamário apresentando:

- Maior eixo: 11,0 mm.

- Tipo histológico: sólido.

- Grau histológico: alto grau.

- Necrose: presente e multifocal, $20 \%$ do tamanho da lesão.

- Infiltração vascular: não evidenciada.

- Infiltração linfática: não evidenciada.

- Infiltração perineural: não evidenciada.

- Infiltrado inflamatório: presente, leve e misto.

- Fibroplasia estromal: não evidenciada.

- PUL - Pulmão: múltiplos focos de metástase de carcinoma mamário.

- LS - Linfonodo sentinela: metástase linfonodal de carcinoma mamário.

- LC - Linfonodo contralateral: aspecto histológico habitual.

- FI - Fígado: aspecto histológico habitual.

- BA - Baço: congestão passiva crônica.

- RI - Rim: aspecto histológico habitual.

- COR - Coração: aspecto histológico habitual.

- CE - Cérebro: hipoxemia neuronal difusa.

- Animal2

- TU - Tumor: foco de leve fibrose estromal.

- MA - Mama: aspecto histológico habitual.

- PUL - Pulmão: aspecto histológico habitual.

- LS - Linfonodo sentinela: aspecto histológico habitual.

- LC - Linfonodo contralateral: aspecto histológico habitual.

- FI - Fígado: aspecto histológico habitual.

- BA - Baço: aspecto histológico habitual.

- RI - Rim: aspecto histológico habitual.

- COR - Coração: aspecto histológico habitual.

- CE - Cérebro: hipoxemia neuronal difusa.

- Animal 3

- TU - Tumor: carcinoma mamário apresentando:

- Maior eixo: 15,0 mm.

- Tipo histológico: sólido.

- Grau histológico: alto grau.

- Necrose: não evidenciada.

- Infiltração vascular: não evidenciada.

- Infiltração linfática: não evidenciada.

- Infiltração perineural: não evidenciada.

- Infiltrado inflamatório: presente, moderado e linfocítico.

- Fibroplasia estromal: presente e leve.

- MA - Mama: aspecto histológico habitual.

- PUL - Pulmão: aspecto histológico habitual.

- LS - Linfonodo sentinela: aspecto histológico habitual.

- LC - Linfonodo contralateral: aspecto histológico habitual.

- FI - Fígado: aspecto histológico habitual.

- BA - Baço: aspecto histológico habitual.

- RI - Rim: aspecto histológico habitual.

- COR - Coração: aspecto histológico habitual.

- CE - Cérebro: hipoxemia neuronal difusa. 


\section{- GRUPO PARCIALMENTE SISTÊMICO (ENDOVENOSO E IRRADIAÇÃO LOCAL)}

- Animal 1

- TU - Tumor: aspecto histológico habitual.

- MA - Mama: aspecto histológico habitual.

- PUL - Pulmão: aspecto histológico habitual.

- LS - Linfonodo sentinela: aspecto histológico habitual.

- LC - Linfonodo contralateral: aspecto histológico habitual.

- FI - Fígado: aspecto histológico habitual.

- BA - Baço: aspecto histológico habitual.

- RI - Rim: aspecto histológico habitual.

- COR - Coração: aspecto histológico habitual.

- CE - Cérebro: hipoxemia neuronal difusa.

- Animal 2

- TU - Tumor: aspecto histológico habitual.

- MA - Mama: aspecto histológico habitual.

- PUL - Pulmão: aspecto histológico habitual.

- LS - Linfonodo sentinela: aspecto histológico habitual.

- LC - Linfonodo contralateral: aspecto histológico habitual.

- FI - Fígado: aspecto histológico habitual.

- BA - Baço: aspecto histológico habitual.

- RI - Rim: aspecto histológico habitual.

- $\mathrm{COR}$ - Coração: aspecto histológico habitual.

- CE - Cérebro: hipoxemia neuronal difusa.

- TU - Tumor: aspecto histológico habitual.

- MA - Mama: aspecto histológico habitual.

- PUL - Pulmão: aspecto histológico habitual.

- LS - Linfonodo sentinela: aspecto histológico habitual.

- LC - Linfonodo contralateral: aspecto histológico habitual.

- FI - Fígado: aspecto histológico habitual.

- BA - Baço: aspecto histológico habitual. Fragmento de pâncreas com aspecto histológico habitual.

- RI - Rim: aspecto histológico habitual.

- COR - Coração: aspecto histológico habitual.

Animal 4

CE - Cérebro: hipoxemia neuronal difusa.

- TU - Tumor: carcinoma mamário apresentando:

- Maior eixo: 30,0 mm.

- Tipo histológico: sólido.

- Grau histológico: alto grau.

- Necrose: presente e central, $15 \%$ da área tumoral.

- Infiltração vascular: não evidenciada.

- Infiltração linfática: não evidenciada.

- Infiltração perineural: não evidenciada.

- Infiltrado inflamatório: presente, leve e misto.

- Fibroplasia estromal: não evidenciada.

- MA - Mama: foco de hemorragia intraparenquimatosa.

- PUL - Pulmão: múltiplos focos de metástase de carcinoma mamário.

- LS - Linfonodo sentinela: aspecto histológico habitual.

- LC - Linfonodo contralateral: aspecto histológico habitual.

- FI - Fígado: múltiplos focos de metástase de carcinoma mamário.

- BA - Baço: múltiplos focos de metástase de carcinoma mamário.

- RI - Rim: aspecto histológico habitual.

- COR - Coração: aspecto histológico habitual. Animal 5

- $\mathrm{CE}$ - Cérebro: hipoxemia neuronal difusa.

- $\mathrm{TU}$ - Tumor: foco de leve fibrose estromal. 
- PUL - Pulmão: aspecto histológico habitual.

- LC - Linfonodo contralateral: aspecto histológico habitual.

- FI - Fígado: aspecto histológico habitual.

- BA - Baço: aspecto histológico habitual.

- RI - Rim: aspecto histológico habitual.

- COR - Coração: aspecto histológico habitual.

- $\mathrm{CE}$ - Cérebro: hipoxemia neuronal difusa.

- GRUPO LOCAL ( INTRATUMORAL COM IRRADIAÇÃO SISTÊMICA)

$\circ \quad$ Animal 1

- TU - Tumor: foco de leve fibrose estromal e infiltrado inflamatório linfocítico associado a edema intersticial.

- MA - Mama: aspecto histológico habitual.

- PUL - Pulmão: aspecto histológico habitual.

- LS - Linfonodo sentinela: aspecto histológico habitual.

- LC - Linfonodo contralateral: aspecto histológico habitual.

- FI - Fígado: aspecto histológico habitual.

- BA - Baço: aspecto histológico habitual.

- RI - Rim: aspecto histológico habitual.

- COR - Coração: aspecto histológico habitual.

- CE - Cérebro: hipoxemia neuronal difusa.

- Animal 2

- TU - Tumor: carcinoma mamário apresentando:

- Maior eixo: $21,0 \mathrm{~mm}$.

- Tipo histológico: sólido.

- Grau histológico: alto grau.

- Necrose: presente e multifocal, $60 \%$ da área tumoral.

- Infiltração vascular: não evidenciada.

- Infiltração linfática: não evidenciada.

- Infiltração perineural: não evidenciada.

- Infiltrado inflamatório: presente, leve e misto.

- Fibroplasia estromal: não evidenciada.

- MA - Mama: aspecto histológico habitual.

- PUL - Pulmão: múltiplos focos de metástase de carcinoma mamário.

- LS - Linfonodo sentinela: aspecto histológico habitual.

- LC - Linfonodo contralateral: aspecto histológico habitual.

- FI - Fígado: aspecto histológico habitual.

- BA - Baço: aspecto histológico habitual.

- RI - Rim: aspecto histológico habitual.

- COR - Coração: aspecto histológico habitual.

- CE - Cérebro: hipoxemia neuronal difusa.

- Animal 3

- TU - Tumor: carcinoma mamário apresentando:

- Maior eixo: $28,0 \mathrm{~mm}$.

- Tipo histológico: sólido.

- Grau histológico: alto grau.

- Necrose: presente e central, $15 \%$ da área tumoral.

- Infiltração vascular: não evidenciada.

- Infiltração linfática: não evidenciada.

- Infiltração perineural: não evidenciada.

- Infiltrado inflamatório: presente, leve e misto.

- Fibroplasia estromal: não evidenciada.

- MA - Mama: foco de moderado infiltrado inflamatório linfocítico intraparenquimatoso.

- PUL - Pulmão: múltiplos focos de metástase de carcinoma mamário.

- LS - Linfonodo sentinela: metástase linfonodal de carcinoma mamário.

- LC - Linfonodo contralateral: metástase linfonodal de carcinoma mamário.

- FI-Fígado: múltiplos focos de metástase de carcinoma mamário. 
- BA - Baço: múltiplos focos de metástase de carcinoma mamário.

- RI - Rim: aspecto histológico habitual.

- COR - Coração: trombo intramural em ventrículo direito.

- CE - Cérebro: hipoxemia neuronal difusa.

- MA - Mama: aspecto histológico habitual.

- PUL - Pulmão: foco de metástase de carcinoma mamário.

- LS - Linfonodo sentinela: aspecto histológico habitual.

- LC - Linfonodo contralateral: aspecto histológico habitual.

- FI - Fígado: aspecto histológico habitual.

- BA - Baço: congestão passiva crônica.

- RI - Rim: aspecto histológico habitual.

- COR - Coração: aspecto histológico habitual.

- $\mathrm{CE}$ - Cérebro: hipoxemia neuronal difusa.

\section{- GRUPO NE-ALCLFT}

$\circ$ Animal 1

- TU - Tumor: carcinoma mamário apresentando:

- Maior eixo: 19,0 mm.

- Tipo histológico: sólido.

- Grau histológico: alto grau.

- Necrose: presente e central, $40 \%$ da área tumoral.

- Infiltração vascular: não evidenciada.

- Infiltração linfática: não evidenciada.

- Infiltração perineural: não evidenciada.

- Infiltrado inflamatório: presente, leve e misto.

- Fibroplasia estromal: não evidenciada.

- MA - Mama: aspecto histológico habitual.

- PUL - Pulmão: múltiplos focos de metástase de carcinoma mamário.

- LS - Linfonodo sentinela: aspecto histológico habitual.

- LC - Linfonodo contralateral: aspecto histológico habitual.

- FI - Fígado: múltiplos focos de metástase de carcinoma mamário.

- BA - Baço: múltiplos focos de metástase de carcinoma mamário.

- RI - Rim: aspecto histológico habitual.

- COR - Coração: aspecto histológico habitual.

- CE - Cérebro: hipoxemia neuronal difusa.

- TU - Tumor: aspecto histológico habitual.

- MA - Mama: aspecto histológico habitual.

- PUL - Pulmão: aspecto histológico habitual.

- LS - Linfonodo sentinela: aspecto histológico habitual.

- LC - Linfonodo contralateral: aspecto histológico habitual.

- FI - Fígado: aspecto histológico habitual.

- BA - Baço: aspecto histológico habitual.

- RI - Rim: aspecto histológico habitual.

- COR - Coração: aspecto histológico habitual.

- $\mathrm{CE}$ - Cérebro: hipoxemia neuronal difusa.

- Animal 3

- TU - Tumor: carcinoma mamário apresentando:

- Maior eixo: 9,0 mm.

- Tipo histológico: sólido.

- Grau histológico: alto grau.

- Necrose: presente e central, $20 \%$ da área tumoral.

- Infiltração vascular: não evidenciada.

- Infiltração linfática: não evidenciada.

- Infiltração perineural: não evidenciada.

- Infiltrado inflamatório: presente, leve e misto.

- Fibroplasia estromal: não evidenciada. 
- MA - Mama: aspecto histológico habitual.

- PUL - Pulmão: foco de hemorragia recente intraparenquimatosa.

- LS - Linfonodo sentinela: presença de substância endógena basofílica em seio subcapsular de linfonodo.

- LC - Linfonodo contralateral: aspecto histológico habitual.

- FI - Fígado: aspecto histológico habitual.

- BA - Baço: aspecto histológico habitual.

- RI - Rim: aspecto histológico habitual.

- COR - Coração: aspecto histológico habitual.

- $\mathrm{CE}$ - Cérebro: hipoxemia neuronal difusa.

Animal 4

- TU - Tumor: foco de leve fibrose estromal e infiltrado inflamatório linfocítico associado a edema intersticial.

- MA - Mama: aspecto histológico habitual.

- PUL - Pulmão: aspecto histológico habitual.

- LS - Linfonodo sentinela: aspecto histológico habitual.

- LC - Linfonodo contralateral: aspecto histológico habitual.

- FI - Fígado: aspecto histológico habitual.

- BA - Baço: aspecto histológico habitual.

- RI - Rim: aspecto histológico habitual.

- COR - Coração: aspecto histológico habitual.

- $\mathrm{CE}$ - Cérebro: hipoxemia neuronal difusa.

Animal 5

- TU - Tumor: carcinoma mamário apresentando:

- Maior eixo: $9,0 \mathrm{~mm}$.

- Tipo histológico: sólido.

- Grau histológico: alto grau.

- Necrose: presente e multifocal, $60 \%$ da área tumoral.

- Infiltração vascular: não evidenciada.

- Infiltração linfática: não evidenciada.

- Infiltração perineural: não evidenciada.

- Infiltrado inflamatório: presente, leve e misto.

- Fibroplasia estromal: não evidenciada.

- MA - Mama: aspecto histológico habitual.

- PUL - Pulmão: aspecto histológico habitual.

- LS - Linfonodo sentinela: metástase linfonodal de carcinoma mamário.

- LC - Linfonodo contralateral: aspecto histológico habitual.

- FI - Fígado: aspecto histológico habitual.

- BA - Baço: aspecto histológico habitual.

- RI - Rim: aspecto histológico habitual.

- COR - Coração: aspecto histológico habitual.

- $\mathrm{CE}$ - Cérebro: hipoxemia neuronal difusa.

- GRUPO CONTROLE POSITIVO

$\circ$ Animal 1

- TU - Tumor: aspecto histológico habitual.

- MA - Mama: aspecto histológico habitual.

- PUL - Pulmão: aspecto histológico habitual.

- LS - Linfonodo sentinela: aspecto histológico habitual.

- FI - Fígado: aspecto histológico habitual.

- BA - Baço: aspecto histológico habitual.

- RI - Rim: aspecto histológico habitual.

- COR - Coração: aspecto histológico habitual.

- $\mathrm{CE}$ - Cérebro: hipoxemia neuronal difusa.

- Animal 2

- TU - Tumor: carcinoma mamário apresentando:

- Maior eixo: $11,0 \mathrm{~mm}$.

- Tipo histológico: sólido. 
- Grau histológico: alto grau.

- Necrose: presente e central, $20 \%$ da área tumoral.

- Infiltração vascular: não evidenciada.

- Infiltração linfática: não evidenciada.

- Infiltração perineural: não evidenciada.

- Infiltrado inflamatório: presente, leve e misto.

- Fibroplasia estromal: não evidenciada.

- MA - Mama: aspecto histológico habitual.

- PUL - Pulmão: múltiplos focos de metástase de carcinoma mamário.

- LS - Linfonodo sentinela: aspecto histológico habitual.

- LC - Linfonodo contralateral: aspecto histológico habitual.

- FI - Fígado: aspecto histológico habitual.

- BA - Baço: congestão passiva crônica.

- RI - Rim: aspecto histológico habitual.

- $\mathrm{COR}$ - Coração: aspecto histológico habitual.

$\circ \quad$ Animal 3

- $\mathrm{CE}$-Cérebro: hipoxemia neuronal difusa.

- MA - Mama: aspecto histológico habitual.

- PUL - Pulmão: múltiplos focos de metástase de carcinoma mamário.

- LS - Linfonodo sentinela: metástase linfonodal de carcinoma mamário.

- LC - Linfonodo contralateral: aspecto histológico habitual.

- FI - Fígado: leve hepatite neutrofílica periportal, sem necrose.

- BA - Baço: aspecto histológico habitual.

- RI - Rim: metástase de carcinoma mamário em glândula adrenal.

- $\mathrm{COR}$ - Coração: aspecto histológico habitual.

- Animal 4

- CE - Cérebro: hipoxemia neuronal difusa.

- TU - Tumor: aspecto histológico habitual.

- MA - Mama: foco de leve infiltrado inflamatório linfocítico associado e edema intersticial.

- PUL - Pulmão: presença de hiperplasia linfóide reacional, padrão parafolicular em linfonodos de peri-hilares.

- LS - Linfonodo sentinela: aspecto histológico habitual.

- LC - Linfonodo contralateral: aspecto histológico habitual.

- FI - Fígado: aspecto histológico habitual.

- BA - Baço: aspecto histológico habitual.

- RI - Rim: aspecto histológico habitual.

- COR - Coração: aspecto histológico habitual.

- CE - Cérebro: hipoxemia neuronal difusa.

- GRUPO LED

- Animal 1

- TU - Tumor: carcinoma mamário apresentando:

- Maior eixo: 21,0 mm.

- Tipo histológico: sólido.

- Grau histológico: alto grau.

- Necrose: presente e central, $40 \%$ da área tumoral.

- Infiltração vascular: não evidenciada.

- Infiltração linfática: não evidenciada.

- Infiltração perineural: não evidenciada.

- Infiltrado inflamatório: presente, leve e misto.

- Fibroplasia estromal: não evidenciada.

- MA - Mama: aspecto histológico habitual.

- PUL - Pulmão: múltiplos focos de metástase de carcinoma mamário.

- LS - Linfonodo sentinela: metástase linfonodal de carcinoma mamário.

- LC-Linfonodo contralateral: aspecto histológico habitual.

- FI - Fígado: múltiplos focos de metástase de carcinoma mamário.

- BA - Baço: múltiplos focos de metástase de carcinoma mamário. 
- RI - Rim: metástase de carcinoma mamário em glândula adrenal.

- COR - Coração: aspecto histológico habitual.

- CE - Cérebro: hipoxemia neuronal difusa.

Animal 2

- MA - Mama: foco de leve fibrose estromal e infiltrado inflamatório linfocítico associado a edema intersticial.

- PUL - Pulmão: múltiplos focos de metástase de carcinoma mamário.

- LS - Linfonodo sentinela: aspecto histológico habitual.

- LC - Linfonodo contralateral: metástase linfonodal de carcinoma mamário.

- FI - Fígado: múltiplos focos de metástase de carcinoma mamário.

- BA - Baço: congestão passiva crônica.

- RI - Rim: aspecto histológico habitual.

- COR - Coração: aspecto histológico habitual.

- CE - Cérebro: hipoxemia neuronal difusa.

- TU - Tumor: carcinoma mamário apresentando:

- Maior eixo: 22,0 mm.

- Tipo histológico: sólido.

- Grau histológico: alto grau.

- Necrose: presente e multifocal, $60 \%$ da área tumoral.

- Infiltração vascular: não evidenciada.

- Infiltração linfática: não evidenciada.

- Infiltração perineural: não evidenciada.

- Infiltrado inflamatório: presente, leve e misto.

- Fibroplasia estromal: não evidenciada.

- MA - Mama: aspecto histológico habitual.

- PUL - Pulmão: múltiplos focos de metástase de carcinoma mamário.

- LS - Linfonodo sentinela: metástase linfonodal de carcinoma mamário.

- LC - Linfonodo contralateral: aspecto histológico habitual.

- FI - Fígado: múltiplos focos de metástase de carcinoma mamário.

- BA - Baço: congestão passiva crônica.

- RI - Rim: aspecto histológico habitual.

- COR - Coração: metástase de carcinoma mamário intramúsculo cardíaco em ventrículo esquerdo.

- Animal 4

CE - Cérebro: hipoxemia neuronal difusa.

- MA - Mama: carcinoma mamário apresentando:

- Maior eixo: 8,0 mm.

- Tipo histológico: sólido.

- Grau histológico: alto grau.

- Necrose: presente e central, $10 \%$ do tamanho da lesão.

- Infiltração vascular: não evidenciada.

- Infiltração linfática: não evidenciada.

- Infiltração perineural: não evidenciada.

- Infiltrado inflamatório: presente, leve e misto.

- Fibroplasia estromal: não evidenciada.

- PUL - Pulmão: múltiplos focos de metástase de carcinoma mamário.

- LS - Linfonodo sentinela: metástase linfonodal de carcinoma mamário.

- LC - Linfonodo contralateral: aspecto histológico habitual.

- FI - Fígado: leve hepatite neutrofílica periportal, sem necrose.

- BA - Baço: congestão passiva crônica.

- RI - Rim: aspecto histológico habitual.

- COR - Coração: aspecto histológico habitual.

- $\mathrm{CE}$ - Cérebro: hipoxemia neuronal difusa.

\section{- GRUPO CONTROLE NEGATIVO}

○ Animal 1

- TU - Tumor: aspecto histológico habitual. 
- MA - Mama: aspecto histológico habitual.

- PUL - Pulmão: aspecto histológico habitual.

- LS - Linfonodo sentinela: aspecto histológico habitual.

- LC - Linfonodo contralateral: aspecto histológico habitual.

- FI - Fígado: aspecto histológico habitual.

- BA - Baço: aspecto histológico habitual.

- RI - Rim: aspecto histológico habitual.

- COR - Coração: aspecto histológico habitual.

Animal 2

- $\mathrm{CE}$ - Cérebro: hipoxemia neuronal difusa.

- TU - Tumor: aspecto histológico habitual.

- MA - Mama: aspecto histológico habitual.

- PUL - Pulmão: aspecto histológico habitual.

- LS - Linfonodo sentinela: aspecto histológico habitual.

- LC - Linfonodo contralateral: aspecto histológico habitual.

- FI - Fígado: aspecto histológico habitual.

- BA - Baço: aspecto histológico habitual.

- RI - Rim: aspecto histológico habitual.

- COR - Coração: aspecto histológico habitual.

- CE - Cérebro: hipoxemia neuronal difusa.

- TU - Tumor: aspecto histológico habitual.

- MA - Mama: aspecto histológico habitual.

- PUL - Pulmão: aspecto histológico habitual.

- LS - Linfonodo sentinela: aspecto histológico habitual.

- LC - Linfonodo contralateral: aspecto histológico habitual.

- FI - Fígado: aspecto histológico habitual.

- BA - Baço: aspecto histológico habitual.

- RI - Rim: aspecto histológico habitual.

- COR - Coração: aspecto histológico habitual.

- CE-Cérebro: hipoxemia neuronal difusa.

○ Animal 4

- MA - Mama: aspecto histológico habitual.

- PUL - Pulmão: aspecto histológico habitual.

- LS - Linfonodo sentinela: aspecto histológico habitual.

- LC - Linfonodo contralateral: aspecto histológico habitual.

- FI - Fígado: aspecto histológico habitual.

- BA - Baço: aspecto histológico habitual.

- RI - Rim: aspecto histológico habitual.

- COR - Coração: aspecto histológico habitual.

- CE - Cérebro: hipoxemia neuronal difusa.

○ Animal 5

- TU - Tumor: aspecto histológico habitual.

- MA - Mama: aspecto histológico habitual.

- PUL - Pulmão: aspecto histológico habitual.

- LS - Linfonodo sentinela: aspecto histológico habitual.

- LC - Linfonodo contralateral: aspecto histológico habitual.

- FI - Fígado: aspecto histológico habitual.

- BA - Baço: aspecto histológico habitual.

- RI - Rim: aspecto histológico habitual.

- $\mathrm{COR}$ - Coração: aspecto histológico habitual.

- CE-Cérebro: hipoxemia neuronal difusa. 
ANEXO 1

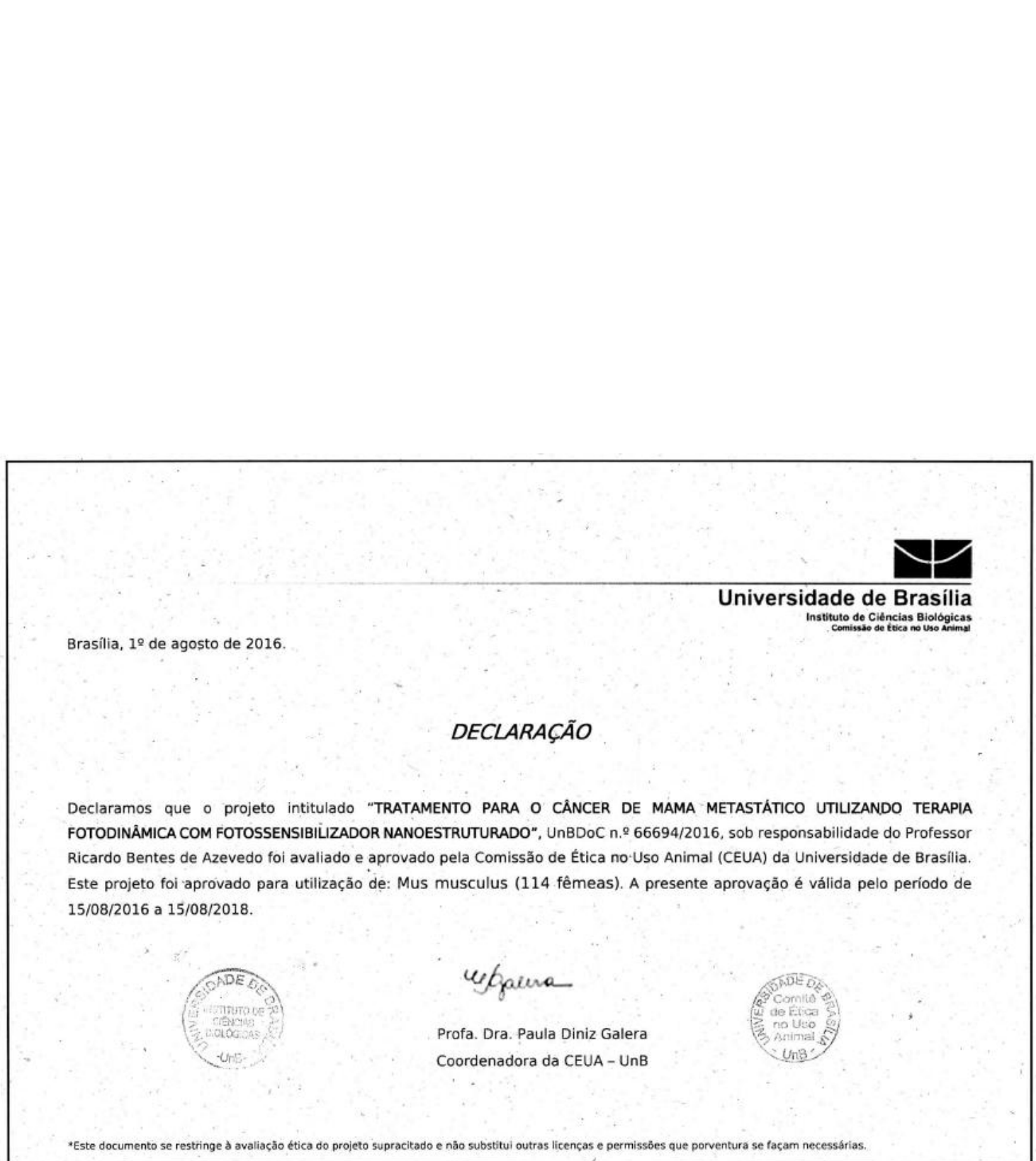

